\title{
BLT-EC (Breach, Leach Transport, and Equilibrium \\ Chemistry), a Finite-Element \\ Model for Assessing the Release \\ of Radionuclides From \\ Low-Level Waste Disposal Units
}

Background, Theory, and Model Description

Manuscript Completed: August 1994

Date Published: August 1995

Prepared by

R. J. MacKinnon, T. M. Sullivan, S. A. Simonson*/BNL

C. J. Suen/CSU

Brookhaven National Laboratory

Upton, NY 11973

California State University at Fresno

Fresno, CA 93740-0024

R. E. Cady, NRC Project Manager

Prepared for

Division of Regulatory Applications

Office of Nuclear Regulatory Research

U.S. Nuclear Regulatory Commission

Washington, DC 20555-0001

NRC Job Code A3276

* Massachusetts Institute of Technology

Cambridge, MA 02139-4307 



\section{DISCLAIMER}

Portions of this document may be illegible in electronic image products. Images are produced from the best available original document. 


\begin{abstract}
Performance assessment models typically account for the processes of sorption and dissolution-precipitation by using an empirical distribution coefficient, commonly referred to as $\mathrm{K}_{\mathrm{d}}$, that combines the effects of all chemical reactions between solid and aqueous phases. In recent years, however, there has been an increasing awareness that performance assessments based solely on empirically based $\mathrm{K}_{\mathrm{d}}$ models may be incomplete, particularly for applications involving radionuclides having sorption and solubility properties that are sensitive to variations in the in-situ chemical environment. To accommodate variations in the in-situ chemical environment, and to assess its impact on radionuclide mobility, it is necessary to model radionuclide release, transport, and chemical processes in a coupled fashion. This modeling has been done and incorporated into the two-dimensional, finite-element, computer code BLT-EC (Breach, Leach, Transport, Equilibrium Chemistry). BLT-EC is capable of predicting container degradation, waste-form leaching, and advective-dispersive, multispecies, solute transport. BLTEC accounts for retardation directly by modeling the chemical processes of complexation, sorption, dissolution-precipitation, ion-exchange, and oxidation-reduction reactions. In this report we: 1) present a detailed description of the various physical and chemical processes that control the release and migration of radionuclides from shallow land LLW disposal facilities; 2) formulate the mathematical models that represent these processes; 3) outline how these models are incorporated and implemented in BLT-EC; and 4) demonstrate the application of BLT-EC on a set of example problems.
\end{abstract}

\title{
DISCLAIMER
}

This report was prepared as an account of work sponsored by an agency of the United States Government. Neither the United States Government nor any agency thereof, nor any of their employees, makes any warranty, express or implied, or assumes any legal liability or responsibility for the accuracy, completeness, or usefulness of any information, apparatus, product, or process disclosed, or represents that its use would not infringe privately owned rights. Reference herein to any specific commercial product, process, or service by trade name, trademark, manufacturer, or otherwise does not necessarily constitute or imply its endorsement, recommendation, or favoring by the United States Government or any agency thereof. The views and opinions of authors expressed herein do not necessarily state or reflect those of the United States Government or any agency thereof. 



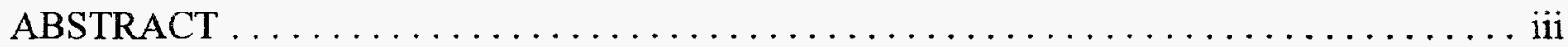

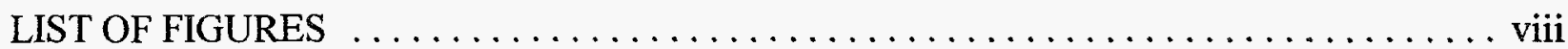



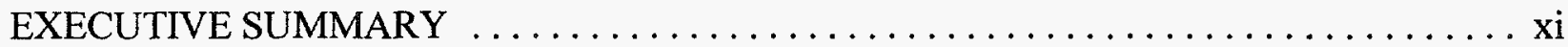

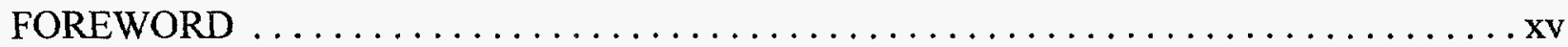

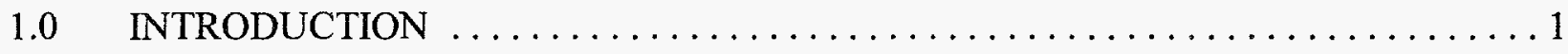

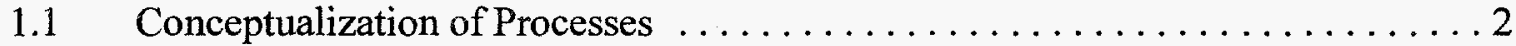

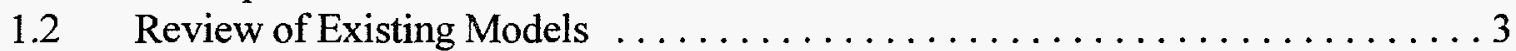

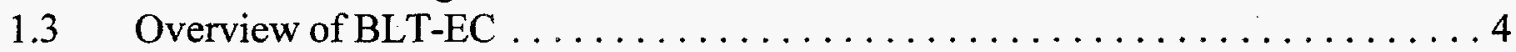

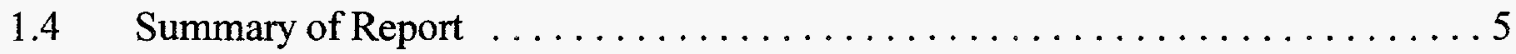

2.0 RELEVANT PHYSICAL AND CHEMICAL PROCESSES $\ldots \ldots \ldots \ldots \ldots \ldots$

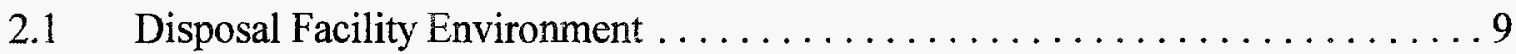

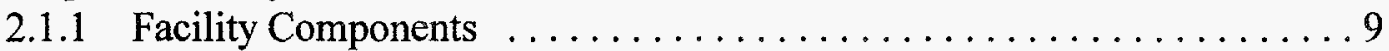

2.1.2 Chemical Processes .............................. 11

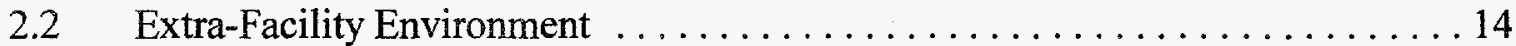

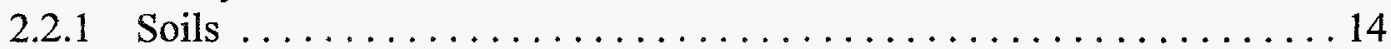

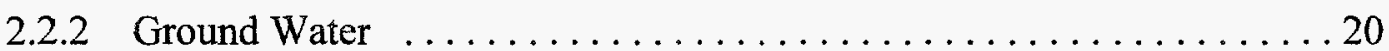

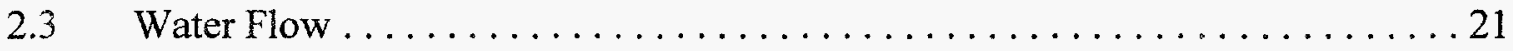

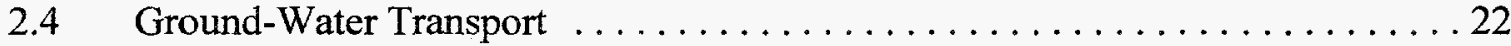

2.5 Summary of Processes Controlling the Mobilities and Concentrations of Radionuclides ...................................23

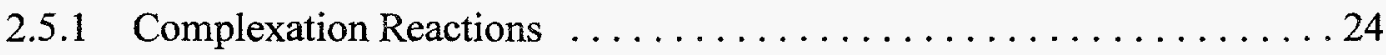

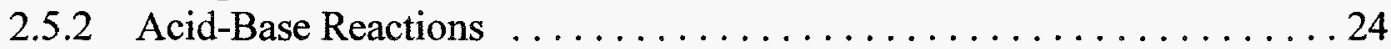

2.5.3 Oxidation-Reduction Reactions ...................... 25

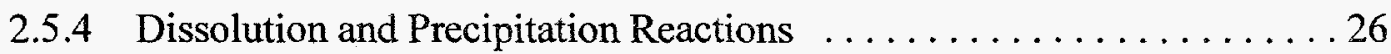

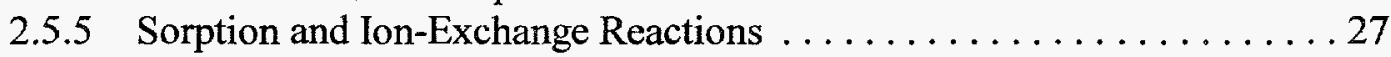

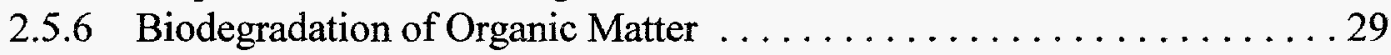

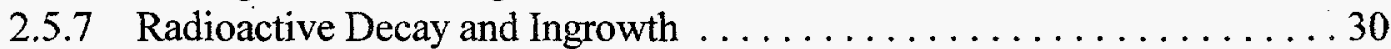

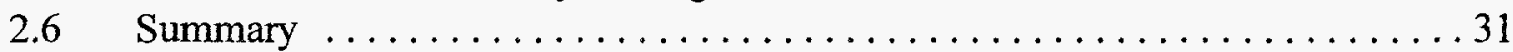

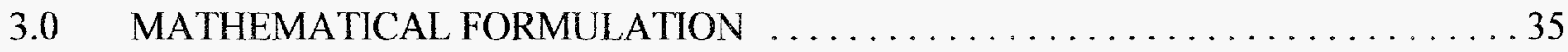

3.1 Multiphase, Multispecies, Reactive Transport .................. 35

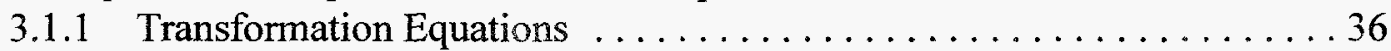

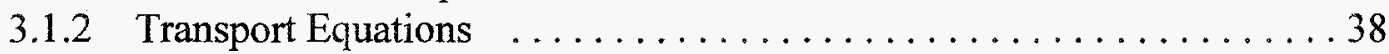



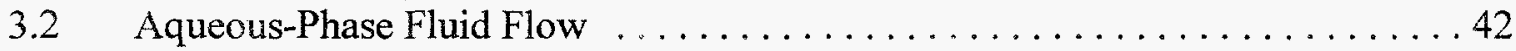

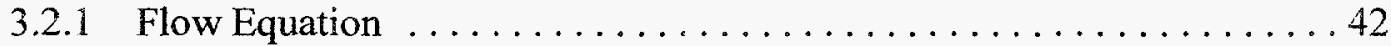

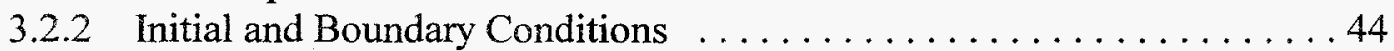

3.3 Multispecies, Aqueous-Phase Transport with Sorption $\ldots \ldots \ldots \ldots \ldots \ldots 45$

3.3 .1 Transport Equations . . . . . . . . . . . . . . . . . . . . 45 
3.3.2 Initial and Boundary Conditions $\ldots \ldots \ldots \ldots \ldots \ldots \ldots \ldots \ldots \ldots$

3.4 Multispecies, Aqueous-Phase Transport with Equilibrium Chemistry . . . . . . . 49

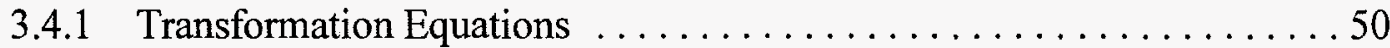

3.4.2 Transport with Chemical Equilibrium Reactions ............. 52

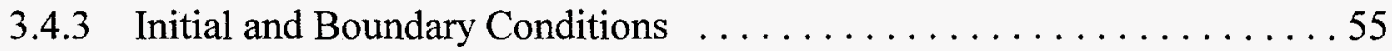

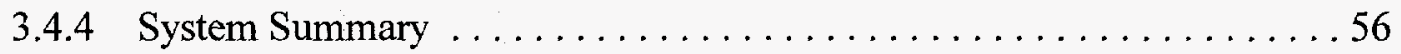

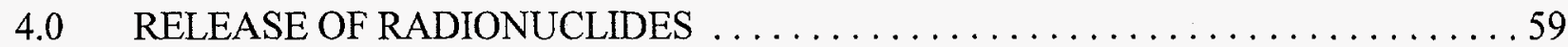

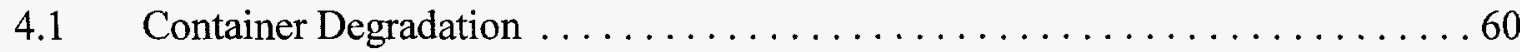

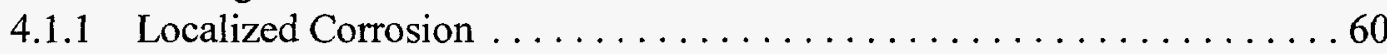

4.1.2 Generalized Corrosion - Time to Failure . . . . . . . . . . . . 61

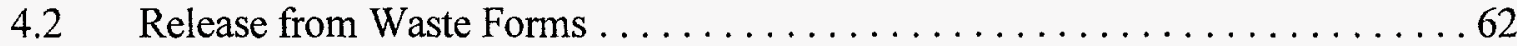



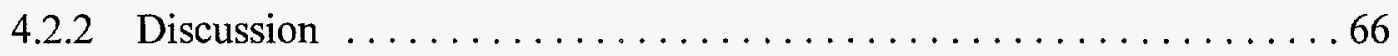

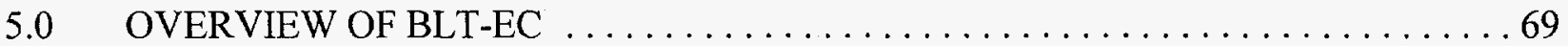

$5.1 \quad$ Coupling Between Major Process Models . . . . . . . . . . . . . . . . . . . 69

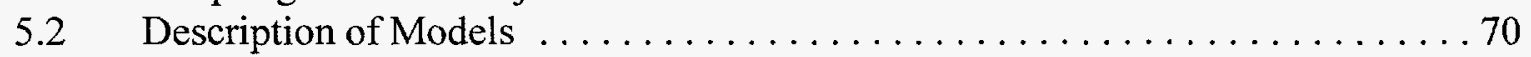

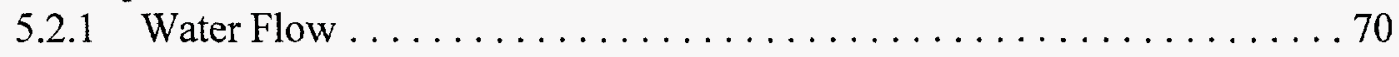

5.2.2 Container Degradation: BREACH Module $\ldots \ldots \ldots \ldots \ldots \ldots \ldots$

5.2 .3 Release from Waste Forms: LEACH Module $\ldots \ldots \ldots \ldots \ldots \ldots .70$

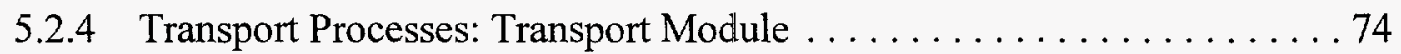

5.2.5 Chemical Processes: EC Module . . . . . . . . . . . . . . . 74

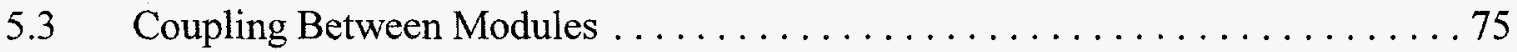

5.3.1 BREACH and LEACH Modules $\ldots \ldots \ldots \ldots \ldots \ldots \ldots \ldots \ldots$

5.3 .2 Transport and EC Modules ........................ 75

5.3.3 Flow, BREACH, LEACH, Transport, and EC Modules $\ldots \ldots \ldots \ldots 76$

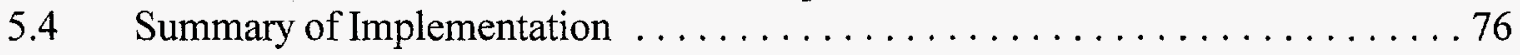

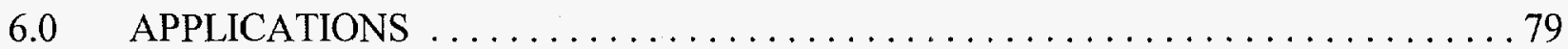

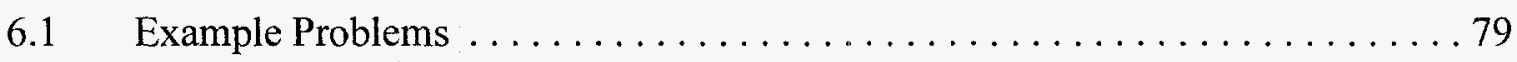

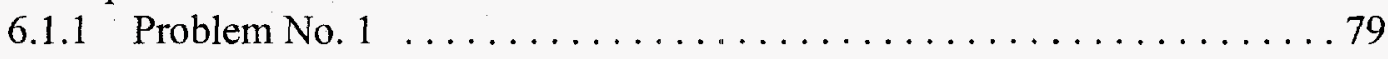

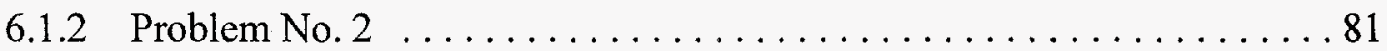

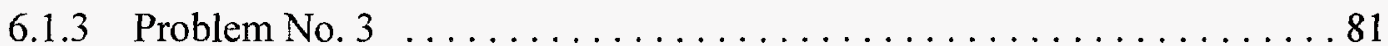

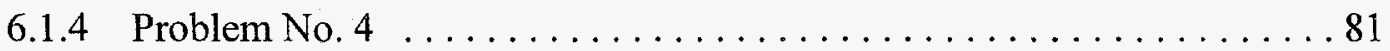

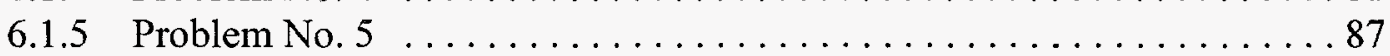

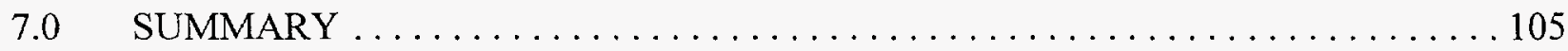

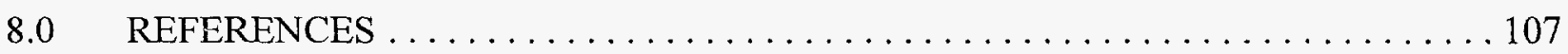


APPENDIX 1: $\quad$ Chemistry of Leachates $\ldots \ldots \ldots \ldots \ldots \ldots \ldots \ldots \ldots \ldots \ldots \ldots \ldots$

APPENDIX 2: $\quad$ Summary of the Chemistry and Available Data for the Significant Radionuclides . . . . . . . . . . . . . . . . . . . . . . . . .

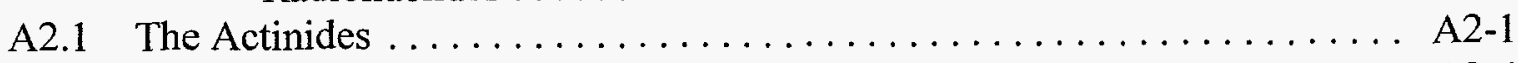

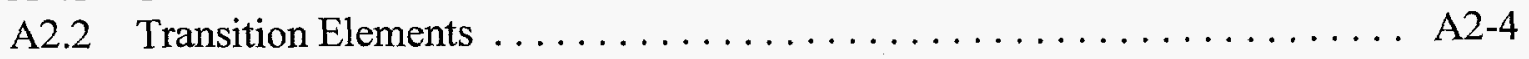

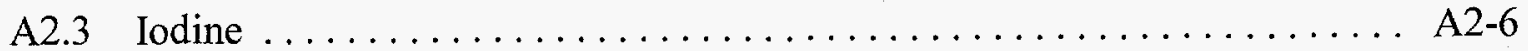

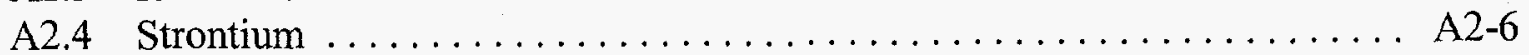

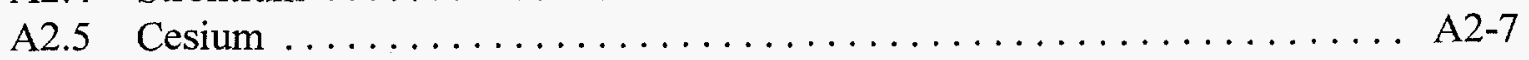

A2.6 Hydrogen (Tritium) and Carbon $\ldots \ldots \ldots \ldots \ldots \ldots \ldots \ldots \ldots \ldots \ldots \ldots \ldots \ldots \ldots \ldots$

APPENDIX 3: $\quad$ Colloid Facilitated Contaminant Transport $\ldots \ldots \ldots \ldots \ldots$ A3-1

APPENDIX 4: $\quad$ Adjustments to Equilibrium Constants and Activity Coefficients ... A4-1

APPENDIX 5: $\quad$ Adsorption Models $\ldots \ldots \ldots \ldots \ldots \ldots \ldots \ldots \ldots \ldots \ldots \ldots \ldots \ldots \ldots \ldots \ldots$ 


\section{LIST OF FIGURES}

Page

Figure 1.1 Schematic diagram of low-level waste leachate infiltration into the subsurface. . . . . . . . . . . . . . . . . . . . 3

Figure 1.2 Coupling between FLOW, BREACH, LEACH, TRANSPORT

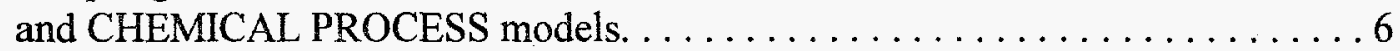

Figure $2.1 \quad$ Schematic diagram of a low-level waste disposal unit. $\ldots \ldots \ldots \ldots \ldots$

Figure 2.2 Generation of ferrous iron, calcium hydroxide and contaminants due to container corrosion and leaching of waste form and concrete barrier. . . . . . . . . . . . . . . . . . . . 13

Figure 4.1 Idealized representation of radionuclide release from a breached container. . . . 59

Figure 4.2 One-dimensional representation of a waste form that undergoes dissolution at a velocity $u$. $x$ is the distance variable. $y$ is a normalized distance variable that always has the dissolution front at $y=1$.

Figure $5.1 \quad$ Conceptual mixing bath model. $\ldots \ldots \ldots \ldots \ldots \ldots \ldots \ldots \ldots$

Figure $5.2 \quad$ Top-level flow chart of the BLT-EC code. . . . . . . . . . . 77

Figure 6.1 Initial distribution of total calcium, carbonate, magnesium, and sulfate. . . . 86

Figure 6.2 Distribution of Total Calcium Carbonate at (a) 50 days

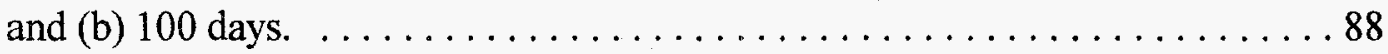

Figure 6.3 Distribution of Total Magnesium Carbonate at (a) 50 days and (b) 100 days.

Figure $6.4 \quad$ Schematic diagram of example field-scale problem. $\ldots \ldots \ldots \ldots \ldots$

Figure $6.5 \quad$ Finite-element mesh for the steady-state flow problem. . . . . . . . . 93

Figure $6.6 \quad$ Steady-state distribution of moisture content. $\ldots \ldots \ldots \ldots \ldots \ldots \ldots$

Figure $6.7 \quad$ Steady-state distribution of hydraulic head. $\ldots \ldots \ldots \ldots \ldots \ldots \ldots$

Figure 6.8 Distribution of total uranium at 30 and 200 years. $\ldots \ldots \ldots \ldots$

Figure 6.9 Distribution of precipitated uranium at 30 and 200 years. . . . . . . 97 


\section{LIST OF FIGURES (cont.)}

$\underline{\text { Page }}$

Figure 6.10 Distribution of dissolved uranium at 30 and 200 years. . . . . . . . . 98

Figure 6.11 Distribution of adsorbed uranium at 30 and 200 years. $\ldots \ldots \ldots \ldots \ldots 99$






\section{LIST OF TABLES}

$\underline{\text { Page }}$

Table $2.1 \quad$ Common Primary Soil Minerals $\ldots \ldots \ldots \ldots \ldots \ldots \ldots \ldots \ldots \ldots \ldots \ldots \ldots \ldots \ldots$

Table 2.2 Common Secondary Soil Minerals $\ldots \ldots \ldots \ldots \ldots \ldots \ldots \ldots \ldots \ldots \ldots$

Table 2.3 Trace Elements Coprecipitated with Secondary Soil Minerals and

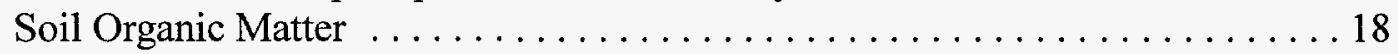

Table $2.4 \quad$ The Content of Various Elements in Soils . . . . . . . . . . . . . . . . . . 19

Table $2.5 \quad$ Representative Chemical Species in Soil Solutions $\ldots \ldots \ldots \ldots \ldots \ldots \ldots$

Table 2.6 pH Effect on $\mathrm{K}_{\mathrm{d}}$ Values in Ground Water Equilibrated Site Soil . . . . . . . . 25

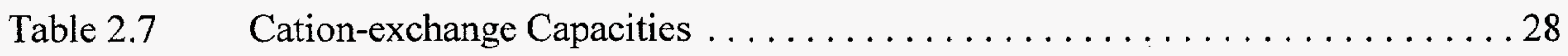

Table 2.8 A Summary of the Chemical Processes Important in Dissolved Containment Transport ......................... 32

Table 2.9 Major Chemical Reactions and Significant Radionuclides $\ldots \ldots \ldots \ldots \ldots 33$

Table 6.1. Species Concentrations at Equilibrium for Problem No. $1 \ldots \ldots \ldots \ldots \ldots 80$

Table 6.2. Species Concentrations at Equilibrium for Problem No. $2 \ldots \ldots \ldots \ldots . \ldots 8$

Table 6.3. Species Concentrations at Equilibrium for Problem No. $3 \ldots \ldots \ldots \ldots . \ldots 3$

Table $6.4 \quad$ Chemical Species for Problem No. $4 \ldots \ldots \ldots \ldots \ldots \ldots \ldots \ldots \ldots$



Table $6.6 \quad$ Hypothetical Field-Scale Problem $\ldots \ldots \ldots \ldots \ldots \ldots \ldots \ldots \ldots \ldots \ldots \ldots \ldots \ldots \ldots$ 


\section{EXECUTIVE SUMMARY}

The objective of the source term evaluation project is to provide system models capable of predicting radionuclide release rates from low-level radioactive waste (LLW) shallow land burial trenches. Four models have been developed thus far under this program. Two of these models, DUST (Disposal Unit Source Term) [Sullivan, 1993] and BLT (Breach-LeachTransport) [Sullivan and Suen, 1989], are single-species (single-solute) codes. DUST is a one-dimensional finite-difference model which was developed to permit rapid simulation of a large number of simple cases and is extremely useful for screening studies to determine, for example, the radionuclide released at the highest rate. BLT is a two-dimensional finite-element model designed to permit more detailed analyses that take into account the effects of geometry and material anisotropy due to different facility designs and hydrogeologic conditions.

Although DUST and BLT are applicable to a wide range of LLW performance assessment problems, they can only calculate the release and aqueous phase transport of one chemical species at a time. In some applications, this limitation precludes adequate assessment of potentially important processes of radionuclide decay and geochemical interactions between the various radionuclides, chemicals, and host porous media. To better address these processes, two extended versions of BLT, BLT-MS (Breach, Leach, Transport-Multiple Species) and BLT-EC (Breach, Leach, Transport-Equilibrium Chemistry), have been developed. Both of these codes simulate waste container degradation, waste form leaching, and multispecies transport in two dimensions. BLT-MS will simulate both sequential and branched decay wherein each parent radionuclide may decay to two progeny nuclides. BLT-MS will be discussed fully in a subsequent report. BLT-EC is designed to simulate important chemical processes and their impact on radionuclide transport in addition to sequential and branched decay.

This report begins with a top-level conceptualization of important processes that control the transport rates of radionuclides into the subterranean environment surrounding a LLW facility, along with a review of existing transport-geochemistry models. Although existing models treat many of the physical and chemical phenomena identified to be influential in radionuclide transport, these models do not account for container degradation, leaching of radionuclides from waste forms, engineered barrier degradation, and radioactive decay processes. An additional shortcoming with many existing reactive transport models is that their implementation requires the user to identify relevant reactions a-priori and construct an input file containing the corresponding stoichiometry and thermodynamic data. This process requires fairly extensive knowledge of the pertinent geochemistry and quickly becomes cumbersome and time consuming for most practical problems involving several chemical reactions. Moreover, this approach is prone to misapplication through improper identification of important reactions.

The objective of this program is to develop a computer model which incorporates the essential set of processes necessary for adequate understanding and assessment of transport and geochemical factors controlling the release of radionuclide contaminants from LLW disposal facilities. This computer model should meet the following requirements: 
(1) The model must be capable of calculating container degradation and leaching of radionuclides from typical waste forms.

(2) The model must be capable of simulating important chemical reactions including dissolution/precipitation, sorption, ion exchange, reduction/oxidation, complexation, and acid-base reactions.

(3) The model must account for the impact of cement based engineered barriers, waste forms, and container corrosion on the chemical environment in the disposal facility and near-field.

(4) The model must be capable of simulating radioactive decay processes including branched decay and progeny ingrowth.

(5) The model must be modular to facilitate future modifications.

(6) The model must be user friendly and transportable between UNIX workstations and high-end personal computer systems.

(7) The model must operate with its own thermodynamic database which can be conveniently updated and expanded as necessary.

Towards meeting the stated objective and requirements, we have developed the computer model BLT-EC (Breach, Leach, Transport, Equilibrium Chemistry). This model is comprised of modified versions of the breach and leach modules contained in BLT, the hydrological transport module contained in HYDROGEOCHEM [Yeh and Tripathi, 1990 and 1991], and the geochemical computer model MINTEQA2 [Allison et al, 1991] and its associated thermodynamic database. The transport module of HYDROGEOCHEM was chosen both because of its modularity and similarity, in terms of variable names and structure, with the transport module presently in BLT. These features facilitated coding modifications and incorporation of the breach and leach modules in BLT. The fact that MINTEQA2 has a large user community was an important factor in the selection of this code for BLT-EC. In addition, this code's extensive thermodynamic database is based on the well documented WATEQ3 [Ball et al, 1981] database and is continually being expanded for applications in radioactive waste management [Erikson et al., 1990; Turner et al., 1992].

The present version of BLT-EC:

(1) Can simulate multispecies transport in two dimensions;

(2) Can compute container degradation and leaching of radionuclides from typical waste forms; 
(3) Can simulate important chemical reactions including dissolution/precipitation, sorption, ion exchange, reduction/oxidation, complexation, and acid-base reactions;

(4) Is modular to facilitate future modifications; and

(5) Operates with its own thermodynamic database which can be conveniently updated and expanded as necessary.

During development, efforts have been taken to ensure that BLT-EC is user friendly and transportable between UNIX and DOS based platforms. For example, to help the user create an input file, menu driven preprocessors that guide the user through the necessary steps of creating or modifying input files have been developed. We are also currently developing a menu-driven postprocessor to facilitate graphical display of one- and two-dimensional output data.

The present version of BLT-EC needs to be extended to include:

- Source models for the release of chemical components from cement based waste forms, engineered barriers, and metallic containers; and

- $\quad$ Radioactive decay processes including branched decay and progeny ingrowth.

The following associated activities are also needed:

- Updating and expanding the thermodynamic database to include radionuclide data from the most recent published compilations;

- $\quad$ Further testing of BLT-EC on representative laboratory-scale and field-scale problems;

- Improving and further testing of BLTECIN, the menu driven program that guides the user through the steps required to create an input file for BLT-EC;

- Developing a postprocessor to facilitate graphical and tabular display of output; and

- Incorporating a Newton-Raphson solution algorithm in FEMWATER.

In this report we: (1) present a detailed description of the various processes that control the release of radionuclides from LLW shallow land disposal facilities; (2) formulate the mathematical models that represent these processes; (3) outline how these models are incorporated in BLT-EC; and (4) demonstrate the application of BLT-EC on a set of example problems. 



\section{FOREWORD}

This technical contractor report is a product of Brookhaven National Laboratory under project FIN A3276. The purpose of this program is to develop a coupled geochemical transport computer code. This code will be capable of predicting time-dependent changes in chemistry that are likely to occur in low-level waste disposal facilities. These changes in chemistry will impact on contaminant mobility and source term release.

NUREG/CR-6305 is not a substitute for NRC regulations and compliance is not required. The approaches and/or methods described in this NUREG/CR are provided for information only. Publication of this report does not necessarily constitute NRC approval or agreement with the information contained herein. 


\subsection{INTRODUCTION}

During the past several years Brookhaven National Laboratory (BNL) has been developing a family of computer models that predict the release and ground-water transport of radionuclides from low-level nuclear waste (LLW) disposal facilities. These models are capable of predicting waste container degradation, waste form leaching, and radionuclide migration with retardation and first-order decay in unsaturated or saturated porous media. Two of these models, DUST (Disposal Unit Source Term)[Sullivan, 1993] and BLT (Breach-Leach-Transport) [Sullivan and Suen, 1989], are single-species (single-solute) codes. DUST is a one-dimensional finite-difference model which was developed to permit simulation of a large number of simple cases, yet flexible enough to allow simulation of a wide range of conditions. The DUST code, because of its flexibility and ability to compute release rates quickly, is ideally suited for screening studies to determine, for example, the radionuclides released at the highest rate and upper bounds to release rates. BLT is a two-dimensional finite-element model designed to permit more detailed analyses that take into account the effects of geometry and material anisotropy due to different facility designs and hydrogeologic conditions.

Although DUST and BLT are applicable to a wide range of LLW performance assessment problems, they can only calculate the release and aqueous phase transport of one chemical species at a time. In some applications, this limitation precludes accurate assessment of potentially important processes of radionuclide decay and geochemical interactions between the various chemicals and host porous media. In particular, radionuclide sorption and solubility properties are dependent on spatial and temporal variations in the chemical environment, both in the disposal unit and along the migration path. As a consequence, modeling radionuclide transport without considering solution chemistry can result in unrealistic predictions of longterm radionuclide migration. Moreover, demonstrating that these predictions are conservative within the framework of the reasonable assurance concept can be highly problematic. Another important situation involves the capability for adequately accounting for the chain-decay process. This capability is essential when decay products pose potentially greater health risks and exhibit substantially different mobility characteristics than the parent. In these cases, satisfactory representations of chain decay may require a multispecies modeling capability; that is, one transport equation for each parent and progeny species may be required to adequately predict total radiological exposures.

To better address the issues of chain decay and the impact of the chemical environment on facility performance, we have developed two extended versions of BLT, BLT-MS (Breach, Leach, Transport-Multiple Species) and BLT-EC (Breach, Leach, Transport-Equilibrium Chemistry). Both of these codes simulate waste container degradation, waste form leaching, and multispecies transport in two dimensions. BLT-MS will simulate both sequential and branched decay wherein each parent radionuclide may decay to two progeny nuclides. BLT-MS will be discussed fully in a subsequent report. BLT-EC is designed to simulate important chemical processes and their impact on radionuclide transport. Eventually, this model will also simulate both sequential and branched radioactive decay.

The purpose of this report is to: (1) present a qualitative description of the various processes that control the release of radionuclides from LLW shallow land disposal facilities; 


\subsection{Introduction}

(2) formulate the mathematical models that represent these processes; (3) outline how these models are incorporated in BLT-EC; and (4) demonstrate the application of BLT-EC on a set of example problems.

\subsection{Conceptualization of Processes}

A LLW disposal facility is a complex open chemical system. The chemical composition and physical characteristics of a facility's contents, engineered barriers (if any), and surrounding soil all contribute to the chemical environment within and in the vicinity of a facility. The chemical environment within the facility influences, and may even control, releases from the waste forms. The chemical environment in the facility, together with the site geochemistry and hydrogeology, determine the transport rates of radionuclides beyond the facility.

Figure 1.1 depicts a contamination scenario associated with the release of radionuclides and their subsequent migration into a ground-water system comprised of unsaturated and saturated zones. A disposal unit may contain a multi-layered cover to divert water away from the waste, an engineered barrier to further reduce water flow to the wastes (for trench disposal there is no engineered barrier), and metallic, concrete, or high density polyethylene waste containers. The waste exists in several forms, a partial list of which includes: wastes solidified by one of several processes (e.g., cement, VES, bitumen), dewatered resins, activated metals, and dry active solids (e.g. contaminated paper, cloth, rubber, plastic, glass, etc.). Unsaturated zones are typically shallow and range to depths as shallow as a few meters, to as deep as 200 meters in arid environments. The extent of saturated zones is determined in the vertical direction by geologic stratigraphy and in the horizontal direction by geologic features such as faults or the location of man-made receptors. Horizontal distances of interest may range up to thousands of meters.

The first step in the aqueous phase contaminant transport process begins when water infiltrates into the disposal unit and comes in contact with the waste containers. This contact initiates container corrosion, which eventually results in container breach and communication between water and waste form. As a result, contaminants transfer from the waste form into the water and are subsequently transported into adjacent backfill material and soil exterior to the disposal facility. As depicted in Figure 1.1, the bulk of the contaminants escaping the disposal facility are migrating downward with the infiltrating water. In time, some of the aqueous leachate may eventually reach the saturated zone, mix, and spread laterally in the flowing ground water. Dissolved contaminant concentrations in the migrating leachate are primarily determined by waste, waste form, and container characteristics and limited by sorption, ion-exchange, and precipitation reactions. These reactions are strongly affected by contaminant speciation, which in turn are influenced by ground-water and leachate composition, $\mathrm{pH}$, and redox state of the leachate. In the unsaturated zone, high vapor-pressure contaminants can also volatilize and be transported away by gas-phase diffusion and advection, forming a gaseous envelope around the leachate plume. Additional mechanisms including microbially-mediated reactions, colloid facilitated transport, container and engineered barrier degradation, and radioactive decay also combine to influence dissolved concentrations of contaminants. 


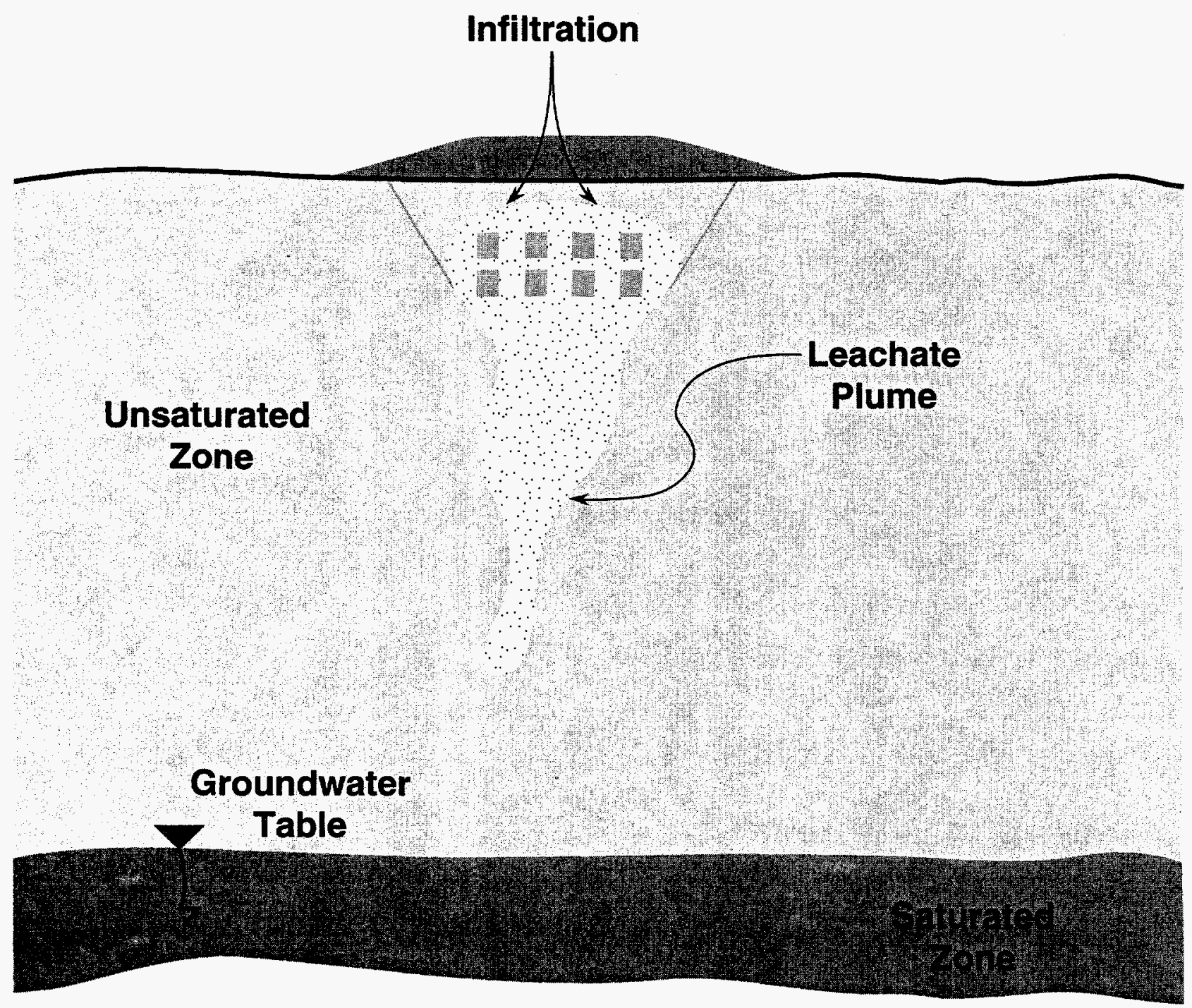

Figure 1.1 Schematic diagram of low-level waste leachate infiltration into the subsurface.

\subsection{Review of Existing Models}

Several models have been developed in the past decade to assess the role of coupled transport and chemical processes on the subsurface migration of reactive solutes, notably Miller and Benson [1983], Cederberg et al. [1985], Lichtner [1985], Kirkner et al. [1985], Narasimhan et al. [1986], Hostetler et al. [1989], Liu and Narasimhan [1989a, 1989b], Yeh and Tripathi [1991], Matsunaga et al. [1993], and Sevougian et al. [1993]. The most comprehensive of these models are those by Liu and Narasimhan [1989a, 1989b] and Yeh and Tripathi $[1989,1990$, 1991]. Liu and Narasimhan [1989a,1989b] developed the model, DYNAMIX, to simulate redox-controlled, multiple-species, reactive chemical transport in two dimensions. This model 


\subsection{Introduction}

represents both kinetic and equilibrium chemical interactions between aqueous and solid phases. Yeh and Tripathi [1990] developed the two-dimensional, finite-element model, HYDROGEOCHEM, for simulating transport of reactive multispecies solutes in two dimensions under the assumption of chemical equilibrium. This model employs an efficient twostep solution approach wherein the transport equation and chemistry equation systems are solved separately and sequentially in iterative fashion. The model is designed for application to heterogeneous, anisotropic, variably saturated porous media under transient or steady state flow conditions, and simulates the chemical processes of dissolution-precipitation, complexation, sorption, ion exchange, redox and acid-base reaction.

A major drawback with many of the existing reactive transport models, as with HYDROGEOCHEM for example, is that their implementation requires the user to identify relevant reactions a-priori and construct an input file containing the corresponding stoichiometry and thermodynamic data. This process requires a fairly extensive knowledge of the pertinent geochemistry and quickly becomes cumbersome and time consuming for most practical problems involving several chemical reactions. In addition, this approach is prone to misapplication through improper identification of important reactions.

\subsection{Overview of BLT-EC}

Although existing models treat many of the physical and chemical phenomena identified to be influential in chemical transport, these models do not account for container degradation, leaching of radionuclides from waste forms, engineered barrier degradation, and radioactive decay processes. The objective of this program is to develop a computer model which incorporates the essential set of processes necessary for adequate understanding and assessment of the factors controlling the release of radionuclide contaminants from LLW disposal facilities. This computer model should meet the following requirements:

(1) The model must be capable of calculating container degradation and leaching of radionuclides from typical waste forms.

(2) The model must be capable of simulating important chemical reactions including dissolution/precipitation, sorption, ion exchange, reduction/oxidation, complexation, and acid-base reactions.

(3) The model must account for the impact of cement based engineered barriers, waste forms, and container corrosion on the chemical environment in the disposal facility and near-field.

(4) The model must be capable of simulating radioactive decay processes including branched decay and progeny ingrowth.

(5) The model must be modular to facilitate future modifications. 
(6) The model must be user friendly and transportable between UNIX workstations and high-end personal computer systems.

(7) The model must operate with its own thermodynamic database which can be conveniently updated and expanded as necessary.

Towards meeting the stated objective and requirements, we have developed the computer model BLT-EC. This model is comprised of modified versions of the breach and leach modules contained in BLT, the hydrological transport module contained HYDROGEOCHEM [Yeh and Tripathi, 1991], and the geochemical computer model MINTEQA2 [Allison et al, 1991] and its associated thermodynamic data base. The transport module of HYDROGEOCHEM was chosen both because of its modularity and similarity, in terms of variable names and structure, with the transport module presently in BLT. These features facilitated coding modifications and incorporation of the breach and leach modules in BLT. The fact that MINTEQA2 has a large user community was an important factor in the selection of this code for BLT-EC. In addition, this code's extensive thermodynamic data base is based on the well documented WATEQ3 [Ball et al, 1981] database and is continually being expanded for applications in radioactive waste management [Erikson et al., 1990; Turner et al., 1992].

Efforts are being made to ensure that BLT-EC is modular, reasonably user friendly, and transportable between UNIX and DOS based platforms. For example, to help the user create an input file, menu driven preprocessors that guide the user through the necessary steps of creating or modifying input files have been developed. We are also currently developing a menu-driven postprocessor to facilitate graphical display of one- and two-dimensional output data.

The modular structure of the complete BLT-EC code package is illustrated in Figure 1.2. This package consists of six modules: (1) an optional preprocessor that assists the user in preparing source, transport, and chemical input data; (2) the BLT module that simulates radionuclide release and migration; (3) the EC module that simulates the chemical reactions; (4) the hydrogeologic data module that transfers data from FEMWATER's finite-element mesh to BLT-EC's finite-element mesh for use by the BLT module; (5) the thermodynamic data base that provides the EC module with the pertinent reactions and data; (6) the postprocessing module that provides tabular and graphical displays of output.

\subsection{Summary of Report}

The remainder of this report is organized as follows. In the next chapter, a discussion of subsurface physical and chemical characteristics and processes relevant to the post-closure performance of a LLW facility is presented. This discussion addresses several topics including: the impact of the chemical environment in the facility on the release of radionuclides; characteristics of soils and ground water; ground-water flow and transport processes; and important chemical, biochemical, and radioactive decay reactions. 
Optional Preprocessor

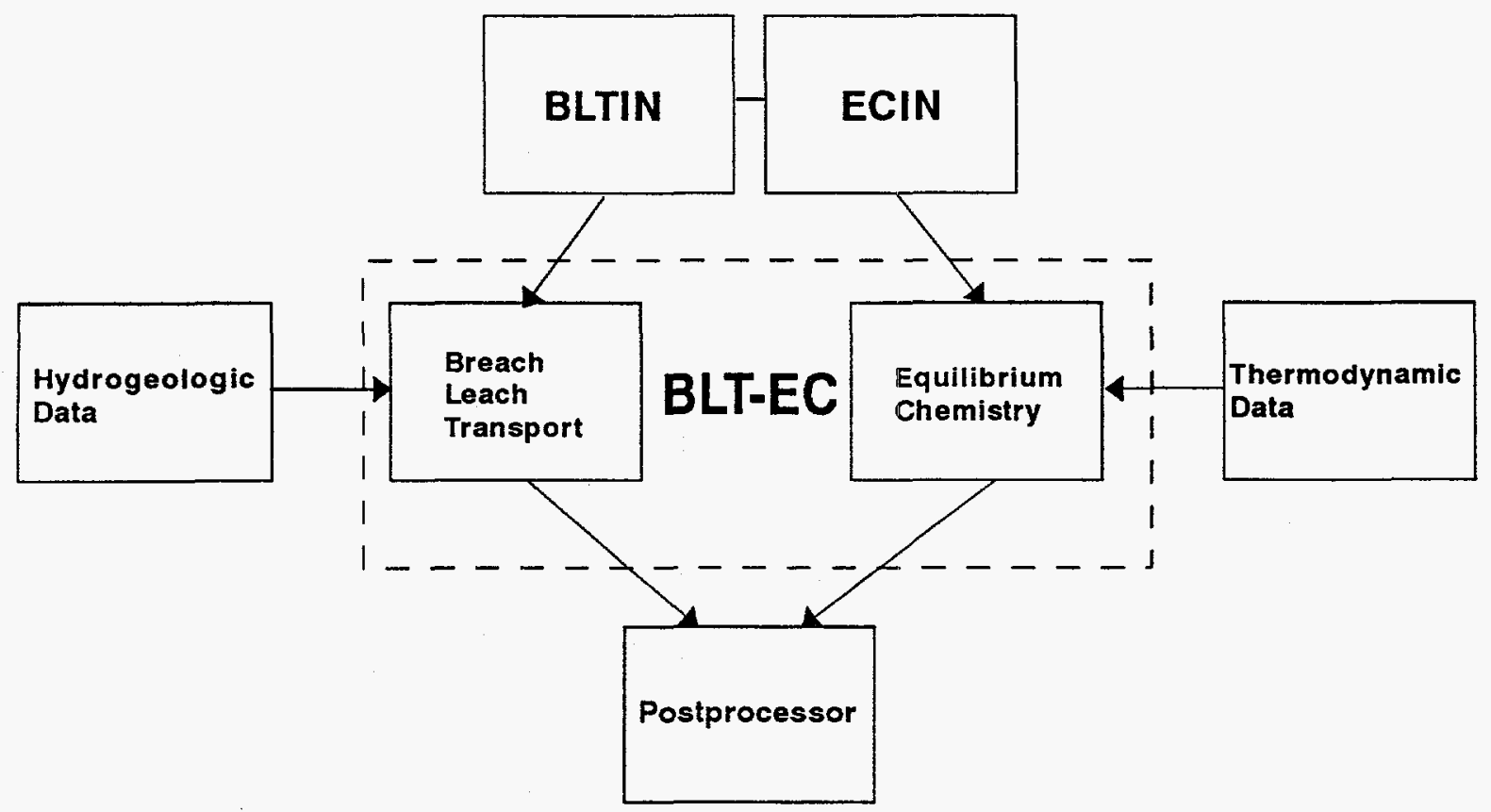

Figure 1.2 Coupling between FLOW, BREACH, LEACH, TRANSPORT, and CHEMICAL PROCESS models.

Two appendices augment Chapter 2. The chemistry of leachates is reviewed in Appendix 1. This review is based primarily on published data from studies of leachates and ground waters collected at Maxey Flats, West Valley, Barnwell, and Sheffield sites. In Appendix 2, we review the chemistry and available data for significant radionuclides.

In Chapter 3, mathematical models are formulated to quantitatively describe the important processes operating in a LLW facility environment. This formulation presents equations for water flow and reactive multispecies chemical transport; the latter includes equations for abiotic, biotic, and radioactive decay reactions. The transport formulation is first presented in a general framework without specification of kinetically-limited and chemical equilibrium reactions. This formulation is then reduced to three simplified descriptions: 1) water flow in variably saturated media; 2 ) multispecies, aqueous-phase transport with sorption; 3) multispecies, aqueous-phase transport with equilibrium chemistry. This approach to presenting the formulation of the governing partial differential equations was designed to facilitate both identification of important assumptions implicit in these three often used formulations and future extensions of models to include chemical kinetics and biotic reactions.

Appendices 3, 4, and 5 augment Chapter 3 . Appendix 3 outlines an approach to approximate colloid facilitated transport by employing a "modified" retardation coefficient that can be easily implemented in the DUST, BLT, and BLT-MS codes. Appendix 4 provides details on constitutive relations for the chemical equilibrium formulation. Appendix 5 summarizes sorption models in BLT-EC. 


\subsection{Introduction}

The mathematical models presented in Chapter 3 neglect the transport of radionuclides in the gaseous phase. Under certain environmental conditions this process may be important. To reduce the complexity of modeling the ground-water and gaseous release pathways, modeling of gas-phase radionuclide release was undertaken as an effort separate from the development of BLT-EC. This effort is described in Appendix 6.

A special feature of BLT-EC that distinguishes it from other transport-geochemistry codes is its ability to model container degradation and release of radionuclides from a variety of waste forms. In Chapter 4, we describe the mathematical models for these processes.

The implementation of the simplified reactive transport formulation in BLT-EC is summarized in Chapter 5 . Solution algorithms, basic code structure, and code-user implementation are briefly described.

In Chapter 6, we demonstrate the application of BLT-EC on simple model problems and a hypothetical field-scale problem.

Finally, a brief summary is offered in Chapter 7 . 



\subsection{RELEVANT PHYSICAL AND CHEMICAL PROCESSES}

The post-closure impact of a LLW facility on the subsurface environment is influenced by several processes that take place within and in the vicinity of the facility. These processes include:

(1) biotic and abiotic interactions between the disposal facility contents, engineered barrier materials, and natural substances in the ground water and host soil;

(2) water flow in the unit and surrounding soil;

(3) release of contaminants from waste forms to the intruding water;

(4) radioactive decay and ingrowth; and

(5) transport of contaminants within and beyond the disposal unit.

These processes, and the influence they exert on the release of radionuclides, are described in this chapter. Relevant characteristics of host soils and ground water are also summarized.

\subsection{Disposal Facility Environment}

This section presents an overview of facility components and processes which interact to control the leachability and mobility of radionuclides in a LLW disposal unit.

\subsubsection{Facility Components}

The major components of a disposal unit are illustrated in Figure 2.1; shown are metallic, concrete, and/or high density polyethylene waste containers that contain a variety of waste forms and wastes; an engineered concrete barrier to further reduce water flow to the wastes (for trench disposal there is no engineered barrier); a permeable backfill (e.g. clay, sand, activated carbon); and a multi-layered cover to divert water away from the waste.

Low-level wastes contain an array of radionuclides. Following Cowgill and Sullivan [1992], inventories can be separated into two groups; short-lived and long-lived radionuclides. Long-lived is arbitrarily defined as having a half-life greater than Cs-137, i.e. 30.1 years. Based on their radiotoxicity rankings and the 1989 Richland inventory data, the short-lived radionuclides of concern are: $\mathrm{Cs}-137, \mathrm{Sr}-90, \mathrm{H}-3, \mathrm{Co}-60, \mathrm{Fe}-55$, and $\mathrm{Cs}-134$. The majority of the important long-lived radionuclides are isotopes of the actinides including thorium, uranium, neptunium, plutonium, and americium. Radium is also relatively important. Other isotopes of potential importance include $\mathrm{C}-14, \mathrm{I}-129, \mathrm{Ni}-63, \mathrm{Tc}-99, \mathrm{Ni}-59, \mathrm{Te}-123$, and $\mathrm{Cl}-36$. A summary of the geochemistry of several significant radionuclides is given in Appendix 2. 


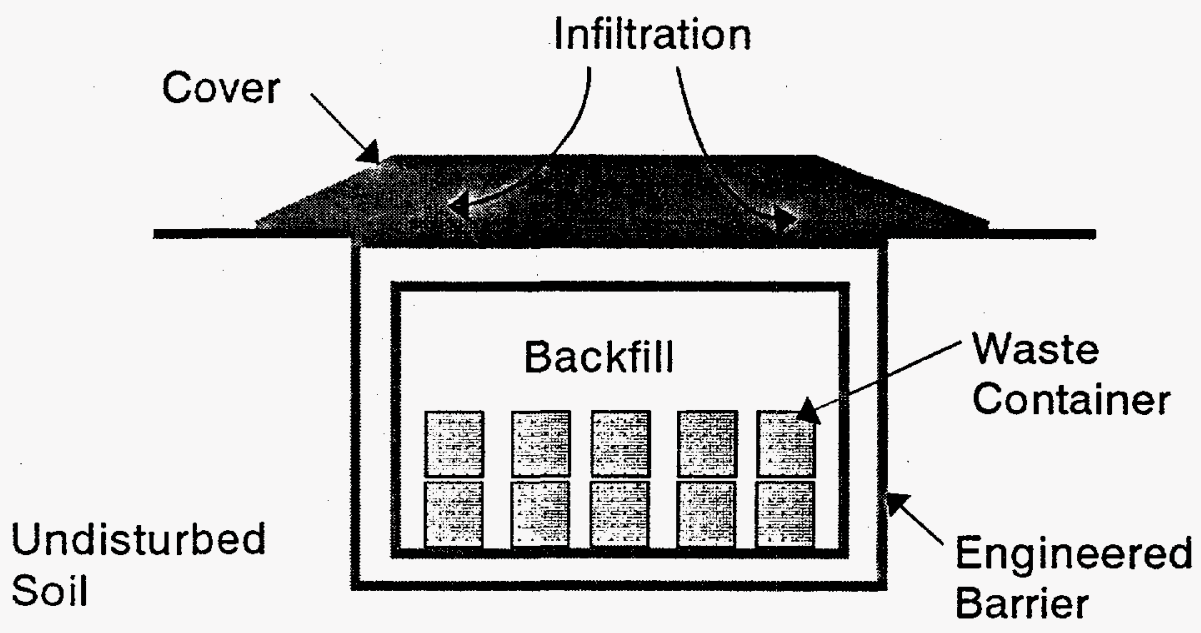

Figure 2.1 Schematic diagram of a low-level waste disposal unit.

The waste form is the physical form of the waste in the disposal container. A wide range of waste forms are used in LLW disposal. A review of the compilation of data from the commercial shipping manifests [Roles, 1990] indicate that there are over 22 categories of waste streams. These waste streams may be placed untreated into the container, or they may be treated with sorbents to absorb free liquids, solidification agents such as portland cement, modified sulfur cement, vinyl-ester styrene, bitumen, or surrounded with sand to minimize void space in the container. Knowledge of the waste form is crucial in developing the conceptual models for release from the waste package.

The wide variety of waste forms necessitates grouping them into major categories based on the inventory of the wastes. Examination of the inventory data indicate the following major waste form types: activated metals, cement solidified wastes, dry solids (lab trash, papers, plastics, glassware, etc.), de-watered resins, evaporator bottoms, filter sludges, and solid noncombustibles. These waste forms contain over $95 \%$ of the total activity [Cowgill and Sullivan, 1993]. Although, these are the major waste forms, consideration must be provided on a radionuclide specific basis. For example, in 1989 100\% of the Th-232 disposed at the commercial site at Richland, Washington, was disposed of in a sorbent [Cowgill and Sullivan, 1993].

Low-level waste containers span a wide variety of sizes, shapes, and materials of construction. A review of the shipping manifests for commercial waste disposal indicates that in the period of 1987 - 1989 there were approximately 80,000 waste containers disposed of annually. The containers ranged in size from $0.02 \mathrm{ft}^{3}$ to $1500 \mathrm{ft}^{3}$ [Roles, 1990]. Over $75 \%$ of the 


\subsection{Relevant Physical and Chemical Processes}

low-level waste containers are 55 gallon carbon steel drum. The majority of the other containers are also carbon steel. However, the more active wastes, Class $\mathrm{B}$ and $\mathrm{C}$ wastes, are often disposed in high integrity containers (HIC's). Materials used to construct HIC's include stainless steels, Ferallium (a duplex stainless steel), and high-density polyethylene (HDPE). Concerns over long term creep of HDPE have caused these containers to be surrounded by a concrete overpack.

Although the percentage of HIC's disposed of annually is small compared to all containers, they contain the higher activity wastes. In fact, they contain a substantial percentage of the total inventory. The exact amount disposed in HIC's is not easy to ascertain. It would require examining the shipping manifests on a case by case basis and summing the inventory for HIC's. This process could be facilitated through access to the computerized databases which store this information.

Engineered barriers such as concrete vaults and sorbent backfills (i.e., clays, sand, activated carbon) are emplaced to reduce water intrusion and prevent radionuclide migration from the facility. Concrete barriers have low matrix permeability and high structural strength. During the post-closure time frame, however, concrete barriers are likely to sustain significant cracking because of rebar corrosion, volume change, and differential settling, thus reducing their effectiveness [Seitz et al, 1992] for reducing water through the facility. Although concrete is used in the construction of engineered barriers primarily because of its physical properties and reasonable costs, cementitious materials also help provide favorable geochemical conditions (e.g. high $\mathrm{pH}$ ) for immobilizing radionuclides.

\subsubsection{Chemical Processes}

As ground water infiltrates through the disposal unit, its chemistry will change due to mixing with pore water and reaction with various waste form, container, barrier, contaminant, and soil constituents. The reactions that take place will modify the existing chemical form of the contaminants in the disposal facility and therefore alter their leachability and mobility. This degree of alteration will largely depend on two factors; the chemical properties of the infiltrating water and the evolution of water chemistry as the infiltrating water passes through the disposal unit. The latter factor will be a function of the frequency and volume of water infiltration through the disposal unit. If the residence time of the infiltrating water in the disposal unit is short, the redox and $\mathrm{pH}$ conditions will be controlled by factors external to the disposal unit. That is, the infiltrating water will have composition, redox, and $\mathrm{pH}$ characteristics that will be continually altered by the local geochemistry as it migrates from the ground surface through the soil and disposal unit. However, if the residence time of the water in the source zone is long, then the redox and $\mathrm{pH}$ conditions may be controlled by interactions between the water and contents of the source zone. "Short" and "long" residence times mean short or long relative to typical reaction times of the dominant chemical and biological processes.

Container corrosion and leaching of waste forms and engineered barriers modify the chemistry of infiltrating water by generating ferrous iron and calcium hydroxide. These processes are depicted in Figure 2.2. Corrosion of steel containers provides an appreciable 


\subsection{Relevant Physical and Chemical Processes}

source of iron to the aqueous phase which helps buffer oxidizing conditions in the region around the containers. In addition, corrosion products of steel containers provide a good substrate for sorption on radionuclides. When cement based waste forms and barriers are leached, they provide a source of $\mathrm{Ca}^{2+}$ and $\mathrm{OH}^{-}$ions and a buffering effect on the system $\mathrm{pH}$.

The chemical form of a radionuclide directly influences mechanisms that determine its leachability. For example, if a soluble species exists as a solid simply because it is not in contact with water, its release by dissolution will be rapid upon contact with infiltrating water. However, for a soluble species distributed throughout a waste form, for example $\mathrm{UO}_{2} \mathrm{OH}^{+}$in cement, release to the backfill will be controlled by diffusion through the pore water in the waste form (see Figure 2.2). If a species is insoluble in water or chemically bonded, its release will take place only after chemical reactions occur which either transform the contaminant or modify the chemical conditions so that the contaminant becomes soluble. For example, activated metals will release radionuclides after corrosion of the metal matrix. The release of radionuclides from waste forms is discussed in detail in Chapter 4.

Sorption reactions are also sensitive to the chemical form of the contaminant. These reactions depend not only on the distribution of adsorbents on soil mineral surfaces; but also on the concentrations of compatible adsorbate species in solution. For example, metal oxyanions such as $\mathrm{CrO}_{4}^{2}$ will have substantially less affinity, as opposed to the cation $\mathrm{Cr}^{+2}$, to adsorb to negatively charged soil mineral surfaces. The reverse is obviously true for net positively charged adsorbents such as some insoluble organic matter.

The most important parameters controlling the chemical form and mobilities of radionuclides in a LLW facility are [Serne et al, 1990]:

- composition of the ground water and host soil

- $\quad$ prevailing $\mathrm{pH}$

- redox potential (Eh)

- temperature conditions

Compositions of ground water and soil phases are important because they determine, in large part, which chemical and biological reactions will take place, how species of a radionuclide are distributed in solution, and the prevailing $\mathrm{pH}$ and Eh conditions. Compositions of typical soils and ground waters are discussed in detail in the next section. Key chemical and biological reactions are discussed in Section 2.5.

$\mathrm{pH}$ is an important parameter in determining leachability and mobility of contaminants because of its effect on solubility, sorption, and speciation characteristics of radionuclide species. The concentration of hydroxides, for example, directly affects the solubility of metal hydroxide and radionuclide species; as pore water becomes more acidic the concentration of the hydroxide ion decreases, causing an increase in radionuclide concentration and solubility. Moreover, a soil's capacity to adsorb contaminants is frequently influenced by $\mathrm{pH}$. For example, amorphous precipitates such as iron oxyhydroxides have a zero point of charge (ZPC) of approximately 8.5 [Stumm and Morgan, 1981]. At pH levels below the ZPC, the surface charge 


\subsection{Relevant Physical and Chemical Processes}



\subsection{Relevant Physical and Chemical Processes}

is positive. Thus, cations will be less adsorbing in the presence of these minerals at $\mathrm{pH}$ levels below the ZPC and more adsorbing at $\mathrm{pH}$ levels above the ZPC. Many radionuclides are also susceptible to changes in speciation because of changes in $\mathrm{pH}$. For example, many radionuclides form carbonate precipitates at higher $\mathrm{pH}$ levels while they do not form carbonate compounds at lower $\mathrm{pH}$ levels.

Redox conditions are particularly important because many hazardous and radioactive chemicals, such as the actinides, have multiple valences and are subject to redox reactions which yield species that have sharply contrasting solubility and sorption characteristics. For example, reducing conditions favor the lower oxidation states of the actinides (e.g., $\mathrm{U}, \mathrm{Pu}, \mathrm{Tc}$, and $\mathrm{Np}$ ), which generally have substantially lower solubilites than higher oxidation states.

Large variations in system temperature can have a strong impact on complexation, $\mathrm{pH}$, solubility, and sorption [Lemire and Tremaine, 1980; Stumm and Morgan, 1981; Meijer, 1990]. In LLW facilities, significant variations in system temperature due to radioactive decay are negligible. However, natural temperature variations, due to geothermal gradients and seasonal climate changes, may be significant and their impact on radionuclide mobilities must be evaluated on a site-specific basis.

Finally, it should be noted that under certain conditions, microbially mediated processes can also significantly alter the quantities and release of radionuclides from the facility. The generation of byproducts by microorganisms can significantly affect chemical processes and thereby indirectly impact the mobility of contaminants. Redox conditions can become more reducing by the action of organic reducing agents acting through bacterial catalysts [Stumm and Morgan, 1981; Manahan, 1991]. Microbial produced organic chelates can enhance the mobility of heavy metals and radionuclides by forming soluble and poor adsorbing complexes [Stumm and Morgan, 1981; Toste et al., 1984; Carlsen et al., 1989; Serne et al., 1990; Francis and Dodge, 1993]. In addition, actinides and heavy metals can adsorb directly onto microorganisms and thus be immobilized [Spor et al., 1993].

\subsection{Extra-Facility Environment}

The geochemical properties of the host soil and ground water can exert a significant influence on the dominant chemical and biological processes operating in a LLW facility. In the following two sections, geochemical characteristics of typical soils and ground waters are described.

\subsubsection{Soils}

The soils surrounding a facility provide both a chemical and physical barrier to radionuclide migration. Soils are comprised of solid, liquid, and gaseous phases. The solid phase includes soil minerals and soil organic matter. Soil water (or ground water) and soil gas (or air) make up the other two phases. Soil organic matter also includes various kinds of microorganisms which act as catalysts for many chemical reactions. 
The solid phase can be divided into inorganic and organic fractions. Typically, inorganic components constitute more than $90 \%$ of the solid materials. They range in size from tiny colloids $(<2 \mu \mathrm{m})$ to large gravels $(>2 \mathrm{~mm})$ and rocks, and include both primary and secondary soil minerals. Primary minerals are formed at elevated temperatures and inherited unchanged from igneous and metamorphic rocks, sometimes through a sedimentary cycle. Secondary minerals are formed by low temperature reactions. They are either inherited from sedimentary rocks or formed directly by chemical weathering. The most abundant primary minerals in soils are quartz $\left(\mathrm{SiO}_{2}\right)$ and feldspars $\left(\mathrm{MAlSi}_{3} \mathrm{O}_{8}\right)$, where $\mathrm{M}$ represents combinations of the cations $\mathrm{Na}^{+}$, $\mathrm{K}^{+}$, and $\mathrm{Ca}^{2+}$. Table 2.1 lists the most common primary minerals along with their chemical formulas. Common secondary minerals in soils include carbonate and sulfur minerals, layer silicates (e.g., clays), and various oxides (Table 2.2).

The decomposition of primary silicate minerals provides the soluble cationic species in soil water. These species include $\mathrm{Na}^{+}, \mathrm{Mg}^{2+}, \mathrm{K}^{+}, \mathrm{Ca}^{2+}, \mathrm{Mn}^{2+}$, and $\mathrm{Fe}^{2+}$, and constitute the major element composition of natural waters. Trace elements, such as $\mathrm{Co}^{2+}, \mathrm{Cu}^{2+}$, and $\mathrm{Zn}^{2+}$ are also produced by decomposition of primary minerals. Many trace elements coprecipitate with secondary minerals. These elements are either adsorbed by or form solid solution in secondary mineral phases. For example, transition metals like $\mathrm{Fe}$ or $\mathrm{Ni}$ can be adsorbed onto soil organic matter, and secondary aluminosilicates may incorporate $\mathrm{Ni}, \mathrm{Cu}$, and $\mathrm{Zn}$ to replace $\mathrm{Al}$ in their structures. Table 2.3 summarizes the trace elements coprecipitated with secondary minerals and organic matter.

The chemical composition of soil varies according to the soil type, which in turn is a function of the primary materials, history of weathering, and climate. Listed in Table 2.4 are elements often found in soils; it also shows the typical range of concentrations for each element.

Soils also contain a variety of organic components that originate from plant and animal sources, molecules composed of carbon and hydrogen, with carbon representing the skeletal structure. Organic materials occur in surface soils in proportions as small as $0.5 \%$ to $5 \%$ by weight. Although normally present in much smaller quantities than inorganic components, they may significantly alter soil properties by providing a source of cation exchange capacity and soil $\mathrm{pH}$ buffering. Organic components are also a large geochemical reservoir of carbon.

Organic matter can either be classified according to their state of degradation, or into humic and non-humic materials. The states of degradation include unaltered organics (fresh and old non-transformed organics) and transformed organics which are further classified into amorphous materials and decayed materials. The non-humic components are organics which remain undecomposed or are only partially degraded, whereas humic substances are those arising from the chemical and biological degradation of non-humic material. Humic substances are classified into humic acids, fulvic acids, and humins according to their solubility to acid. 
2.0 Relevant Physical and Chemical Processes

Table 2.1 Common Primary Soil Minerals

Name

Chemical Formula

Importance

\begin{tabular}{|c|c|c|}
\hline Quartz & $\mathrm{SiO}_{2}$ & Abundant in sand and silt \\
\hline Feldspar & $(\mathrm{Na}, \mathrm{K}) \mathrm{AlO}_{2}\left[\mathrm{SiO}_{2}\right]_{3}$ & $\begin{array}{l}\text { Abundant in soil that is not leached } \\
\text { extensively }\end{array}$ \\
\hline Mica & $\begin{array}{l}\mathrm{K}_{2} \mathrm{Al}_{2} \mathrm{O}_{5}\left[\mathrm{Si}_{2} \mathrm{O}_{5}\right]_{3} \mathrm{Al}_{4}(\mathrm{OH})_{4} \\
\mathrm{~K}_{2} \mathrm{Al}_{2} \mathrm{O}_{5}\left[\mathrm{Si}_{2} \mathrm{O}_{5}\right]_{3}(\mathrm{Mg}, \mathrm{Fe})_{6}(\mathrm{OH})_{4}\end{array}$ & $\begin{array}{l}\text { Source of } \mathrm{K} \text { in most temperate-zone } \\
\text { soils }\end{array}$ \\
\hline Amphibole & $\begin{array}{l}(\mathrm{Ca}, \mathrm{Na}, \mathrm{K})_{2,3}(\mathrm{Mg}, \mathrm{Fe})_{6}(\mathrm{OH})_{2} \\
{\left[(\mathrm{Si}, \mathrm{Al})_{4} \mathrm{O}_{11}\right]_{2}}\end{array}$ & $\begin{array}{l}\text { Easily weathered to clay minerals and } \\
\text { oxides }\end{array}$ \\
\hline Pyroxene & $(\mathrm{Ca}, \mathrm{Mg}, \mathrm{Fe}, \mathrm{Ti}, \mathrm{Al})(\mathrm{Sl}, \mathrm{Al}) \mathrm{O}_{3}$ & Easily weathered \\
\hline Olivine & $(\mathrm{Mg}, \mathrm{Fe})_{2} \mathrm{SiO}_{4}$ & Easily weathered \\
\hline Epidote & $\mathrm{Ca}_{2}(\mathrm{Al}, \mathrm{Fe})_{3}(\mathrm{OH}) \mathrm{Si}_{3} \mathrm{O}_{12}$ & $\begin{array}{l}\text { Highly resistant to chemical weathering; } \\
\text { used as "index mineral" in pedologic } \\
\text { studies }\end{array}$ \\
\hline Tourmaline & $\left.\mathrm{NaMg}_{3} \mathrm{Al}_{6} \mathrm{~B}_{3} \mathrm{Si}_{6} \mathrm{O}_{27}(\mathrm{OH}, \mathrm{F})_{4}\right\}$ & $\begin{array}{l}\text { Highly resistant to chemical weathering; } \\
\text { used as "index mineral" in pedologic } \\
\text { studies }\end{array}$ \\
\hline Zircon & $\mathrm{ZrSiO}_{4}$ & Highly stable \\
\hline
\end{tabular}


Table 2.2 Common Secondary Soil Minerals

Name Chemical Formula Importance

\begin{tabular}{|c|c|c|}
\hline $\begin{array}{l}\text { Kaolinite } \\
\text { Smectite }\end{array}$ & $\mathrm{Si}_{4} \mathrm{Al}_{4} \mathrm{O}_{10}(\mathrm{OH})_{8}$ & $\begin{array}{l}\text { Abundant in clay as products of } \\
\text { weathering; source of exchangeable }\end{array}$ \\
\hline $\begin{array}{l}\text { Vermiculite } \\
\text { Chlorite }\end{array}$ & $\left.\begin{array}{l}\mathrm{M}_{\mathrm{x}}(\mathrm{Si}, \mathrm{Al})_{8}(\mathrm{Al}, \mathrm{Fe}, \mathrm{Mg})_{4} \mathrm{O}_{20}(\mathrm{OH})_{4} \\
\text { where } \mathrm{M}=\text { interlayer cation }\end{array}\right\}$ & cations in soils \\
\hline Allophane & $\mathrm{Si}_{3} \mathrm{Al}_{4} \mathrm{O}_{12} \cdot \mathrm{nH}_{2} \mathrm{O}$ & $\begin{array}{l}\text { Abundant in soils derived from } \\
\text { volcanic ash deposits }\end{array}$ \\
\hline Gibbsite & $\mathrm{Al}(\mathrm{OH})_{3}$ & Abundant in leached soils \\
\hline Geothite & $\mathrm{FeO}(\mathrm{OH})$ & Most abundant Fe oxide \\
\hline Pyrite & $\mathrm{FeS}_{2}$ & Common in reduced sediment \\
\hline Hematite & $\mathrm{Fe}_{2} \mathrm{O}_{3}$ & Abundant in warm regions \\
\hline Ferrihydrite & $\mathrm{Fe}_{10} \mathrm{O}_{15} \cdot 9 \mathrm{H}_{2} \mathrm{O}$ & $\begin{array}{l}\text { Abundant in organic horizons and as } \\
\text { coatings on other minerals }\end{array}$ \\
\hline Birnessite & $\left.(\mathrm{Na}, \mathrm{Ca}) \mathrm{Mn}_{7} \mathrm{O}_{14} 2.8 \mathrm{H}_{2} \mathrm{O}\right)$ & Most abundant Mn oxide \\
\hline $\left.\begin{array}{l}\text { Calcite } \\
\text { Dolomite }\end{array}\right\}$ & $\left.\begin{array}{l}\mathrm{CaCO}_{3} \\
\mathrm{MgCa}\left(\mathrm{CO}_{3}\right)_{2}\end{array}\right\}$ & Most abundant carbonates \\
\hline Gypsum & $\mathrm{CaSO}_{4} 2 \mathrm{H}_{2} \mathrm{O}$ & Abundant in arid regions \\
\hline
\end{tabular}


2.0 Relevant Physical and Chemical Processes

Table 2.3 Trace Elements Coprecipitated with Secondary Soil Minerals and Soil Organic Matter

Solid

Coprecipitated Trace Elements

Fe and Al oxides

B, P, V, Mn, Ni, Cu, Zn, Mo, As, Se

Mn oxides

$\mathrm{P}, \mathrm{Fe}, \mathrm{Co}, \mathrm{Ni}, \mathrm{Zn}, \mathrm{Mo}, \mathrm{As}, \mathrm{Se}, \mathrm{Pb}$

Ca carbonates

P, V, Mn, Fe, Co, Cd, Mg, Zn, Cu, Al

Illites

B, V, Nl, Co, Cr, Cu, Zn, Mo, As, Se, Pb

Smecites

V, Ti, V, Cr, Mn, Fe, Co, Ni, Cu, Zn, Pb

Organic matter

$\mathrm{Al}, \mathrm{V}, \mathrm{Cr}, \mathrm{Mn}, \mathrm{Fe}, \mathrm{Ni}, \mathrm{Cu}, \mathrm{Zn}, \mathrm{Cd}, \mathrm{Pd}$ 
2.0 Relevant Physical and Chemical Processes

Table 2.4 The Content of Various Elements in Soils

\begin{tabular}{|c|c|c|}
\hline Elements & $\begin{array}{c}\text { Common Range } \\
\text { for soil } \\
\text { (ppm) } \\
\end{array}$ & $\begin{array}{c}\text { Average for soils } \\
\text { (ppm) }\end{array}$ \\
\hline $\mathrm{Ag}$ & $0.01-5$ & 0.05 \\
\hline $\mathrm{Al}$ & $10,000-300,000$ & 71,000 \\
\hline As & $1-50$ & 5 \\
\hline B & $2-100$ & 10 \\
\hline $\mathrm{Ba}$ & $100-3,000$ & 430 \\
\hline $\mathrm{Be}$ & $0.1-40$ & 6 \\
\hline $\mathrm{Br}$ & $1-10$ & 5 \\
\hline $\mathrm{C}$ & & 20,000 \\
\hline $\mathrm{Ca}$ & $7,000-500,000$ & 13,700 \\
\hline $\mathrm{Cd}$ & $0.01-0.70$ & 0.06 \\
\hline $\mathrm{Cl}$ & $20-900$ & 100 \\
\hline $\mathrm{Co}$ & $1-40$ & 8 \\
\hline $\mathrm{Cr}$ & $1-1,000$ & 100 \\
\hline $\mathrm{Cs}$ & $0.3-25$ & 6 \\
\hline $\mathrm{Cu}$ & $2-100$ & 30 \\
\hline $\mathbf{F}$ & $10-4,000$ & 200 \\
\hline $\mathrm{Fe}$ & $7,000-550,000$ & 38,000 \\
\hline $\mathrm{Ga}$ & $5-70$ & 14 \\
\hline $\mathrm{Ge}$ & $1-50$ & 1 \\
\hline $\mathrm{Hg}$ & $0.01-0.3$ & 0.3 \\
\hline I & $0.1-40$ & 5 \\
\hline K & $400-30,000$ & 8,300 \\
\hline $\mathrm{La}$ & $1-5,000$ & 30 \\
\hline $\mathrm{Ll}$ & $5-200$ & 20 \\
\hline $\mathrm{Mg}$ & $600-6,000$ & 5,000 \\
\hline $\mathrm{Mn}$ & $20-3,000$ & 600 \\
\hline Mo & $0.2-5$ & 2 \\
\hline $\mathrm{N}$ & $200-4,000$ & 1,400 \\
\hline $\mathrm{Na}$ & $750-7,500$ & 6,300 \\
\hline $\mathrm{Nl}$ & $5-500$ & 40 \\
\hline $\mathrm{O}$ & & 490,000 \\
\hline $\mathrm{P}$ & $200-5,000$ & 600 \\
\hline $\mathrm{Pb}$ & $2-200$ & 10 \\
\hline $\mathrm{Rb}$ & $50-500$ & 10 \\
\hline $\mathrm{S}$ & $30-10,000$ & 700 \\
\hline Sc & $5-50$ & 7 \\
\hline $\mathrm{Se}$ & $0.1-2$ & 0.3 \\
\hline $\mathrm{Si}$ & $230,000-350,000$ & 320,000 \\
\hline $\mathrm{Sn}$ & $2-200$ & 10 \\
\hline $\mathrm{Sr}$ & $50-1,000$ & 200 \\
\hline $\mathrm{Tl}$ & $1,000-10,000$ & 4,000 \\
\hline V & $20-500$ & 100 \\
\hline $\mathrm{Y}$ & $25-250$ & 50 \\
\hline $\mathrm{Zn}$ & $10-300$ & 50 \\
\hline $\mathrm{Zr}$ & $60-2,000$ & 300 \\
\hline
\end{tabular}

Adapted from W.L. Lindsay, Chemical Equilibrium in Soils, Copyright (C) 1979 John Wiley \& Sons. Reprinted by permission of John Wiley \& Sons, Inc. 


\subsection{Relevant Physical and Chemical Processes}

All soils contain significant amounts of microorganisms. One kilogram of fertile soil may contain 500 billion bacteria [Sposito, 1989]. The predominant effect of microbial action on geochemistry is that microorganisms serve as catalysts for oxidation-reduction reactions during biodegradation. As a result of aerobic biodegradation, free oxygen is consumed, metals such as $\mathrm{Fe}^{3+}$, sulfates, nitrates and organic compounds are reduced, and products, such as $\mathrm{CO}_{2}, \mathrm{H}_{2} \mathrm{O}$, $\mathrm{CH}_{4}, \mathrm{NH}_{3}$, and $\mathrm{H}_{2} \mathrm{~S}$ are produced.

\subsubsection{Ground Water}

Ground water is an extremely heterogeneous mixture composed of small amounts of organic materials, common exchangeable cations and associated anions, and lesser amounts of more insoluble soil materials. Table 2.5 lists some representative chemical species in soil water. A normal soil water will easily contain between 100-200 different soluble complexes, many of them involving metal cations and organic ligands.

Table 2.5 Representative Chemical Species in Soil Solutions

\begin{tabular}{|c|c|c|}
\hline \multirow[b]{2}{*}{ Cation } & \multicolumn{2}{|c|}{ Principal Species } \\
\hline & Acid Soils & Alkaline Soils \\
\hline $\mathrm{Na}^{+}$ & $\mathrm{Na}^{+}$ & $\mathrm{Na}^{+}, \mathrm{NaNaHCO}_{3}^{\circ}, \mathrm{NaSO}_{4}^{-}$ \\
\hline $\mathrm{Mg}^{2+}$ & $\mathrm{Mg}^{2+}, \mathrm{MgSO}_{4}{ }^{0}$, org $^{2}$ & $\mathrm{Mg}^{2+}, \mathrm{MgSO}_{4}^{\circ}, \mathrm{MgCO}_{3}^{\circ}$ \\
\hline $\mathrm{Al}^{3+}$ & Org, $\mathrm{AlF}^{2+}, \mathrm{AlOH}^{2+}$ & $\mathrm{Al}(\mathrm{OH})_{4}^{-}$, org \\
\hline $\mathrm{Si}$ & $\mathrm{Si}(\mathrm{OH})_{4}{ }^{\circ}$ & $\mathrm{Si}(\mathrm{OH})_{4}$ \\
\hline $\mathrm{K}^{+}$ & $\mathbf{K}^{+}$ & $\mathrm{K}^{+}, \mathrm{KSO}_{4}^{-}$ \\
\hline $\mathrm{Ca}$ & $\mathrm{Ca}^{2+}, \mathrm{CaSO}_{4}{ }^{\circ}$, org & $\mathrm{Ca}^{2+}, \mathrm{CaSO}_{4}{ }^{\circ}, \mathrm{CaHCO}_{3}^{+}$ \\
\hline $\mathrm{Cr}^{3+}$ & $\mathrm{CrOH}^{2+}$ & $\mathrm{Cr}(\mathrm{OH})_{4}^{-}$ \\
\hline $\mathrm{Cr}^{6+}$ & $\mathrm{CrO}_{4}{ }^{\circ-}$ & $\mathrm{CrO}_{4}^{-}$ \\
\hline $\mathrm{Mn}^{2+}$ & $\mathrm{Mn}^{2+}, \mathrm{MNSO}_{4}^{\circ}$, org & $\mathrm{Mn}^{2+}, \mathrm{MnSO}_{4}{ }^{\circ}, \mathrm{MnCO}_{3}{ }^{\circ}, \mathrm{MnHCO}_{3}^{+}$ \\
\hline $\mathrm{Fe}^{2+}$ & $\mathrm{Fe}^{2+}, \mathrm{FeSO}_{4}{ }^{\circ}, \mathrm{FeH}_{2} \mathrm{PO}_{4}^{+}$ & $\mathrm{FeCO}_{3}{ }^{\circ}, \mathrm{Fe}^{2+}, \mathrm{FeHCO}_{3}^{+}, \mathrm{FeSO}_{4}^{\circ}$ \\
\hline $\mathrm{Fe}^{3+}$ & $\mathrm{FeOH}^{2+}, \mathrm{Fe}(\mathrm{OH})_{3}^{\circ}$, org & $\mathrm{Fe}(\mathrm{OH})_{3}{ }^{\circ}$, org \\
\hline $\mathrm{Ni}^{2+}$ & $\mathrm{Ni}^{2+}, \mathrm{NiSO}_{4}{ }^{\circ}, \mathrm{NiHCO}_{3}^{+}, \mathrm{Ni}^{2+}$ & $\mathrm{NiCO}_{3}^{\circ}, \mathrm{NiHCO}_{3}^{+}, \mathrm{Ni}^{2+}$ \\
\hline $\mathrm{Cu}^{2+}$ & org, $\mathrm{Cu}^{2+}$ & $\mathrm{CuCO}_{3}{ }^{\circ}$, orh \\
\hline $\mathrm{Zn}^{2+}$ & $\mathrm{Zn}^{2+}, \mathrm{ZnSO}_{4}^{\circ}$, org & $\mathrm{ZnHCO}_{3}{ }^{+}, \mathrm{ZnCO}_{3}^{\circ}$, org, $\mathrm{Zn}^{2+}, \mathrm{ZnSQ}_{4}^{\circ}$ \\
\hline $\mathrm{Sr}^{+2}$ & $\mathrm{Sr}^{+2}$ & $\mathrm{Sr}^{+2}, \mathrm{SrHCO}_{3}^{-}$ \\
\hline $\mathrm{Mo}^{3+}$ & $\mathrm{H}_{2} \mathrm{MoO}_{4}{ }^{\circ}, \mathrm{HMoO}_{4}^{-}$ & $\mathrm{HMoO}_{4}^{-}, \mathrm{MoO}_{4}^{2-}$ \\
\hline $\mathrm{Cd}^{2+}$ & $\mathrm{Cd}^{2+}, \mathrm{CdSO}_{4}{ }^{0}, \mathrm{CdCl}^{+}$ & $\mathrm{Cd}^{2+}, \mathrm{CdCl}^{+}, \mathrm{CdSO}_{4}{ }^{\circ}, \mathrm{CdHCO}_{3}{ }^{1}$ \\
\hline & $\mathrm{I}_{2}, \mathrm{I}^{-\mathrm{b}}$ & $\mathrm{IO}_{3}^{-}, \mathrm{I}^{\mathrm{c}}$ \\
\hline $\mathrm{Pb}^{2+}$ & $\mathrm{Pb}^{2+}$, org, $\mathrm{PbSO}_{4}{ }^{\circ}, \mathrm{PbHC} \mathrm{CO}_{3}^{+}$ & $\mathrm{PbCO}_{3}{ }^{\circ}, \mathrm{PbHCO}_{3}{ }^{+}$, org $, \mathrm{Pb}\left(\mathrm{CO}_{3}\right)_{2+}{ }^{2-}, \mathrm{PbOH}^{+}$ \\
\hline $\mathrm{U}^{+6}$ & $\mathrm{UO}_{2}^{+2}$ & $\mathrm{UO}_{2}\left(\mathrm{CO}_{3}\right)_{3}^{-4}$ \\
\hline $\mathrm{Np}^{+6}$ & $\mathrm{NpO}_{2}^{+2}$ & $\mathrm{NpO}_{2}\left(\mathrm{CO}_{3}\right)_{3}{ }^{-4}$ \\
\hline
\end{tabular}

${ }^{a}$ Organic complexes (e.g., fulvic acid complexes).

${ }^{\mathrm{b}} \mathrm{I}$ when $\mathrm{Eh}$ below 0.8 volts.

${ }^{c}{ }^{\top}$ when Eh below 0.4 volts. 
Chemical speciation in soil water is strongly controlled by solution $\mathrm{pH}$ and pe (or Eh), the $\log$ activities of free protons and electrons in the system, respectively. A low $\mathrm{pH}$ favors formations of free metal cations and protonated anions, while a high $\mathrm{pH}$ favors carbonate or hydroxyl complexes. Just as large values of $\mathrm{pH}$ results in the existence of proton-poor species, large values of pe favor the existence of electron-poor (i.e., oxidized) species. On the other hand, small values of pe favor electron-rich, or reduced species, just as small values of $\mathrm{pH}$ favor proton-rich acid species. $\mathrm{pH}$ and pe values in ordinary soils range from 3.5 to 9 [Lindsay, 1979] and -6.0 to +13.0 [Sposito, 1989].

As contaminants are leached from the waste form into the surrounding ground water, the composition of the water is modified by chemical interaction between the waste form and contacting water. The chemistry of the modified water or leachate is controlled by the composition of the uncontaminated ground water, and the amount and composition of the materials leached from the waste forms. Several studies have been performed on the chemistry of leachates and ground waters from commercial low-level waste disposal sites [Fowler et al., 1983; Dayal et al., 1984, 1986; Kelly, 1987; Peters et al., 1992]. The most detailed of these studies were conducted at Brookhaven National Laboratory (BNL) by Dayal et al. [1984, 1986] on four commercial LLW sites - Maxey Flats, West Valley, Barnwell, and Sheffield. The findings of these studies are summarized in Appendix 1.

\subsection{Water Flow}

Water flow in the unsaturated zone is transient due to intermittent precipitation events. Transient water flow begins with the entry of water at the ground surface and subsequent infiltration downward into the disposal facility. The rate of infiltration into the facility and beyond is controlled by the rate and duration of water application at the surface, the hydraulic conductivity of engineered barriers, backfill and surrounding soil, and the matric and gravity potential gradients. If the backfill materials and adjacent soils are dry, the capacity of these materials to take in water will initially be high due to large matric potential gradients. This capacity will gradually decrease as the moisture content increases and the hydraulic conductivity in the near-surface soil approaches the saturated conductivity value. If the duration and application of water influx are sufficiently large, the wetting front will penetrate deep into the soil beyond the facility along with increasing moisture contents. Simultaneously, the potential gradient in the near surface region will asymptotically approach unity and the infiltration rate will become equal to the average saturated hydraulic conductivity. If the application rate of water at the ground surface exceeds the average hydraulic conductivity, water will pond at the surface.

Once the application of water stops, water flow in the near-surface soil will cease while the deeper penetrating water will continue to redistribute as it flows downward beyond the disposal facility in a spreading wetting pattern or pulse. At the advancing edge of this pulse water contents will increase and at the upper trailing edge water contents will decrease. Eventually, at some distance from the ground surface, transient effects will dampen out and the downward flowing water will reach a steady infiltration rate. The distance at which steady infiltration occurs is sometimes referred to as the penetration depth [Eagleson, 1978; Salvucci, 


\subsection{Relevant Physical and Chemical Processes}

1993]. Thus, the unsaturated zone is essentially comprised of two regions: an unsteady flow region between the ground surface and penetration depth wherein a disposal facility will be situated, and a steady flow region between the penetration depth and the saturated zone (water table). The steady flux in the lower unsaturated region is equal to the annual rate of ground-water recharge and, therefore, is comprised of contributions, not only from the most recent pulse, but from previous precipitation events as well. Note that highly heterogeneous unsaturated zones containing, for example, soil interbeds of low permeability or fractures of high permeability will force an infiltrating pulse to follow a very tortuous path. Moreover, if the thickness of the unsaturated zone is also significantly less than the required penetration depth, water flow will be entirely unsteady and the ground water recharge may itself also be intermittent. Finally, net infiltration to the saturated zone can actually be negative (i.e., upwards) in some arid settings.

In contrast to flow in the unsaturated zone, ground-water flow in the saturated zone is often reasonably steady and unidirectional in the horizontal axis. Exceptions to this generalization might occur in cases where substantial water recharge or extraction by pumping is taking place and in highly heterogeneous and anisotropic aquifer systems.

\section{$2.4 \quad$ Ground-Water Transport}

The same processes that control the transport of contaminants within the disposal facility also control the mobilities of contaminants once they leave the disposal facility. As contaminants migrate away from their release point, they will encounter progressive changes in the chemical and biological conditions (i.e., pH, Eh, soil textural composition and mineralogical constituents, microbe populations) and experience consequent changes in their chemical form. These changes may produce significant alterations in solubilities and sorption capacities of the contaminants and ultimately their transport rates. Such complex interactions between leaching, flow, chemistry, and transport will progress downward in a stepwise fashion as each succeeding pulse travels through the unsaturated zone. Again, as in the disposal facility, residence time is likely to play an important role in determining the chemical properties of contaminants, their degree of attenuation, and most importantly their rate of influx to the saturated zone.

The intermittent nature of water infiltration and flow in the disposal facility and unsaturated zones may, under some conditions, yield long-term contaminant loadings to the saturated zone that are substantially different than a steady-state constant retardation analysis might predict. We are unaware of any field and laboratory investigations addressing this issue. There is some numerical evidence, however, that a steady-state treatment might be adequate when nonreactive solutes are involved. Suen et al. [1988] found that if contaminant release is proportional to infiltration rate, the total amount of water that flows through the system determines the rate of movement of contaminants. The modeling study by Jones and Watson [1987] found that after intermittent leaching, if hysteresis effects on flow are neglected, a nonreactive solute becomes fairly uniformly distributed as it travels deeper into the unsaturated zone. In contrast, however, they also found that if hysteresis is accounted for, the solute travels downward in a series of well defined peaks. In this case, contaminant influx into the ground water will also be intermittent. 
Contaminant migration in the saturated zone is usually advection dominated and many of the same chemical and physical processes that attenuate migration in the disposal unit and unsaturated zone also operate in the saturated zone. Hydrodynamic dispersion can also have a significant impact on transport in the saturated zone. Aquifer systems as a rule are three dimensional, heterogeneous, and anisotropic. As a consequence, dispersion effects on contaminant migration can be significant, particularly over large distances [Gelhar et al., 1979; Dagan, 1984]. Whereas retardation reduces the apparent velocity of a contaminant, dispersion causes the contaminant to spread out from the path it would be expected to follow if transported by advection only.

Contaminant migration in both the unsaturated and saturated zones may be significantly enhanced by the presence of mobile colloids. Colloids are particles with diameters less than ten microns and commonly occur in natural and engineered soil and water systems. These particles include microorganisms, humic substances, mineral precipitates, clay minerals, and iron oxides [McCarthy and Zachara, 1989]. There are at least two potential sources of colloids in a LLW disposal facility. The corrosion of metal containers can give rise to colloids in the form of amorphous iron oxides. Degradation of cementitious waste forms and engineered concrete barriers may also lead to the formation of colloidal-size calcium carbonate particles. Colloids have high specific surface areas which can make them highly reactive adsorbents for radionuclides. As a result, colloids can substantially enhance the migration of radionuclides that might otherwise adsorb to the host porous media. Colloids may be removed from suspension during transport, however, by mechanical filtration, adsorption onto the soil, and neutralization of their repulsive surface charges by acid-base and complexation reactions, thus allowing them to coagulate. Reviews of the significance of colloid facilitated transport can be found in [Eichholz et al., 1982; McCarthy and Zachara, 1989; Mills et al., 1991].

\subsection{Summary of Processes Controlling the Mobilities and Concentrations of Radionuclides}

It is apparent from the preceding discussions that several physical and chemical processes play a role in determining the post-closure performance of a LLW disposal facility. The following sections summarize the major chemical processes that control the mobilities and concentrations of radionuclides being transported by ground water, including:

- Complexation Reactions

- $\quad$ Acid-Base Reactions

- Oxidation-Reduction Reactions

- Dissolution-Precipitation Reactions

- $\quad$ Sorption and Ion Exchange Reactions

- Biodegradation of Organic Matter

- $\quad$ Radioactive Decay and Ingrowth 


\subsection{Relevant Physical and Chemical Processes}

\subsubsection{Complexation Reactions}

In complexation reactions, a central cation such as a radionuclide or metal ion reacts with an anion, commonly called a ligand, to form a new soluble species called a complex. Complexation reactions are especially important because these reactions significantly modify the solubility and hence mobility of actinides and transition metals. Inorganic ligands include common anions in natural waters, e.g. $\mathrm{OH}^{-}, \mathrm{Cl}^{-}, \mathrm{SO}_{4}{ }^{2-}, \mathrm{CO}_{3}{ }^{2-}, \mathrm{PO}_{4}{ }^{3-}$, etc. Inorganic ligands are typically present in solution in excess compared to radionuclides and metals they bind with.

Important organic ligands include molecules associated with natural humic substances and synthetic organic complexing agents. Organic ligands tend to form stronger bonds than inorganic ligands. When there is more than one site for bonding, the ligand is known as a chelating agent. Chelating agents are used in the decontamination of nuclear power plants. These artificial chelating agents found in LLW sites include: EDTA (ethylenediaminetetraacetic acid), HEDTA (n-hydroxyethylethylene-diaminetriacetic acid), and ED3A (ethylenediaminetriacetic acid) [Dayal et al., 1984]. These chelating agents play a very important role in mobilizing radionuclides such as Co-60, which was reported to occur mostly in the form of anionic complexes in contaminated ground water at the Chalk River LLW site, Canada [Killey et al., $1984]$.

\subsubsection{Acid-Base Reactions}

Acid-base reactions involve the transfer of the proton $\left(\mathrm{H}^{+}\right)$between two species. Chemical species which lose a proton are called acids; species which gain a proton are called bases. Acid-base reactions can be classified as either aqueous complexation, precipitation, or sorption reactions. The $\mathrm{pH}$ of a solution is a measure of the activity of $\mathrm{H}^{+}$(more precisely, $\mathrm{H}_{3} \mathrm{O}^{+}$ ion) in solution, and it is defined as the negative logarithm of the $\mathrm{H}^{+}$activity $\left(\mathrm{pH}=-\log \mathrm{a}_{\mathrm{H}^{+}}\right)$.

$\mathrm{pH}$ can be considered as one of the master parameters controlling speciation in solution because it directly affects the solubility of compounds, the sorption behavior of elements (e.g. $K_{d}$ values), complex formation, and oxidation-reduction processes. For example, under oxidizing conditions, $\mathrm{Pu}^{6+}$ species is in the form of $\mathrm{PuO}_{2}{ }^{2+}$ at low pH $(<5)$. At $\mathrm{pH}$ between 5 and 7 , it is in the form of $\mathrm{PuO}_{2}(\mathrm{OH})^{+}$and at $\mathrm{pH}$ above 7 it is in the form of $\mathrm{PuO}_{2}(\mathrm{OH})_{3}^{-}$. The corresponding measured values for $\mathrm{K}_{\mathrm{d}}$ range from less than $10(\mathrm{ml} / \mathrm{g})$ at low $\mathrm{pH}$ to between 10 and $100(\mathrm{ml} / \mathrm{g})$ for the neutral $\mathrm{pH}$ range, to over $1000(\mathrm{ml} / \mathrm{g}$ ) at high $\mathrm{pH}$ (see data in Table 2.6). $\mathrm{pH}$ also influences the rate of metal container corrosion. Below $\mathrm{pH}$ of 7 , lower soil $\mathrm{pHs}$ tend to increase corrosion rate.

The typical range of measured $\mathrm{pH}$ values in leachates from LLW shallow land burial sites is between 6 and 8 [Dayal et al, 1986], not too different from normal ground water. However, two samples from Maxey Flats show a $\mathrm{pH}$ value of about 12 . This indicates that the waste content may have significant control over the $\mathrm{pH}$ of the leachate. This is especially true in the presence of cement waste forms. 
2.0 Relevant Physical and Chemical Processes

Table 2.6 pH Effect on Kd Values in Ground Water Equilibrated Site Soil

\begin{tabular}{|c|c|c|c|c|c|c|c|}
\hline & $\begin{array}{c}\mathrm{pH} \\
4 \\
\end{array}$ & $\begin{array}{c}\mathrm{pH} \\
5 \\
\end{array}$ & $\begin{array}{c}\text { MEASURED } \\
\mathrm{pH} \\
6 \\
\end{array}$ & Kd & $\begin{array}{c}\mathrm{pH} \\
8 \\
\end{array}$ & $\begin{array}{c}\mathrm{pH} \\
9 \\
\end{array}$ & $\begin{array}{l}\mathrm{pH} \\
10 \\
\end{array}$ \\
\hline $\mathrm{Co}$ & 5 & 20 & 450 & 12000 & $500(10 K)$ & 80 & 10 \\
\hline \multicolumn{8}{|l|}{ Cs } \\
\hline a & 6 & 10 & 20 & 50 & 90 & 110 & 250 \\
\hline $\mathrm{b}$ & 60 & 120 & 200 & 600 & 900 & 800 & 500 \\
\hline \multirow[t]{2}{*}{$\mathrm{c}$} & 400 & 700 & 1,100 & 1,500 & 1,800 & 1,200 & 800 \\
\hline & {$[\mathrm{a}=5 \mathrm{E}-4 \mathrm{M} \mathrm{Cs}$} & $\mathrm{b}=5 \mathrm{E}-6 \mathrm{M} \mathrm{Cs}$ & $\mathrm{c}=5 \mathrm{E}-8 \mathrm{M} \mathrm{Cs}]$ & & & & \\
\hline $\mathrm{Pu}(\mathrm{III})$ & 3,000 & $>10,000$ & 20,000 & 130,000 & 10,000 & 7,000 & 5,000 \\
\hline $\mathrm{Pu}(\mathrm{IV})$ & 100 & 300 & 3,000 & 7,000 & 6,000 & 4,400 & 3,000 \\
\hline $\mathrm{Pu}(\mathrm{VI})$ & 7 & 11 & 20 & 80 & 16,000 & 1,000 & 700 \\
\hline $\mathrm{Sr}$ & 2 & 20 & 320 & 2,000 & 100 & 80 & 60 \\
\hline
\end{tabular}

Adapted from Hoeffner, 1985

\subsubsection{Oxidation-Reduction Reactions}

Oxidation-reduction (redox) reactions involve the transfer of electrons from one species to another resulting in changes in oxidation states of elements. Redox reactions can be classified as either aqueous complexation, precipitation, or adsorption reactions. The transfer of electrons in these reactions are similar to the transfer of protons $\left(\mathrm{H}^{+}\right)$in acid-base reactions. Analogous to $\mathrm{pH}$, the activity of electrons in solution is defined by the parameter pe which equals the negative logarithm of the electron activity. pe can also be expressed in terms of the redox potential, Eh (the millivolt difference in potential between a platinum electrode and the standard hydrogen electrode), as follows:

$$
p e=\frac{F}{2.3 R T} E h
$$




\subsection{Relevant Physical and Chemical Processes}

where $\mathrm{F}$ is the Faraday constant, $\mathrm{R}$ is the gas constant, and $\mathrm{T}$ is the absolute temperature.

Redox conditions can significantly alter the mobility of multiple-oxidation state radionuclides because the effectiveness of adsorption mechanisms often depends on the oxidation state of the radionuclide. In addition, concentrations of ligands, which can enhance the solubility of radionuclides, are also dependent on redox conditions Serne et al. [1990]. Important radionuclides that exhibit multiple oxidation states include iodine, the transition metals, and the important actinides uranium and plutonium. $\mathrm{I}-129$ can occur in two species, $\mathrm{I}^{-}$and $\mathrm{IO}_{3}{ }^{-}$ions, depending on the prevailing redox conditions. These species have substantially different sorption behaviors [Strickert et al., 1980]. Both Pu and $U$ can occur in $+3,+4,+5$, or +6 oxidation states. Consequently, their speciation and hence mobility can strongly depend on redox conditions.

\subsubsection{Dissolution and Precipitation Reactions}

The dissolution-precipitation process is one of two fundamental chemical processes that directly removes (or releases) radionuclides from solution, the other process being sorption. Under some conditions, large quantities of mass can be precipitated or transferred from the liquid phase to the solid phase. Therefore, precipitation of dissolved species can play a very important role in retarding radionuclide transport. Large amounts of precipitate can also alter the pore structure of the soil and cause a decrease in its permeability. The converse of precipitation is dissolution. Dissolution is a primary mechanism of releasing radionuclides from the waste form into the adjacent environment. Dissolution is also the source of most inorganic ions in ground water.

Dissolution-precipitation of a solid phase in an aqueous solution is a dissociationassociation process in which two or more soluble ionic species are released into or removed from solution. It is subjected to the common ion effect, which occurs when a solution already contains the same ions that would be released or removed when the solid dissolves or precipitates. The presence of common ions from other sources reduces the solubility of the solid relative to its solubility in pure water.

A dissolution-precipitation reaction can be treated appropriately as a mass-action equilibrium reaction, and the degree of solubility can be related to the equilibrium constant as follows:

$$
x A+y B \leftrightarrow A_{x} B_{y}
$$

where $\mathrm{A}$ and $\mathrm{B}$ are dissolved species, $\mathrm{A}_{\mathrm{x}} \mathrm{B}_{\mathrm{y}}$ is a solid compound, and $\mathrm{x}$ and $\mathrm{y}$ are stoichiometric coefficients. The mass action equilibrium expression can be written as: 


\subsection{Relevant Physical and Chemical Processes}

$$
K_{e q}=\frac{\left[a_{A}\right]^{x} \cdot\left[a_{B}\right]^{y}}{\left[a_{A_{x} B_{y}}\right]}
$$

where $\mathrm{a}_{\mathrm{A}}$ and $\mathrm{a}_{\mathrm{B}}$ are activities of the dissolved species in solution, and $\mathrm{a}_{\mathrm{AxB}}$ is the activity of the solid, which is equal to unity by definition. Therefore, equation (2.5.3) can be written as:

$$
K_{s p}=\left[a_{A}\right]^{x} \cdot\left[a_{B}\right]^{y}
$$

where $\mathrm{K}_{\mathrm{sp}}$ is called the solubility product of the solid compound. It therefore limits the activities (hence concentrations) of species A and B in solution.

Another important factor which controls precipitation and dissolution of solid phases is the kinetic factor. However, kinetic data for precipitation and dissolution of relevant radionuclide-containing trace compounds are largely unavailable.

With the exception of $\mathrm{H}-3$, all significant radionuclides are subject to precipitation and dissolution reactions. $\mathrm{H}-3$ is incorporated into water molecules, and therefore it has practically unlimited solubility when the dominant species is in the form of tritiated water. Only C-14 and Fe-55 can occur in major mineral phases in the soil; $\mathrm{C}$ in carbonates or organic matter and $\mathrm{Fe}$ in iron carbonate, oxide, and hydroxide minerals. The other radionuclides occur either as trace components of major phases, or in trace compounds (or minerals). However, separation and identification of these trace compounds in a soil sample is difficult, and currently, little work has been carried out to positively identify trace radioactive compounds in soils from waste sites. Therefore, when modeling dissolution-precipitation reactions, it is necessary to rely on thermodynamic data which are assumed to be reasonably accurate.

Finally, because the solubility of a solid is a function of the activities of its component ionic species in solution, it is controlled indirectly by all other speciation reactions in the solution, which include complexation, acid-base, and oxidation-reduction reactions.

\subsubsection{Sorption and Ion Exchange Reactions}

Sorption is the attachment (detachment) of chemical species on mineral surfaces. Sorption affects almost all radionuclides to some extent with the possible exception of $\mathrm{H}-3$. Sorption of radionuclide ions occurs primarily because of the positive or negative charges they carry and surface complexation reactions that bind them to solid surfaces. Interactions between mineral surfaces and dissolved ions can depend strongly on solution $\mathrm{pH}$ and the mineral's zero point of charge (ZPC)[Stumm and Morgan, 1981]. If the $\mathrm{pH}$ of the contacting solution is above the ZPC, the mineral surface will have a net negative charge and an affinity for cations; the reverse occurs if the $\mathrm{pH}$ is less than the ZPC. This phenomena is particularly important in systems containing clays and particles coated with common hydrous oxides such as those of aluminum, manganese, and iron. These materials are often dominant sorbents in geochemical systems. Clay minerals tend to have overall negative charges for all but very acidic conditions 


\subsection{Relevant Physical and Chemical Processes}

(i.e. $\mathrm{pH}<5$ ). Metal oxides on the other hand tend to provide reactive sites capable of removing anionic radionuclide species from solution for near neutral $\mathrm{pH}$.

While there are a few studies that document the presence of radionuclides on soils near commercial shallow land burial LLW sites (Weiss and Colombo [1980a, 1980b]; Czyscinski and Weiss [1981]; Dayal et al. [1984]); there are no studies that identify the actual mineralradionuclide associations (Serne et al. [1990]). The presence of heavy metals and radionuclides in sediments as adsorbed species on metal oxides has been reported in non-commercial radioactive waste field studies. Suarez and Langmuir [1976] found that $\mathrm{Co}, \mathrm{Ni}, \mathrm{Cu}, \mathrm{Zn}, \mathrm{Pb}, \mathrm{Ag}$, and $\mathrm{Cd}$ in a Pennsylvania soil were present largely in $\mathrm{Fe}$ and $\mathrm{Mn}$ oxide phases. Means et al. [1978a, 1978b] documented that Co-60 and the actinides, Pu-238, Am-241, and Cm-244 in sediments around a nuclear waste disposal site were present as adsorbed species on Mn oxides.

Ion exchange reactions are an important control on the mobility of radionuclide species in soils, especially in soils with high contents of clays and organic matter. Most of the radionuclides of concern are potentially affected by ion exchange, with the exception of $\mathrm{H}-3$ and $\mathrm{C}-14$. Ion-exchange reactions are in effect similar to adsorption reactions. Minerals exchange ions because of the presence of negatively charged sites (electrostatic forces) on the mineral, resulting from the substitution of an atom of lower oxidation number for one of higher number. Organic materials exchange cations because of the presence of basic functional groups such as the carboxylate group.

The ability of soils to exchange ions is expressed by the cation exchange capacity (CEC), which is defined as the number of milliequivalents (meq) of monovalent cations per unit mass of dry soil. The equivalent of an ion is its molecular weight divided by the absolute value of its charge. Typical CEC values for soils containing organic materials range from 30 to 100 $\mathrm{meq} / 100 \mathrm{~g}$, depending on the mineral type, $\mathrm{pH}$, and composition of the contacting solution. Table 2.7 gives the range of reported values of CEC for clay minerals.

Table 2.7 Cation-exchange Capacities (meq/100 g) of clay minerals.

$\begin{array}{ll}\text { Smectities } & 80-150 \\ \text { Vermiculites } & 120-200 \\ \text { Illites } & 10-40 \\ \text { Kaolinite } & 1-10 \\ \text { Chlorite } & <10\end{array}$

Drever, J., Geochemistry of Natural Waters, (c)1982.

Adapted by permission of Prentice Hall, Upper Saddle River, New Jersey. 


\subsection{Relevant Physical and Chemical Processes}

The relative ease of the replacement of one cation by another is [Stumm and Morgan]:

$$
\mathrm{Li}^{+}<\mathrm{Na}^{+}<\mathrm{K}^{+}<\mathrm{Rb}^{+}<\mathrm{Cs}^{+}<\mathrm{Mg}^{2+}<\mathrm{Ca}^{2+}<\mathrm{Sr}^{2+}<\mathrm{Ba}^{2+}<\mathrm{H}^{+}
$$

Note that the affinity for replacement increases with ionic radii (non-hydrated). In other words, the ion with the larger hydrated radius is subjected to replacement by an ion of smaller hydrated radius.

\subsubsection{Biodegradation of Organic Matter}

Natural organic matter is present in soils, and a large amount of organic materials are present in LLW waste. Organic wastes include contaminated clothing, paper products, animal carcasses, and tissues used in biological experiments. Biodegradation of organic matter is mainly a result of redox processes involving microorganisms (mostly bacteria) as catalysts. Under aerobic conditions oxygen acts as the electron acceptor and the resulting products are carbon dioxide and water. Under anoxic and anaerobic conditions, other species can act as electron acceptors. Important anoxic and anaerobic microbial processes in soils can be represented by the following reactions given by Domenico and Schwartz [1990]:

Reduction of $\mathrm{Fe}^{3+}$ :

$$
\frac{1}{4} \mathrm{CH}_{2} \mathrm{O}+\mathrm{Fe}(\mathrm{OH})_{3}+2 \mathrm{H}^{+}=\frac{1}{4} \mathrm{CO}_{2}(g)+\mathrm{Fe}^{2+}+\frac{11}{4} \mathrm{H}_{2} \mathrm{O}
$$

Denitrification:

$$
\mathrm{CH}_{2} \mathrm{O}+\frac{4}{5} \mathrm{NO}_{3}^{-}+\frac{4}{5} \mathrm{H}^{+}=\mathrm{CO}_{2}(g)+\frac{2}{5} \mathrm{~N}_{2}+\frac{7}{5} \mathrm{H}_{2} \mathrm{O}
$$

Sulfate reduction:

$$
\mathrm{CH}_{2} \mathrm{O}+\frac{1}{2} \mathrm{SO}_{4}^{2-}+\frac{1}{2} \mathrm{H}^{+}=\frac{1}{2} \mathrm{HS}^{-}+\mathrm{H}_{2} \mathrm{O}+\mathrm{CO}_{2}(\mathrm{~g})
$$

Methane formation (reduction of $\mathrm{CO}_{2}$ ):

$$
\mathrm{CH}_{2} \mathrm{O}+\frac{1}{2} \mathrm{CO}_{2}(\mathrm{~g})=\frac{1}{2} \mathrm{CH}_{4}+\mathrm{CO}_{2}(\mathrm{~g})
$$

where $\mathrm{CH}_{2} \mathrm{O}$ is used to represent the common organic compounds.

Another important aspect of biodegradation reactions is that they produce gaseous species such as $\mathrm{CO}_{2}, \mathrm{CH}_{4}$, and $\mathrm{H}_{2} \mathrm{~S}$. These gaseous species provide an alternate mode of transport for C-14 and $\mathrm{H}-3$ in addition to the modeled solute transport processes. A model for simulating gaseous release has been developed and tested as part of this program (Yim, 1994). 


\subsection{Relevant Physical and Chemical Processes}

\subsubsection{Radioactive Decay and Ingrowth}

For some radionuclides, particularly actinides and transuranics, several progeny products may be produced before the parent species decays to a stable element. These progeny products may differ significantly from their parents physically, chemically, and toxicologically. For example, consider the decay of Am-241 to the progeny Np-237. In this case, the progeny is significantly more toxic than the parent [International Commission on Radiological Protection, 1979]. The adsorption properties of the two radionuclides are also apparently quite different. Sheppard and Thibault [1990] report $\mathrm{K}_{\mathrm{d}}$ values for Am and $\mathrm{Np}$ in sandy soils as $1900(\mathrm{~L} / \mathrm{kg})$ and $5(\mathrm{~L} / \mathrm{kg})$. Again it should be emphasized the mobility of many radionuclides is dependent upon the chemical conditions in the disposal unit and along the flow path. These values of $K_{d}$ reported here represent generic geometric mean values derived from a literature compilation of $\mathrm{K}_{\mathrm{d}}$ values for a variety of chemical systems.

Radioactive decay occurs mainly by the emission of electrically charged particles, either a helium nucleus in alpha decay or a positive (positron) or negative (negatron) electron in beta decay. In some cases gamma radiation accompanies the particle emission. A radioactive element can decay by more than one mode (branched decay) and produce two or more progeny elements. Furthermore, a radioactive element can be produced by more than parent element.

As an example of element decay, consider the first two steps in the decay chain of radionuclide ${ }^{\mathrm{Al}} \mathrm{X}$ :

$\underline{\text { Step } 1}$

$$
{ }^{A_{1}} X_{1} \rightarrow{ }^{A_{2}} X_{2}+{ }^{4} \mathrm{He}
$$

$\underline{\text { Step } 2}$

$$
{ }^{A_{2}} X_{2} \rightarrow{ }^{A_{3}} X_{3}+\beta^{-}
$$

where the first step is an alpha decay process and the second step is a beta decay process. Branched decay can be similarly represented by considering each branch as separate simultaneous reactions:

Branch 1

$$
{ }^{A_{1}} X_{1} \rightarrow{ }^{A_{2}} X_{2}+{ }^{4} \mathrm{He}
$$


Branch 2

$$
{ }^{A_{1}} X_{1} \rightarrow{ }^{A_{3}} X_{3}+\beta^{-}
$$

The fate of chemical species which involve one or more radioactive elements must also be considered. After decay, nonradioactive element(s) in the species may disassociate or remain associated to the progeny element. Molecular bonds typically do not remain intact during the alpha decay process; however, many species survive beta and gamma decay processes with their chemical bonds intact because so little energy is available for bond rupture. Consider the beta decay reaction [Choppin and Rydberg, 1980]:

$$
\mathrm{TeO}_{3}^{2-} \rightarrow \mathrm{IO}_{3}^{-}+\boldsymbol{\beta}^{-}
$$

In this example, the oxygen atoms remain bonded to the iodine as it was produced by the tellurium. These reactions are referred to herein as association decay reactions. An example of a disassociation decay reaction involving alpha decay of a uranyl ion is:

$$
\mathrm{UO}_{2}^{2+} \rightarrow{ }^{234} \mathrm{Th}+\mathrm{O}_{2}+{ }^{4} \mathrm{He}
$$

\subsection{Summary}

The foregoing discussion addressed several chemical processes important to the postclosure performance of a LLW facility. These processes and their impact on transport are summarized in Table 2.8. Chemical reactions identified as potentially important to the transport of significant radionuclides are noted in Table 2.9. 


\subsection{Relevant Physical and Chemical Processes}

\section{Table 2.8 Summary of The Chemical Processes Important in Dissolved Containment Transport}

\begin{tabular}{|c|c|c|}
\hline Process & Definition & Impact on Transport \\
\hline Radioactive Decay & $\begin{array}{l}\text { Irreversible decline in the activity of a radionu- } \\
\text { clide through a nuclear reaction. }\end{array}$ & $\begin{array}{l}\text { An important mechanism for con- } \\
\text { taminant attenuation when the half- } \\
\text { life for decay is comparable to or } \\
\text { less than the residence time of the } \\
\text { flow system. Also adds complexity } \\
\text { in production of progeny products. }\end{array}$ \\
\hline Adsorption & $\begin{array}{l}\text { Partitioning of a contaminant between the } \\
\text { ground water and mineral or organic solids in the } \\
\text { aquifer. It is mainly a sorption phenomenon. }\end{array}$ & $\begin{array}{l}\text { An important mechanism that } \\
\text { reduces the rate at which the con- } \\
\text { taminants are apparently moving. } \\
\text { Makes it more difficult to remove } \\
\text { contaminant at a site. }\end{array}$ \\
\hline Ion-exchange & $\begin{array}{l}\text { Replacement of an ion in the solid phase by } \\
\text { another ion in solution. }\end{array}$ & $\begin{array}{l}\text { Cation exchange is particularly } \\
\text { important in reducing the mobility } \\
\text { of cations in clay-rich soil. }\end{array}$ \\
\hline $\begin{array}{l}\text { Dissolution/ } \\
\text { precipitation }\end{array}$ & $\begin{array}{l}\text { The process of adding contaminants to, or } \\
\text { removing them from, solution by reactions, } \\
\text { dissolving or creating various solids. }\end{array}$ & $\begin{array}{l}\text { Contaminant precipitation is an } \\
\text { important attenuation mechanism } \\
\text { that can control the concentration of } \\
\text { contaminant in solution. Solution } \\
\text { concentration is mainly controlled } \\
\text { either at the source or at a reaction } \\
\text { front. }\end{array}$ \\
\hline Acid/base reactions & Reactions involving a transfer of protons $\left(\mathrm{H}^{+}\right)$. & $\begin{array}{l}\text { Control pH of ground water and } \\
\text { therefore modify solubility, sorption } \\
\text { and mobility of contaminants. }\end{array}$ \\
\hline Complexation & $\begin{array}{l}\text { Combination of cations and anions to form a } \\
\text { more complex ion. }\end{array}$ & $\begin{array}{l}\text { An important mechanism resulting } \\
\text { in increased solubility of metals in } \\
\text { ground water, if adsorption is not } \\
\text { enhanced. Major ion complexation } \\
\text { will increase the quantity of solid } \\
\text { dissolved in solution. }\end{array}$ \\
\hline $\begin{array}{l}\text { Redox reaction } \\
\text { (including } \\
\text { corrosion of } \\
\text { metal) }\end{array}$ & $\begin{array}{l}\text { Reactions that involve a transfer of electrons and } \\
\text { include elements with more than one oxidation } \\
\text { state. }\end{array}$ & $\begin{array}{l}\text { An extremely important family of } \\
\text { reactions in retarding contaminant } \\
\text { migration through the precipitation } \\
\text { of metals. }\end{array}$ \\
\hline $\begin{array}{l}\text { Biological } \\
\text { transformations }\end{array}$ & $\begin{array}{l}\text { Biologically mediated mass transfer. Reactions } \\
\text { involving the degradation of organic compounds, } \\
\text { whose rate is controlled by the abundance of the } \\
\text { microorganisms and redox conditions. }\end{array}$ & $\begin{array}{l}\text { Important mechanism for contami- } \\
\text { nant reduction, but can lead to } \\
\text { undesirable progeny products. }\end{array}$ \\
\hline
\end{tabular}

Modified from National Research Council, 1990. 


\subsection{Relevant Physical and Chemical Processes}

Table 2.9 Major Chemical Reactions and Significant Radionuclides

\begin{tabular}{|c|c|c|c|c|c|c|c|}
\hline \begin{tabular}{|l} 
Process \\
Radioactive \\
Element
\end{tabular} & $\begin{array}{l}\text { Radioactive } \\
\text { Decay }\end{array}$ & $\begin{array}{l}\text { Adsorption lon- } \\
\text { exchange }\end{array}$ & $\begin{array}{l}\text { Dissolution/ } \\
\text { Precipitation }\end{array}$ & $\begin{array}{l}\text { Redox } \\
\text { Reaction }\end{array}$ & $\begin{array}{l}\text { Acid/Base } \\
\text { Reaction }\end{array}$ & Complexation & $\begin{array}{l}\text { Biological } \\
\text { fransformation }\end{array}$ \\
\hline $\mathrm{H}-3$ & $\checkmark$ & & & & & & $\checkmark$ \\
\hline C-14 & $\checkmark$ & & $\checkmark$ & $\checkmark$ & $\checkmark$ & $\checkmark$ & $\checkmark$ \\
\hline $\begin{array}{l}\text { Cs-137 } \\
\text { Cs-134 }\end{array}$ & $\checkmark$ & $\checkmark$ & $\checkmark$ & & & & \\
\hline Sr-90 & $\checkmark$ & $\checkmark$ & $\checkmark$ & & & $\checkmark$ & \\
\hline $\mathrm{I}-129$ & $\checkmark$ & $\checkmark$ & $\checkmark$ & $\checkmark$ & $\checkmark$ & $\checkmark$ & \\
\hline $\mathrm{Fe}-55$ & $\checkmark$ & & $\checkmark$ & $\checkmark$ & $\checkmark$ & $\checkmark$ & \\
\hline $\mathrm{Co}-60$ & $\checkmark$ & $\checkmark$ & $\sqrt{ }$ & $\checkmark$ & $\sqrt{ }$ & $\checkmark$ & \\
\hline Тc-99 & $\sqrt{ }$ & & $\checkmark$ & $\checkmark$ & $\checkmark$ & $\checkmark$ & \\
\hline Th-232 & $\checkmark$ & $\checkmark$ & $\checkmark$ & & $\checkmark$ & $\checkmark$ & \\
\hline $\mathrm{U}-238$ & $\checkmark$ & $\checkmark$ & $\bar{\checkmark}$ & & $\checkmark$ & $\checkmark$ & \\
\hline $\mathrm{Pu}-239$ & $\checkmark$ & $\checkmark$ & $\checkmark$ & $\sqrt{ }$ & $\checkmark$ & $\checkmark$ & \\
\hline
\end{tabular}



The mathematical description of important processes occurring in a shallow land LLW disposal facility is based upon flow and transport equations governing the movement and conservation of each fluid and chemical species, mass transfer equations governing the release of contaminants from waste forms, and abiotic and biotic reaction equations governing the interaction of the various chemical species with each other as well as with indigenous microorganisms and the host porous media. We begin the presentation of these equations with a general formulation of reactive chemical transport in variably saturated porous media. This formulation is subsequently used as a basis to develop, by simplification, governing equations for fluid flow, multispecies aqueous-phase transport with sorption, and reactive multispecies aqueous-phase transport under the assumption of thermodynamic equilibrium. This hiearchical approach is undertaken to facilitate identification of assumptions implicit in the BLT-EC formulation, as well as in the more common nonreactive transport formulations based on the " $\mathrm{K}_{d}$ " concept such as those used in BLT, DUST, and BLT-MS models.

\subsection{Multiphase, Multispecies, Reactive Transport}

To facilitate the presentation of the theory, it is helpful to first define some terminology. The fluids present are soil gas (air) and ground water, often referred to hereafter as gaseous and aqueous phases. Each fluid phase may contain a number of chemical elements, microorganisms, suspended particles (colloids), and free electrons; each of which are referred to as "elements". "Elements" are linearly independent basis entities that linearly combine to produce all "species" in the system [Van Zeggeren and Storey, 1970]. For example, two chemical "elements" can combine in the usual way to form a chemical "species". A chemical "element" can also combine with a colloid "element" to form a colloid "species". In similar fashion, a chemical "element" can combine with an electron "element" to form a reduced chemical "species" [Walsh, 1983; Allison et al.,1991].

Now, consider a multiphase, permeable system composed of $\mathrm{N}_{\mathrm{e}}$ elements. These elements combine to form: $\mathrm{N}_{\mathrm{s}}$ distinct chemical species which participate in $\mathrm{N}_{\mathrm{cr}}$ chemical reactions, $\mathrm{N}_{\mathrm{br}}$ microbially-mediated reactions, and $\mathrm{N}_{\mathrm{dr}}$ radioactive decay reactions. These reactions take place within and between two mobile fluid phases (aqueous and gaseous) and two stationary phases (soil and precipitate). Within each fluid phase, species transport can occur due to bulk phase advection, as well as molecular diffusion and mechanical dispersion effects. Interphase transfer of mass can occur due to physical phase change (volatilization and condensation) in addition to the heterogeneous reactions of precipitation-dissolution and sorption. In this formulation, phase change is represented as a heterogeneous chemical reaction. Additional transformations due to radioactive decay can also occur.

Throughout this presentation, the characters $\mathrm{j}$ and $\alpha$ are used to denote specie and phase, respectively, and $c_{j \alpha}$ denotes concentration in units of moles of species $j$ per unit volume of phase $\alpha$ and is equal to the product of the molar density, $\xi_{\alpha}$, and species mole fraction, $\mathrm{x}_{\mathrm{j} \alpha}$. The following numbering is used for phase index $\alpha$ : (1) aqueous, (2) gaseous, (3) solid, and (4) precipitate. Element index $\mathrm{k}$ ranges from 1 to $\mathrm{N}_{\mathrm{e}}$, the number of elements. 


\subsection{Mathematical Formulation}

\subsubsection{Transformation Equations}

Recall that the term "elements" refers to chemical elements, microorganisms, colloids, and free electrons. By definition, each chemical element has an atomic weight and oxidation state [Sevougian et al, 1993]. Therefore, isotopes, as well as oxidation states of the same chemical element, are considered to be different "elements". In an analogous fashion, different types of microorganisms and colloids are considered to be different "elements". As described previously, elements combine to form species. Furthermore, each species, $j=1,2, \ldots, N_{s}$, can exist in each phase, $\alpha=1,2,3,4$, and each "element" is also a "species" (element species).

The various species include radioactive and nonradioactive substances introduced into the subsurface by waste disposal and those naturally present in the subsurface. The molecular formula, $\mathrm{B}_{j \alpha}$, of each species $\mathrm{j}$ in phase $\alpha$ can be represented by:

$$
B_{j \alpha}=\sum_{k=1}^{N_{e}} \epsilon_{j k}^{\alpha} e_{k}
$$

for $j=1,2, \ldots, N_{s}$ and $\alpha=1,2,3,4$, where $B_{j \alpha}$ is a symbol vector for the species (e.g., $B_{11}=H_{2}{ }^{16} 0, B_{21}$ $={ }^{238} \mathrm{U}^{16} \mathrm{O}_{2}$, etc. $), \mathrm{e}_{\mathrm{k}}$ is the symbol vector for the elements (e.g. ${ }^{3} \mathrm{H}^{+},{ }^{14} \mathrm{C}^{2+}$, etc. for chemical elements, $M_{1}, M_{2}$, etc. for microbe elements, and $P_{1}, P_{2}$, etc. for colloidal particles), and $\epsilon_{j k}^{\alpha}$ is a formula matrix, with each row vector denoting the quantity of each element in the corresponding species. Note that by definition, the set of elements $e_{k}$ is comprised of the minimum number of elements necessary to define all species present in the system.

Key reactions involving species $\mathrm{B}_{\mathrm{j} \alpha}$ include complexation, acid-base, oxidation-reduction, precipitation-dissolution, sorption, and ion exchange. These reactions include both reversible and irreversible reactions and may be written in symbolic form as:

\section{$\underline{\text { Chemical }}$}

$$
0 \Leftrightarrow \sum_{\alpha=1}^{4} \sum_{j=1}^{N_{s}} v_{j r}^{\alpha} B_{j \alpha}
$$

for $\mathrm{r}=1,2, \ldots, \mathrm{N}_{\mathrm{cr}}$, and

Microbial

$$
0 \Leftrightarrow \sum_{\alpha=1}^{4} \sum_{j=1}^{N_{s}} b_{j r}^{\alpha} B_{j \alpha}
$$


for $r=1,2, \ldots, N_{b r}$, where the notation $(\Leftrightarrow)$ is used to indicate a reaction and $v_{\mathrm{jr}}^{\alpha}$ and $b_{\mathrm{jr}}^{\alpha}$ are stoichiometric reaction matrices whose members are negative for reactant species and positive for product species. Reactions involving colloid species are surface complexation reactions and therefore are included in the chemical reactions.

Transformations due to radioactive decay are also important. Radioactive elements (element species) in the system undergo spontaneous change producing progeny elements. The various radioactive decay reactions described in Section 2.5.7 can be written in symbolic form as:

$$
\sum_{\alpha=1}^{4} \sum_{j=1}^{N_{s}} \omega_{j r} B_{j \alpha} \rightarrow 0
$$

for $\mathrm{r}=1,2, . . \mathrm{N}_{\mathrm{d} r}$, where $\omega_{j r}$ is the species stoichiometric radioactive decay matrix, the members of which are positive for parent species and negative for progeny species.

Each of the reactions in equations (3.1.2) - (3.1.4) have a rate associated with them:

\section{Chemical}

$$
\left(\frac{d\left(\theta_{\alpha} c_{j \alpha}\right)}{d t}\right)_{c h e m}=\sum_{r=1}^{N_{c r}} v_{j p}^{\alpha} f_{r}^{c}
$$

Microbial

$$
\left(\frac{d\left(\theta_{\alpha} c_{j \alpha}\right)}{d t}\right)_{b i o}=\sum_{r=1}^{N_{b r}} b_{j r}^{\alpha} f_{r}^{b}
$$

Radioactive decay

$$
\left(\frac{d\left(\theta_{\alpha} c_{j \alpha}\right)}{d t}\right)_{r a d}=\sum_{r=1}^{N_{d r}} \omega_{j p}^{\alpha} f_{r}^{d}
$$

where $\mathrm{f}_{r}^{\mathrm{d}}, \mathrm{f}_{r}^{\mathrm{b}}$, and $\mathrm{f}_{r}^{\mathrm{c}}$ are rate laws $\left[\mathrm{mol} \cdot \mathrm{cm}^{-3} \cdot \mathrm{s}^{-1}\right]$ for decay, biochemical, and chemical reactions, respectively. The subscripts "chem", "bio", and "rad" denote changes in the concentrations of species $\mathrm{j}$ in phase $\alpha$ per unit bulk volume $\left[\mathrm{mol} \cdot \mathrm{cm}^{-3}\right]$ (i.e. $\theta_{\alpha} \mathrm{C}_{\mathrm{j} \alpha}$ ) due solely to chemical, microbial, and radioactive decay processes, respectively. 


\subsection{Mathematical Formulation}

\subsubsection{Transport Equations}

Let the rates of reaction of steps (3.1.2) through (3.1.4) be denoted by $r_{j \alpha} r_{j \alpha}^{b}$ and $r_{j \omega}^{d}$ respectively $\left[\mathrm{mol} \cdot \mathrm{cm}^{-3} \cdot \mathrm{s}^{-1}\right]$. Then the macroscopic mass balance equations governing the spatial and temporal variations in concentrations of each species, within each phase present, can be expressed as:

Mobile Fluid Phases $(\alpha=1,2)$

$$
\frac{\partial\left(\theta_{\alpha} \xi_{\alpha} x_{j \alpha}\right)}{\partial t}+\nabla \cdot J_{j \alpha}=\Gamma_{j \alpha}
$$

Stationary Solid Phases $(\alpha=3,4)$

$$
\frac{\partial\left(\theta_{\alpha} \xi_{\alpha} x_{j \alpha}\right)}{\partial t}=\Gamma_{j \alpha}
$$

where $\theta_{\alpha}$ is the volume fraction of phase $\alpha\left[\mathrm{cm}^{3} \bullet \mathrm{cm}^{-3}\right], \mathrm{x}_{\mathrm{j} \alpha}$ represents the species mole fraction $\left[\mathrm{mol} \cdot \mathrm{mol}^{-1}\right]$ and $\xi_{\alpha}$ is the molar density of phase $\alpha\left[\mathrm{mol} \cdot \mathrm{cm}^{-3}\right]$. The term $\Gamma_{j \alpha}$ is the net rate of accumulation of moles of species $\mathrm{j}$ in phase $\alpha\left[\mathrm{mol} \cdot \mathrm{cm}^{-3} \cdot \mathrm{s}^{-1}\right]$ and is given by:

$$
\Gamma_{j \alpha}=r_{j \alpha}^{c}+r_{j \alpha}^{b}+r_{j \alpha}^{d}+s_{j \alpha}^{w}+s_{j \alpha}^{s}+q_{j \alpha}
$$

where the additional terms $\mathrm{s}_{\mathrm{j} \alpha}^{\mathrm{w}}, \mathrm{s}_{\mathrm{j} \omega}^{\mathrm{s}}$ and $\mathrm{q}_{\mathrm{j} \alpha}$ respectively represent $\left[\mathrm{mol} \cdot \mathrm{cm}^{-3} \mathrm{~s}^{-1}\right]:$ (1) the release of radioactive and nonradioactive species from buried wastes into phase $\alpha$; (2) the release of species from engineered structures (i.e., leaching of $\mathrm{Ca}(\mathrm{OH})_{2}$ ) and waste containers (i.e., $\mathrm{Fe}^{+2}$ ) into phase $\alpha$; and (3) the supply of species $\mathrm{j}$ to phase $\alpha$ due to external sources such as injection or extraction. The molar flux vector for species $\mathrm{j}$ in flowing phase $\alpha, \mathbf{J}_{j \alpha}\left[\mathrm{mol} \cdot \mathrm{cm}^{-2} \mathrm{~s}^{-1}\right]$, is comprised of two components, advective flux and dispersive flux:

$$
J_{j \alpha}=\xi_{\alpha} x_{j \alpha} \nu_{\alpha}-\theta_{\alpha} \xi_{\alpha} D_{j \alpha} \cdot \nabla x_{j \alpha}
$$

for $\alpha=1,2$. The superficial phase velocity (volumetric flow rate per unit area), $\mathbf{v}_{\alpha}\left[\mathrm{cm} \cdot \mathrm{s}^{-1}\right]$, is 
given by the multiphase version of Darcy's Law:

$$
v_{\alpha}=\frac{-K k_{r \alpha}}{\mu_{\alpha}}\left(\nabla p_{\alpha}+\rho_{\alpha} g I\right)
$$

for $\alpha=1,2$, where $\mathrm{k}_{\text {r } \alpha}$ is the dimensionless relative permeability of phase $\alpha, \mathbf{K}$ is the intrinsic permeability of the porous media $\left[\mathrm{cm}^{2}\right], \mu_{\alpha}$ is the viscosity of phase $\alpha\left[\mathrm{g} \bullet \mathrm{s}^{-1} \cdot \mathrm{cm}^{-1}\right], \mathrm{p}_{\alpha}$ is the phase pressure $\left[\mathrm{cm}^{-1} \cdot \mathrm{g} \bullet \mathrm{s}^{-2}\right], \rho_{\alpha}$ is the mass density $\left[\mathrm{g}^{\bullet} \mathrm{cm}^{-3}\right]$, and $\mathbf{I}$ is the unit vector acting in the direction of $\mathrm{g}$, the gravitational acceleration $\left[\mathrm{cm} \cdot \mathrm{s}^{-2}\right]$.

In (3.1.11), $\mathrm{D}_{j \alpha}$ is the hydrodynamic dispersion tensor $\left[\mathrm{cm}^{2} \bullet \mathrm{s}^{-1}\right]$ given by [Bear 1972]:

$$
D_{j \alpha}=D_{m j \alpha} \tau \delta_{k l}+\varepsilon_{T}\left|v_{\alpha}\right| \delta_{k l}+\left(\varepsilon_{L}-\varepsilon_{T}\right) \frac{v_{\alpha}^{k} v_{\alpha}^{\prime}}{\left|v_{\alpha}\right|}
$$

for $\alpha=1,2$, where $\mathbf{D}_{\mathrm{mj} \alpha}$ is the molecular diffusion coefficient $\left[\mathrm{cm}^{2} \bullet \mathrm{s}^{-1}\right], \tau$ is a tortuosity factor $\left[\mathrm{cm} \bullet \mathrm{cm}^{-1}\right], \mathbf{V}_{\alpha}{ }^{k}$ and $V_{\alpha}^{1}$ are the components of the Darcy velocity vector $\left[\mathrm{cm}^{\bullet} \mathrm{s}^{-1}\right]$, and $\varepsilon_{\mathrm{L}}$ and $\varepsilon_{\mathrm{T}}$ are longitudinal and transverse dispersivities $[\mathrm{cm}]$, respectively.

The phasic continuity equations follow from summing equations (3.1.8) and (3.1.9) from 1 to the number of species, $N_{s}$. That is, for mobile phases $(\alpha=1,2)$

$$
\frac{\partial\left(\xi_{\alpha} \theta_{\alpha}\right)}{\partial t}+\nabla \cdot J_{\alpha}=\sigma_{\alpha}+s_{\alpha}{ }^{w}+s_{\alpha}^{s}+q_{\alpha}
$$

and for immobile phases $(\alpha=3,4)$

$$
\frac{\partial\left(\xi_{\alpha} \theta_{\alpha}\right)}{\partial t}=\sigma_{\alpha}
$$

where $\sigma_{\alpha}\left(\mathrm{mol} \cdot \mathrm{cm}^{-3} \cdot \mathrm{S}^{-1}\right)$ represents the net accumulation of phase $\alpha$ due to heterogeneous reactions. The total molar flux of fluid phase $\alpha, J_{\alpha}\left[\mathrm{mol} \cdot \mathrm{cm}^{-2} \cdot \mathrm{s}^{-1}\right]$, is the sum of species molar fluxes in phase $\alpha$, and can be written as: 
3.0 Mathematical Formulation

$$
J_{\alpha}=\sum_{j=1}^{N_{s}} J_{j \alpha}=\xi_{\alpha} \nu_{\alpha}-\theta_{\alpha} \xi_{\alpha} \sum_{j=1}^{N_{s}} D_{j \alpha} \cdot \nabla x_{j \alpha}
$$

for $\alpha=1,2$. Equations (3.1.14) and (3.1.15) are constrained by the following conditions:

Volume fraction - Volume fractions sum to unity.

$$
\sum_{\alpha=1}^{4} \theta_{\alpha}=1
$$

Phase composition - Mole fractions sum to unity.

$$
\sum_{j=1}^{N_{s}} x_{j \alpha}=1, \quad \alpha=1,2,3,4
$$

Interphase Mass Transfer - Net accumulation of mass in a phase is due to heterogeneous reactions. (i.e., dissolution, precipitation, volatilization, adsorption, etc.)

$$
\sum_{j=1}^{N_{s}} r_{j \alpha}^{c}=\sigma_{\alpha}^{c}, \quad \sum_{j=1}^{N_{s}} r_{\alpha}^{b}=\sigma_{\alpha}^{b}, \quad \sum_{j=1}^{N_{s}} r_{j \alpha}^{d}=\sigma_{\alpha}^{d}, \quad \alpha=1,2,3,4
$$

Mass Conservation - Mass is conserved among phases.

$$
\sum_{\alpha=1}^{4} \sigma_{j \alpha}=0, \quad \sum_{\alpha=1}^{4} r_{j \alpha}=0 \quad \alpha=1,2,3,4
$$

where

$$
\sigma_{j \alpha}=\sigma_{j \alpha}^{c}+\sigma_{j \alpha}^{b}+\sigma_{j \alpha}^{d}
$$




$$
r_{j \alpha}=r_{j \alpha}^{c}+r_{j \alpha}^{b}+r_{j \alpha}^{d}
$$

$\underline{\text { Source }}$

$$
s_{\alpha}{ }^{w}=\sum_{j=1}^{N_{s}} s_{j \alpha}{ }^{w} ; \quad s_{\alpha}^{s}=\sum_{j=1}^{N_{s}} s_{j \alpha}^{s} ; \quad q_{\alpha}=\sum_{j=1}^{N_{s}} q_{j \alpha} ; \quad \alpha=1,2
$$

Auxiliary relations required to close the system include equations of state for phase densities and viscosities, equations that express the relationship between phase relative permeabilities, capillary pressures, and volumetric fluid contents, the stoichiometry and rate laws for the chemical, biochemical, and radioactive decay reactions, and equations that describe the release of substances from waste forms, waste containers, and engineered structures.

The reactive, transport formulation represented by reaction equations (3.1.2)-(3.1.7) and transport equations (3.1.8)-(3.1.16), along with the auxiliary relations described above, provides a system of $4 \mathrm{~N}_{\mathrm{s}}$ equations for $4 \mathrm{~N}_{\mathrm{s}}$ unknowns. Because of the requirements (3.1.17) and (3.1.18) there are 3 independent volume fractions and $4\left(\mathrm{~N}_{\mathrm{s}}-1\right)$ independent mole fractions for a total of $4 \mathrm{~N}_{\mathrm{s}}-1$ unknowns. The additional unknown is a single fluid phase pressure since there is only one independent phase pressure for a total of $4 \mathrm{~N}_{\mathrm{s}}$ unknowns.

The formulation is completed by specifying appropriate initial and boundary conditions. The number of required initial conditions for equations (3.1.8), (3.1.9), and (3.1.14) consist of $4\left(\mathrm{~N}_{\mathrm{s}}-1\right)$ mole fractions, 3 phase volume fractions, and 1 fluid pressure. The specification of these values is sufficient to determine the phase fluxes $\mathbf{J}_{j \alpha}$ and reaction rates at time $t=0$, given the necessary constitutive relations. Boundary conditions may be given, for example, by specifying homogeneous species and phase fluxes at far field boundaries for $4\left(\mathrm{~N}_{\mathrm{s}}{ }^{-1}\right)$ mole fractions and single fluid pressure, and Cauchy species flux and Dirichlet pressure conditions along inlet boundaries to the system.

\subsubsection{Summary}

To solve the system of equations described above, it is necessary to characterize the nature of the transformation reactions. If reaction rates are fast relative to the rate of advective transport, then reactions can be approximated under the assumption of local chemical equilibrium. The assumption of local chemical equilibrium allows the relationship between the activities of products and reactants in each reaction to be expressed by an algebraic equation. In the simplest case of local chemical equilibrium, it is assumed that aqueous phase species do not interact with each other and that the ratio of soil phase species concentration to that in solution can be described by a distribution coefficient commonly named $\mathrm{K}_{\mathrm{d}}$. The more general case of chemical equilibrium represents each type of reaction explicitly with an algebraic mass-action equation. Conversely, if reaction rates are slow relative to advective transport, the reactions must be treated as kinetically limited reactions and reaction rate laws must be specified as functions of 


\subsection{Mathematical Formulation}

system composition, temperature, and pressure.

In a real system, it is likely that both equilibrium and kinetic reactions occur in combination. Biochemical reactions, and many heterogeneous chemical reactions, are rate-limited reactions [Stumm and Morgan, 1981; Bahr, 1990]. Hence, there are four primary categories of reactive transport; (1) equilibrium-Kd, (2) general equilibrium, (3) kinetic, and (4) mixed. The approaches to modeling these four different cases are quite different and are discussed in Lichtner [1985], Bahr and Rubin [1987], and Kirkner and Reeves [1988].

The two most common approaches to modeling radionuclide migration from LLW facilities are the equilibrium- $\mathrm{K}_{\mathrm{d}}$ and general equilibrium approaches. This situation is due in part to the computational simplicity of these approaches as compared to the kinetic and mixed cases and the lack of kinetic data. Both equilibrium cases are approximated by simpler forms of governing equations as compared to the kinetic formulations, with fewer and simpler associated auxiliary equations and boundary conditions. Moreover, kinetic data is virtually nonexistent for the reactions of concern in LLW performance assessments. This shortage of kinetic data presently limits the practical utility of kinetic and mixed formulations, although this condition may change in the future.

In the following sections, we consider three cases of the general reactive transport system described above. The first case is widely applied in practice to describe nonreactive water flow in variably saturated media. The other two cases include equilibrium- $K_{d}$ transport or transport with sorption, and transport with equilibrium chemistry.

\subsection{Aqueous-Phase Fluid Flow}

Advection of radionuclides with the flow field will often be the dominant process controlling the release and migration of radionuclides from a LLW facility. The ground-water flow model is therefore a crucial component of performance assessments because of the need to define the ground-water flow field, both in unsaturated and saturated (variably saturated) porous media. The governing equation for variably saturated flow considered in this study is similar to that used in previous formulations [Yeh and Ward, 1980; Jury et al., 1991].

\subsubsection{Flow Equation}

The flow field in variably saturated porous media can be described by the well known multidimensional form of Richard's equation. This equation can be obtained from equation (3.1.14) by making the following simplifying assumptions:

(1) The gas phase plays a negligible role in the water flow process.

(2) The aqueous phase is incompressible and density variations due to solute concentrations are negligible.

(3) Phasic volume changes associated with chemical, biochemical, and radioactive decay 
reactions are negligible.

(4) Phasic volumes associated with the mass introduced by species source terms, $\mathrm{s}_{\alpha}^{\mathrm{w}}$ and $\mathrm{s}_{\infty}^{\mathrm{s}}$ are negligible.

(5) Dispersive components of the total mass flux are negligible.

(6) Gravity acts in the direction of the vertical coordinate direction $\mathrm{z}$.

(7) Hysteresis effects are ignored and the volumetric content of the aqueous phase is a unique function of pressure head, i.e., $\theta_{\mathrm{a}}=\theta_{\mathrm{a}}(\mathrm{h})$.

The first five assumptions allow equation (3.1.14) to be written, for the aqueous phase, as:

$$
\frac{\partial \theta_{a}}{\partial t}+\nabla \cdot v_{a}=\frac{q_{a}}{\xi_{a}}
$$

where we have introduced equation (3.1.16) and neglected the dispersive terms due to assumption (5). Invoking assumptions (6) and (7), we obtain the following well known equation for variably saturated flow:

$$
\frac{\partial \theta_{a}}{\partial t}=F \frac{\partial h}{\partial t}=-\nabla \cdot v_{a}+Q_{a}
$$

with

$$
\boldsymbol{v}_{a}=-\boldsymbol{K}^{\boldsymbol{c}} \cdot \nabla H
$$

where the subscript a is used to denote the aqueous phase. In equation (3.2.2), the hydraulic conductivity tensor $\mathbf{K}^{\mathrm{c}}\left[\mathrm{cm}^{-1} \mathrm{~s}^{-1}\right]$, coefficient $\mathrm{F}\left[\mathrm{cm}^{-1}\right]$, total pressure head $\mathrm{H}[\mathrm{cm}]$, and source-sink term $\mathrm{Q}_{\mathrm{a}}\left[\mathrm{cm}^{3} \bullet \mathrm{cm}^{-3} \bullet \mathrm{s}^{-1}\right]$ are given, respectively, by:

$$
K^{c}=\frac{K k_{r a} \rho_{\alpha} g}{\mu_{\alpha}}
$$


3.0 Mathematical Formulation

$$
\begin{gathered}
H=h+z=\frac{p_{a}}{\rho_{a} g}+z \\
F=\frac{d \theta_{a}}{d h} \\
Q_{a}=\frac{q_{a}}{\xi_{a}}
\end{gathered}
$$

where $\mathrm{z}$ is the potential head $[\mathrm{cm}]$, and all other terms have been defined in the previous section.

\subsubsection{Initial and Boundary Conditions}

The initial distribution of pressure head, $\mathrm{h}[\mathrm{cm}]$, in the flow domain $\Omega$ is required for the solution of equation (3.2.2), that is:

$$
h=h_{I}(x, y, z, t) ; \quad t=0
$$

for all points $(\mathrm{x}, \mathrm{y}, \mathrm{z})$ in the problem domain $\Omega$ enclosed by boundary $\Gamma$.

Boundary conditions include:

Dirichlet (specified head)

$$
h=h_{D}(x, y, z, t) \quad(x, y, z) \in \Gamma_{D}, \quad t>0
$$

Neumann (specified dispersive flux)

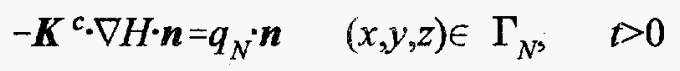

Cauchy (mixed condition)

$$
\nabla H \cdot \boldsymbol{n}+\beta H=f_{C} \cdot \boldsymbol{n} \quad(x, y, z) \in \Gamma_{C}, \quad>0
$$


where $H_{D}$ and $q_{N}$ are the prescribed total head $[\mathrm{cm}]$ and Neumann flux $\left[\mathrm{cm}^{3} \cdot \mathrm{cm}^{-2} \cdot \mathrm{s}^{-1}\right], \beta$ and $f_{C}$ are known functions, and $\Gamma_{D}, \Gamma_{N}$, and $\Gamma_{C}$ are segments of boundary $\Gamma$ on which the corresponding boundary conditions apply, and the symbol $\epsilon$ is read "belonging to."

\subsection{Multispecies, Aqueous-Phase Transport with Sorption}

Performance assessment models typically account for the processes of sorption and dissolution-precipitation by using linear or nonlinear isotherms that lump the effects of all reactions between solid and aqueous phases into an empirical distribution coefficient $K_{d}$ $\left[\mathrm{cm}^{3} \cdot \mathrm{g}^{-1}\right]$. We refer to this treatment as transport with sorption. The use of this simple approach formally requires that sorption reaches equilibrium quickly, is reversible, and is independent of variations in solution chemistry and mineralogy. These conditions rarely exist in actual field settings; however, in some cases it may be shown that this approach, for appropriate choice of $\mathrm{K}_{d}$ values, conservatively estimates the extent of radionuclide migration.

In this section, we formulate a multispecies model for solute transport in the aqueous phase. Chemical and biochemical reactions that change chemical speciation are ignored, as is colloid-facilitated transport. We do, however, include biodegradation and radioactive decay as first-order decay and ingrowth processes.

\subsubsection{Transport Equations}

We denote phases as follows: the aqueous phase, $\alpha=1$, is now $\alpha=\mathrm{a}$, gaseous phase $\alpha=\mathrm{g}$, precipitated phase $\alpha=\mathrm{p}$, and sorbed phase $\alpha=\mathrm{s}$. The starting point for our development is the overall balance equation for species $\mathrm{j}$, which can be determined by summing equations (3.1.8) and (3.1.9) over their respective phases and combining the resulting equations to obtain:

$$
\begin{gathered}
\frac{\partial}{\partial t}\left[\theta_{a} \xi_{a} x_{j a}+\theta_{g} \xi_{g} x_{j g}+\theta_{p} \xi_{p} x_{j p}+\theta_{s} \xi_{s} x_{j s}\right]+\nabla \cdot\left[J_{j a}+J_{j g}\right] \\
=\Gamma_{j a}+\Gamma_{j g}+\Gamma_{j p}+\Gamma_{j s}
\end{gathered}
$$

for $\mathrm{j}=1,2, \ldots, \mathrm{N}_{\mathrm{s}}$.

We next state the major assumptions that are employed to simplify (3.3.1); during the following presentation we will refer back to these assumptions as they are introduced. The major assumptions are:

(1) The transfer of mass between the gaseous phase and other phases present in the pore space is negligible. 


\subsection{Mathematical Formulation}

(2) Mass transport in the gaseous phase is negligible.

(3) Colloid facilitated transport is negligible.

(4) Volume changes in the precipitate phase are negligible and dissolution/precipitation reactions can be neglected, i.e., $\partial\left(\theta_{p} \xi_{p} x_{j p}\right) / \partial t=0$.

(5) The molar density of the aqueous phase is constant.

(6) The contaminant source term, $s_{j \alpha}^{\mathrm{w}}$, and external source-sink term, $\mathrm{Q}_{j \alpha}$, are nonzero for the aqueous phase only.

(7) The species source term $s_{j \alpha}^{s}$, due to leaching of engineered barriers and corrosion of containers, is negligible.

(8) The chemical and microbially-mediated reactions may be represented as first-order reactions.

(9) The ingrowth of radioactive species can be represented by first-order decay of parent species.

(10) Chemical reactions among migrating species are nonexistent.

(11) Chemical equilibrium exists between the aqueous and sorbed phases.

(12) Each species migrates according to its own particular retardation coefficient.

Invoking the first seven assumptions, equation (3.3.1) reduces to an equation that represents aqueous phase transport with general chemical and biochemical reactions:

$$
\begin{array}{r}
\frac{\partial}{\partial t}\left[\theta_{a} c_{j a}+\theta_{s} c_{j s}\right]+\nabla \cdot\left[c_{j a} v_{a}-\theta_{\alpha} D_{j a} \cdot \nabla c_{j a}\right] \\
=r_{j a}^{c}+r_{j a}^{b}+r_{j a}^{d}+r_{j s}^{c}+r_{j s}^{b}+r_{j s}^{d}+s_{j a}^{w}+q_{j a}
\end{array}
$$

for $\mathrm{j}=1,2, \ldots, \mathrm{N}_{\mathrm{s}}$, where we have made use of equations (3.1.10) and (3.1.11) in (3.3.1).

Assumptions (8) through (10) limit the form of the reactions to be considered and permit us to write equation (3.3.2) as: 


$$
\begin{aligned}
& \frac{\partial}{\partial t}\left[\theta_{a} c_{j a}+\theta_{s} c_{j s}\right]+\nabla \cdot\left[c_{j a} \nu_{a}-\theta_{d} D_{j a} \cdot \nabla c_{j a}\right] \\
& =\theta_{a}\left(\gamma_{j a}^{c}+\gamma_{j a}^{b}-\lambda_{j}\right) c_{j a}+\theta_{a} \sum_{p} \lambda_{p j} c_{p a} \\
& \quad+\theta_{s}\left(\gamma_{j s}^{c}+\gamma_{j s}^{b}-\lambda_{j}\right) c_{j s}+\theta_{s} \sum_{p} \lambda_{p j} c_{p s}+s_{j a}^{w}+q_{j a}
\end{aligned}
$$

where $\lambda_{\mathrm{pj}}$ is the partial decay constant of parent species $\mathrm{p}$ for progeny species $\mathrm{j}\left[\mathrm{s}^{-1}\right]$, the sum is over all parents of species $\mathrm{j}, \lambda_{\mathrm{j}}$ is the total radioactive decay constant for species $\mathrm{j}\left[\mathrm{s}^{-1}\right]$, and $\gamma_{\mathrm{js}}^{\mathrm{b}}, \gamma_{\mathrm{js}}^{\mathrm{b}}$ and $\gamma_{\mathrm{ja}}^{\mathrm{c}}, \gamma_{\mathrm{js}}^{\mathrm{c}}$ are first-order biotic and abiotic decay(-) or production $(+)$ constants $\left[\mathrm{s}^{-1}\right]$.

Because of assumptions (11) through (13), we may relate the concentration of a species in the sorbed phase (moles per unit volume of solid phase), $\mathrm{c}_{\mathrm{js}}\left[\mathrm{mol} \cdot \mathrm{cm}^{-3}\right]$, in terms of its concentration in the aqueous phase (moles per unit volume of aqueous phase), $\mathrm{c}_{\mathrm{ja}}\left[\mathrm{mol} \cdot \mathrm{cm}^{-3}\right]$. Three common relationships relating $\mathrm{c}_{\mathrm{js}}$ to $\mathrm{c}_{\mathrm{ja}}$ are linear, Langmuir, and Freundlich isotherms given, respectively, as:

Linear

$$
\frac{c_{j s} \theta_{s}}{\rho_{b}}=k_{d j} c_{j a},
$$

$\underline{\text { Langmuir }}$

$$
\frac{c_{j s} \theta_{s}}{\rho_{b}}=\frac{\omega_{j s}^{* \max } k_{L j} c_{j a}}{\left(1+k_{L j} c_{j a}\right)},
$$

and

Freundlich

$$
\frac{c_{j s} \theta_{s}}{\rho_{b}}=k_{F j} c_{j a}^{n},
$$

where $\omega_{\mathrm{js}}^{* \max }$ is the maximum potential sorbed concentration in units of moles of sorbed species per unit mass of solid, and distribution coefficient $\mathrm{k}_{\mathrm{d}}$ and parameters $\mathrm{n}, \mathrm{k}_{\mathrm{Lj}}\left[\mathrm{cm}^{3} \cdot \mathrm{mol}^{-1}\right]$, and $\mathrm{k}_{\mathrm{Fj}}$ 
3.0 Mathematical Formulation

$\left[\left(\mathrm{cm}^{3 \mathrm{n}} \bullet \mathrm{g}^{-1} \cdot(\mathrm{mol})^{1-\mathrm{n}}\right)\right]$ are experimentally derived constants.

In particular, if we use (3.3.4) in (3.3.3), we obtain:

$$
\begin{gathered}
\theta_{a} R_{j} \frac{\partial c_{j a}}{\partial t}+c_{j a} \frac{\partial\left(R_{j} \theta_{a}\right)}{\partial t}+\nabla \cdot\left(v_{a} c_{j a}\right)-\nabla \cdot\left(\theta_{a} D_{j a} \cdot \nabla c_{j a}\right) \\
=\gamma_{j a}^{b} \theta_{a} c_{j a}\left(1+\frac{\rho_{b} k_{d} \gamma_{j s}^{b}}{\theta_{a} \gamma_{j a}^{b}}\right)+\gamma_{j a}^{c} \theta_{a} c_{j a}\left(1+\frac{\rho_{b} k_{d} \gamma_{j s}^{c}}{\theta_{a} \gamma_{j a}^{c}}\right) \\
-\lambda_{j} R_{j} \theta_{a} c_{j a}+\theta_{a} \sum_{p} \lambda_{p j} R_{p} c_{p a}+q_{j a}+s_{j a}^{w}
\end{gathered}
$$

where $R_{j}$ is the retardation factor for species $\mathrm{j}$ and takes the form:

$$
R_{j}=1+\frac{\rho_{b} k_{d j}}{\theta_{a}}
$$

In the formulation of equation (3.3.7) we assumed that colloid facilitated transport is negligible, see assumption (3) above. Under certain conditions, colloid facilitated transport can be approximated by implementing a "modified" retardation coefficient. This approach is outlined in Appendix 3.

\subsubsection{Initial and Boundary Conditions}

The solution of equation (3.3.7) requires knowledge of the initial concentration field in the flow domain $\Omega$, that is:

$$
c_{j a}(x, y, z, 0)=c_{j a}^{I}(x, y, z)
$$

where the aqueous concentration of each species $j\left[\mathrm{~mol} \cdot \mathrm{cm}^{-3}\right], j=1,2, \ldots \mathrm{N}_{\mathrm{s}}$, is a prescribed function of $\mathrm{x}, \mathrm{y}$, and $\mathrm{z}$.

Three types of boundary conditions are useful for LLW performance assessments, Dirichlet, Neumann, and Cauchy. Dirichlet conditions applied on boundary segment $\Gamma_{\mathrm{D}}$ of $\Omega$ are given by: 


\subsection{Mathematical Formulation}

$$
c_{j a}(x, y, z, t)=c_{j a}^{b c}(x, y, z, t), \quad(x, y, z) \in \Gamma_{D}, t>0
$$

where $c_{j a}^{b c}$ are prescribed aqueous species concentrations $\left[\mathrm{mol} \bullet \mathrm{cm}^{-3}\right]$. The Neumann boundary condition on segment $\Gamma_{\mathrm{N}}$ is:

$$
-\theta_{a} \boldsymbol{D} \cdot \nabla\left(c_{j a}\right) \cdot \boldsymbol{n}=\boldsymbol{q}_{j a}^{N} \cdot \boldsymbol{n}, \quad(x, y, z) \in \Gamma_{N^{\prime}}>0
$$

The Cauchy boundary condition prescribed on segment $\Gamma_{\mathrm{C}}$ is:

$$
-\theta_{a} \boldsymbol{D} \cdot \nabla\left(c_{j a}\right) \cdot \boldsymbol{n}+\boldsymbol{v}_{a} c_{j a} \cdot \boldsymbol{n}=\boldsymbol{q}_{j a}^{C} \cdot \boldsymbol{n}, \quad(x, y, z) \in \Gamma_{C}, t>0
$$

In equations (3.3.11) and (3.3.12), $\mathbf{n}$ is the outward unit normal vector, $\mathbf{q}_{\mathbf{j a}}^{\mathrm{N}}$ is the prescribed outward Neumann (dispersive) flux across boundary segment $\Gamma_{\mathrm{N}}\left[\mathrm{mol} \cdot \mathrm{cm}^{-2} \cdot \mathrm{s}^{-1}\right]$, and $\mathbf{q}_{\mathrm{ja}}^{\mathrm{C}}$ is the outward Cauchy (total) flux vector across $\Gamma_{\mathrm{C}}\left[\mathrm{mol} \cdot \mathrm{cm}^{-2} \bullet \mathrm{s}^{-1}\right]$.

\subsection{Multispecies, Aqueous-Phase Transport with Equilibrium Chemistry}

In recent years there has been an increasing awareness that performance assessments based solely on empirically based $\mathrm{K}_{\mathrm{d}}$ models may be inadequate, particularly for applications involving radionuclides (i.e., uranium, plutonium, neptunium, and technetium) having sorption and solubility properties that are sensitive to variations in the in-situ chemical environment. To accommodate variations in the chemical environment, and to assess its impact on radionuclide migration, it is necessary to couple transport and chemical reaction processes directly. In this section, we present a formulation that couples transport with chemical reactions under the assumption that all chemical reactions given by equation (3.1.2) are sufficiently fast that the principle of local equilibrium is applicable. Other important assumptions include:

(1) Variations in molar densities are assumed negligible.

(2) Volume changes in the precipitated phase are negligible.

(3) The system temperature is invariant.

(4) Microbiaily mediated reactions are ignored.

(5) Colloid facilitated transport is negligible.

(6) The composition of the gaseous phase is constant.

(7) Radioactive decay reactions are homogeneous and occur only in the aqueous, precipitated, and adsorbed phases. 


\subsection{Mathematical Formulation}

(8) Intraphase transport occurs in the aqueous phase only.

(9) The contaminant source term, $s_{j \alpha}^{\mathrm{w}}$, and external source-sink term, $\mathrm{Q}_{\mathrm{j} \alpha}$, are nonzero for the aqueous phase only.

\subsubsection{Transformation Equations}

To begin, we rewrite equation (3.1.2) in symbolic matrix form as:

$$
0 \Leftrightarrow N B
$$

As a consequence of equilibrium, if the rank of reaction matrix $\mathbf{N}$ is $M$, it follows that the collection of $\mathrm{N}_{\mathrm{s}}$ chemical species can be partitioned into $\mathrm{M}$ independent reactant species, referred to herein as "components", and $\left(\mathrm{N}_{\mathrm{s}}-\mathrm{M}\right)$ dependent or "product" species [Van Zeggeren and Storey, 1970; Allison et al., 1991] that is, $\left\{\mathrm{c}_{1 \alpha}, \ldots, \mathrm{c}_{\mathrm{M} \alpha}: \mathrm{c}_{(\mathrm{M}+1) \alpha}, \ldots, \mathrm{c}_{\mathrm{Ns \alpha}}\right\}$. The total number of components, $M$, is further divided into two sets $\left\{\mathrm{c}_{1 \alpha}, \ldots, \mathrm{c}_{\mathrm{Ma}}: \mathrm{c}_{(\mathrm{Ma}+1) \alpha}, \ldots, \mathrm{c}_{\mathrm{M \alpha}}\right\}$ consisting of $\mathrm{M}_{\mathrm{a}}$ aqueous components and $\mathrm{M}_{\mathrm{s}}=\mathrm{M}-\mathrm{M}_{\mathrm{a}}$ adsorbent components (including ion-exchange sites). In addition, each $\mathrm{M}_{\mathrm{a}}$ aqueous component can exist in each phase present (i.e., aqueous, gaseous, precipitate, solid) in the system. Moreover, each product species can be expressed as a linear combination of the components and no component can be expressed as a linear combination of the other components. Thus, the $\left(\mathrm{N}_{\mathrm{s}}-\mathrm{M}\right)$ linear combinations of the $\mathrm{M}$ components are chemical reactions which form the $\left(\mathrm{N}_{\mathrm{s}}-\mathrm{M}\right)$ product species. These reactions can be separated into aqueous complexation, dissolution-precipitation, and sorption reactions as follows.

\section{Aqueous Complexation}

$$
\sum_{k=1}^{M} \bar{v}_{k l}^{a} B_{k a}{ }^{\leftrightarrow} B_{i a} \quad \forall \text { product species } i \in A
$$

\section{Dissolution-Precipitation}

$$
\sum_{k=1}^{M} \bar{v}_{k l}^{a} B_{k \alpha} \leftrightarrow B_{l p} \quad \forall \text { product species } l \in \boldsymbol{P}
$$


$\underline{\text { Sorption Reactions }}$

$$
\sum_{k=1}^{M} \bar{v}_{k m}^{a} B_{k a}+\sum_{k=1}^{M} \bar{v}_{k m}^{s} B_{k s}+B_{m s} \quad \forall \text { product species } m \in S
$$

where $\mathbf{A}, \mathbf{P}$, and $\mathbf{S}$ denote the sets of species that may be present in the aqueous, precipitated, and sorbed phases, respectively, the symbol $\forall$ is read "for every," and $\epsilon$ is read "belonging to." As in the preceding section, we denote the phases as follows: the aqueous phase, $\alpha=1$, is now $\alpha=a$, gaseous phase $\alpha=\mathrm{g}$, precipitated phase $\alpha=\mathrm{p}$, and sorbed phase $\alpha=\mathrm{s}$. The stoichiometric reaction matrices, $\overline{\mathrm{v}}_{\mathrm{ki}}^{\alpha}$ are in general different than the matrices, $\mathrm{v}_{\mathrm{ki}}^{\alpha}$, in equations (3.1.2) and (3.1.5) hence, the overbar to denote this distinction.

To simplify the representation of radioactive decay reactions, we make the assumption that radionuclides are component species. This assumption, in conjunction with assumption (7), permits the following simplified representation of equation (3.1.4):

\section{$\underline{\text { Radioactive Decay Reactions }}$}

$$
\sum_{k=1}^{M} \bar{\omega}_{k r}^{\alpha} B_{k \alpha}-0
$$

for $\alpha=\mathrm{a}, \mathrm{p}, \mathrm{s}, \mathrm{r}=1, \ldots, \mathrm{N}_{\mathrm{dr}}$, where $\bar{\omega}_{\mathrm{kr}}^{\alpha}$ is the component species stoichiometric radioactive decay matrix.

Under the assumption of chemical equilibrium, the mass-action relations corresponding to reactions (3.4.2)-(3.4.4) are:

\section{Aqueous Complexation}

$$
Y_{i a}=K_{i a} \prod_{k=1}^{M} X_{k a}^{\bar{v}_{k i}^{a}}
$$

\section{Precipitation-Dissolution}

$$
Y_{l p}=K_{l p} \prod_{k=1}^{M} X_{k a}^{\bar{v}_{k l}^{a}}
$$


3.0 Mathematical Formulation

$\underline{\text { Sorption }}$

$$
Y_{m s}=K_{m s} \prod_{k=1}^{M} X_{k a}^{\bar{v}_{k m}^{a}} \prod_{k=1}^{M} X_{k s}^{\bar{v}_{k m}^{s}}
$$

where $\prod$ indicates the product over all component species $\mathrm{k}, \mathrm{K}_{\mathrm{j} \alpha}$ is the equilibrium constant for the formation of species $\mathrm{j}$ in phase $\alpha$, and $\mathrm{X}_{\mathrm{k} \alpha}$ and $\mathrm{Y}_{\mathrm{i} \alpha}$ are thermodynamic activities of component species and product species $\left[\mathrm{mol} \cdot \mathrm{cm}^{-3}\right]$, respectively.

The net rate of radioactive decay associated with each decay reaction in equation (3.4.5) is given by:

$$
r_{k \alpha}^{d}=\sum_{r=1}^{N_{\alpha r}} \bar{\omega}_{k a}^{\alpha} f_{r}^{d}=-\lambda_{k} \theta_{\alpha} \sum_{i} \bar{v}_{k i}^{\alpha} c_{i \alpha}+\theta_{\alpha} \sum_{p} \lambda_{p k} \sum_{\pi} \bar{v}_{k \pi}^{\alpha} c_{\pi \alpha}
$$

where $\lambda_{\mathrm{pk}}$ is the partial decay constant for the parent component species of progeny component species $\mathrm{k}\left[\mathrm{s}^{-1}\right]$, and $\lambda_{\mathrm{k}}$ is the total radioactive decay constant for component species $\left.\mathrm{k}^{-1} \mathrm{~s}^{-1}\right]$, and the last sum is over all parent species $\pi$.

The thermodynamic activities are approximated by the relations:

$$
Y_{i \alpha}=\gamma_{i \alpha} c_{i \alpha}
$$

and

$$
X_{k \alpha}=\gamma_{k \alpha} c_{k \alpha}
$$

where $\gamma_{k \alpha}$ and $\gamma_{i \alpha}$ are activity coefficients of the component and product species.

In general, equilibrium constants in equations (3.4.6)-(3.4.8) and activity coefficients in (3.4.10) and (3.4.11) are functions of temperature and ionic strength. Often used approximations for these parameters are described in Appendix 4.

\subsubsection{Transport with Chemical Equilibrium Reactions}

We begin by representing transport equations (3.1.8) and (3.1.9) symbolically as:

$$
L_{j \alpha}(c)=\Gamma_{j \alpha} \quad \alpha=a, p, s
$$


where the operator $\mathrm{L}_{\mathrm{j} \alpha}$ is a parabolic advection-diffusion operator given by:

$$
\begin{array}{ll}
L_{j \alpha}(c)=\frac{\partial}{\partial t}\left(\theta_{\alpha} c_{j \alpha}\right)+\nabla \cdot\left(c_{j \alpha} v_{\alpha}-\theta_{\alpha} D_{j \alpha} \cdot \nabla c_{j \alpha}\right) & \alpha=a \\
L_{j \alpha}(c)=\frac{\partial}{\partial t}\left(\theta_{\alpha} c_{j \alpha}\right) & \alpha=p, s
\end{array}
$$

Here, $\Gamma_{\mathrm{j} \alpha}$ represents the net rate at which the $\mathrm{j}^{\text {th }}$ species is added to phase $\alpha$ due to chemical and radioactive decay reactions, waste-form leaching, container corrosion and engineered barrier degradation, and injection/extraction (see equation (3.1.10):

$$
\Gamma_{j \alpha}=r_{j \alpha}^{c}+r_{j \alpha}^{d}+s_{j \alpha}^{w}+s_{j \alpha}^{s}+q_{j \alpha}
$$

Since we make use of the assumption of local chemical equilibrium, we may eliminate the chemical reaction rate terms, $r_{j \alpha}^{c}\left[\mathrm{~mol} \bullet \mathrm{cm}^{-3} \cdot \mathrm{s}^{-1}\right]$, as variables from transport equation (3.4.12). To accomplish this task, we make use of the following conservation relation:

$$
R_{k}^{c}=\sum_{i} \bar{v}_{k l}^{a} r_{i a}^{c}+\sum_{l} \bar{v}_{k l}^{a} r_{l p}^{c}+\sum_{m} \bar{v}_{k m}^{a} r_{m s}^{c}=0
$$

which states that the net change in total mass of aqueous component $\mathrm{k}$, by chemical transformation, is zero. Solving equation (3.4.12) for $r_{\mathrm{ia}}^{\mathrm{c}}, \mathrm{r}_{\mathrm{lp}}^{\mathrm{c}}$, and $\mathrm{r}_{\mathrm{ms}}^{\mathrm{c}}$, respectively, and introducing the results into (3.4.15) we obtain the following result:

$$
\begin{gathered}
\sum_{i \in A} \bar{v}_{k l}^{a} L_{i a}(c)+\sum_{l \in P} \bar{v}_{k J}^{a} L_{l p}(c)+\sum_{m \in S} \bar{v}_{k m}^{a} L_{m s}(c)= \\
\theta_{a} \frac{\partial T_{k}}{\partial t}+\left(C_{k s}+C_{k p}\right) \frac{\partial \theta_{a}}{\partial t}+v_{a} \cdot \nabla C_{k a}-\nabla \cdot \theta_{a} D \cdot \nabla C_{k a}+C_{k a}\left[\frac{\partial \theta_{a}}{\partial t}+\nabla \cdot v_{a}\right]= \\
R_{k}^{d}+S_{k}{ }^{w}+Q_{k}
\end{gathered}
$$

where we have made the assumption that source term $\mathrm{S}_{\mathrm{k}}^{\mathrm{s}}$ is negligible. The last term in brackets on line two of this equation can be replaced with $\mathrm{Q}_{\mathrm{a}}$ using the aqueous phase continuity equation (recall equation (3.2.2)):

$$
Q_{a}=\frac{\partial \theta_{a}}{\partial t}+\nabla \cdot v_{a}
$$




\subsection{Mathematical Formulation}

Hence, we obtain:

$$
\begin{gathered}
\theta_{a} \frac{\partial T_{k}}{\partial t}+T_{k} \frac{\partial \theta_{a}}{\partial t}+v_{a} \cdot \nabla T_{k a}-\nabla \cdot \theta_{a} D \cdot \nabla T_{k} \\
=C_{k a} \frac{\partial \theta_{a}}{\partial t}+v_{a} \cdot \nabla\left(C_{k s}+C_{k p}\right)-\nabla \cdot \theta_{d} D \cdot \nabla\left(C_{k s}+C_{k p}\right) \\
+R_{k}^{d}+S_{k}^{w}+S_{k}^{w}+Q_{k}-Q_{a} C_{k a}
\end{gathered}
$$

where

$$
T_{k}=C_{k a}+C_{k p}+C_{k s}
$$

Here, $\mathrm{C}_{\mathrm{ka}}, \mathrm{C}_{\mathrm{kp}}$, and $\mathrm{C}_{\mathrm{ks}}$ are total concentrations of component $\mathrm{k}$ in moles of $\mathrm{k}$ per unit volume of the aqueous phase $\left[\mathrm{mol} \cdot \mathrm{cm}^{-3} \cdot \mathrm{s}^{-1}\right]$ in the aqueous, precipitated, and sorbed phases, respectively, and are given by:

$$
\begin{gathered}
C_{k p}=\frac{V_{p}}{V_{\alpha}} \sum_{i \in \boldsymbol{P}} \bar{v}_{k i}^{a} c_{i p} \\
C_{k a}=\sum_{i \in \boldsymbol{A}} \bar{v}_{k i}^{a} c_{i a} \\
C_{k s}=\frac{V_{s}}{V_{a}} \sum_{i \in \boldsymbol{S}} \bar{v}_{k i}^{a} c_{i s}
\end{gathered}
$$

The total radioactive decay rate, $R_{k}^{d}$, and total source terms. $S_{k}^{w}$ and $Q_{k}$, for component $k$, are given by:

$$
\begin{aligned}
& R_{k}^{a}=\sum_{i} \bar{v}_{k l}^{a} r_{i a}^{a}+\sum_{l} \bar{v}_{k l}^{a} r_{l p}^{a}+\sum_{m} \bar{v}_{k m}^{a} r_{m s}^{a} \\
& =r_{k a}^{d}+r_{k p}^{d}+r_{k s}^{d}=-\theta_{a}\left[\lambda_{k} T_{k}-\sum_{n} \lambda_{p k} T_{p}\right]
\end{aligned}
$$


and

$$
\begin{gathered}
S_{k}^{w}=\sum_{i} \bar{v}_{k i}^{a} s_{i a}{ }^{w} \\
Q_{k}=\sum_{i} \bar{v}_{k i}^{a} q_{i a}
\end{gathered}
$$

Equations governing conservation of adsorbent and ion-exchange site components are required to complete the system of transport equations. From equation (3.1.9) we obtain:

$$
\frac{\partial\left(\theta_{d} A_{k s}\right)}{\partial t}=0
$$

with

$$
A_{k s}=\frac{V_{s}}{V_{a}} \sum_{k} \bar{v}_{k i}^{s} c_{i s}
$$

for $\mathrm{k}$ ranging over the adsorbent and ion-exchange site components only and where $\mathrm{A}_{\mathrm{ks}}$ is the total concentration of adsorbent component $\mathrm{k}$.

\subsubsection{Initial and Boundary Conditions}

The solution of aqueous phase transport equation (3.4.18) and sorption/ion exchange conservation equation (3.4.26) requires that the initial total analytical concentrations of all components $\left[\mathrm{mol} \cdot \mathrm{cm}^{-3}\right]$, including aqueous phase and adsorbent components and number of equivalents of ion exchange sites $\left[\mathrm{mol} \cdot \mathrm{gm}^{-1}\right]$, be specified in the flow domain $\Omega$, that is:

$$
T_{k}(x, y, z, 0)=T_{k}^{I}(x, y, z)
$$

and

$$
A_{m s}(x, y, z, 0)=A_{m s}^{I}(x, y, z)
$$




\subsection{Mathematical Formulation}

where $\mathrm{k}$ ranges over the aqueous components, $\mathrm{m}$ ranges over the adsorbent components and ionexchange sites, and the superscript I denotes initial values.

Three types of boundary conditions may be applied on the boundary $\Gamma$ of flow domain $\Omega$ . Dirichlet conditions prescribe analytical concentrations on boundary segment $\Gamma_{\mathrm{D}}$ :

$$
T_{k}(x, y, z, t)=T_{k}^{D}(x, y, z, t), \quad(x, y, z) \epsilon_{D},>0
$$

Note that boundary conditions are not required for adsorbent components and ion exchange sites because these quantities are not transported and are properties of the porous media. The second and third types of boundary conditions are the Neumann and Cauchy conditions:

Neumann

$$
-\theta_{d} D \cdot \nabla\left(C_{k a}\right) \cdot \boldsymbol{n}=\boldsymbol{q}_{k a}^{N} \cdot \boldsymbol{n}, \quad(x, y, z) \in_{N},>0
$$

Cauchy

$$
-\theta_{a} \boldsymbol{D} \cdot \nabla\left(C_{k a}\right) \cdot \boldsymbol{n}+\boldsymbol{v}_{a} C_{k a} \cdot \boldsymbol{n}=\boldsymbol{q}_{k a}^{C} \cdot \boldsymbol{n}, \quad(x, y, z) \epsilon_{C}, t>0
$$

where $\mathrm{k}$ ranges over the aqueous components, $\mathbf{n}$ is the outward unit normal vector to $\Gamma, \mathbf{q}_{\mathrm{ja}}^{\mathrm{N}}$ is the prescribed outward Neumann (dispersive) flux across boundary segment $\Gamma_{\mathrm{N}}\left[\mathrm{mol} \bullet \mathrm{cm}^{-2} \bullet \mathrm{s}^{-1}\right]$, and $q_{\mathrm{ja}}$ is the outward Cauchy (total) flux vector across $\Gamma_{\mathrm{C}}\left[\mathrm{mol} \bullet \mathrm{cm}^{-2} \bullet \mathrm{s}^{-1}\right]$.

\subsubsection{System Summary}

In general, all $\mathrm{N}_{\mathrm{s}}$ chemical species are present at all $(\mathrm{x}, \mathrm{y}, \mathrm{z}, \mathrm{t})$ in the spatial and temporal problem domain. Recall that the $N_{s}$ chemical species are divided into $M_{a}+M_{s}$ independent species called components and $\mathrm{N}_{\mathrm{s}}-\mathrm{M}_{\mathrm{a}}-\mathrm{M}_{\mathrm{s}}$ dependent species called product species. Therefore, in general, at each $(\mathrm{x}, \mathrm{y}, \mathrm{z}, \mathrm{t})$ we have $\mathrm{M}_{\mathrm{a}}$ unknown aqueous component concentrations, $\mathrm{M}_{\mathrm{s}}$ unknown adsorbent component concentrations and number of ion-exchange site equivalents, and $3\left(N_{s}-M_{a}-\right.$ $\mathrm{M}_{\mathrm{s}}$ ) unknown product species concentrations. These unknowns are determined by $\mathrm{M}_{\mathrm{a}}$ transport equations (3.4.18), $\mathrm{M}_{\mathrm{s}}$ conservation equations (3.4.26), and $3\left(\mathrm{~N}_{\mathrm{s}}-\mathrm{M}_{\mathrm{a}}-\mathrm{M}_{\mathrm{s}}\right)$ algebraic equations (3.4.6)-(3.4.8). The unknown dependent quantities $C_{k s}$ and $C_{k p}$ in equation (3.4.18) are determined from product species concentrations according to equations (3.4.20) and (3.4.22). The system of equations is completed by auxiliary relations (3.4.10) and (3.4.11), (activities) and associated equations in Appendix 3, the total radioactive decay rate given by (3.4.23), the wasteform release term given by $(3.4 .24)$, and the source term given by $(3.4 .25)$ due to 
injection/extraction.

In the following section, we present equations describing the release of substances from waste forms. The definition of equations describing the source term, $S_{k}^{s}$, due to engineered barriers and containers, is a subject of future work. 



\section{0}

In this section we formulate the radionuclide release term $S_{\mathrm{k}}^{\mathrm{w}}$. Recall that this term (see equation (3.4.24)), represents the mass release rate of radionuclides $\left[\mathrm{mol} \cdot \mathrm{cm}^{-3} \cdot \mathrm{t}^{-1}\right]$ from waste forms and waste containers.

A schematic representation of radionuclide release from a breached waste container is depicted in Figure 4.1. The following processes are illustrated: 1) container degradation, which, upon container breach, allows water to enter the container and contact the waste forms; 2) the transfer of radionuclides from the waste forms into the contacting water; and 3) the flow of the radionuclide-laden water (leachate) out of the container and into the adjacent backfill.

Mathematical representations for these processes and how they are combined to yield $S_{k}^{\mathrm{w}}$ are described below.

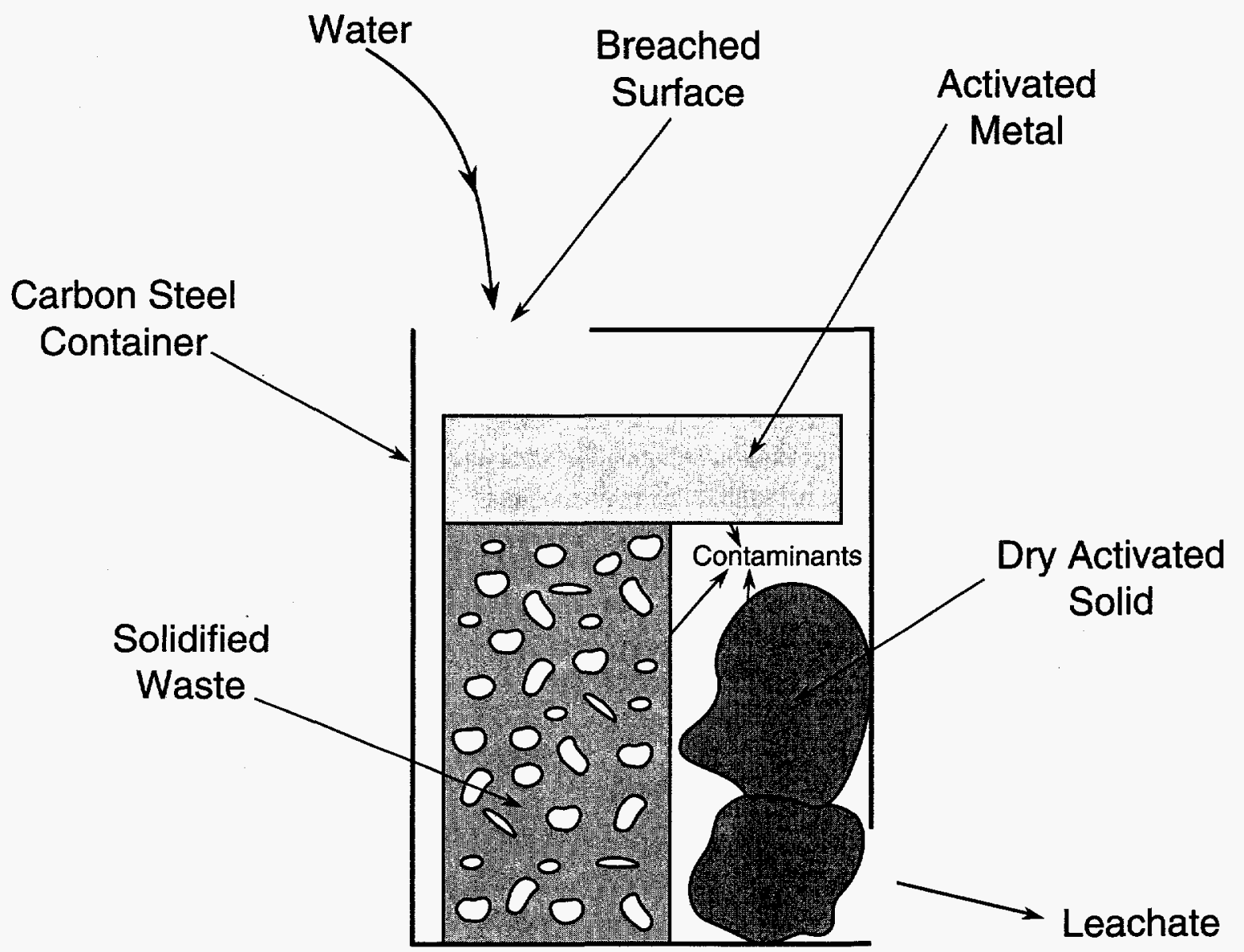

Figure 4.1 Idealized representation of radionuclide release from a breached container. 


\subsection{Release of Radionuclides}

\subsection{Container Degradation}

Before water can contact a waste form and mediate the release of radioactivity, the container surrounding the waste form must be breached. Therefore, to predict total release it is essential to know the time at which breach occurs for each container in the system, the number of breached containers at any given time, the area breached per container, and the rate at which the breached area increases.

Because of low cost and relative durability, carbon steel containers are the most commonly used low-level waste package containers. Containers made of various stainless steels, concrete, and high density polyethylene (HDPE) are used to a lesser extent. Carbon steel containers are subject to chemical attack (corrosion) which eventually leads to breach. These containers are susceptible to general as well as localized corrosion in soil environments.

In the present treatment, both localized corrosion, as represented by pitting corrosion, and generalized corrosion are considered.

\subsubsection{Localized Corrosion}

We represent the localized corrosion process by empirical correlations for pitting depth and area breached that are based on data obtained by the National Bureau of Standards (NBS), (currently the National Institute of Standards and Technology)[Romanoff, 1957].

The maximum pit depth takes the form:

$$
h=k t^{n}\left(\frac{A}{372}\right)^{a}
$$

where $\mathrm{h}$ is the maximum pit depth in $\mathrm{cm}, \mathrm{k}$ is the pitting parameter in $\mathrm{cm} / \mathrm{yr}$, $t$ is the time in years, $\mathrm{n}$ is the pitting exponent which depends on soil properties, $\mathrm{A}$ is the surface area of the container in $\mathrm{cm}^{2}$, the constant $372 \mathrm{~cm}^{2}$ is a scaling factor, and "a" is an experimentally derived correlation coefficient.

Values of "a" depend on the material and soil. Extensive studies by Logan, [1939] indicated that, for wrought irons and carbon steels, "a" ranged form 0.08 to 0.32 with a mean value of 0.15 .

Values of $n$ strongly depend on soil aeration; in practice $n$ is often selected as $0.26,0.39$, 0.44 , or 0.59 for good, fair, poor, and very poor aeration, respectively. These values are the averages determined from the NBS study for their respective soil aeration. If the clay content is known, $\mathrm{n}$ may be estimated from: 


$$
n=n_{0} \theta_{1}(1-C L)^{0.4}
$$

where $\mathrm{n}_{0}=1,1.5,2.0$, or 2.5 for good, fair, poor, and very poor aeration, respectively.

Values of pitting parameter $\mathrm{k}$ are determined from the following relationships [Sullivan and Suen, 1989]:

$$
\begin{gathered}
k=0.01458(10-p H), p H<6.8 \\
k=0.0457,6.8<p H<7.3 \\
k=0.0256(p H-5.13), 7.3<p H
\end{gathered}
$$

If the pit depth, $h$, given by equation (4.1.1) does not exceed the container thickness, the container is unbreached and water cannot access the waste form. When $h$ does exceed the container thickness, the area breached is represented by the following relationship:

$$
A_{b}=N_{p} \pi\left(h^{2}-M T^{2}\right)
$$

where $A_{b}$ is the area breached in $\mathrm{cm}^{2} ; N_{p}$ is the number of penetrating pits per container, estimates of this value range from 1000 - 10000 for a surface area of a 55 gallon drum (i.e., $21,000 \mathrm{~cm}^{2}$ ) [Sullivan et al., 1988], and MT is the thickness of the metal container [cm]. Equation (4.1.6) arises from the assumption that the pits are hemispherical in shape and continue to grow at the same rate once the metal has been penetrated.

\subsubsection{Generalized Corrosion - Time to Failure}

The general corrosion of metal is calculated assuming that the corrosion rate is constant and independent of time. This approach is likely to be conservative because the NBS general corrosion data indicate that the rate decreases in time. For a constant corrosion rate, the thickness of metal corroded, $\mathrm{d}[\mathrm{cm}]$, is simply:

$$
d=g t
$$

where $\mathrm{g}$ is the general corrosion rate in $\mathrm{cm} / \mathrm{sec}$ and $\mathrm{t}$ is the time in seconds.

If $d$ exceeds the container thickness, the entire surface area of the container is assumed to be corroded away. At this time, the container does not provide any barrier for water access to the container. 


\subsection{Release of Radionuclides}

The general corrosion model can be viewed as a time to failure model. Time to failure models are commonly used in low-level waste performance assessment codes [Sullivan, 1993]. In the absence of site-specific corrosion rate data, analysts often assume that all containers of a certain type fail at a fixed time. This can be accomplished in the BLT-EC model through appropriate choice of the corrosion rate, container thickness, and time of failure.

Corrosion rate data may not be applicable for HDPE or concrete containers. It is recommended to use a time to failure for these container types. Often, these containers are assumed to last 300 years, the minimum design lifetime for high integrity containers. Cowgill [1992a] provides a discussion of failure mechanisms and rates for HDPE containers.

\subsection{Release from Waste Forms}

The waste form is the physical form of the waste in the disposal container. A wide range of waste forms are used in LLW disposal. A review of the compilation of data from the commercial shipping manifests [Roles, 1990] indicate that there are over 22 categories of waste streams. These waste streams may be placed untreated into the container, or they may be treated with sorbents to absorb free liquids, solidification agents such as portland cement, modified sulfur cement, vinyl-ester styrene, or bitumen, compacted to reduce volume, or surrounded with sand to minimize void space in the container. Knowledge of the waste form is crucial in developing the conceptual models for release from the waste package.

The wide variety of waste forms necessitates grouping them into major categories based on the inventory of the wastes. Examination of the inventory data indicate the following major waste form types: activated metals, cement solidified wastes, dry solids (lab trash, papers, plastics, glassware, etc.), de-watered resins, evaporator bottoms, filter sludges, and solid noncombustibles. These waste forms contain over $95 \%$ of the total activity [Cowgill and Sullivan, 1993]. Although these are the major waste forms, consideration must be provided on a radionuclide specific basis. For example, in $1989100 \%$ of the Th-232 disposed at the commercial site at Richland, Washington, was disposed of in a sorbent [Cowgill and Sullivan, $1993]$.

In general each waste form may release radionuclides by a combination of release mechanisms. These mechanisms include:

(1) diffusional transport of material through a porous solidified waste form to the waste form surface;

(2) the release of materials from bulk solids by dissolution of the matrix or solid phase; and

(3) the release of surface residing materials by surface rinse.

\subsubsection{Mathematical Formulation}

Recall the conceptual picture of the breached container and waste forms shown in Figure 


\subsection{Release of Radionuclides}

4.1. In the following development, we treat the environment within the container as a mixing bath; that is, transport processes outside the waste forms are fast enough to maintain a uniform concentration within the container environment. We also make the following important assumptions:

(1) the volumetric flow rate of water through the mixing bath occurs at a rate determined by the product of the Darcy velocity in the neighborhood of the container and one half the breached area of the container (the factor of one half is based on the assumption that water enters a container through half of the breached area and exits through the other half);

(2) radionuclides are delivered to the mixing bath from the waste forms at a rate determined by one or more of the three release mechanisms noted above; and

(3) the impact of chemical processes on radionuclide transport within the waste forms may be ignored.

Performing a mass balance on the mixing bath gives:

$$
\begin{gathered}
\theta_{a}^{m b} \frac{d\left(c_{j a}^{m b}\right)}{d t}=\theta_{a}^{m b} v^{w f}\left(c_{j a}^{I}-c_{j a}^{m b}\right)+s_{j a}^{d i f}+s_{j a}^{d i s}+s_{j a}^{r} \\
-\lambda_{j} \theta_{a}^{m b} c_{j a}^{m b}+\theta_{a}^{m b} \sum_{p} \lambda_{p j} c_{p a}^{m b}
\end{gathered}
$$

where $j$ ranges over the number of radionuclide species, $\rho_{a}^{\mathrm{mb}}$ and $\theta_{\mathrm{a}}^{\mathrm{mb}}$ represent average aqueous phase density and moisture content values in the mixing bath, $\mathrm{c}_{\mathrm{j}}^{\mathrm{mb}}$ is the average concentration of species $\mathrm{j}$ in the mixing bath, $\mathrm{c}_{\mathrm{ja}}^{\mathrm{I}}$ is the average concentration of species $\mathrm{j}$ entering the mixing bath, and $\mathrm{s}_{\mathrm{ja}}^{\mathrm{dif}}, \mathrm{s}_{\mathrm{ja}}^{\mathrm{dis}}$, and $\mathrm{s}_{\mathrm{ja}}^{\mathrm{r}}$ are release rates of radionuclides from waste forms by diffusion, dissolution, and surface rinse, respectively. The last two terms on the rhs of equation (4.2.1) represent radioactive decay and ingrowth (refer to Section 3.3.1).

The term, $v^{\text {wf }}$, in (4.2.1) represents the leachant renewal frequency $\left(\mathrm{s}^{-1}\right)$ and is a measure of how fast water within the mixing bath is replenished. $v^{\text {wf }}$ is the ratio of volumetric flow rate into the mixing bath divided by the volume of water in the mixing bath, that is:

$$
v^{w f}=\frac{0.5 v_{d} A_{b}}{\theta_{1}^{m b} V^{m b}}
$$

where $v_{a}$ is the Darcy velocity of the aqueous phase given by equation $(3.2 .3)$ and $\mathrm{V}^{\mathrm{mb}}$ is the volume of the mixing bath. 
4.0 Release of Radionuclides

The source term $\mathrm{s}_{\mathrm{ja}}^{\mathrm{r}}$ is due to mass release via surface rinse and takes the form:

$$
s_{j a}^{r}=\Gamma_{j}^{r}\left(1-\frac{c_{j a}^{m b}}{c_{j a}^{s a t}}\right)
$$

where $c_{j a}$ sat is the saturation concentration (solubility limit) of species $\mathrm{j}$ in the mixing bath solution. $\Gamma_{\mathrm{j}}^{\mathrm{r}}$ is given by [Sullivan, 1991]:

$$
\Gamma_{j}^{r}=\frac{\delta\left(M_{j}^{a}(t)-\left(\frac{K_{j}^{p}}{\beta}\right) M_{j}^{s}(t)\right)}{V^{m b} \theta_{1}^{m b}\left(1+\frac{K_{j}^{p}}{\beta}\right)}
$$

where $\delta$ is an empirical constant having units of $\mathrm{s}^{-1}, \mathrm{M}_{\mathrm{j}}^{\mathrm{a}}(\mathrm{ts})$ is the mass of species $\mathrm{j}$ available for rinse release at time $t, M_{j}^{s}(t)$ is the mass of species $j$ in the mixing bath at time $t, K_{j}^{p}$ is the partition coefficient for species $\mathrm{j}$, and $\beta=\theta_{\mathrm{a}} \mathrm{V}^{\mathrm{mb}} / \rho \mathrm{V}^{\mathrm{wf}}$. Equation (4.2.4) is based on the assumption that release is governed by equilibrium between the solid waste form and the aqueous phase. As material is moved out of the mixing bath, more material is released to maintain equilibrium. Examining equation (4.2.4), we see that as $\mathrm{K}_{\mathrm{j}} \rightarrow 0$, all the mass is subject to be released at a rate controlled solely by $\delta$. In the other extreme, as $\mathrm{K}_{j}^{\mathrm{p}} \rightarrow \infty$, the mass released is negative and equal to the total mass in solution. That is, all of the mass that enters the mixing bath is adsorbed on the solid at a rate determined by $\delta$.

We next consider the release of radionuclide species $\mathrm{j}$ from a solid, porous, dissolving waste form. A one-dimensional representation of this waste form undergoing dissolution is shown in Figure 4.2. As the outer surface of the waste form dissolves, radionuclides present in the removed region enter the contacting water. Simultaneously, radionuclides diffuse from within the porous waste form outwards towards the moving surface where they exit according to Fick's Law. Under these conditions the release of radionuclides is given by:

$$
s_{j a}^{d i s}+s_{j a}^{d i f}=\frac{S A}{V^{m b}} u\left(\theta_{a}^{w f} c_{j a}^{w f}-(1-\eta) F_{j}\right)-\frac{S A}{V^{m b}} \theta_{a}^{p} D_{j} \frac{\partial c_{j a}^{p}}{\partial x}
$$

where the first and second terms on the rhs of (4.2.5) are contributions due to dissolution and diffusion, respectively, $\mathbf{u}$ is the dissolution velocity, $\eta$ is the porosity of the waste form, SA is the surface area of the waste form, $D_{j}$ is the species diffusion coefficient for the waste form, $F_{j}$ is the immobile matrix concentration of species $\mathrm{j}, \mathrm{c}_{\mathrm{ja}}^{\mathrm{wf}}$ is the aqueous phase concentration in the waste form, and $\theta_{a}^{\text {wf }}$ is the volumetric moisture content in the waste form. 


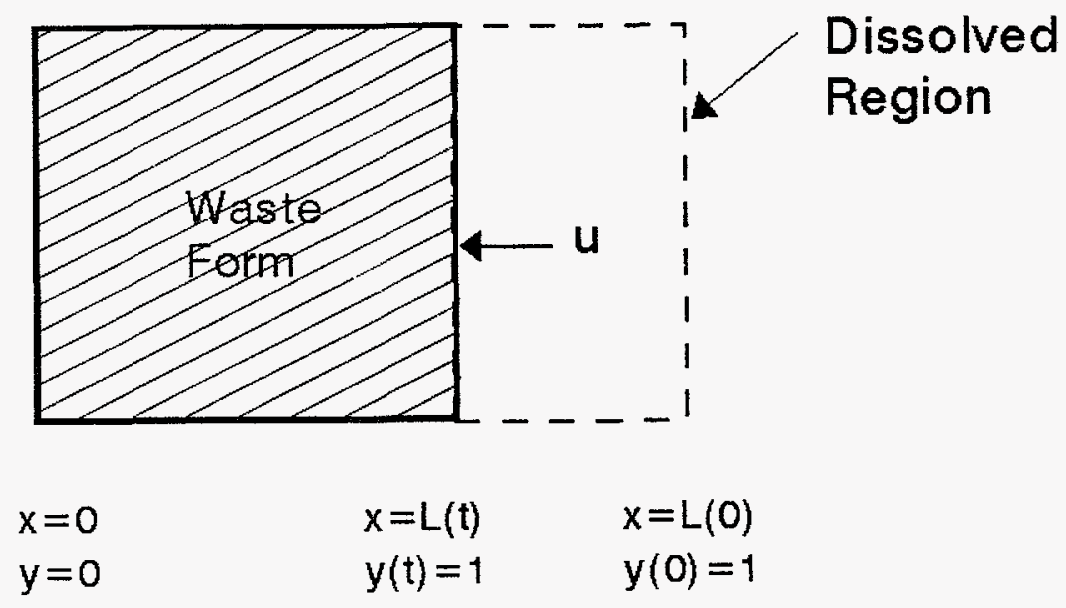

Figure 4.2 One-dimensional representation of a waste form that undergoes dissolution at a velocity $\mathrm{u} . \mathrm{x}$ is the distance variable. $\mathrm{y}$ is normalized distance variable that always has the dissolution at $y=1$.

Note that the dissolution contribution in equation (4.2.5) consists of two parts, radionuclides present in the aqueous phase and radionuclides associated with the solid matrix.

The second term on the rhs in equation (4.2.1) requires the concentration field of species $\mathrm{j}, \mathrm{c}_{\mathrm{ja}}{ }^{\mathrm{wf}}$, in the waste form. In a dissolving region, this concentration field is described by [Sullivan and Suen, 1991]:

$$
\begin{gathered}
\theta_{a}^{w f} \frac{\partial c_{j a}^{w f}}{\partial t}=\frac{\theta_{a}^{w f} D}{L^{2}} \frac{\partial^{2} c_{j a}^{w f}}{\partial y^{2}}+\frac{\left(v_{a}^{w f}+\theta_{a}^{w f} u y\right)}{L} \frac{\partial c_{j a}^{w f}}{\partial y} \\
+C_{y l}\left(\frac{-\theta_{a}^{w f} D}{y L^{2}} \frac{\partial c_{j a}^{w f}}{\partial y}+\frac{v_{a}^{w f} c_{j a}^{w f}}{y L}\right)-\theta_{a} \lambda_{j} c_{j a}^{w f}+\theta_{a}^{p} \sum_{p} \lambda_{p j} c_{p a}^{w f}
\end{gathered}
$$

where $v_{a}^{\text {wf }}$ is the advection velocity through the waste form, $\lambda_{j}$ is the species decay constant, $s_{j a}^{\text {wf }}$ is the source/sink term for the diffusive species (it may be a function of concentration, solubility limit, immobile species concentration or other parameters), $\mathrm{C}_{\mathrm{yl}}$ takes the value of 0 for plane geometry and 1 for cylindrical geometry, and $\mathrm{L}$ is the length of the modeled region at time $\mathrm{t}$. $\mathrm{y}$ is a dimensionless distance variable given by: 
4.0 Release of Radionuclides

$$
y=\frac{x}{L(t)}
$$

Some species are attached to the structure of the waste form, these species are not transported in the solid phase. In this case, equation (4.2.6) simplifies to:

$$
(1-\eta) \frac{\partial F_{j}}{\partial t}=\frac{(1-\eta) u y}{L} \frac{\partial F_{j}}{\partial y}-(1-\eta)\left(\lambda_{j} F_{j}+\sum_{p} \lambda_{p} F_{p}\right)
$$

where $F_{j}$ and $\eta$ are the immobile phase concentration and waste-form porosity.

The associated boundary and initial conditions are:

$$
c_{j l}=c_{j l}^{m b}, \quad \text { on } \Gamma_{w f}
$$

and

$$
c_{j l}=c_{j l}^{0}, \quad t=0,(x, y) \in \Omega^{w f}
$$

Equations (4.2.1) - (4.2.10) form the basis for calculating the concentration of species $\mathrm{j}, \mathrm{c}_{\mathrm{ja}}^{\mathrm{mb}}$, in the mixing bath.

The release of chemical species $\mathrm{j}$ from the mixing bath for transport, source term $\mathrm{s}_{\mathrm{ja}}^{\mathrm{w}}$, is expressed as:

$$
s_{j a}^{w}=\mathbf{u}^{w f}\left(c_{j a}^{m b}-c_{j a}^{I}\right)
$$

The total source term for component $\mathrm{k}, \mathrm{S}_{\mathrm{k}}^{\mathrm{w}}$, is obtained by introducing equation (4.2.11) into equation (3.4.24):

$$
S_{k}^{w}=\mathrm{v}^{w f} \sum_{j} \bar{v}_{k g}^{a}\left(c_{j a}^{m b}-c_{j a}^{l}\right)
$$

\subsubsection{Discussion}

We should emphasize that the release models presented above, by equations (4.2.1)(4.2.11), describe the release of different radionuclide species (i.e., $\mathrm{UO}_{2} \mathrm{OH}^{+}$vs. $\mathrm{UO}_{2}(\mathrm{OH})_{2}$ ). Note that the chemical processes that determine the solubility and sorption properties of 


\subsection{Release of Radionuclides}

radionuclides in waste forms are the same as those acting in the ground water. Therefore, as discussed previously, these properties, and hence the leachability, are species dependent. This point is important because species-specific data parameters $\mathrm{D}_{\mathrm{j}}, \mathrm{M}_{\mathrm{j}}^{\mathrm{a}}, \mathrm{K}_{\mathrm{j}}^{\mathrm{p}}$, and $\mathrm{c}_{\mathrm{ja}}^{\mathrm{sat}}$ are typically not available or measured during waste-form leaching studies. Rather, these parameters are typically available as homogenized values; that is, they are determined experimentally by measuring total radionuclide release rates without specification of the chemical form of the radionuclides. The implications of this issue on characterization and modeling of waste-form leaching processes needs to be examined further. From the standpoint of implementing the source models in BLTEC, however, this issue poses no difficulty as long as radionuclides are chosen by the user to be components as defined in Section 3.4. 



\subsection{OVERVIEW OF BLT-EC}

This section provides an overview of the various numerical models for flow, breach, leach, transport, and chemical processes and their implementation in BLT-EC. Basic code structure and code-user implementation are also briefly described. A much more detailed presentation of the numerical models and algorithms in BLT-EC will be published in a subsequent companion report.

\subsection{Coupling Between Major Process Models}

Modeling the release of contaminants from a LLW disposal unit can be divided into five processes:

(1) water flow in the unit and surrounding subsurface;

(2) container degradation to the point that water can contact the waste form (breach);

(3) release of the contaminants from the waste form to the water (leach);

(4) transport of the contaminants within and beyond the disposal unit; and

(5) geochemical interactions between the contaminants, container and engineered barrier materials, natural substances in the ground water, and the host soil.

These processes are not independent of one another and, therefore, proper simulation requires coupling between their corresponding models.

Recall that the coupling between the five process models was previously illustrated in Figure 1.2. In this figure, it can be seen that the water flow is assumed to be independent of all other processes. The independence of water flow is assumed because the dependence of water flow parameters, such as hydraulic conductivity, on container degradation and waste form leaching are expected to be small. All other processes are coupled to water flow. Container degradation (breach) modeling involves the prediction of pitting and general corrosion rates. These processes are, in general, functions of the moisture content, $\mathrm{pH}$, and redox conditions in the backfill adjacent to the containers. Waste-form release (leach) modeling requires information from all four other process models. This information includes: the breached area as a function of time from the container degradation model; the concentration of contaminants in solution adjacent to the waste form from the transport-chemical process models; and the inlet and outlet flow rates and moisture content from the water flow model. Chemical process modeling requires, besides thermodynamic data, concentrations of all chemical components in the system, these are provided by the transport model. Transport modeling requires material release rates from the leaching and soil/container/barrier release models, and the water velocity field and moisture content distribution in the soil. 


\subsection{Overview of BLT-EC}

\subsection{Description of Models}

\subsubsection{Water Flow}

The flow of water in unsaturated and saturated porous media is described by nonlinear partial differential equation (3.2.2) and constitutive relations for $\mathbf{K}^{\mathrm{c}}$ and $\mathrm{F}$ (see equations (3.2.4) and (3.2.6)) that relate water content to hydraulic conductivity and pressure head. We presently solve the water flow problem using a modified version of the two-dimensional finite-element code FEMWATER [Yeh and Ward, 1980]. This code discretizes the flow equations in space with linear finite elements and in time with a variable two-point finite-difference scheme. The final linearized matrix equation is solved using direct elimination with Picard iteration to iterate the nonlinearity. The flow solution is postprocessed to provide the velocity vector (defined by equation (3.2.3)) required by the discrete advection-dispersion chemical transport equations in BLT-EC. Although we use FEMWATER in our applications other codes may be easily adapted to BLT-EC calculations.

\subsubsection{Container Degradation: BREACH Module}

The BREACH module in BLT-EC computes the following quantities:

(1) the time at which breach occurs for each container in the system;

(2) the number of breached containers at any given time;

(3) the area breached per container; and

(4) the rate at which the breached area increases.

These quantities are computed for both localized as well as generalized corrosion. Refer to equations (4.1.1)- (4.1.7). General failure is modeled through a user-specified time of failure. The time to failure may be estimated, for example, as the corrosion allowance of the container divided by the time-averaged corrosion rate, that is, $\mathrm{t}=\mathrm{d} / \mathrm{g}$. Refer to equation (4.1.7). Corrosion rates should be obtained from site specific data whenever possible. If such data are not available, the data base generated by the National Bureau of Standards, NBS (currently the National Institute for Standards and Technology) [Romanoff, 1957] for stainless steels may be used for these materials. Localized corrosion is modeled by empirical correlations, equations (4.1.1)(4.1.6), which are based on the NBS data base. The parameters in this correlation depend on soil-water $\mathrm{pH}$, degree of soil aeration, moisture content, and clay content.

\subsubsection{Release from Waste Forms: LEACH Module}

Radionuclide release from the waste form commences upon container failure. Several different waste forms may be present in a LLW facility. In general, each waste form may release radionuclides by a combination of different mechanisms. To cover a wide range of conditions, four release mechanisms are modeled in the $\mathbf{L E A C H}$ model: surface rinse limited by partitioning 
(see equations (4.2.3) and (4.2.4)), uniform release (equation (4.2.5)), diffusion through solidified waste forms (equation (4.2.6)), and solubility-limited release. All models include the effects of solubility limits and radioactive decay. Daughter ingrowth in the waste forms is currently not accounted for in the present version of BLT-EC. This capability will be implemented in the future. Release models and their implementation are briefly described below.

\section{Surface Rinse}

The surface rinse submodel approximates the release of radionuclides that are washed off the surface of the waste form (see equations (4.2.3) and (4.2.4)). In general, radionuclides can be bound on the waste-form surfaces by mechanisms such as adhesion, sorption, and ion exchange. The net effect of these binding mechanisms is modeled by a linear partition coefficient, which is an equilibrium ratio relating the amount of contaminant on the waste form to that in solution. If the partition coefficient is set to zero, instantaneous release of the entire waste form inventory will occur upon contact with water. This approach is frequently used to provide an upper bound on release and in situations where there is very little data to support use of other mechanisms to represent waste form release. Lack of appropriate leaching data occurs for many waste forms including dry active wastes, dewatered resins, filter sludges, and evaporator bottoms.

\section{Diffusion Release}

The diffusion submodel approximates diffusive transport of radionuclides from within the matrix of a solidified waste form to the waste-form surface (see equation (4.2.6)), where release rates are governed by Fick's law (see equation (4.2.5)). The diffusion model considers two geometries most widely used in LLW disposal: cylindrical (drums) and rectangular (boxes). The user has the option of using one of two approaches to approximate the diffusion process. One approach assumes that the concentration in the solution contacting the waste form is zero; this allows an analytical solution to be implemented and leads to the highest release rates. The other approach models diffusion in the waste form using a one-dimensional finite-difference method; this approach allows the effect of time-dependent concentrations in the contacting solution to be accounted for. The diffusion submodel is most often used for wastes solidified in a binder, e.g., cement, VES, etc. The diffusion coefficient should be determined experimentally for the waste-stream/binder combination used for disposal. If experimental data does not exist, the diffusion coefficient is often assumed to be the minimum value approved for an acceptable solidification agent by the NRC [U.S. Nuclear Regulatory Commission, 1991].

\section{Uniform Release}

The uniform release submodel simulates the release of radionuclides from waste forms that are dissolving or undergoing corrosion at a user-specified dissolution rate (see equations (4.2.5)-(4.2.8)). This submodel is commonly applied to represent release from activated metals and glass waste forms. In practice, the dissolution velocity is assumed constant. Its value is based on experimental data for metallic corrosion or glass dissolution. With a constant dissolution velocity and geometry of the waste form, the inventory fractional release rate can be calculated. Many computer codes require the fractional release rate as an input parameter. 


\subsection{Overview of BLT-EC}

\section{Solubility Limited Release}

Solubility limited release permits an instantaneous release to solution until the solubility limit is reached. Further releases are controlled by the migration of radionuclides away from the waste form. Solubility limited release is enforced on a radionuclide specific basis for all waste forms. It frequently becomes the rate controlling release mechanism for uranium and other actinides which have low solubility limits in many ground-water systems. In some cases, the other release mechanism models, e.g., rinse, diffusion or dissolution, may predict radionuclides at a rate such that the solubility limit would be exceeded. This is handled by restricting releases from these models such that a user-specified saturation limit is not exceeded.

In the present version of BLT-EC, solubility limited release from a waste form is uncoupled from the equilibrium chemistry model. That is, the code user provides, as input, a saturation limit for each of the radionuclide species in the waste inventory. These saturation limits remain constant during simulation and, in general, may be different than the corresponding solubility limits calculated by the equilibrium model. In cases where the user-specified saturation limit exceeds the corresponding solubility limit calculated by the equilibrium chemistry model, contaminants will leach from the waste forms and immediately precipitate in the region surrounding the waste form. This phenomena is illustrated in the last example application presented in Chapter 6 . The code user should be aware that if user-specified saturation limits are less than the corresponding computed solubility limits, release rates may be underestimated.

\section{Implementation of Waste Form Release Models}

The most complex of the waste-form release models [Sullivan and Suen, 1991] considers all four release mechanisms simultaneously. A partial differential equation is used to represent diffusion, waste-form dissolution, radioactive decay, and surface rinse with partitioning (see equation (4.2.1)). The solution concentration is supplied from calculations which model the transport of radionuclides in the ground water after they have been released from the waste form (see equation (3.4.18)). Release from waste forms is directly coupled to solution concentration. The equation representing movement within the waste form (see equation (4.2.6)) is solved using the method of finite differences.

A simpler approach, which is frequently used, is to consider each of the four release mechanisms as an independent process. In this case, total release from the waste form is the sum of the rinse, diffusion, and dissolution release modeis with the constraint that the release will not cause user-specified solubility limits to be exceeded. This approach is a useful approximation because, for many waste forms, one release mechanism will dominate over the others.

When treating multiple waste-form release mechanisms, the fraction of mass available for each release mechanism must be supplied by the model user. This approach can be useful for homogenization of several different waste forms into an equivalent waste form which is used to model release. For example, consider (1) a cement solidified waste form, containing 5 Curies of contaminant, in which diffusion controls release, (2) an activated metal waste form, containing 3 Curies of contaminant, in which dissolution controls release, and (3) contaminated lab trash with 


\subsection{Overview of BLT-EC}

2 Curies of activity, in which rinse release is the dominant release mechanism. These three waste forms could be modeled as an equivalent waste form with a total inventory of 10 Curies in which $50 \%$ of the inventory is constrained to have diffusion release; $30 \%$ of the inventory releases through the dissolution mechanism, and the remaining $20 \%$ releases by the rinse mechanism.

When treating release mechanisms independently, a check must be performed to insure that the user-specified contaminant saturation limit is not exceeded. This can be achieved by summing over each release mechanism to obtain the total waste-form release. The mass released can be converted to a solution waste-form release concentration provided the volume of water in the computational cell (finite element) in which release occurs is known. The original solution concentration is added to the waste-form release concentration and the result is compared to the user-specified saturation limit. If the solubility limit is exceeded, the mass released is reduced to a level such that the sum of the two concentrations does not exceed the limit. The mass that is not released is transferred to the rinse release model. This is equivalent to assuming an instantaneous reversible precipitation process. Note, by neglecting changes in solution concentration due to transport, the predicted concentration after performing a mass balance for the region will not be exactly equal to the user-specified saturation limit.

When applying the rinse model independently, the entire inventory is released instantly. There are two processes that can limit this release; solubility and partitioning. If the userspecified saturation limit is exceeded, release is restricted to insure that the solution concentration does not exceed the solubility limit. If partitioning is applied, release is limited such that the concentration in solution is related to the amount of mass left in the waste form through the equilibrium partition coefficient.

When applying the diffusion release model, analytical solutions to diffusion from the waste form are used. Several different cases can be modeled depending on the geometry of the waste form. Models exist for the following waste-form geometries: semi-infinite media, and 1, 2 , and 3 - dimensional finite sized waste forms (e.g., planar, cylindrical, rectangular, respectively). The analytical expressions for these cases can be found in [Sullivan and Suen, 1989; Pescatore, 1990]. In all cases, the swept away boundary condition is used at the edge of the waste form; this boundary condition assumes zero solution concentration at the edge of the waste form. This condition provides the maximum concentration gradient and therefore, maximum release rate for a given geometry and diffusion coefficient. However, the swept away boundary condition completely decouples the waste form release from the solution chemistry. In addition, the analytical solutions do not take solubility limits into consideration. A check is made to determine if this limit is exceeded. If exceeded, the mass release is limited as described above.

When applying the dissolution model independently, all of the components of the waste form are released at the same rate. This rate is determined by the dissolution velocity and the ratio of surface area to volume of the waste form. It should be noted that the dissolution rate is controlled by dissolution of the waste-form matrix material. In this case, the radionuclides are released at the matrix dissolution rate and therefore, the mass released may cause the user- 


\subsection{Overview of BLT-EC}

specified saturation limit to be exceeded. When this occurs, a check is made to limit the mass released in a manner similar to that used in the rinse-release model.

\subsubsection{Transport Processes: Transport Module}

The transport model in the BLT-EC computer code is based on a modified version the hydrological transport module contained in the finite-element code HYDROGEOCHEM [Yeh and Tripathi, 1990]. This module approximates the governing transport equations (3.4.18) and (3.4.26) with bilinear finite elements for the spatial discretization, a variable two-point finite-difference scheme for time integration, and either direct or pointwise iteration methods for solution of the matrix equations. The code user can also select the following options: (a) an upstream weighting finite-element approximation for advection-dominated flows, (b) lumping of the mass matrix, and (c) tetrahedral or quadrilateral elements (although the BREACH and LEACH models require quadrilateral elements for their implementation).

\subsubsection{Chemical Processes: EC Module}

As discussed in Chapter 2.0, several chemical processes potentially play a role in determining the sorption and solubility properties, and hence mobilities, of radionuclides in solution. The EC module accounts for several of these processes including complexation, dissolution-precipitation, reduction-oxidation, sorption, and ion exchange. These processes, under the assumption of chemical equilibrium, are represented by the set of mass action equations (3.4.6)-(3.4.8) that describe how the various chemical constituents are distributed among the aqueous, precipitated, and adsorbed phases present in the pore space. $\mathbf{E C}$ has the ability, for a specified solution composition, to automatically select the relevant reactions and thermodynamic data from its associated thermodynamic database. In addition, the EC module can compute $\mathrm{pH}$ and $\mathrm{Eh}$ as solution composition changes in response to complexation and precipitation-dissolution processes. The user also has the option of specifying the $\mathrm{pH}$ and Eh values. Adsorption models in $\mathbf{E C}$ include activity $\mathrm{K}_{\mathrm{d}}$, Langmuir, Freundlich, ion exchange, constant capacitance, triple-layer, and diffusive-layer models. Refer to Appendix 5.

The geochemical model used to solve the chemical equilibrium equations in BLT-EC is a modified version of the geochemical computer code MINTEQA2 [Allison et al., 1991]. MINTEQA2 uses the Newton-Raphson method to solve the governing equations for a mixture of specified composition. Further details of the computational algorithms can be found in Allison et al. [1991]. In a BLT-EC simulation, mixture compositions at each node and time step are provided by the transport module. The pre-solution routines in MINTEQA2 have been modified extensively to interface efficiently with the transport module. 


\subsection{Coupling Between Modules}

\subsubsection{BREACH and LEACH Modules}

The manner in which the BREACH and LEACH modules described above are implemented in BLT-EC is represented schematically in Figure 5.1. Waste containers are located within finite elements, each "waste element" is assigned a specific container type and waste-form type. The container depicted in Figure 5.1 has failed only partially. In this case, the rate of contaminant or "source" supplied for transport by the waste element, equation (4.2.12), is calculated based on a mass balance, equation (4.2.1), that considers the rate of radionuclide release from the waste form (calculated by the submodels described above) and the rate of mass transfer into and out of the waste element due to advection. If a container has failed completely, radionuclides released from the waste form are made directly available for transport.

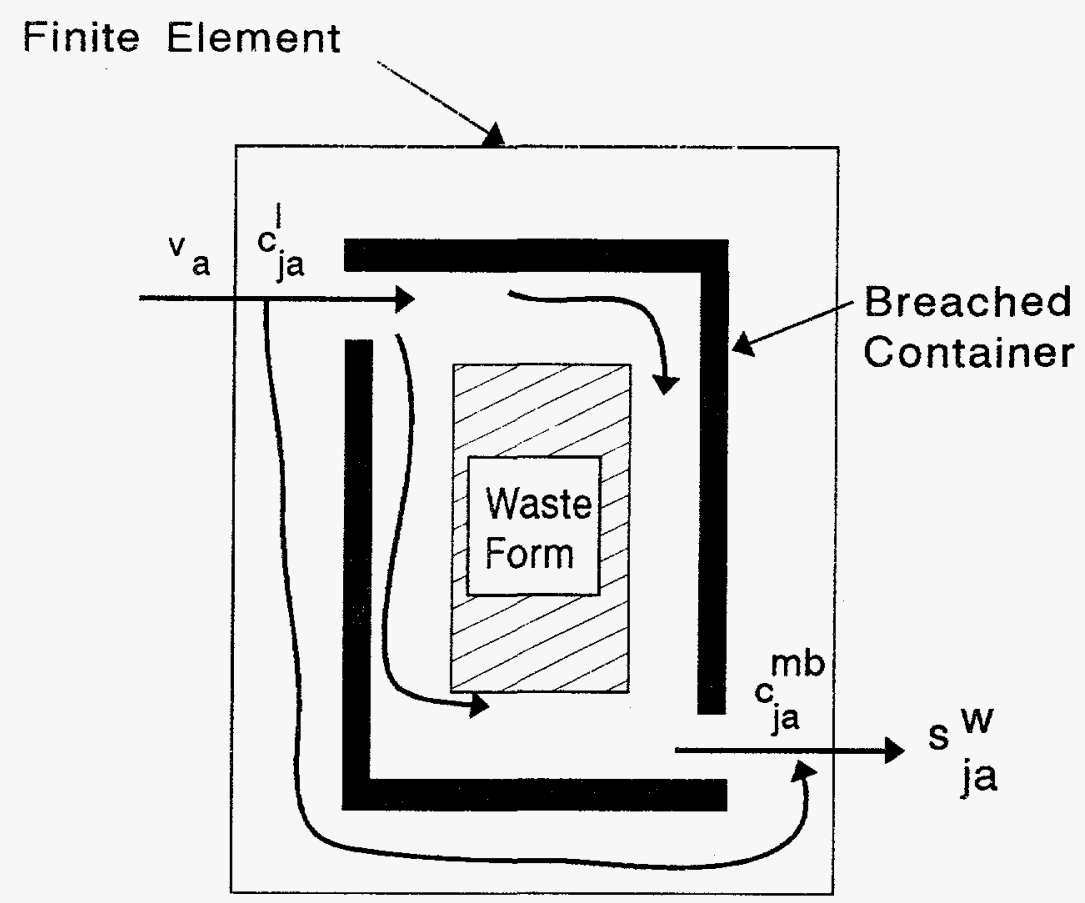

Figure 5.1 Conceptual mixing bath model.

\subsubsection{Transport and EC Modules}

The primary unknowns in aqueous phase transport equation (3.4.18) are the analytical concentrations, $T_{k}$, of the $M_{a}$ chemical components at each node point in the flow domain. Equation (3.4.18) also contains total component concentrations in the precipitated phase, $\mathrm{C}_{\mathrm{kp}}$, and sorbed phase, $\mathrm{C}_{\mathrm{ks}}$, as secondary unknowns. Equation (3.4.18) is nonlinear because of these secondary unknowns, thus requiring an iterative coupling between the transport and EC 


\subsection{Overview of BLT-EC}

modules. This coupling can be described as follows. For each time step, $M_{s} A_{k s}$ adsorbent and/or equivalent concentrations are first calculated (note that $\mathrm{k}$ ranges over adsorbent components only) from equation (3.4.27). Second, equation (3.4.18) is solved for each $T_{k}$, subject to initial and boundary conditions, using $\mathrm{C}_{\mathrm{kp}}$ and $\mathrm{C}_{\mathrm{ks}}$ values from the previous time step (for the solution of (3.4.18) at the first time step, $\mathrm{C}_{\mathrm{kp}}$ and $\mathrm{C}_{\mathrm{ks}}$ are initial system equilibrium values). Third, just computed $T_{k}$ values along with the $M_{s} A_{k s}$ values are input to the chemistry module where new $\mathrm{C}_{\mathrm{kp}}$ and $\mathrm{C}_{\mathrm{ks}}$ concentrations, via equations 3.4.20 and 3.4.22, are computed. The third step is repeated for each node point in the flow domain. The second and third steps are repeated until convergent $T_{k}$ values are obtained or until a user specified number of interations have been completed. The entire process then proceeds to the next time step.

\subsubsection{Flow, BREACH, LEACH, Transport, and EC Modules}

The solution of the entire system is as follows. First, the flow solution is computed. Moisture contents and flow velocities are then made available for the BREACH, LEACH, and transport modules. Second, container degradation and waste-form leaching are computed as described in Sections 5.2.2 and 5.2.3. Third, transport and chemistry calculations are carried out as described in Sections 5.2.4 and 5.2.5. The second and third time steps are repeated for each time step until the desired simulation time is reached. Note that if the flow field is transient, the flow calculation, in general, would have to be computed at every time step. Presently, the coupling between the flow model and BLT-EC is designed for steady-state flow analyses.

\subsection{Summary of Implementation}

Substantial effort has been directed towards making the BLT-MS and BLT-EC codes modular, user friendly, and transportable between UNIX and DOS based platforms. To help the user create an input file, menu driven preprocessors that guide the user through the necessary steps of creating or modifying input files have been developed. We are also currently developing a menu-driven postprocessor to facilitate graphical display of one- and two-dimensional output data.

The modular structure of the complete BLT-EC code package is illustrated in Figure 5.2. This package consists of six modules: (1) an optional preprocessor that assists the user in preparing source, transport, and chemical input data; (2) the BLT module that simulates radionuclide release and migration; (3) the $\mathbf{E C}$ module that simulates the chemical reactions; (4) the hydrogeologic data module that transfers data from FEMWATER's finite-element mesh to BLT-EC's finite-element mesh for use by the BLT module; (5) the thermodynamic data base that provides the $\mathbf{E C}$ module with the pertinent reactions and data; (6) the postprocessing module that provides tabular and graphical displays of output. 


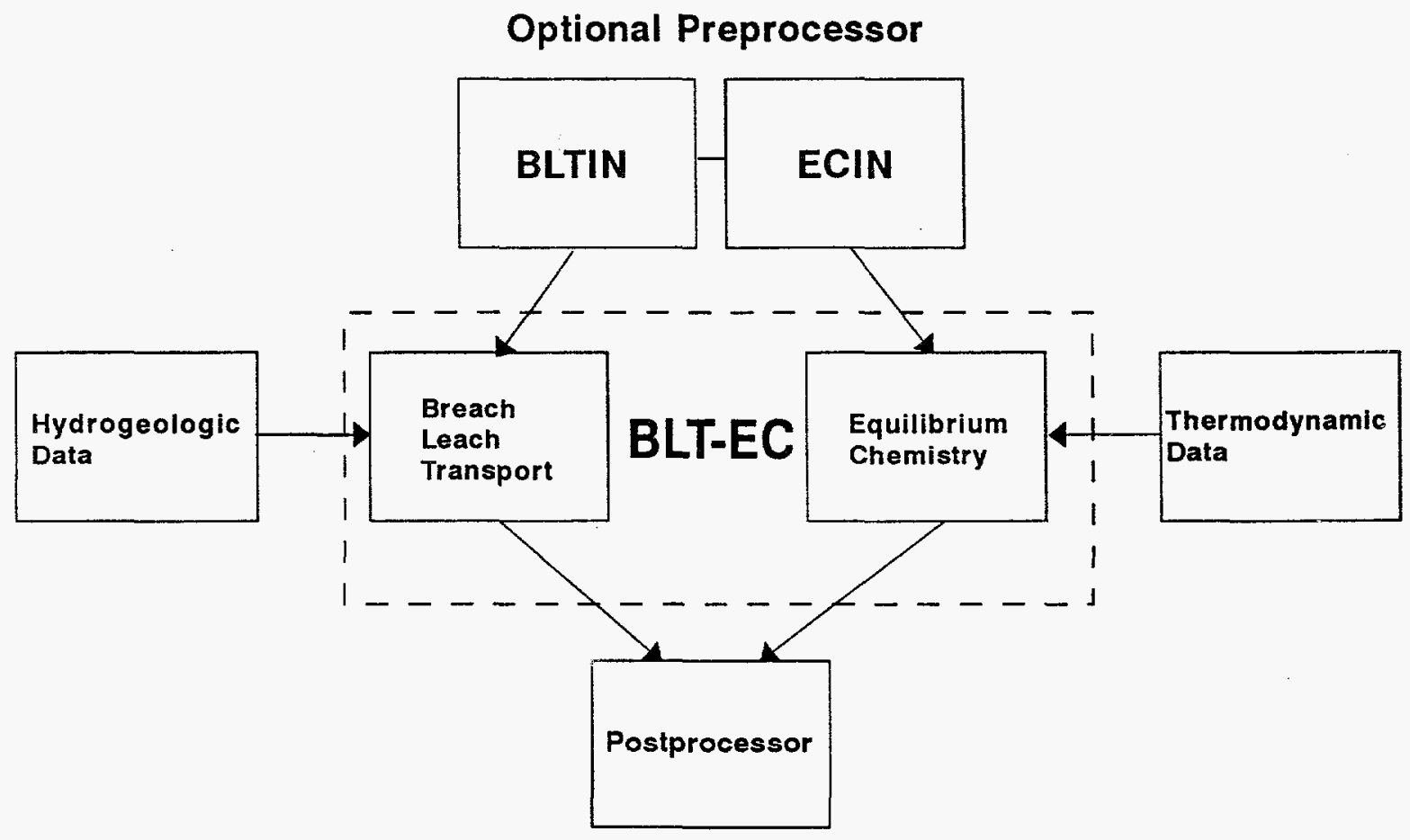

Figure 5.2 Top-level flow chart of the BLT-EC code. 



\subsection{APPLICATIONS}

In this section we present five example problems which partially verify and demonstrate the capabilities of BLT-EC. The first four problems make comparisons between solutions computed with HYDROGEOCHEM and BLT-EC. The first three of these problems focus on testing the equilibrium chemistry module at a single node point; complexation, redox, acid-base, and precipitation reactions are considered. The fourth problem considers both transport and reaction in a one-dimensional column. These four problems were used previously as

HYDROGEOCHEM verification problems in the earlier work by Yeh and Tripathi [1990]. The final example problem is more representative of a performance assessment application and simulates the release of uranium from a hypothetical two-dimensional shallow land burial trench. This example is non-site specific and is designed to demonstrate BLT-EC's ability to couple transport, chemical reaction, container degradation, and waste-form release.

\subsection{Example Problems}

\subsubsection{Problem No. 1}

This problem considers aqueous complexation of the following components, $\mathrm{Na}^{+}, \mathrm{Pb}^{2+}$, $\mathrm{H}^{+}$, and $\mathrm{Cl}^{-}$in a solution having a fixed hydrogen activity of $\mathrm{pH}=7.10535$. The initial analytical concentrations (mol/liter) of these components are $1.0 \times 10^{-1}, 2.9 \times 10^{-4}, 1.0 \times 10^{-1}$, and $2.9 \times 10^{-4}$, respectively. Two BLT-EC simulations were performed; (1) reactions are specified a priori and correspond with the reactions considered in the HYDROGEOCHEM simulation, and (2) reactions are not predefined and are automatically selected by the equilibrium module and thermodynamic database. The HYDROGEOCHEM solution was obtained from Yeh and Tripathi [1990]. Species concentrations at equilibrium, along with equilibrium constants, are presented in Table 6.1. Slight differences in computed equilibrium concentrations between simulations are apparent. By comparing the tabulated results we see that BLT-EC concentration results, $\mathrm{C}^{(2)}$, agree closely with the HYDROGEOCHEM results, the exception being hydrogen concentration. It is stated in the HYDROGEOCHEM problem description [Yeh and Tripathi, 1990] that hydrogen activity is fixed at $\mathrm{pH}=7.10535$, yet the negative $\log$ of the computed equilibrium hydrogen concentration is given as 7.11 ( 7.10535 rounded up). However, activity and concentration values are equal only in solutions of very low ionic strength. Note that the negative log of the BLT-EC hydrogen concentration, which corresponds to $\mathrm{pH}=7.10535$, is 6.99 .

BLT-EC results, $\mathrm{C}^{(3)}$, are computed by allowing BLT-EC to select, from its database, the relevant reactions. These results are significantly different than the HYDROGEOCHEM results because a significant quantity of $\mathrm{Pb}(\mathrm{OH})_{2}$ precipitates. As a result, the concentrations of free $\mathrm{Pb}^{2+}$ differ substantially. This latter simulation illustrates the advantage of having the computational capability to automatically access a thermodynamic database. This capability eases the burden of having to predefine the reactions, which may lead to errors or misleading results if important reactions are neglected. Moreover, an automatically accessible database eliminates the cumbersome and error prone task of organizing and inputing the required stoichiometric and thermodynamic constants. 


\begin{tabular}{|c|c|c|c|c|c|c|c|c|c|c|}
\hline \multirow[b]{2}{*}{ Species } & \multirow[b]{2}{*}{$\log K^{(1)}$} & \multirow[b]{2}{*}{$\mathrm{C}^{(1)}$} & \multirow[b]{2}{*}{$\log K^{(2)}$} & \multirow[b]{2}{*}{$\mathrm{C}^{(2)}$} & \multirow[b]{2}{*}{$\log K^{(3)}$} & \multirow[b]{2}{*}{$\mathrm{C}^{(3)}$} & \multicolumn{4}{|c|}{ Components and Stoichiometry } \\
\hline & & & & & & & $\mathrm{Na}^{+}$ & $\mathrm{Pb}^{2+}$ & $\mathrm{H}^{+}$ & $\mathrm{Cl}^{-}$ \\
\hline $\mathrm{Na}^{+}$ & 0.00 & $1.000 \mathrm{E}-1$ & 0.00 & $1.000 \mathrm{E}-1$ & 0.00 & $1.000 \mathrm{E}-1$ & 1 & 0 & 0 & 0 \\
\hline $\mathrm{Pb}^{2+}$ & 0.00 & $2.570 \mathrm{E}-4$ & 0.00 & $2.600 \mathrm{E}-4$ & 0.00 & $2.421 \mathrm{E}-6$ & 0 & 1 & 0 & 0 \\
\hline $\mathrm{H}^{+}$ & 0.00 & $7.845 \mathrm{E}-8$ & 0.00 & $1.012 \mathrm{E}-7$ & 0.00 & $1.012 \mathrm{E}-7$ & 0 & 0 & 1 & 0 \\
\hline $\mathrm{Cl}^{-}$ & 0.00 & $1.000 \mathrm{E}-1$ & 0.00 & $1.000 \mathrm{E}-1$ & 0.00 & $1.000 \mathrm{E}-1$ & 0 & 0 & 0 & 1 \\
\hline $\mathrm{OH}^{-}$ & -13.99 & $1.660 \mathrm{E}-7$ & -13.99 & $1.647 \mathrm{E}-7$ & -13.99 & $1.646 \mathrm{E}-7$ & 0 & 0 & -1 & 0 \\
\hline $\mathrm{Pb}(\mathrm{OH})^{+}$ & -7.71 & $3.090 \mathrm{E}-5$ & -7.71 & $2.999 \mathrm{E}-5$ & -7.71 & $2.796 \mathrm{E}-7$ & 0 & 1 & -1 & 0 \\
\hline \multicolumn{11}{|c|}{ Other species from database: } \\
\hline $\mathrm{Pb}_{3}(\mathrm{OH})_{4}^{2+}$ & - & $=$ & & -- & -23.88 & $6.369 \mathrm{E}-14$ & 0 & 3 & -4 & 0 \\
\hline $\mathrm{Pb}(\mathrm{OH})_{4}{ }^{2-}$ & - & - & & - & -39.69 & $1.261 \mathrm{E}-17$ & 0 & 1 & -4 & 0 \\
\hline $\mathrm{PbCl}^{+}$ & $\ldots$ & -- & & -- & 1.60 & $3.485 \mathrm{E}-6$ & 0 & 1 & 0 & 1 \\
\hline $\mathrm{PbCl}_{2}$ & -- & - & & -- & 1.80 & $3.245 \mathrm{E}-7$ & 0 & 1 & 0 & 2 \\
\hline $\mathrm{PbCl}_{3}^{-}$ & - & -- & & --- & 1.69 & $2.631 \mathrm{E}-8$ & 0 & 1 & 0 & 3 \\
\hline $\mathrm{PbCl}_{4}{ }^{2-}$ & - & -- & & -- & 1.38 & 2.099E-9 & 0 & 1 & 0 & 4 \\
\hline $\mathrm{Pb}(\mathrm{OH})_{2}$ & -- & -- & & -- & -17.12 & $1.047 \mathrm{E}-9$ & 0 & 1 & -2 & 0 \\
\hline $\mathrm{Pb}(\mathrm{OH})_{3}^{-}$ & - & $\cdots$ & & -- & -28.06 & $2.016 \mathrm{E}-13$ & 0 & 1 & -3 & 0 \\
\hline $\mathrm{Pb}_{2} \mathrm{OH}^{3+}$ & -- & -- & & - & -6.36 & $4.193 \mathrm{E}-11$ & 0 & 2 & -1 & 0 \\
\hline \multicolumn{11}{|c|}{ Precipitated solids from database: } \\
\hline $\mathrm{Pb}(\mathrm{OH})_{2}$ & - & $-\cdots$ & & --- & -8.15 & $2.835 \mathrm{E}-4$ & 0 & 1 & -2 & 0 \\
\hline
\end{tabular}

C(1) HYDROGEOCHEM solution

$\mathrm{C}^{(2)} \quad$ BLT-EC solution

$\mathrm{C}^{(3)} \quad$ BLT-EC solution involving additional reactions provided by MINTEQA2 database 


\subsection{Applications}

For further verification, this problem was also examined using MINTEQA2. The results of BLT-EC, concentrations $\mathrm{C}^{(3)}$, and MINTEQA2 were in exact agreement with each other.

\subsubsection{Problem No. 2}

This problem considers acid-base and redox reactions involving $\mathrm{Fe}^{3+}, \mathrm{SO}_{4}{ }^{2-}, \mathrm{H}^{+}$, and $\mathrm{e}$. The initial concentrations (mol/liter) of these components are, respectively, $2.0 \times 10^{-1}, 3.0 \times 10^{-1}$, $1.0 \times 10^{-2}$, and $1.3 \times 10^{-8}$. Equilibrium concentrations of these components, associated dependent species, and equilibrium constants are given in Table 6.2. In this problem, the reactions that are automatically selected by BLT-EC correspond with the reactions considered in the HYDROGEOCHEM simulation. Disagreements in concentrations are significant for several species, particularly for $\mathrm{Fe}^{3+}, \mathrm{Fe}(\mathrm{OH})_{2}{ }^{+}$, and $\mathrm{HSO}_{4}^{-}$. These differences are likely do in part to differences between equilibrium constants for $\mathrm{Fe}$ species. Comparisons between MINTEQA2 and BLT-EC showed exact agreement with each other.

\subsubsection{Problem No. 3}

This problem considers complexation and precipitation-dissolution reactions involving $\mathrm{Na}^{+}, \mathrm{UO}_{2}{ }^{2+}, \mathrm{H}^{+}, \mathrm{CO}_{3}{ }^{2-}, \mathrm{SO}_{4}{ }_{4}^{2-}$, and $\mathrm{Cl}$. The equilibrium results are presented in Table 6.3. The HYDROGEOCHEM concentrations are denoted by $\mathrm{C}^{(1)}$. Two BLT-EC simulations were performed. In the first simulation, BLT-EC was allowed to select, from its database, the relevant reactions; the resulting concentrations are denoted by $\mathrm{C}^{(2)}$. Moreover, several of the equilibrium constants differ from those used in the HYDROGEOCHEM simulation. In the second BLT-EC simulation, the database was modified so that the reactions and equilibrium constants matched those in the HYDROGEOCHEM calculations. Reasonable agreement between the HYDROGEOCHEM and BLT-EC results is obtained with very slight differences occurring between the two BLT-EC simulations. In addition, results computed using BLT-EC (i.e., $C^{(2)}$ ) and MINTEQA2 were in exact agreement.

\subsubsection{Problem No. 4}

This application compares BLT-EC and HYDROGEOCHEM simulation results for a problem involving transport with reaction in a one-dimensional column. The reactions involve components $\mathrm{Ca}^{2+}, \mathrm{Mg}^{2+}, \mathrm{CO}_{3}^{2-}, \mathrm{SO}_{4}^{2-}$, and $\mathrm{H}^{+}$in water. Twelve aqueous species and eight minerals were considered as shown in Table 6.4. 
Table 6.2. Species Concentrations at Equilibrium for Problem No. 2

\begin{tabular}{|c|c|c|c|c|c|c|c|c|}
\hline \multirow[b]{2}{*}{ Species } & \multirow[b]{2}{*}{$\log K^{(1)}$} & \multirow[b]{2}{*}{$C^{(1)}$} & \multirow{2}{*}{$\log \mathrm{K}^{(2)}$} & \multirow{2}{*}{$C^{(2)}$} & \multicolumn{4}{|c|}{ Components and Stoichiometry } \\
\hline & & & & & $\mathrm{Fe}^{3+}$ & $\mathrm{SO}_{4}^{2-}$ & $\mathrm{H}^{+}$ & $\mathrm{e}^{-}$ \\
\hline $\mathrm{Fe}^{3+}$ & 0.00 & $6.516 \mathrm{E}-4$ & 0.00 & $1.398 \mathrm{E}-2$ & 1 & 0 & 0 & 0 \\
\hline $\mathrm{SO}_{4}^{2-}$ & 0.00 & $2.148 \mathrm{E}-2$ & 0.00 & $5.598 \mathrm{E}-2$ & 0 & 1 & 0 & 0 \\
\hline $\mathrm{H}^{+}$ & 0.00 & $1.633 \mathrm{E}-3$ & 0.00 & $8.528 \mathrm{E}-3$ & 0 & 0 & 1 & $\underline{0}$ \\
\hline$e^{-}$ & 0.00 & $4.426 \mathrm{E}-19$ & 0.00 & $2.772 \mathrm{E}-19$ & 0 & 0 & 0 & 1 \\
\hline $\mathrm{OH}^{-}$ & -13.99 & $6.266 \mathrm{E}-12$ & -13.99 & $2.273 \mathrm{E}-12$ & 0 & 0 & -1 & 0 \\
\hline $\mathrm{FeSO}_{4}^{+}$ & 3.92 & $1.167 \mathrm{E}-1$ & 3.92 & $1.198 \mathrm{E}-1$ & 1 & 1 & 0 & 0 \\
\hline $\mathrm{Fe}\left(\mathrm{SO}_{4}\right)_{2}^{-}$ & 5.42 & $7.925 \mathrm{E}-2$ & 5.42 & $5.599 \mathrm{E}-2$ & 1 & 2 & 0 & 0 \\
\hline $\mathrm{FeOH}^{2+}$ & -2.19 & $2.576 \mathrm{E}-3$ & -2.19 & $2.771 \mathrm{E}-3$ & 1 & 0 & -1 & $\underline{0}$ \\
\hline $\mathrm{Fe}(\mathrm{OH})_{2}^{+}$ & -5.67 & $5.236 \mathrm{E}-4$ & -5.67 & $5.481 \mathrm{E}-5$ & 1 & 0 & -2 & 0 \\
\hline $\mathrm{Fe}(\mathrm{OH})_{3}$ & -13.60 & $3.767 \mathrm{E}-9$ & -13.60 & $6.972 \mathrm{E}-11$ & 1 & 0 & -3 & $\underline{0}$ \\
\hline $\mathrm{Fe}(\mathrm{OH})_{4}^{-}$ & -21.60 & $2.307 \mathrm{E}-14$ & -21.60 & $1.694 \mathrm{E}-16$ & 1 & 0 & -4 & 0 \\
\hline $\mathrm{Fe}_{2}(\mathrm{OH})_{2}{ }^{4+}$ & -2.95 & $1.791 \mathrm{E}-4$ & -2.95 & $2.965 \mathrm{E}-3$ & 2 & 0 & -2 & 0 \\
\hline $\mathrm{Fe}_{3}(\mathrm{OH})_{4}{ }^{5+}$ & -6.31 & $1.914 \mathrm{E}-5$ & -6.31 & $4.871 \mathrm{E}-4$ & 3 & 0 & -4 & $\underline{0}$ \\
\hline $\mathrm{FeSO}_{4}$ & 15.21 & $1.005 \mathrm{E}-8$ & 2.25 & $5.103 \mathrm{E}-9$ & 1 & 1 & 0 & 1 \\
\hline $\mathrm{FeOH}^{+}$ & 3.51 & $5.715 \mathrm{E}-16$ & -9.50 & $1.492 \mathrm{E}-16$ & 1 & 0 & -1 & 1 \\
\hline $\mathrm{Fe}(\mathrm{OH})_{2}$ & -7.56 & $2.979 \mathrm{E}-24$ & -20.61 & $1.375 \mathrm{E}-25$ & 1 & 0 & -2 & 1 \\
\hline $\mathrm{Fe}(\mathrm{OH})_{3}$ & -17.99 & $6.776 \mathrm{E}-32$ & -31.01 & $1.241 \mathrm{E}-33$ & 1 & 0 & -3 & 1 \\
\hline $\mathrm{HSO}_{4}^{-}$ & 1.99 & $3.428 \mathrm{E}-3$ & 1.99 & $1.223 \mathrm{E}-2$ & 0 & 1 & 1 & 0 \\
\hline $\mathrm{Fe}^{2+}$ & 13.01 & $2.951 \mathrm{E}-9$ & 13.03 & $7.897 \mathrm{E}-9$ & 1 & 0 & 0 & 1 \\
\hline
\end{tabular}

C(1) HYDROGEOCHEM solution

$\mathrm{C}^{(2)} \quad$ BLT-EC solution 


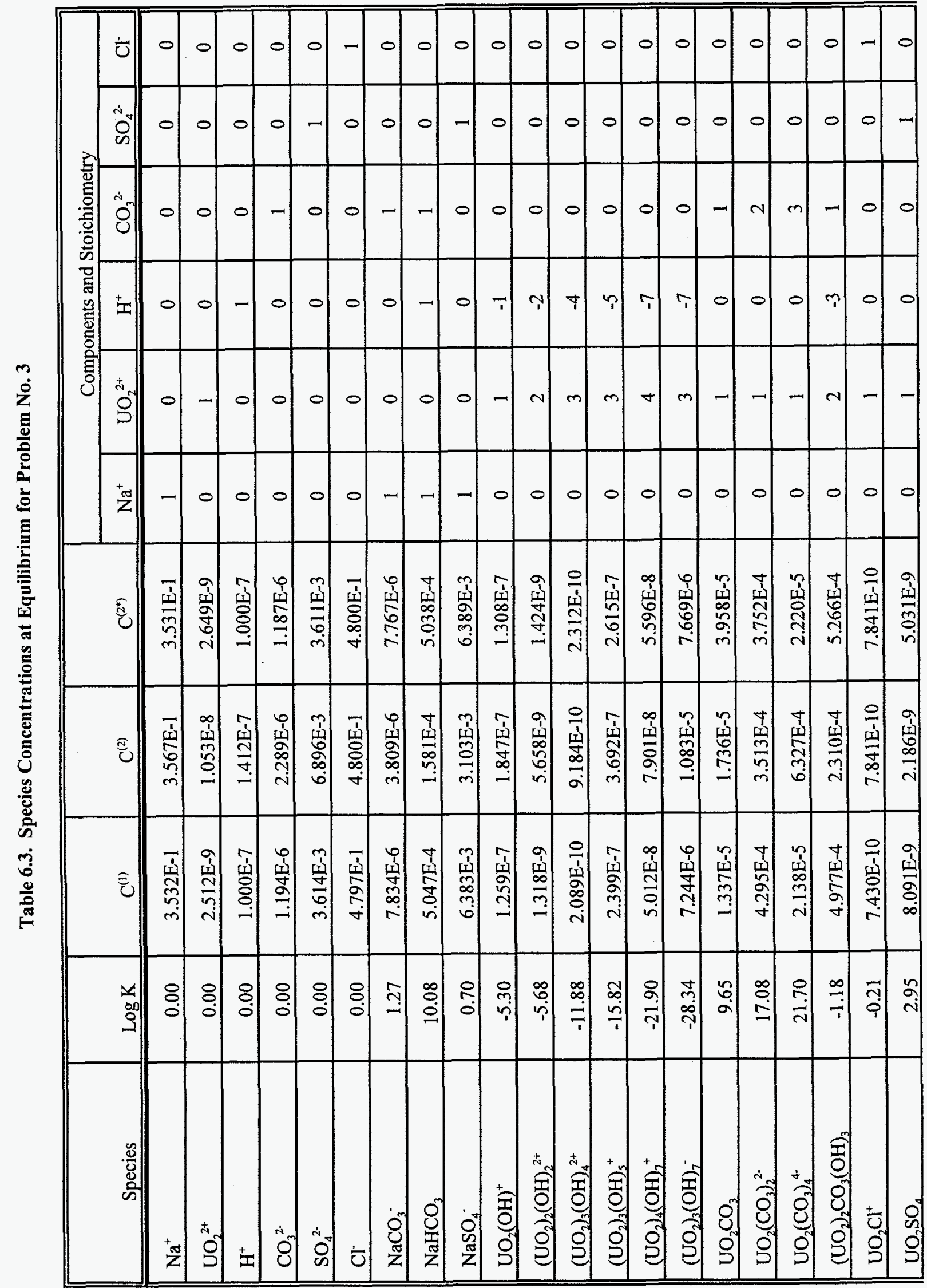




\begin{tabular}{|c|c|c|c|c|c|c|c|c|c|c|}
\hline \multirow[b]{2}{*}{ Species } & \multirow[b]{2}{*}{$\log K$} & \multirow[b]{2}{*}{$C^{(1)}$} & \multirow[b]{2}{*}{$\mathrm{C}^{(2)}$} & \multirow[b]{2}{*}{$\mathrm{C}^{\left(2^{*}\right)}$} & \multicolumn{6}{|c|}{ Components and Stoichiometry } \\
\hline & & & & & $\mathrm{Na}^{+}$ & $\mathrm{UO}_{2}{ }^{2+}$ & $\mathrm{H}^{+}$ & $\mathrm{CO}_{3}^{2-}$ & $\mathrm{SO}_{4}^{2-}$ & $\mathrm{Cl}^{-}$ \\
\hline $\mathrm{UO}_{2}\left(\mathrm{SO}_{4}\right)_{2}^{2-}$ & 4.00 & $3.273 \mathrm{E}-10$ & $5.037 \mathrm{E}-10$ & $5.485 \mathrm{E}-10$ & 0 & 1 & 0 & 0 & 2 & 0 \\
\hline $\mathrm{HCO}_{3}^{-}$ & 10.32 & $2.495 \mathrm{E}-3$ & $1.737 \mathrm{E}-3$ & $2.535 \mathrm{E}-3$ & 0 & 0 & 1 & 1 & 0 & 0 \\
\hline $\mathrm{H}_{2} \mathrm{CO}_{3}$ & 16.67 & $5.585 \mathrm{E}-4$ & $2.497 \mathrm{E}-4$ & $5.693 \mathrm{E}-4$ & 0 & 0 & 2 & 1 & 0 & 0 \\
\hline $\mathrm{HSO}_{4}$ & 1.99 & $3.532 \mathrm{E}-8$ & $2.379 \mathrm{E}-8$ & $3.505 \mathrm{E}-8$ & 0 & 0 & 1 & 0 & 1 & 0 \\
\hline $\mathrm{UO}_{2}(\mathrm{OH})_{2}^{+}$(Schoepite) & -5.40 & $1.517 \mathrm{E}-3$ & $1.502 \mathrm{E}-3$ & $1.486 \mathrm{E}-3$ & 0 & 1 & -2 & 0 & 0 & 0 \\
\hline $\mathrm{UO}_{2} \mathrm{CO}_{3}$ (Rutherfordin) & 13.03 & - & - & -- & 0 & 1 & 0 & 1 & 0 & 0 \\
\hline
\end{tabular}

C(1) HYDROGEOCHEM solution

$\mathrm{C}^{(2)}$ BLT-EC solution

$\mathrm{C}^{\left(2^{*}\right)} \quad$ BLT-EC solution (activity coefficients $=1$ ) 
Table 6.4 Chemical Species for Problem No. 4

\begin{tabular}{|c|c|c|c|c|c|c|}
\hline \multirow[b]{2}{*}{ Species } & \multirow[b]{2}{*}{$\log K$} & \multicolumn{5}{|c|}{ Components and Stoichiometry } \\
\hline & & $\mathrm{H}^{+}$ & $\mathrm{CO}_{3}^{2-}$ & $\mathrm{Ca}^{2+}$ & $\mathrm{Mg}^{2+}$ & $\mathrm{SO}_{4}^{2-}$ \\
\hline & & \multicolumn{5}{|c|}{ Aqueous Species } \\
\hline $\mathrm{H}^{+}$ & 0.0 & 1 & 0 & 0 & 0 & 0 \\
\hline $\mathrm{CO}_{3}{ }^{2-}$ & 0.0 & 0 & 1 & 0 & 0 & 0 \\
\hline $\mathrm{Ca}^{2+}$ & 0.0 & 0 & 0 & 1 & 0 & 0 \\
\hline $\mathrm{Mg}^{2+}$ & 0.0 & 0 & 0 & 0 & 1 & 0 \\
\hline $\mathrm{SO}_{4}^{2-}$ & 0.0 & 0 & 0 & 0 & 0 & 1 \\
\hline $\mathrm{OH}^{-}$ & -13.99 & -1 & 0 & 0 & 0 & 0 \\
\hline $\mathrm{CaCO}_{3}$ & 3.22 & 0 & 1 & 1 & 0 & 0 \\
\hline $\mathrm{CaHCO}_{3}^{+}$ & 11.43 & 1 & 1 & 1 & 0 & 0 \\
\hline $\mathrm{CaSO}_{4}$ & 2.31 & 0 & 0 & 1 & 0 & 1 \\
\hline $\mathrm{CaOH}^{+}$ & -12.85 & -1 & 0 & 1 & 0 & $\mathbf{0}$ \\
\hline $\mathrm{MgCO}_{3}$ & 2.98 & 0 & 1 & 0 & 1 & 0 \\
\hline $\mathrm{MgHCO}_{3}^{+}$ & 11.40 & 1 & 1 & 0 & 1 & 0 \\
\hline $\mathrm{MgSO}_{4}$ & 2.25 & 0 & 0 & 0 & 1 & 1 \\
\hline $\mathrm{MgOH}^{+}$ & -11.44 & -1 & 0 & 0 & 1 & 0 \\
\hline $\mathrm{HCO}_{3}^{-}$ & 10.32 & 1 & 1 & 0 & 0 & 0 \\
\hline $\mathrm{H}_{2} \mathrm{CO}_{3}$ & 16.67 & 2 & 1 & 0 & 0 & 0 \\
\hline $\mathrm{HSO}_{4}^{-}$ & 1.99 & 1 & 0 & 0 & 0 & 1 \\
\hline \multicolumn{7}{|c|}{ Minerals allowed to precipitate } \\
\hline Calcite & 8.48 & 0 & 1 & 1 & 0 & 0 \\
\hline $\mathrm{MgCO}_{3}$ & 8.20 & 0 & 1 & 0 & 1 & 0 \\
\hline Gypsum & 4.62 & 0 & 0 & 1 & 0 & 1 \\
\hline Calcium Hydroxide & -21.90 & -1 & 0 & 1 & 0 & 0 \\
\hline $\mathrm{Mg}_{2}(\mathrm{OH})_{2} \mathrm{CO}_{3}$ & -9.65 & -2 & 1 & 0 & 2 & 0 \\
\hline $\mathrm{Mg}_{5}(\mathrm{OH})_{2}\left(\mathrm{CO}_{3}\right)_{4}$ & 9.72 & -2 & 4 & 0 & 5 & 0 \\
\hline $\mathrm{Mg}(\mathrm{OH})_{2}$ & -16.80 & -2 & 0 & 0 & 1 & 0 \\
\hline $\mathrm{MgSO}_{4}$ & 2.14 & 0 & 0 & 0 & 1 & 1 \\
\hline
\end{tabular}




\subsection{Applications}

The column is $100 \mathrm{dm}$ long with a porosity of 0.3 , a bulk density of $1.2 \mathrm{~g} / \mathrm{cc}$, and dispersivity of $5 \mathrm{dm}$. Water flow is from right to left at a velocity of $0.5 \mathrm{dm} / \mathrm{day}$. For each simulation the column was partitioned into one hundred finite elements of size $1 \mathrm{dm} \times 1 \mathrm{dm}$. Simulations were conducted for 100 days using a constant time step of 0.5 days. One iteration between transport and reaction calculations was allowed.

Initial conditions in the column were the following. The $\mathrm{pH}$ varied linearly from 7.7 at the left end to 8.0 at the right end (the $\mathrm{pH}$ is held fixed during the simulation). The initial $\mathrm{Ca}^{2+}$ concentration was uniform at $10^{-4} \mathrm{~mol} /$ liter. The concentration of $\mathrm{Mg}^{2+}$ decreased linearly from $5 \times 10^{-3} \mathrm{~mol} / \mathrm{liter}$ at the left end to $10^{-3} \mathrm{~mol} /$ liter at the right end. The $\mathrm{SO}_{4}{ }^{2-}$ concentration also decreased linearly from left to right, ranging from $2 \times 10^{-3}$ to $10^{-4} \mathrm{~mol} / \mathrm{liter}$. The $\mathrm{CO}_{3}{ }^{2-}$ concentration increased linearly from $2 \times 10^{-4} \mathrm{~mol} / \mathrm{liter}$ at the left end to $8 \times 10^{-3} \mathrm{~mol} / \mathrm{liter}$ at $85 \mathrm{dm}$ and then finally to $8.6 \times 10^{-3} \mathrm{~mol} / \mathrm{liter}$ at the right end. The initial conditions are illustrated in Figure 6.1.

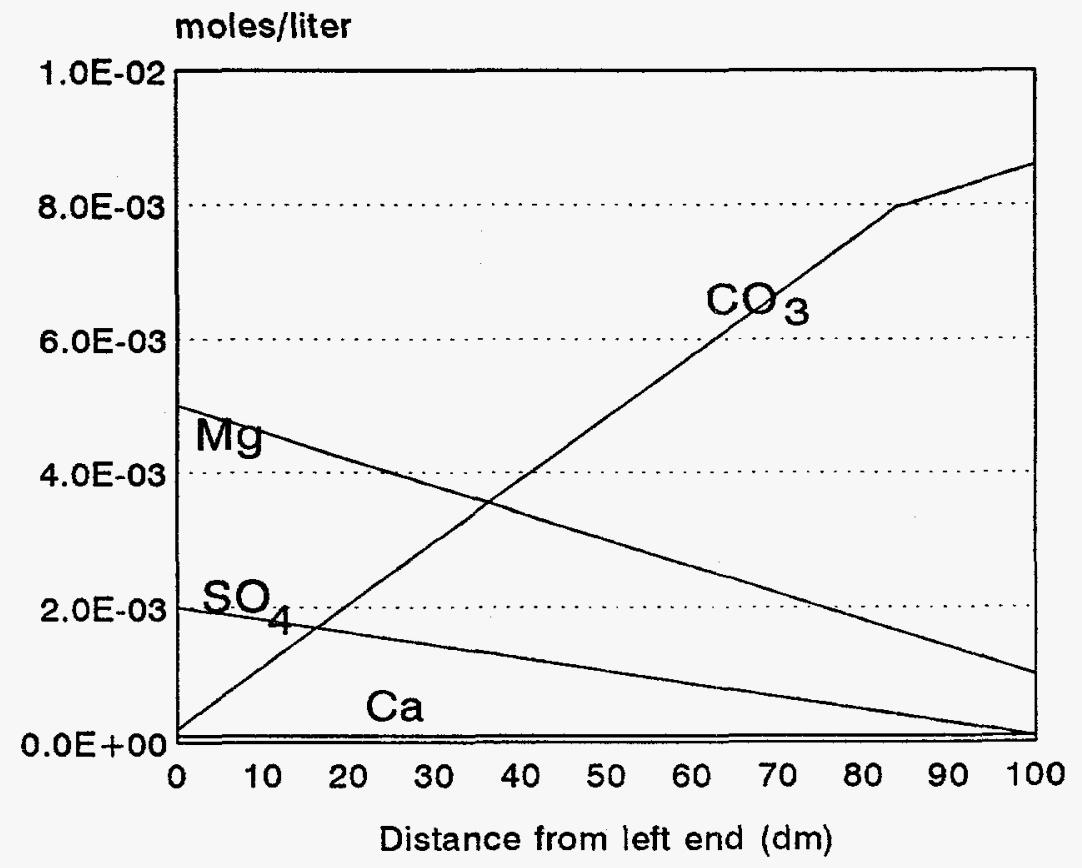

Figure 6.1 Initial distribution of total calcium, carbonate, magnesium, and sulfate. 


\subsection{Applications}

At the right end of the column the boundary conditions describing the composition of the incoming water were as follows: the $\mathrm{pH}$ was held fixed at 8.0 ; the $\mathrm{CO}_{3}{ }^{2-}, \mathrm{Mg}^{2+}$, and $\mathrm{SO}_{4}{ }^{2-}$ concentrations were constant at $2 \times 10^{-3}, 10^{-3}$, and $2 \times 10^{-3}$ mol/liter, respectively; and the concentration of $\mathrm{Ca}^{2+}$ was fixed at $10^{-4} \mathrm{~mol} /$ liter between 0.0 and 1.0 days, $9 \times 10^{-3} \mathrm{~mol} / \mathrm{liter}$ between 1.0 and 9.5 days, and $10^{-4} \mathrm{~mol} /$ liter thereafter.

Simulation results showing calcium carbonate and magnesium carbonate at 50 and 100 days are presented in Figures 6.2 and 6.3. HYDROGEOCHEM results are represented by a solid line and BLT-EC results are represented by triangle symbols. As shown, excellent agreement between the simulations was obtained. Initially magnesium carbonate precipitation existed throughout most of the column. Near the right end of the column, competition for carbonate by the injected calcium pulse, see Figure 6.2, caused gradual dissolution of magnesium carbonate as shown in Figure 6.3. Note that the concentration scales in the figures at 50 and 100 days are different to accommodate the substantial increase in magnesium carbonate precipitation and decrease in calcium carbonate precipitation at the right end after the passing of the injected calcium pulse.

\subsubsection{Problem No. 5}

This example application considers the release of uranium from a hypothetical shallow land burial trench. This example is non-site specific and is designed to demonstrate BLT-EC's ability to simulate important processes associated with the release of radionuclides from LLW disposal facilities. Interactions between transport, complexation, precipitation/dissolution, and adsorption of uranium are considered.

The problem domain is taken to be a two-dimensional vertical cross-section perpendicular to the longitudinal axis of a disposal trench as shown in Figure 6.4. It is assumed that the length of the trench in the longitudinal direction is much longer than the width of the trench. Therefore, a two-dimensional cross-section provides a reasonable representation for simulating radionuclide migration near the central portion of the trench. Symmetry within the cross section is further assumed, thus requiring only half the problem domain to be modeled. The water table is located approximately 30 meters below the ground surface. The waste containing portion of the trench is taken to be 7 meters deep and 28 meters wide, with the side walls slanting at an angle of approximately 12 degrees from vertical. The trench contains 12 waste containers ( 6 in the left half are shown as shaded regions) that are surrounded by backfill. Above the waste region is a 1 meter thick clay layer with a low hydraulic conductivity to minimize water intrusion from above. The clay layer is covered by a high conductivity cap layer, which is 2 meters thick and slants off towards the edge of the trench. The soil properties are assumed to be uniform in each trench region and in the underlying unsaturated zone; values of these parameters are given in Table 6.5. 
6.0 Applications
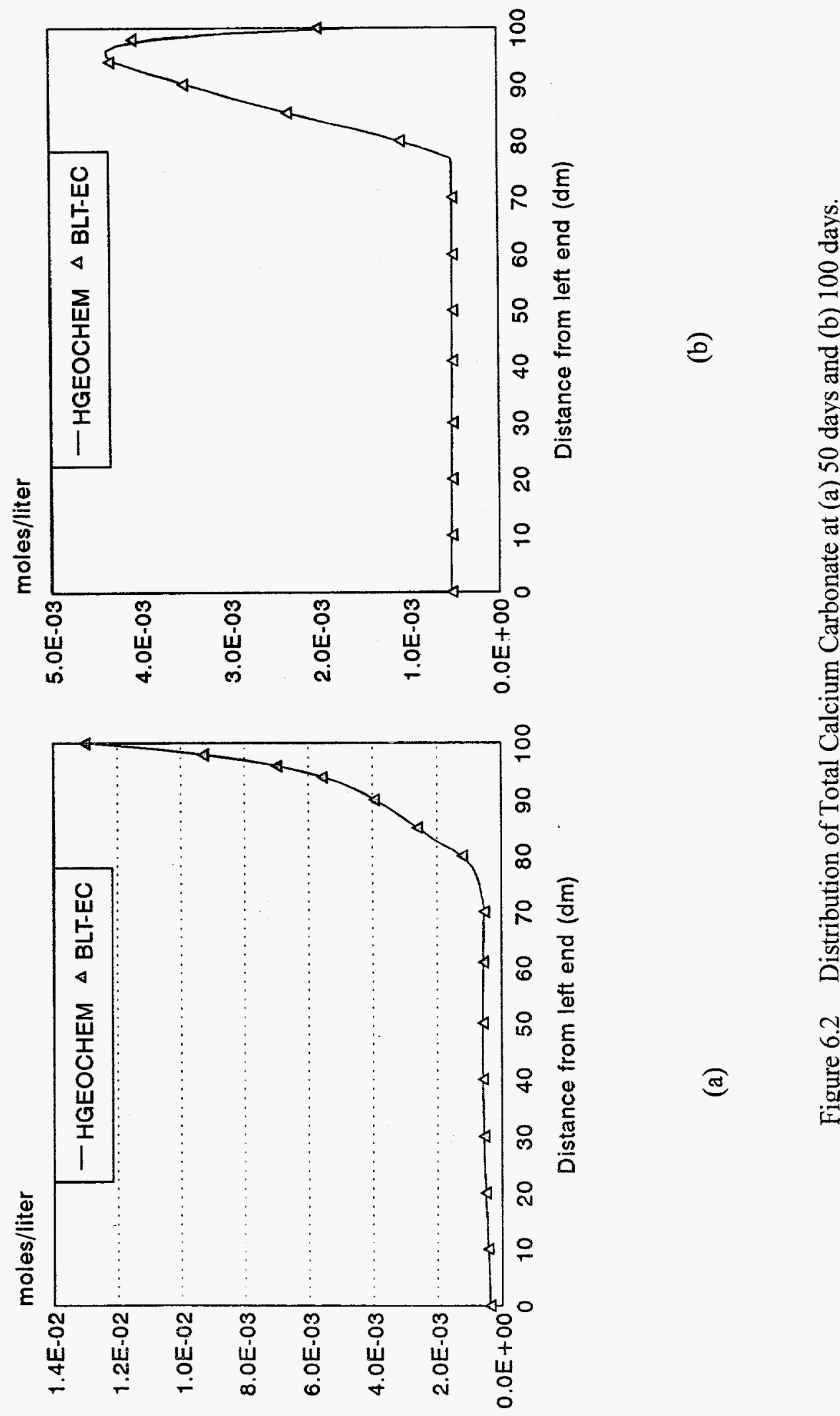




6.0 Applications
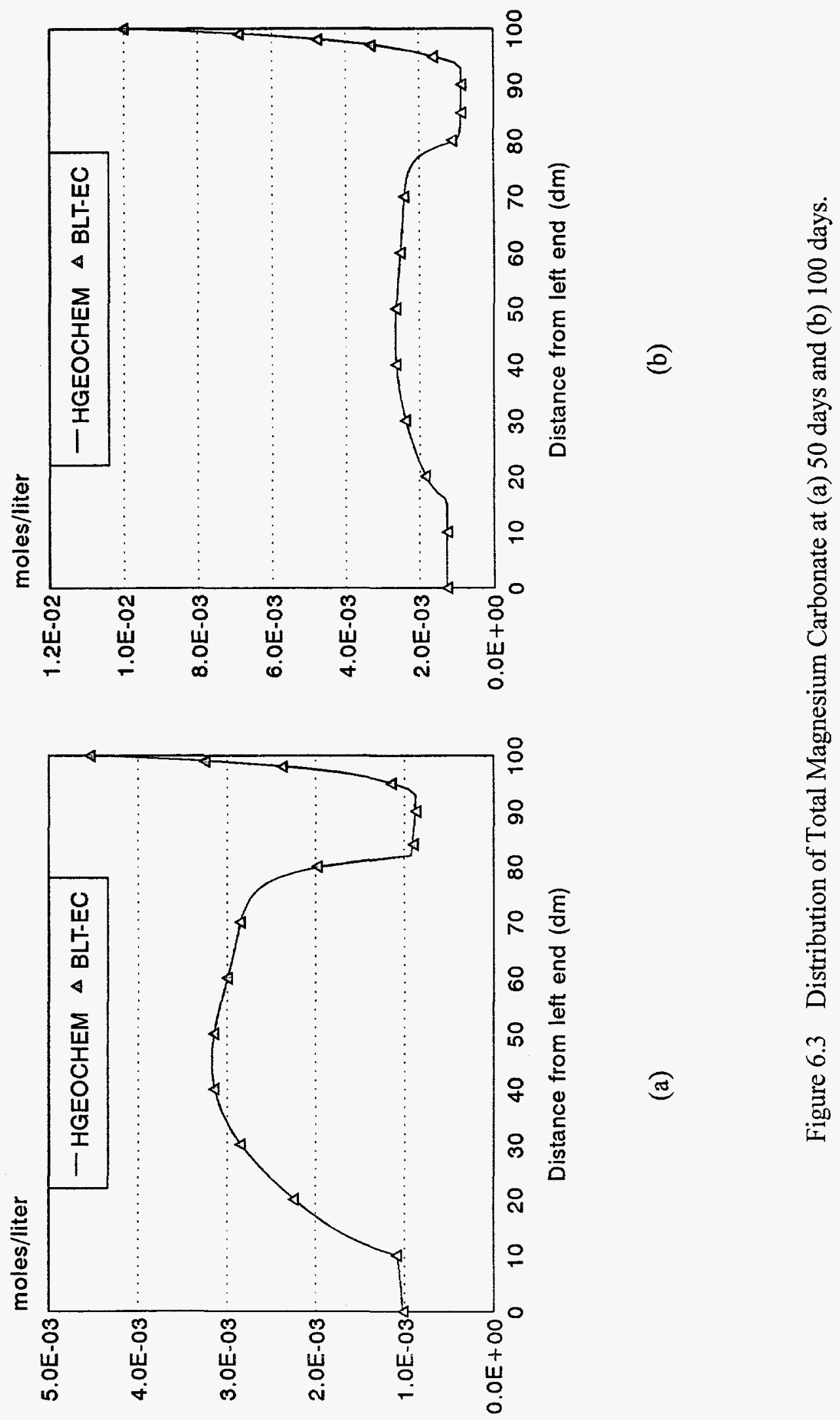




Figure 6.4 Schematic diagram of example field-scale problem. 
Table 6.5 Soil Properties Used

\begin{tabular}{||l|c|c|}
\hline \hline & $\begin{array}{c}\text { Porosity } \\
(\%)\end{array}$ & $\begin{array}{c}\text { Hydraulic Conductivity } \\
(\mathrm{cm} / \mathrm{sec})\end{array}$ \\
\hline Undisturbed soil & 30 & $10^{-4}$ \\
\hline Backfill & 40 & $10^{-3}$ \\
\hline Clay layer & 50 & $10^{-8}$ \\
\hline Gravel cap & 30 & $10^{-5}$ \\
\hline
\end{tabular}

\begin{tabular}{|c|c|c|c|c|c|}
\hline \multirow{2}{*}{$\begin{array}{c}\text { Pressure } \\
\text { Head } \\
(\mathrm{cm}) \\
\end{array}$} & \multicolumn{4}{|c|}{ Moisture Content (Volumetric) } & \multirow{2}{*}{$\begin{array}{c}\begin{array}{c}\text { Relative } \\
\text { Conductivity } \\
\text { (all materials }\end{array} \\
\end{array}$} \\
\hline & (1) & (2) & (3) & (4) & \\
\hline-800.0 & 0.024 & 0.032 & 0.040 & 0.024 & 0.0758 \\
\hline-200.0 & 0.0425 & 0.0567 & 0.0708 & 0.0425 & 0.1120 \\
\hline-100.0 & 0.9 & 0.12 & 0.15 & 0.09 & 0.2758 \\
\hline-25.0 & 0.285 & 0.380 & 0.475 & 0.285 & 0.9483 \\
\hline-12.5 & 0.290 & 0.387 & 0.483 & 0.29 & 0.9655 \\
\hline 0.0 & 0.2925 & 0.390 & 0.4875 & 0.2999 & 0.9655 \\
\hline 100.0 & 0.2995 & 0.3993 & 0.4992 & 0.30 & 0.9999 \\
\hline 2000.0 & 0.30 & 0.40 & 0.50 & 0.30 & 0.9999 \\
\hline \multicolumn{6}{|c|}{$\begin{array}{l}\text { Column (1): undisturbed soil } \\
\text { (2): backfill } \\
\text { (3): clay layer } \\
\text { (4): gravel cap }\end{array}$} \\
\hline
\end{tabular}




\subsection{Applications}

The example application involves two simulations, a steady-state water-flow simulation and a radionuclide transport simulation. The water-flow problem is simulated over the entire cross section, which is divided into 624 bilinear finite elements and 675 nodes (see Figure 6.5). The steady-state flow problem is solved once for the hydrogeologic data (moisture contents and flow velocities) shown in Figures 6.6 and 6.7.

The boundary conditions for the flow simulation are as follows. The vertical left and right boundaries are homogeneous Neumann or no-flow boundaries. The bottom horizontal boundary is a Dirichlet boundary with a prescribed $1000 \mathrm{~cm}$ hydraulic head. The top boundary (ground surface) is a Neumann boundary with a prescribed rain fall infiltration of $5 \mathrm{~cm} / \mathrm{yr}$. Boundary conditions for the radionuclide migration problem is described separately below.

The transport problem considers a soil-surface component, $\mathrm{SOH}$, and five aqueous components including hydronium, carbonate, calcium, sulfate, and uranium in the form of uranium oxide. These components formed 19 aqueous and 3 surface complexes and 11 possible minerals (see Table 6.6). The initial composition of the water (in mole/l) was $\mathrm{CO}_{3}^{-}=1.0 \times 10^{-5}$, $\mathrm{SO}_{4}^{-}=1.0 \times 10^{-5}, \mathrm{Ca}^{+2}=5.0 \times 10^{-4}, \mathrm{SOH}=2.0 \times 10^{-5}$, and $\mathrm{UO}_{2}=0.0$. The component concentrations in the trench (in mole/l) were similar except for the following, $\mathrm{CO}_{3}^{-}=2.0 \times 10^{-5}$ and $\mathrm{SO}_{4}^{-}=5.0 \times 10^{-5}$. At the top infiltration boundary the infiltrating rain water was assumed to contain $\mathrm{Ca}^{+2}$ and $\mathrm{CO}_{3}{ }^{\circ}$ at concentrations of $1.0 \times 10^{-6}$ and $1.0 \times 10^{-5}$ moles $/ 1$, respectively. The vertical and bottom boundaries were no-flow boundaries. The $\mathrm{pH}$ of the ground water was held fixed at 7.5 throughout the problem domain. Redox reactions were not considered.

The source concentration in each $1.0 \mathrm{~m}^{3}$ container was $0.2 \mathrm{~mole} / \mathrm{m}^{3}$ of $\mathrm{UO}_{2}$. Localized and general corrosion resulted in gradual and complete container breach by 20 years. Release from the waste form occurred by rinse release during the first 20 simulation years.

The simulation was performed for 200 years using a time step of 1.0 years. Simulation results are presented for 30 and 200 years. Note that the radionuclide transport problem is solved over a smaller region comprised of 405 elements and 450 nodes. The distributions of total uranium in Figure 6.8 shows that very low concentrations of uranium have migrated from the disposal unit. Most of the uranium, however, has precipitated in the trench as the mineral schoepite. Distributions of uranium precipitation are shown in Figure 6.9. Results show the dissolution of the uranium over time, with the left portion of the precipitation zone dissolving at a much faster rate. This behavior is a consequence of the higher infiltration rates in the outer region of the trench.

Figures 6.10 and 6.11 illustrate the evolution of the dissolved uranium plume and associated adsorbed uranium zone. The adsorbate uranium species and surface reactions are specified in Table 6.6. Adsorption was modelled using the activity Langmuir model. The fraction of adsorption sites occupied by uranium never exceeded 50 per cent of those available at any given location. Observe that concentrations of dissolved uranium are substantially less than adsorbed concentrations on a mole per liter of solution basis. However, because of the low moisture content in the unsaturated region ( 0.025 over most of the unsaturated region) the adsorbed concentrations translate into a relatively low $\mathrm{K}_{\mathrm{d}}$. 
6.0 Applications

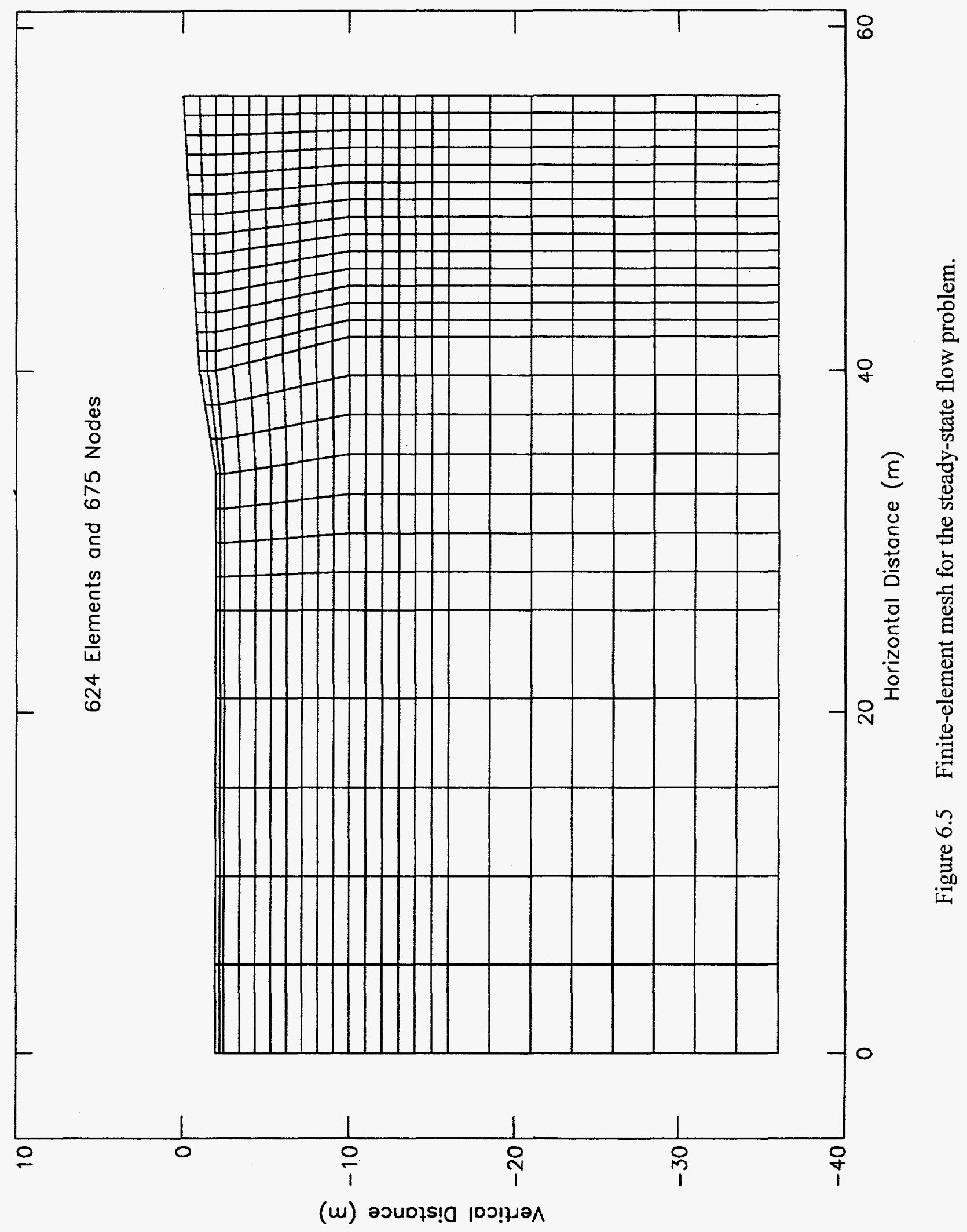


6.0 Applications

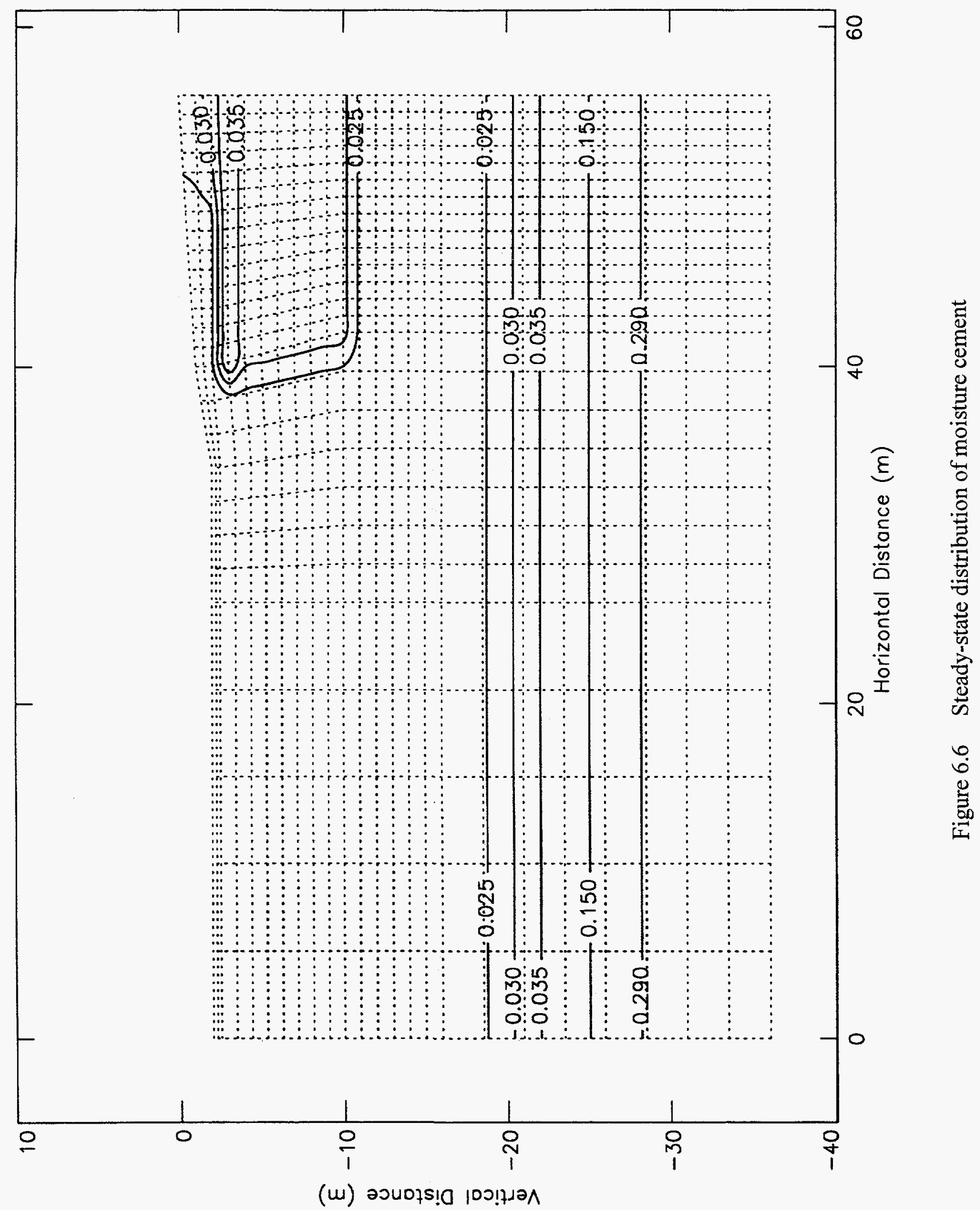


6.0 Applications

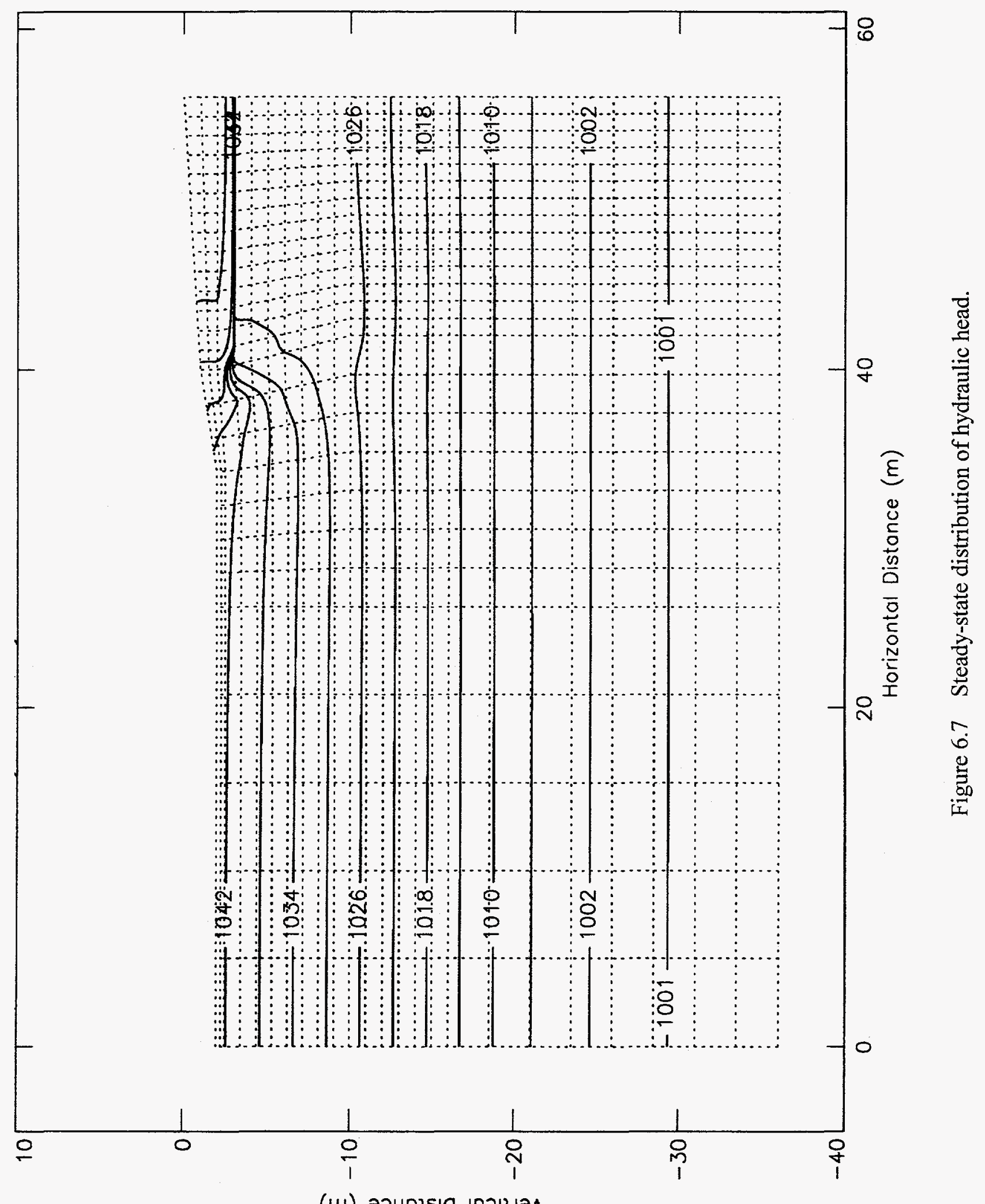

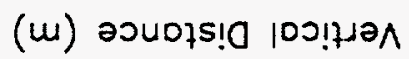


6.0 Applications

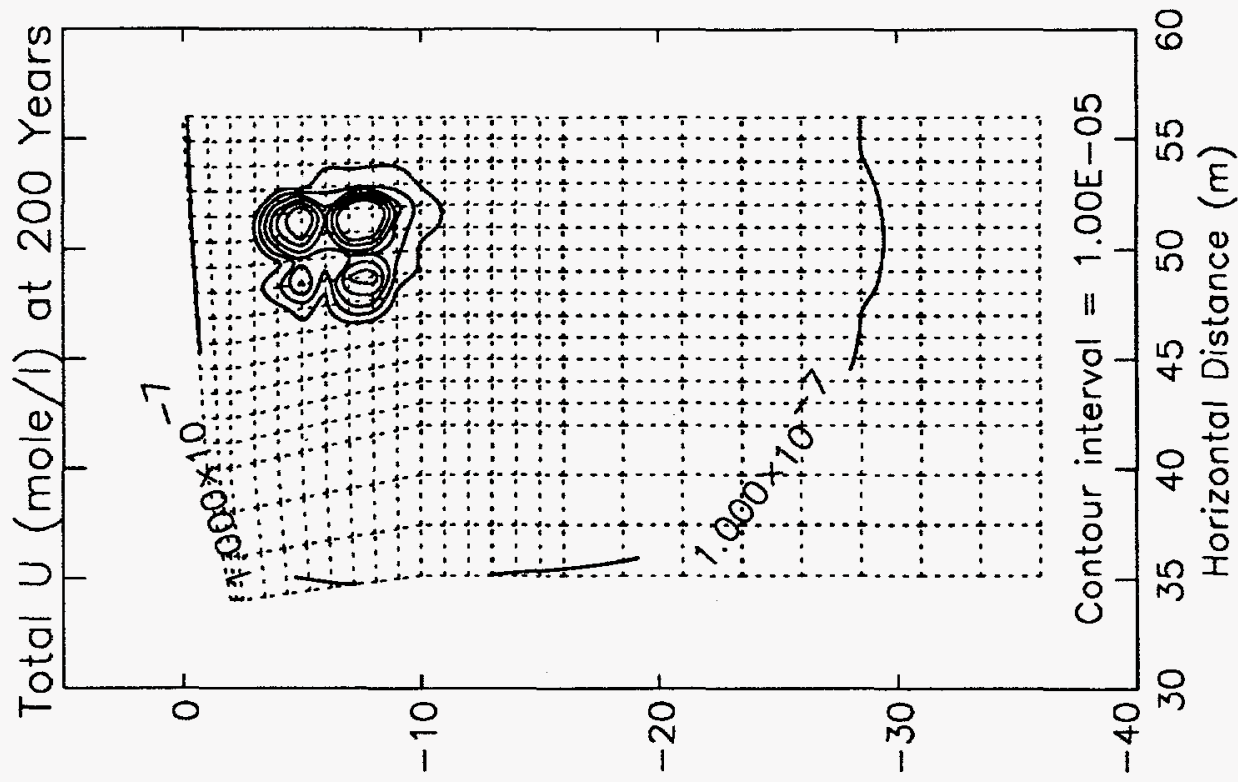

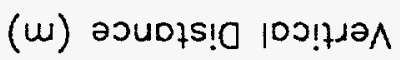

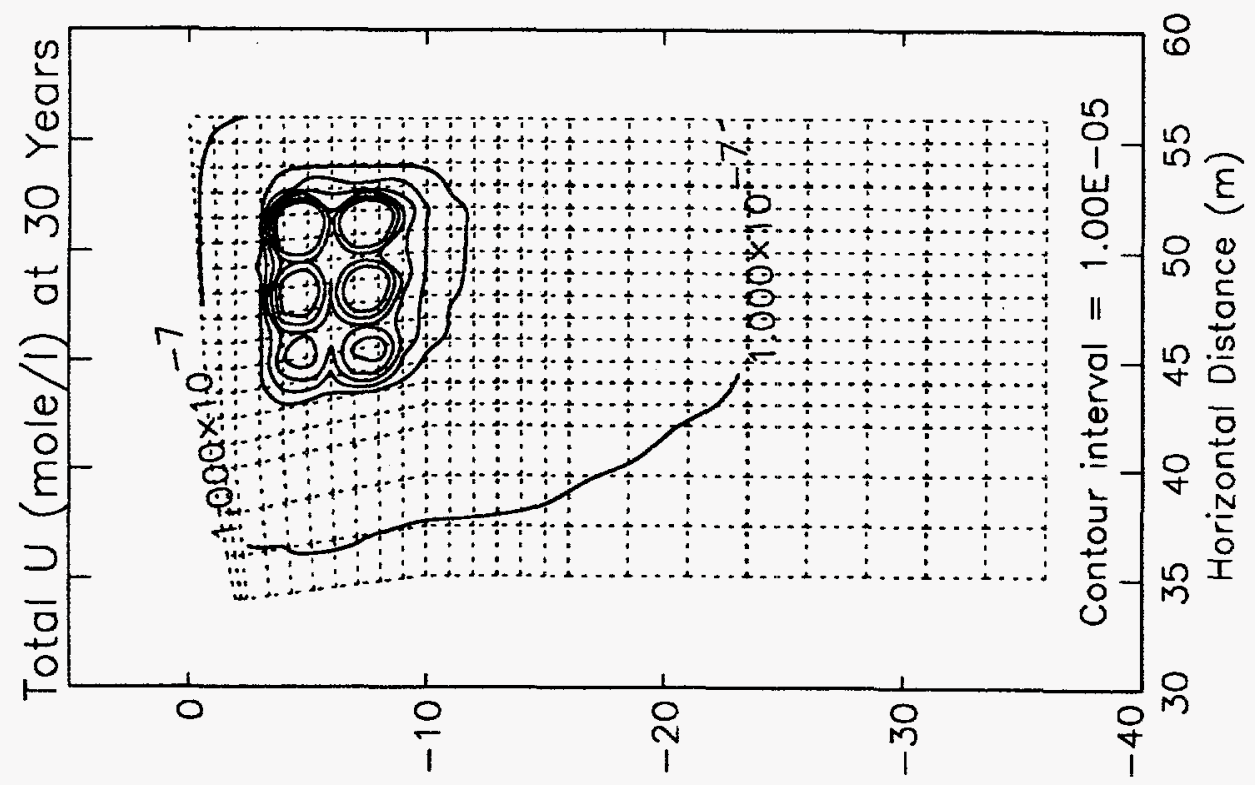



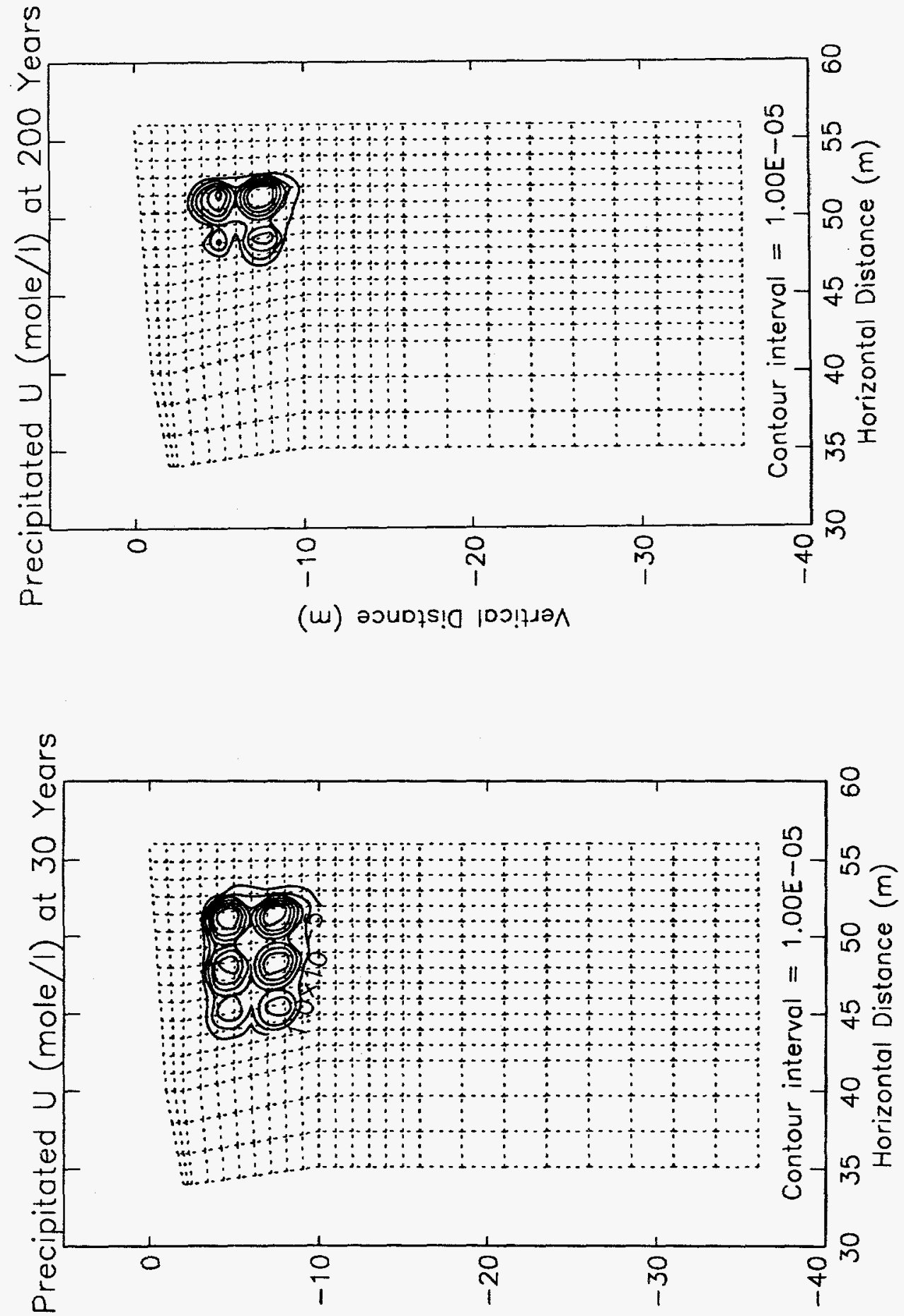

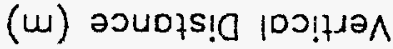


6.0 Applications

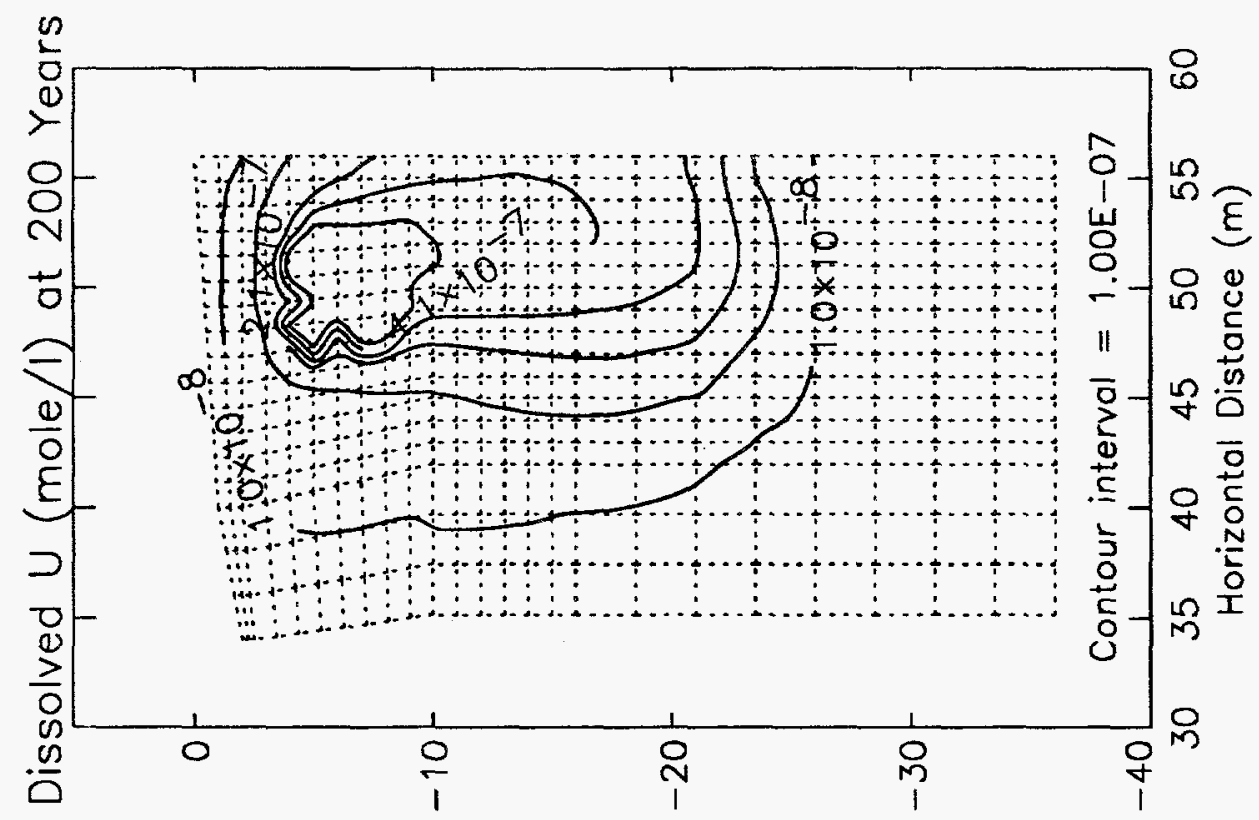

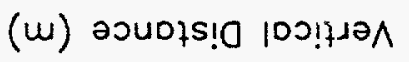




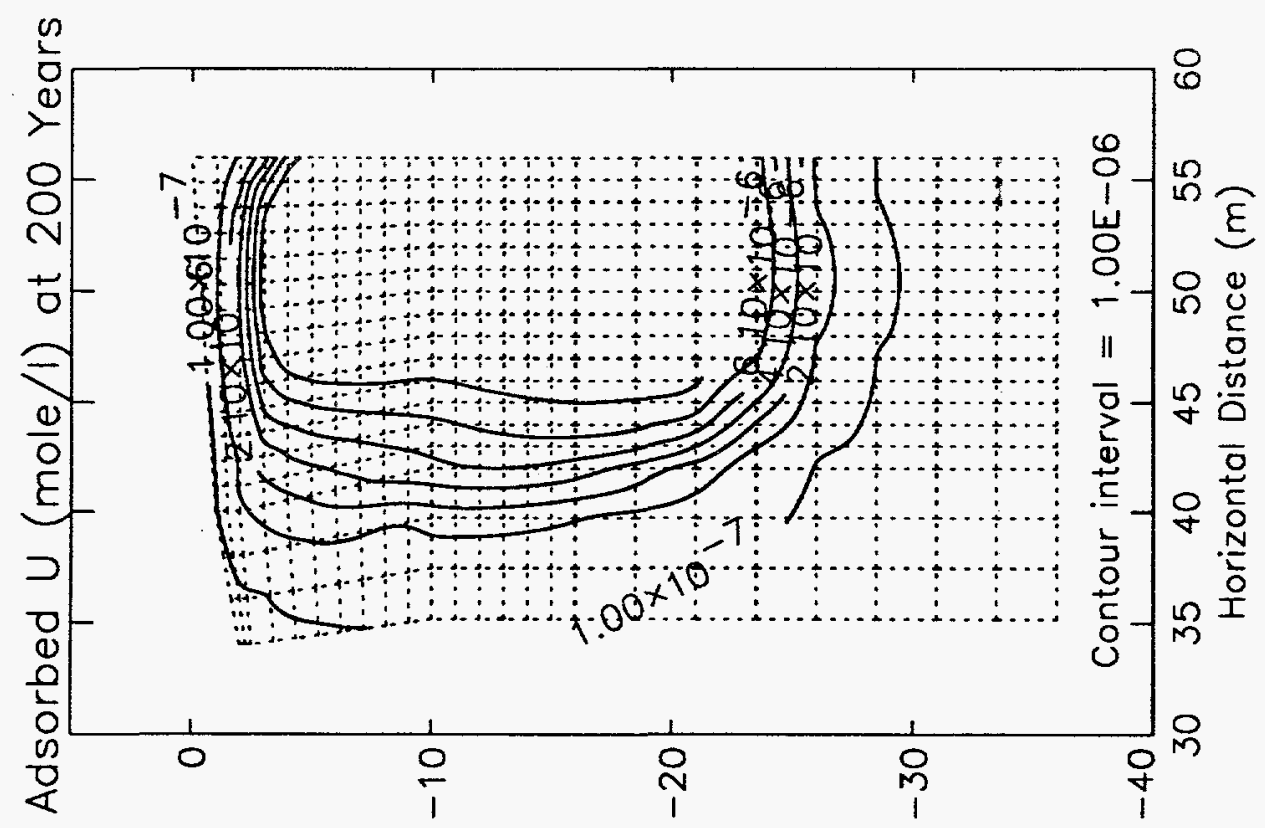

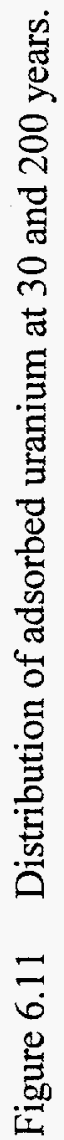

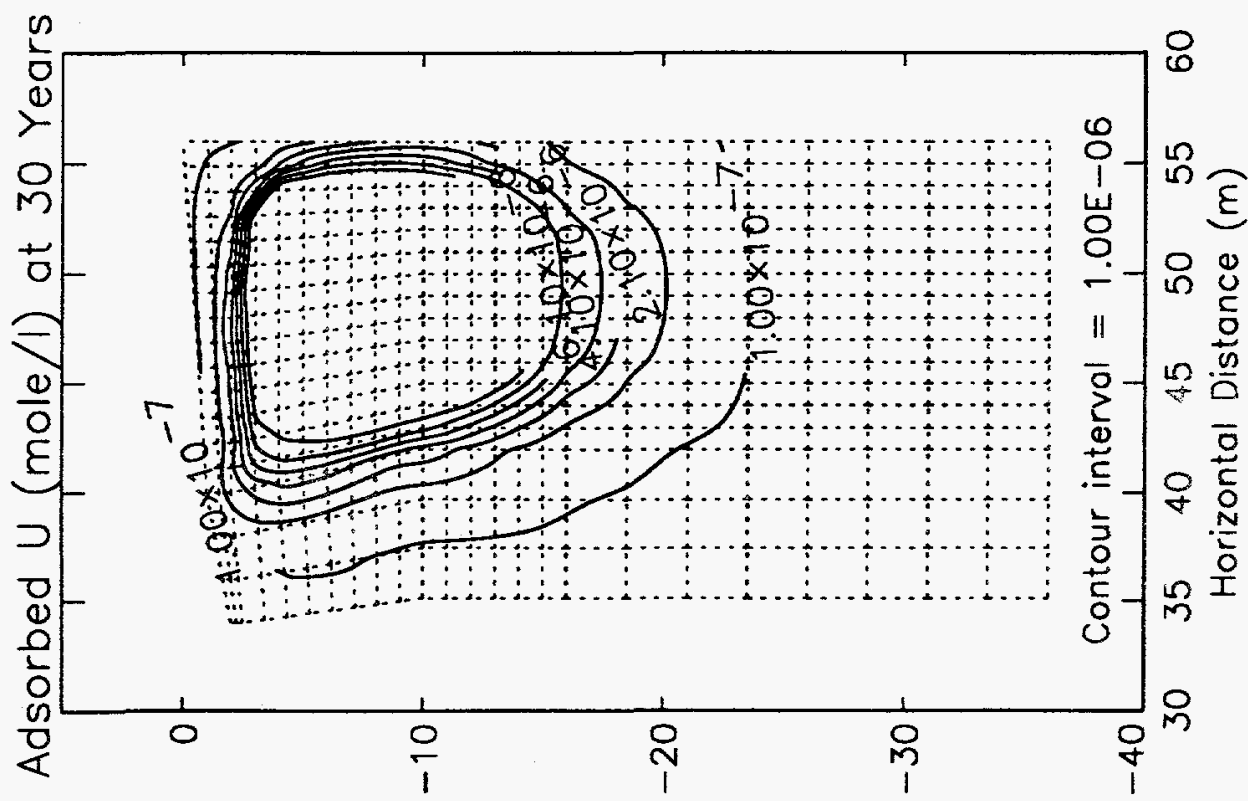

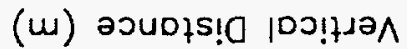


6.0 Applications

Table 6.6 Hypothetical Field-Scale Problem

\begin{tabular}{|c|c|c|c|c|c|c|c|}
\hline \multirow[b]{2}{*}{ Species } & \multirow[b]{2}{*}{$\log K$} & \multicolumn{6}{|c|}{ Components and Stoichiometry } \\
\hline & & $\mathrm{H}^{+}$ & $\mathrm{CO}_{3}^{2-}$ & $\mathrm{Ca}^{2+}$ & $\mathrm{SO}_{4}^{2-}$ & $\mathrm{UO}_{2}^{2+}$ & $\mathrm{SOH}$ \\
\hline \multicolumn{8}{|c|}{ Aqueous Species } \\
\hline $\mathrm{H}^{+}$ & 0.00 & 1 & 0 & 0 & 0 & 0 & 0 \\
\hline $\mathrm{CO}_{3}^{2-}$ & 0.00 & 0 & 1 & 0 & 0 & 0 & 0 \\
\hline $\mathrm{Ca}^{2+}$ & 0.00 & 0 & 0 & 1 & 0 & 0 & 0 \\
\hline $\mathrm{SO}_{4}^{2-}$ & 0.00 & 0 & 0 & 0 & 1 & 0 & 0 \\
\hline $\mathrm{UO}_{2}{ }^{2+}$ & 0.00 & 0 & 0 & 0 & 0 & 1 & 0 \\
\hline $\mathrm{CaOH}^{+}$ & -12.59 & -1 & 0 & 1 & 0 & 0 & 0 \\
\hline $\mathrm{CaHCO}_{3}^{+}$ & 11.33 & 0 & 1 & 1 & 0 & 1 & 0 \\
\hline $\mathrm{CaCO}_{3}$ & 3.15 & 0 & 1 & 1 & 0 & 0 & 0 \\
\hline $\mathrm{CaSO}_{4}$ & 2.31 & 0 & 0 & 1 & 1 & 0 & 0 \\
\hline $\mathrm{HCO}_{3}^{-}$ & 10.33 & 1 & 1 & 0 & 0 & 0 & 0 \\
\hline $\mathrm{HSO}_{4}^{-}$ & 1.99 & 1 & 0 & 0 & 1 & 0 & 0 \\
\hline $\mathrm{H}_{2} \mathrm{CO}_{3}$ & 16.68 & 2 & 1 & 0 & 0 & 0 & 0 \\
\hline $\mathrm{UO}_{2} \mathrm{OH}^{+}$ & -5.09 & -1 & 0 & 0 & 0 & 1 & 0 \\
\hline$\left(\mathrm{UO}_{2}\right)_{2}(\mathrm{OH})_{2}{ }^{2+}$ & -5.64 & -2 & 0 & 0 & 0 & 2 & 0 \\
\hline$\left(\mathrm{UO}_{2}\right)_{3}(\mathrm{OH})_{5}^{+}$ & -15.59 & -5 & 0 & 0 & 0 & 1 & 0 \\
\hline $\mathrm{UO}_{2} \mathrm{CO}_{3}$ & 10.07 & 0 & 1 & 0 & 0 & 1 & 0 \\
\hline $\mathrm{UO}_{2}\left(\mathrm{CO}_{3}\right)_{2}^{-2}$ & 17.01 & 0 & 2 & 0 & 0 & 1 & 0 \\
\hline $\mathrm{UO}_{2}\left(\mathrm{CO}_{3}\right)_{3}^{-4}$ & 21.38 & 0 & 3 & 0 & 0 & 1 & 0 \\
\hline $\mathrm{UO}_{2} \mathrm{SO}_{4}$ & 2.71 & 0 & 0 & 0 & 1 & 1 & 0 \\
\hline \multicolumn{8}{|c|}{ Surface Species } \\
\hline $\mathrm{SOH}$ & 0.00 & 0 & 0 & 0 & 0 & 0 & 1 \\
\hline $\mathrm{SO}^{-}$ & -7.30 & -1 & 0 & 0 & 0 & 0 & 1 \\
\hline $\mathrm{SOH}_{2}^{+}$ & -1.40 & 1 & 0 & 0 & 0 & 0 & 1 \\
\hline$\left(\mathrm{SO}^{-}\right)\left(\mathrm{UO}_{2} \mathrm{OH}^{+}\right)$ & -5.10 & -2 & 0 & 0 & 0 & 1 & 1 \\
\hline
\end{tabular}




\begin{tabular}{|c|c|c|c|c|c|c|c|}
\hline \multirow[b]{2}{*}{ Species } & \multirow[b]{2}{*}{$\log K$} & \multicolumn{6}{|c|}{ Components and Stoichiometry } \\
\hline & & $\mathrm{H}^{+}$ & $\mathrm{CO}_{3}^{2-}$ & $\mathrm{Ca}^{2+}$ & $\mathrm{SO}_{4}^{2-}$ & $\mathrm{UO}_{2}{ }^{2+}$ & $\mathrm{SOH}$ \\
\hline \multicolumn{8}{|c|}{ Minerals } \\
\hline Schoepite & -5.40 & -2 & 0 & 0 & 0 & 1 & 0 \\
\hline $\mathrm{UO}_{3}$ & -7.72 & -2 & 0 & 0 & 0 & 1 & 0 \\
\hline Gummite & -10.40 & -2 & 0 & 0 & 0 & 1 & 0 \\
\hline $\mathrm{B}-\mathrm{UO}_{2}(\mathrm{OH})_{2}$ & -5.54 & -2 & 0 & 0 & 0 & 1 & 0 \\
\hline Rutherfordin & 14.44 & 0 & 1 & 0 & 0 & 1 & 0 \\
\hline Anhydrite & 4.64 & 0 & 0 & 1 & 1 & 0 & 0 \\
\hline Aragonite & 8.36 & 0 & 1 & 1 & 0 & 0 & 0 \\
\hline Calcite & 8.48 & 0 & 1 & 1 & 0 & 0 & 0 \\
\hline Gypsum & 4.85 & 0 & 0 & 1 & 1 & 0 & 0 \\
\hline Lime & -32.80 & -2 & 0 & 1 & 0 & 0 & 0 \\
\hline Portlandite & -22.68 & -2 & 0 & 1 & 0 & 0 & 0 \\
\hline
\end{tabular}





\subsection{SUMMARY}

The objective of the source term evaluation project is to provide system models capable of predicting radionuclide release rates from low-level radioactive waste (LLW) shallow land burial trenches. The goal of this phase of the project is to develop a computer model which incorporates the essential set of physical and chemical processes necessary for adequate understanding and assessment of the factors controlling the release of radionuclide contaminants from LLW disposal facilities. To this end, we have developed the computer code BLT-EC. This code is comprised of modified versions of the breach and leach modules contained in BLT [Sullivan and Suen, 1989], the hydrological transport module contained in HYDROGEOCHEM [Yeh and Tripathi, 1990 and 1991], and the geochemical computer model MINTEQA2 [Allison et al, 1991] and its associated thermodynamic database. This computer code:

(1) Can simulate multicomponent transport in two dimensions;

(2) Can compute container degradation and leaching of radionuclides from typical waste forms;

(3) Can simulate important chemical reactions including dissolution/precipitation, sorption, ion exchange, reduction/oxidation, complexation, and acid-base reactions;

(4) Is modular to facilitate future modifications; and

(5) Operates with its own thermodynamic database which can be conveniently updated and expanded as necessary.

During development, efforts have been taken to ensure that BLT-EC is user friendly and transportable between UNIX and DOS based platforms. For example, to help the user create an input file, menu driven preprocessors that guide the user through the necessary steps of creating or modifying input files have been developed. We are also currently developing a menu-driven postprocessor to facilitate graphical display of one- and two-dimensional output data.

The present version needs to be extended to include:

- Source models for the release of materials from cement based waste forms, engineered barriers, and metallic containers; and

- Radioactive decay processes including branched decay and daughter ingrowth.

The following associated development and documentation activities are also needed:

- Updating and expanding the thermodynamic database to include radionuclide data from the most recent published compilations;

- Further testing of BLT-EC on representative laboratory-scale and field-scale problems; 


\subsection{Summary}

- Improving and further testing of BLTECIN, the menu driven program that guides the user through the steps required to create an input file for BLT-EC;

- Developing a postprocessor to facilitate graphical and tabular display of output;

- Incorporating a Newton-Raphson solution algorithm in FEMWATER;

- Documenting algorithms and structure of BLT-EC;

- Documenting data requirements and structure of input files for BLT-EC; and

- $\quad$ Documenting procedures to use BLT-EC and post-process results. 
Allison, J.D., D.S. Brown, and K.J. Novo-Gradac, "MINTEQA2/PRODEFA2, A Geochemical Assessment Model for Environmental Systems: Version 3.0 User's Manual”, EPA/600/391/021, U.S. Environmental Protection Agency, 1991.

Bahr, J.M., and J. Rubin, "Direct Comparison of Kinetic and Local Equilibrium Formulations for Solute Transport Affected by Surface Reactions," Water Resources Research, Vol. 23, No. 3, pp. 438-452, 1987.

Bahr, J.M., "Kinetically Influenced Terms for Solute Transport Affected by Heterogeneous and Homogeneous Classical Reactions," Water Resources Research, Vol. 26, No. 1, pp. 21-34, 1990.

Ball, J.W., E.A. Jenne, and M.W. Cantrell, "WATEQ3: A Geochemical Model with Uranium Added," U.S. Geological Survey, Open-File Report 81-113, 1981.

Bird, G.M., and V. J. Lopata, "Solution Interaction of Nuclear Waste, Anions With Selected Geological Materials," in Scientific Basis for Waste Management, Vol. 2, pp. 419-426, Plenam Press, New York, 1980.

Bondietti, E.A., and C.W. Francis, "Geologic Migration Potentials of Tc-99 and Np-237," Science, Vol. 203, pp. 1337-1340, 1979.

Brookins, D.G., "Retention of Transuranic and Actinide Elements and Bismuth At the OKLO Natural Reactor, Gabon: Application of Eh-pH Diagrams," Chemical Geology, Vol. 23, pp. 309$323,1978$.

Carlsen, L., O.J. Nielsen, and P. Bo, "The Influence of Complexation on Radionuclide Migration: A Theoretical Study," Waste Management, Vol. 9, pp. 165-169, 1989.

Cederberg, G.A., R.L. Street, and J.O. Leckie, "A Groundwater Mass Transport and Equilibrium Chemistry Model for Multicomponent Systems," Water Resources Research, Vol. 21, pp. 1095$1104,1985$.

Choppin, G.R., and J. Rydberg, Nuclear Chemistry, Theory and Applications, Pergamon Press, Oxford, 1980.

Cleveland, J.M., and T.F. Rees, "Characterization of Plutonium in Maxey Flats Radioactive Trench Leachates," Science, Vol. 212, pp. 1506-1509, 1981.

Comans, R.N.J., M. Haller, and P.D. Preter, "Sorption of Cesium on Illite: Non-Equilibrium Behaviour and Reversibility," Geochim. et Cosmochim. Acta, Vol. 55, pp. 433-440, 1991.

Coughtrey, P.J., and M.C. Thorne, Radionuclide Distribution and Transport in Terrestrial and Aquatic Ecosystems, Vol. 1, A.A. Balkema/Rotterdam, Netherlands, 1983. 


\subsection{References}

Coughtrey, P.J., D. Jackson, and M.C. Thorne, Radionuclide Distribution and Transport in Terrestrial and Aquatic Ecosystems, A Critical Review of Data, Vol. 3. A.A. Balkema/Rotterdam, Netherlands, 1983.

Cowgill, M.G., "Lifetime Estimates for Polyethylene High Integrity Containers," Technical Letter Report, WM-3276-16, Brookhaven National Laboratory, Upton, NY, November 1992.

Cowgill, M.G., and T.M. Sullivan, "Source Term Evaluation for Performance Assessment of LLW Disposal," Waste Management '92, Ed. R. G. Post, Tucson, AZ, 1992.

Cowgill, M.G., and T.M. Sullivan, "Source Term Evaluation for Radioactive Low-level Waste Disposal Performance Assessment," NUREG/CR-5911, BNL-NUREG-52334, Brookhaven National Laboratory, Upton, New York, 1993.

Czyscinski, K.S., R.F. Pietrzak, and A.J. Weiss, "Evaluation of Isotope Migration - Land Burial. Water Chemistry at Commercially Operated Low-Level Radioactive Waste Disposal Sites," Quarterly Progress Report October-December 1980, NUREG/CR-2124, Brookhaven National Laboratory, Upton, New York, 1981.

Czyscinski, K.S., and A.J. Weiss, "Evaluation of Isotope Migration - Land Burial. Water Chemistry at Commercially Operated Low-Level Radioactive Waste Disposal Sites," Status Report October 1979-September 1980, NUREG/CR-1862, Brookhaven National Laboratory, Upton, New York, 1981.

Dagan, G., "Solute Transport in Heterogeneous Porous Formation," Journal of Fluid Mechanics, Vol. 145, pp. 151-177, 1984.

Dayal, R., R.F. Pietrzak, and J.H. Clinton, "Geochemical Investigations at Maxey Flats Radioactive Waste Disposal Site," NUREG/CR-3993, BNL-NUREG-51820, Brookhaven National Laboratory, Upton, New York, 1984.

Dayal, R., R.F. Pietrzak, and J.H. Clinton, "Geochemical Studies of Commercial Low-level Radioactive Waste Disposal Sites," NUREG/CR-4644, BNL-NUREG-52004, Brookhaven National Laboratory, Upton, New York, 1986.

Domenico, P.A., and F.W. Schwartz, Physical and Chemical Hydrology, John Wiley and Sons, New York, 1990.

Drever, J.I., The Geochemistry of Natural Waters, Prentice-Hall, New Jersey, 1982.

Eagleson, P.S., "Climate, Soil and Vegetation, A Simplified Model of Soil Moisture Movement in the Liquid Phase," Water Resources Research, Vol. 14, No. 5, pp. 722-730, 1978.

Eichholz, G.G., B.G. Wahlig, G.G. Powell, and T.F. Craft, "Subsurface Migration of Radioactive Waste Materials by Particulate Transport," Nuclear Technology, Vol. 58, pp. 511-520, 1982. 
Erikson, R.L., C.J. Hostetler, and M.L. Kemner, "Mobilization and Transport of Uranium at Uranium Mill Tailings Disposal Sites," NUREG/CR-5169, PNL-7154, Pacific Northwest Laboratory, 1990.

Fowler, E.B., W.L. Polzer, and E.H. Essington, "Studies of Transport of Waste Radionuclides Through Soil at Maxey Flats, Kentucky, Waste-Burial Site," NUREG/CR-3032, LA-9565-MS, Los Alamos National Laboratory, Los Alamos, New Mexico, 1983.

Francis, A.J. and C.J. Dodge, "Influence of Complex Structure on the Biodegradation of IronCitrate Complexes," Applied and Environmental Microbiology, Vol. 59, No. 1, 1993.

Fuhrmann M. and P. Colombo, "Radionuclide Releases From Cement Waste Forms in Seawater," Radioactive Waste Management and the Nuclear Fuel Cycle, Vol. 11, No. 4, pp. 365$380,1989$.

Gee, G. W., D. Rai, and R. J. Serne, "Mobility of Radionuclides in Soil," in Chemical Mobility and Reactivity in Soil Systems, D.M. Eral, ed., The American Society of Agronomy and the Soil Science Society of America, Atlanta, Georgia, 1981.

Gelhar, L.A, A.L. Guthjar, and R.L. Naff, "Stochastic Analysis of Macrodispersion in a Stratified Aquifer," Water Resources Research, Vol. 15, pp. 1387-1397, 1979.

Hoeffner, S.L., "Radionuclide Sorption on Savannah River Plant Burial Ground Soil" - A Summary and Interpretation of Laboratory Data. DP-1702, E. I. du Pont de Nemour \& Co., SRL, Aiken S. C. 298089, for U.S. DOE, 1985.

Hostetler, C.J., R.L. Erikson, J.S. Fruchter, and C.T. Kincaid, "FASTCHEM package, vol. 1, Overview and Application to a Chemical Transport Problem," Final Report for EPRI EA-5870, Project 2485-2, Pacific Northwest Laboratories, Richland, WA, 1989.

Hsi, C.K.D. and D. Langmuir, "Adsorption of Uranyl Onto Ferric Oxyhydroxides: Application of the Surface Complexation Site-binding Model," Geochim. et Cosmochim. Acta, Vol. 49, pp. 1931-1941, 1985.

International Commission on Radiological Protection, Committee 2, "Limits for Intakes of Radionuclides by Workers," ICRP Publication 30, Parts 1, 2, and 3, Pergamon Press, New York, 1979.

Jackson, K.E., and K.J. Inch, "Partitioning of Strontium-90 Among Aqueous and Mineral Species In a Contaminated Aquifer," Envir. Sci. Tech., Vol. 4, pp. 231-236, 1983.

Jones, M.J. and K.K. Watson, "Effect of Soil Water Hysteresis on Solute Movement During Intermittent Leaching," Water Resources Research, Vol. 23, pp. 1251-1256, 1987. 


\subsection{References}

Jury, W.A., W.R. Gardner, and W.H. Gardner, Soil Physics, 5th ed., John Wiley \& Sons, New York, 1991.

Kelly, W.R., "A Modeling Study of Geochemical Interactions at the Sheffield, Illinois Low-level Radioactive Waste Disposal Sites," Nuclear and Chemical Waste Management, Vol. 7, pp. 191$199,1987$.

Killey, R.W.D., J.O. McHugh, D.R. Champ, Cooper, E.L., and J.L. Young, "Subsurface Cobalt60 Migration from A Low-level Waste Disposal Site," Environ. Sci. Tech., Vol. 18, pp. 148$157,1984$.

Kimmel, G.T. and O.C. Braids, "Leachates Plumes in Ground Water from Babylon and Islip Landlills, Long Island, New York," U.S. Geological Survey, Professional Paper 1085, 1980.

Kirkner, D.J., A.A. Jennings, and T.L. Theis, "Multicomponent Mass Transport with Chemical Interaction Kinetics," Journal of Hydrology, Vol. 76, pp. 107-117, 1985.

Kirkner, D.J., and H. Reeves, "Multicomponent Mass Transport with Homogeneous and Heterogeneous Chemical Reactions: Effect of the Chemistry on the Choice of Numerical Algorithm, 1, Theory," Water Resources Research, Vol. 24, pp. 1719-1729, 1988.

Langmuir, D., "Uranium Solution-Mineral Equilibria at Low Temperatures with Application to Sedimentary Ore Deposits," Geochim. et Cosmochim. Acta, Vol. 42, pp. 547-569, 1978.

Langmuir, D., and J.S. Herman, "The Mobility of Thorium in Natural Waters at Low Temperatures," Geochim. et Cosmochim. Acta, Vol. 44, pp. 1753-1766, 1980

Lemire, R.J., and P.R. Tremaine, "Uranium and plutonium equilibria in aqueous solution to $200^{\circ}$ C," J. Chem. Eng. Data, Vol. 25, pp. 361-370, 1980.

Lichtner, P.C., "Continuum Model for Simultaneous Chemical Reactions and Mass Transport in Hydrothermal Systems," Geochim. Cosmochim. Acta, Vol. 49, pp. 779-800, 1985.

Lindsay, W. L. Chemical Equilibria in Soils, John Wiley \& Sons, 1979.

Liu, W.C., and T.N. Narasimhan, "Redox-Controlled Multiple-Species Reactive Chemical Transport 1. Model Development," Water Resources Research, Vol. 25, No. 5, pp. 869-882, May 1989a.

Liu, W.C., and T.N. Narasimhan, "Redox-Controlled Multiple-Species Reactive Chemical Transport 2. Verification and Application," Water Resources Research, Vol. 25, pp. 883-910, May $1989 \mathrm{~b}$.

Logan, K.H., "Engineering Significance of National Bureau of Standards Soil-Corrosion Data," Journal of Research of the National Bureau of Standards, Vol. 22, 1939. 
Manahan, S.E., Environmental Chemistry, 5th ed., Lewis Publishers, Inc., Chelsea, Michigan, 1991.

Matsunaga, T., G. Karametaxas, H.R. Von Gunten, and P.L. Lichtner, "Redox Chemistry of Iron and Manganese Minerals in River-recharging Aquifers: A Model Interpretation of a Column Experiment," Geochim. et Cosmochim. Acta, Vol. 57, pp. 1691-1704, 1993.

McCarthy, J.F. and J.M. Zachara, "Subsurface Transport of Contaminants," Environ. Sci. Technol., Vol. 23, No. 5, pp. 496-502, 1989.

Means, J. L., D. A. Crerar, and J. O. Duguid, "Migration of Radioactive Wastes: Radionuclide Mobilization by Complexation Agents," Science, Vol. 200, pp. 1477-1481, June 1978a.

Means, J.L., D.A. Crerar, M.P. Borcsik, and J.O. Duguid, "Adsorption of Co and Selected Actinides by $\mathrm{Mn}$ and Fe Oxides in Soils and Sediments," Geochim. et Cosmochim. Acta, Vol. 42, pp. 1763-1773, 1978 b.

Meijer, A., "Yucca Mountain Project Far-Field Sorption Studies and Data Needs,"LA-11671MS/UC-510, Los Alamos National Laboratory, 1990.

Miller, C.W. and L.V. Benson, "Simulation of Solute Transport in a Chemically Reactive Heterogeneous System: Model Development and Application," Water Resources Research, Vol. 19, pp. 381-391, 1983.

Mills, W.B., S. Liu, and F.K. Fong, "Literature Review and Model (COMET) for Colloid/Metals Transport in Porous Media,” Ground Water, Vol. 29, No. 2, pp. 199-208, 1991.

Narasimhan, T.N., A.F. White, and T. Tokunaga, "Groundwater Contamination from an Inactive Uranium Mill Tailings Pile, 2, Application of a Dynamic Mixing Model," Water Resources Research, Vol. 22, pp. 1820-1834, 1986.

National Research Council, Ground Water Models - Scientific and Regulatory Applications, National Academy Press, Washington, D.C., 1990

Pescatore, C., "Improved Expressions for Modeling Diffusive, Fractional Cumulative Leaching form Finite-Size Waste Forms," Waste Management, Vol. 10, pp. 155-159, 1990.

Peters, C.A., R.G. Striegl, P.C. Mills, and R.W. Healy, "Effects of Low-Level RadioactiveWaste Disposal On Water Chemistry in the Unsaturated Zone at a Site Near Sheffield Illinois," 1982-84, Open File Report 90-373, 1992.

Polzer, W.L., E.B. Fowler, and E.H. Essington, "The Interaction of Low-Level, Liquid Radioactive Wastes in Soils: 3. Interaction of Waste Radionuclides with Soil from Horizons of Two Soil Series," Soil Science, Vol. 132, pp. 19-24, 1981. 


\subsection{References}

Rai, D., R. J. Serne, and D. A. Moore, "Solubility of Plutonium Compounds and Their Behavior in Soils," Soil Sci. Soc. Am. J., Vol. 44, pp. 490-495, 1980a.

Rai, D., R.J. Serne, and J.L. Swanson, "Solution Species of Plutonium in the Environment," J. Environ. Qual., Vol. 9, pp. 417-420,1980b.

Roles, G.W., "Characteristics of Low-level Radioactive Waste Disposed During 1987 through 1989,” NUREG-1418, U.S. Nuclear Regulatory Commission, Washington, D.C., 1990.

Romanoff, M., "Underground Corrosion," National Bureau of Standards Circular, 579, 1957.

Salvucci, G.D., “An Approximate Solution for Steady Vertical Flux of Moisture Through an Unsaturated Homogeneous Soil," Water Resources Research, Vol. 29, No. 11, pp. 3749-3753, 1993.

Schulz, R.K., E.B. Fowler, E.H. Essington, and W.L. Polzer, "Studies on Unsaturated Zone Hydrology and Radionuclide Migration at a Shallow-Land Buried Site," Soil Science, Vol. 132, pp. 99-104, 1981.

Seitz, R.R., J.C. Walton, C.A. Dicke, and J.R. Cook, "Near-Field Performance Assessment For the Salstone Disposal Facility," in Scientific Basis for Nuclear Waste Management XV, Mat. Res. Soc. Symp. Proc. Vol. 294, pp. 771-776, 1992.

Serne, R.J., R.C. Arthur, and K.M. Krupka, "Review of Geochemical Processes and Codes for Assessment of Radionuclide Migration Potential at Commercial LLW Sites," NUREG/CR5548, PNL-7285, Pacific Northwest Laboratory, Richland, Washington, 1990.

Sevougian, S.D., R.S. Schechter, and L.W. Lake, "Effect of Partial Local Equilibrium on the Propagation of Precipitation/Dissolution Waves," Ind. Eng. Chem. Res., Vol. 32, No. 10, pp. 281-2304, 1993.

Sheppard, M.I., and D.H. Thibault, "Default Soil Solid/Liquid Partition Coefficients, $\mathrm{K}_{\mathrm{d}} \mathrm{s}$, for Four Major Soil Types: A Compendium," Health Physics, Vol. 59, pp. 471-482, 1990.

Spor, H., M. Trescinski, and M.F. Libert, "Microbial Effects on the Radionuclide Transport in a Deep Nuclear Waste Repository," in Scientific Basis for Nuclear Waste Management XVI, Mat. Res. Soc. Symp. Proc. Vol. 294, pp. 771-776, 1993.

Sposito, G., The Chemistry of Soil, New York, Oxford, Oxford University Press, 1989.

Strickert, R., A.M. Friedman, and S. Fried, "The Sorption of Technetium and Iodine Radioisotopes by Various Minerals," Nuclear Technology, Vol. 49, pp. 253-266, 1980.

Stumm, W., Chemistry of the Solid-Water Interface, John Wiley \& Sons, Inc., New York, 1992. 
Stumm, W., and J.J. Morgan, Aquatic Chemistry, John Wiley \& Sons, Inc., New York, 1981.

Suarez, D.L., and D. Langmuir, "Heavy Metal Relationships in a Pennsylvania Soil," Geochim. et Cosmochim. Acta, Vol. 40, pp. 589-598, 1976.

Suen, C.J., T.M. Sullivan, and E. Sweeney, "Low-Level Waste Source Term Evaluation," Technical Report WM-3276-7, Brookhaven National Laboratory, Upton, New York, 1988.

Sullivan, T.M., C.R. Kempf, C.J. Suen, and S.F. Mughabghab, "Low-level Radioactive Waste Source Term Model Development and Testing," NUREG/CR-5204, BNL-NUREG-52160, Brookhaven National Laboratory, Upton, New York, 1988.

Sullivan, T.M., and C.J. Suen, "Low-level Waste Shallow Land Disposal Source Term Model: Data Input Guides," NUREG/CR-5387, BNL-NUREG-52206, Brookhaven National Laboratory, Upton, New York, 1989.

Sullivan, T.M., "Selection of Models to Calculate the LLW Source Term," NUREG/CR-5773, BNL-NUREG-52295, Brookhaven National Laboratory, Upton, New York, 1991.

Sullivan, T.M., and C.J. Suen, "Low-level Waste Source Term Model Development and Testing," NUREG/CR-5681, BNL-NUREG-52280, Brookhaven National Laboratory, Upton, New York, 1991.

Sullivan, T.M., "Disposal Unit Source Term (DUST) Data Input Guide," NUREG/CR-6041, BNL-NUREG-52375, Brookhaven National Laboratory, Upton, New York, 1993.

Tikhomirov, F.A., and N.I. Sanzharova, "Uptake of Strontium-90 by Herbaceous Plants as An Index of Root Activity Distribution over the Soil Profile," Moscow Univ. Soil Sci. Bull., Vol. 33, pp.54-58, 1978.

Toste, A.P., L.J. Kirby, and T.R. Pahl, "Role of Organics in the Subsurface Migration of Radionuclides in Groundwater," in Geochemical Behavior of Disposed Radioactive Waste, M.J. Comstock (ed.), American Chemical Society, Washington, D.C., pp. 251-270, 1984.

Tripathi, V.S., "Comments on Uranium Solution-mineral equilibria at temperatures with Applications to Sedimentary Ore Deposits," Geochim. et Cosmochim. Acta, Vol. 43, pp. 1989$1990,1979$.

Turner, D.R., T. Griffin, and T.B. Dietrich, "Radionuclide Sorption Modeling Using the MINTEQA2 Speciation Code," in Scientific Basis for Nuclear Waste Management XVI, Mat. Res. Soc. Symp. Proc. Vol. 294, pp. 783-790, 1992.

U.S. Nuclear Regulatory Commission, "Technical Branch Position on Waste Form, Revision 1," Office of Nuclear Materials Safety and Safeguards, January, 24, 1991. 


\subsection{References}

Van Zeggeren, F., and S.H. Storey, The Computation of Chemical Equilibria, Cambridge University Press, Cambridge, U.K., 1970.

Walsh, M.P., "Geochemical Flow Modeling," Ph.D. Dissertation, The University of Texas at Austin, Austin, TX, 1983.

Weiss, A.J., and P. Colombo, "Evaluation of Isotope Migration - Land Burial. Water Chemistry at Commercially Operated Low-Level Radioactive Waste Disposal Sites," Status Report September 30, 1979, NUREG/CR-1289, Brookhaven National Laboratory, Upton, New York, $1980 \mathrm{a}$.

Weiss, A.J., and P. Colombo, "Evaluation of Isotope Migration - Land Burial. Water Chemistry at Commercially Operated Low-Level Radioactive Waste Disposal Sites," Quarterly Progress Report, October-December 1979, BNL-NUREG-51147, Brookhaven National Laboratory, Upton, New York, 1980 b.

Yeh, G.T., and D.S. Ward, "FEMWATER: A Finite-Element Model of Water Flow Through Saturated-Unsaturated Porous Media," ORNL-5567, Oak Ridge National Laboratory, Oak Ridge, Tennessee, 1980.

Yeh, G.T., and V.S. Tripathi, "A Critical Evaluation of Recent Developments in Hydrogeochemical Transport Models of Reactive Multichemical Components," Water Resources Research, Vol. 25, No. 1, pp. 93-108, 1989.

Yeh, G.T., and V.S. Tripathi, "HYDROGEOCHEM: A Coupled Model of Hydrological and Geochemical Equilibrium of Multicomponent Systems," ORNL-6371, Oak Ridge National Laboratory, Oak Ridge, Tennessee, 1990.

Yeh, G.T., and V.S. Tripathi, "A Model for Simulating Transport of Reactive Multispecies Components: Model Development and Demonstration," Water Resources Research, Vol. 27, No. 12, pp. 3075-3094, 1991.

Yim, M.S., "Gas-Phase Release of Radionuclides from Low-Level Radioactive Waste Disposal Facilities," A Thesis submitted to the Faculty of the Harvard School of Public Health, Boston, Massachusetts, May 1994. 


\section{APPENDIX 1}

\section{Chemistry of Leachates}

The shallow land burial characteristics of leachate and ground-water samples collected at the Maxey Flats, West Valley, Barnwell, and Sheffield sites are presented in Table A1.1. Samples show that leachate waters are generally enriched in $\mathrm{Na}^{+}, \mathrm{NH}_{4}{ }^{+}$, dissolved iron and manganese, $\mathrm{Ca}^{2+}, \mathrm{Mg}^{2+}, \mathrm{Cl}^{-}$, alkalinity, dissolved inorganic and organic carbon, relative to unperturbed ground waters of disposal facilities. The Barnwell and Sheffield samples also show significant amounts of calcium and magnesium enrichments. At Maxey Flats and West Valley, the concentrations of dissolved organic carbon (DOC) are significantly elevated relative to ambient ground water. Several samples exhibit over two orders of magnitude elevation. Table A1.2 lists the major ion compositions of trench leachate and ground-water samples from the four studied LLW disposal sites. As shown in this table, the major element composition of the leachate samples show a wide range of compositional variation depending on the sample location. As a result of this chemical variability, a number of water types are identified. They are summarized in Table A1.3.

Table A1.4 shows the average radionuclide concentrations of trench leachates for the four study sites. The significant radionuclides dissolved in the leachates include $\mathrm{H}-3, \mathrm{Sr}-90, \mathrm{Pu}-$ 239, Pu-240, Am-241, Cs-134, Cs-137, and Co-60. Their concentrations may vary up to several orders of magnitude, depending on the site and radionuclide. The data set from Maxey Flats displays the highest variability. The Maxey Flats site was sampled in more detail than the other three sites and the apparent variability may be due to the more extensive sampling rather than actual site conditions.

Trench leachates are considered to exhibit a general depletion in dissolved oxygen, especially those from the Maxey Flats and West Valley sites where trenches are excavated in non-porous shale and glacial till of relatively low hydraulic conductivity, which results in stagnant accumulations of water. Some samples from these two sites exhibit negative redox potential indicative of strongly reducing conditions. The sites at Barnwell and Sheffield are relatively well-drained, and therefore, their samples show relatively milder reducing conditions. This anoxic condition in LLW trenches is similar to conditions found in municipal landfills. LLW contains large amounts of organic wastes, such as paper, clothing, and animal carcasses. Microbial degradation of these materials effectively controls the redox condition in the trench. However, it is expected that the redox potential should increase with increasing distance from the trench. It has been observed in municipal waste leachates that in the far field more oxidizing conditions are restored [Kimmel and Braids, 1980]. This change in Eh (and associated pH change) conditions can account for the precipitation of manganese and iron minerals in the far field, and the resulting decrease in the mobility of these metals in ground water. 
Appendix 1. Chemistry of Leachates

Table A1.1 Characteristics of trench leachates and ground waters from LLW disposal sites

\begin{tabular}{|c|c|c|c|c|c|c|c|c|c|}
\hline Sample & $\begin{array}{c}\text { Temperature } \\
\left({ }^{\circ} \mathrm{C}\right)\end{array}$ & $\mathrm{pH}$ & $\begin{array}{c}\mathrm{Eh}_{\mathrm{t}} \\
(\mathrm{mV})^{\mathrm{a}}\end{array}$ & $\begin{array}{r}\text { Dissolved } \\
\text { Oxygen } \\
(\mathbf{p p m}) \\
\end{array}$ & $\begin{array}{r}\text { Specific } \\
\text { Conductance } \\
\text { (UMho/cm) }\end{array}$ & $\begin{array}{l}\text { lonic } \\
\text { Strength } \\
\left(\times 10^{-9}\right)^{\mathrm{h}}\end{array}$ & $\begin{array}{r}\text { Total } \\
\text { Dissolved } \\
\text { Solids } \\
(\text { ppm) } \\
\end{array}$ & $\begin{array}{r}\text { DOC } \\
(\mathrm{ppm})^{\mathrm{E}}\end{array}$ & $\begin{array}{c}\text { DIC } \\
\text { (apm) }\end{array}$ \\
\hline \multicolumn{10}{|c|}{ Maxey Flate Site } \\
\hline $2(76)$ & 20.0 & 6.7 & d & d & 3400 & 6.0 & 4460 & 210 & 270 \\
\hline $7(76)$ & 22.5 & 6.9 & d & d & 2530 & 3.5 & 2220 & 250 & 210 \\
\hline $7(61)$ & 16.3 & 7.4 & -44 & 0.10 & 12000 & & & & \\
\hline $18(76)$ & 21.5 & 7.0 & d & d & 3450 & 5.1 & 3660 & 500 & 440 \\
\hline $19 s(76)$ & 21.0 & 6.6 & d & $d$ & 2340 & 3.3 & 1830 & 620 & 80 \\
\hline $19 \mathrm{~s}(81)$ & 13.0 & 6.5 & -28 & 0.10 & 2100 & 3.5 & 2080 & 430 & 170 \\
\hline $23(81)$ & 117.0 & 7.5 & -39 & 0.05 & 4800 & 7.2 & 5000 & 780 & 520 \\
\hline $26(76)$ & 21.0 & 6.8 & $d$ & d & 2910 & 3.6 & 2430 & 950 & 150 \\
\hline $27(A v)^{\mathrm{c}}$ & 18.5 & 6.2 & 79 & 0.10 & 13120 & 20 & 8420 & 920 & 25 \\
\hline $27(81)$ & 16.0 & 6.8 & 17 & $<0.05$ & 6000 & 10 & 4340 & 490 & 57 \\
\hline $30(79)$ & 16.0 & 6.5 & 140 & 0.10 & 6900 & 17 & 10380 & 260 & 1500 \\
\hline $32(76)$ & 20.0 & 7.3 & $d$ & $\mathrm{~d}$ & 5750 & 6.9 & 4950 & 790 & 510 \\
\hline $33 \mathrm{~L} 4(78)$ & 12.0 & 12.1 & -7 & 4.1 & 5560 & 3.2 & 3070 & 1100 & 10 \\
\hline $33 \mathrm{~L} 4(81)$ & 17.0 & 12.0 & -54 & 0.05 & 6400 & 4.2 & 4190 & 1300 & $<2$ \\
\hline $33 \mathrm{~L} 8(81)$ & 16.0 & 6.0 & -135 & 0.25 & 2000 & 2.9 & 1800 & 160 & 330 \\
\hline $35(81)$ & 17.0 & 8.2 & -14 & 0.10 & 3400 & 6.4 & 4180 & 540 & 390 \\
\hline $37(76)$ & 20.0 & 5.1 & d & d & 6900 & 19 & 11250 & 3260 & 20 \\
\hline $\mathrm{GW}(\mathrm{MF})$ & d & 6.9 & d & d & d & 7.2 & 3670 & $6^{i}$ & $11^{\mathrm{f}}$ \\
\hline \multicolumn{10}{|c|}{ West Valley Site } \\
\hline $2(77)$ & 11.7 & 7.7 & 47 & d & 6700 & 8.7 & 6120 & 200 & 670 \\
\hline $3(78)$ & 10.5 & 7.3 & -3 & 0.1 & 7600 & 9.5 & 3390 & 1700 & 93 \\
\hline $4(77)$ & 13.5 & 7.2 & 210 & $\mathrm{~d}$ & 8100 & 1.1 & 6830 & 330 & 130 \\
\hline $5(78)$ & 10.5 & 6.7 & 40 & 0.2 & 6730 & 89.7 & 5970 & 2900 & 10 \\
\hline $9(78)$ & 13.5 & 6.7 & 16 & 0.2 & 3400 & 4.9 & 3030 & 1700 & 120 \\
\hline GW(WV) & $d$ & 7.8 & d & d & d & 0.43 & 240 & $\mathrm{~d}$ & d \\
\hline \multicolumn{10}{|l|}{ Barnwell Site } \\
\hline $6(80)$ & 15.3 & 6.1 & 350 & 4 & 260 & 0.37 & 240 & 7 & 8 \\
\hline $8(79)$ & 19.0 & 6.6 & 308 & 2 & 1400 & 1.5 & 1120 & 170 & 130 \\
\hline $8(80)$ & 16.0 & 7.4 & 130 & 0.3 & 2600 & 3.11 & 2220 & 203 & 258 \\
\hline $25 / 21(79)$ & 18.5 & 5.9 & 538 & 1 & 550 & 0.62 & 390 & 12 & 38 \\
\hline
\end{tabular}


Appendix 1. Chemistry of Leachates

Table A1.1 Continued

\begin{tabular}{|c|c|c|c|c|c|c|c|c|c|}
\hline Sample & $\begin{array}{c}\text { Temperature } \\
\left({ }^{\circ} \mathrm{C}\right)\end{array}$ & $\mathrm{pH}$ & $\begin{array}{c}\mathrm{Eh}_{1} \\
(\mathrm{mV})^{\mathrm{a}}\end{array}$ & $\begin{array}{r}\text { Dissolved } \\
\text { Oxygen } \\
(\mathrm{ppm}) \\
\end{array}$ & $\begin{array}{r}\text { Specific } \\
\text { Conductance } \\
(\mu \mathrm{Mho} / \mathrm{cm})\end{array}$ & $\begin{array}{l}\text { Ionic } \\
\text { Strength } \\
\left(\times 10^{-9}\right)^{\mathrm{b}} \\
\end{array}$ & $\begin{array}{r}\text { Total } \\
\text { Dissolved } \\
\text { Solids } \\
(\mathrm{ppm})^{b} \\
\end{array}$ & $\begin{array}{r}\mathrm{DOC} \\
(\mathrm{ppm})^{\mathrm{E}}\end{array}$ & $\begin{array}{c}\mathrm{DIC} \\
(\mathrm{ppm})^{\mathrm{e}}\end{array}$ \\
\hline & 13.3 & 6.2 & 100 & 0.2 & 190 & 0.37 & 230 & d & 18 \\
\hline $\mathrm{GW} /(\mathrm{RW})$ & 18.0 & 6.8 & d & 0.1 & 35 & 0.18 & 13 & 6 & 6 \\
\hline \multicolumn{10}{|l|}{ Sheffield Site } \\
\hline $14 \mathrm{~A}(79)$ & 8.5 & 5.0 & 143 & 0.3 & 600 & 0.93 & 500 & 100 & 40 \\
\hline $18(79)$ & 10.0 & 6.8 & 181 & 0.1 & 1600 & 3.0 & 1700 & 50 & 190 \\
\hline $18(82)$ & 10.5 & 7.1 & 236 & $<0.1$ & 2000 & 3.4 & 1900 & 37 & 275 \\
\hline $\mathrm{GW}(\mathrm{SH})$ & 10.0 & 7.5 & 2 & 2.2 & 310 & 1.1 & 620 & 3 & 70 \\
\hline
\end{tabular}

"Field measurement of Eh are reported relative to the Standard Hydrogen Electrode (SHE).

'Ionic strength and total dissolved solids values are based on WATEQF calculations.

'Represent dissolve organic carbon and dissolved inorganic carbon, respectively.

Not determined.

"Average values based ion leachete samplings conducted in September 1976, May 1978, and October 1979 (Dayal et al., 1984).

'These species were not pressured in well UA3 water. The listed values are means for the species in well UBIA water samples.

(FROM DAYAL, 1986) 
Appendix 1. Chemistry of Leachates

Table A1.2 Major ion compositions of trench leachates and ground waters from LLW disposal sites.

\begin{tabular}{|c|c|c|c|c|c|c|c|c|c|c|c|}
\hline \multicolumn{12}{|c|}{ Concentration $(\mathrm{mg} / \mathrm{L})$} \\
\hline Sample & $\mathrm{Ma}^{+}$ & $\mathbf{K}^{+}$ & $\begin{array}{l}\mathrm{NH}_{4}^{+} \\
\text {(as N) }\end{array}$ & $\mathrm{Fe}_{\mathrm{T}}^{\mathrm{a}}$ & $\mathrm{Mo}_{\mathrm{T}}^{\mathrm{a}}$ & $\mathrm{Ca}^{2+}$ & $\mathrm{Mg}_{+}^{2}$ & $\mathrm{Cl}^{-}$ & $\mathrm{SO}_{4}{ }^{2-}$ & $\begin{array}{r}\mathrm{NO}_{3}+ \\
\mathrm{NO}_{2} \\
\text { (as W) } \\
\end{array}$ & $\begin{array}{r}\text { Alkalinity } \\
\left(\text { as } \mathrm{CaCO}_{3}\right)\end{array}$ \\
\hline \multicolumn{12}{|c|}{ Maxey Flats Site } \\
\hline $2(76)$ & 700 & 66 & $\mathrm{~b}$ & 40 & 0.8 & 29 & 79 & 310 & 11 & $<0.1$ & 1560 \\
\hline $7(76)$ & 240 & 140 & $\mathrm{~b}$ & 61 & 0.5 & 130 & 73 & 220 & $<5$ & $<0.1$ & 1090 \\
\hline $7(81)$ & 2140 & 329 & 75 & 17 & 1.9 & 107 & 193 & 2500 & 1320 & 9 & 1150 \\
\hline $18(76)$ & 540 & 50 & b & 33 & $<0.1$ & 14 & 160 & 310 & 18 & $<0.1$ & 2050 \\
\hline $19 \mathrm{a}(76)$ & 100 & 25 & $\mathbf{b}$ & 150 & 0.8 & 58 & 130 & 150 & $<5$ & $<0.1$ & 980 \\
\hline $19 \mathrm{a}(81)$ & 231 & 27 & 45 & 65 & 0.5 & 49 & 128 & 231 & $<2$ & 0.5 & 1040 \\
\hline $23(81)$ & 825 & 77 & 100 & 7 & $<0.1$ & 11 & 230 & 575 & 57 & 28 & 2420 \\
\hline $26(76)$ & 240 & 39 & $b$ & 65 & 0.5 & 49 & 128 & 231 & $<2$ & 0.5 & 1040 \\
\hline $27(\mathrm{Av})^{\mathrm{c}}$ & 630 & 85 & 70 & 1250 & 116 & 530 & 468 & 4733 & 24 & 0.8 & 354 \\
\hline $27(81)$ & 554 & 87 & 116 & 165 & 1.7 & 220 & 350 & 2340 & $<2$ & 17 & 312 \\
\hline $30(79)$ & 1000 & 43 & 50 & 10 & 0.3 & 32 & 1300 & 200 & 85 & 0.1 & 6400 \\
\hline $32(76)$ & 700 & 210 & b & 16 & 1.2 & 75 & 230 & 370 & 11 & $<0.1$ & 2720 \\
\hline $33 \mathrm{~L} 4(78)$ & 180 & 30 & 18 & 0.3 & $<0.1$ & 650 & $\begin{array}{r}<0 \\
1\end{array}$ & 168 & $<5$ & 11 & 1600 \\
\hline $33 \mathrm{~L} 4(81)$ & 180 & 102 & 26 & 0.2 & $<0.1$ & 864 & $\begin{array}{r}<0 \\
2\end{array}$ & 361 & $<2$ & 10 & 2120 \\
\hline $33 \mathrm{~L} 8(81)$ & 50 & 11 & 50 & 43 & 1.8 & 190 & 49 & 37 & 15 & 2 & 1080 \\
\hline $35(81)$ & 614 & 51 & 37 & 0.9 & 0.3 & 26 & 330 & 235 & $<2$ & 0.7 & 2310 \\
\hline $37(76)$ & 680 & 20 & $b$ & 1100 & 42 & 250 & 730 & 180 & 8000 & 13 & 125 \\
\hline GW(MF) & 300 & 24 & $<1$ & $<0.1$ & $<0.1$ & 220 & 380 & 70 & 2100 & 0.2 & 459 \\
\hline
\end{tabular}

West Valley Site

\begin{tabular}{lrrrrrrrrrrr}
\hline $2(77)$ & 900 & 330 & 230 & 13 & $<0.1$ & 72 & 220 & 470 & $<5$ & $<0.1$ & 3120 \\
$3(78)$ & 1000 & 320 & 300 & 56 & 0.3 & 150 & 180 & 1300 & 26 & 2 & 1730 \\
$4(77)$ & 970 & 330 & 68 & 82 & 0.5 & 180 & 160 & 2100 & $<5$ & $<0.1$ & 1800 \\
$5(78)$ & 690 & 270 & 180 & 540 & 2.3 & 300 & 200 & 820 & $<5$ & 1 & 2300 \\
$9(78)$ & 430 & 91 & 84 & 57 & 0.2 & 130 & 150 & 82 & $<5$ & $<0.1$ & 1000 \\
GW(WV) & 11 & $\mathrm{a}$ & $<1$ & 10 & $<0.1$ & 42 & 5 & 12 & 17 & 0.2 & 167
\end{tabular}

Barnwell Site

$6(80)$

$<1$

$\begin{array}{lll}0.7 & 14 & 1\end{array}$

13

45

4

86 
Appendix 1. Chemistry of Leachates

\section{Table A1.2 Continued}

Concentration $(\mathrm{mg} / \mathrm{L})$

\begin{tabular}{|c|c|c|c|c|c|c|c|c|c|c|c|}
\hline Sample & $\mathrm{Ma}^{+}$ & $\mathbf{K}^{+}$ & $\begin{array}{l}\mathrm{NH}_{4}^{+} \\
(\text {as N) }\end{array}$ & $\mathrm{Fe}_{\mathrm{T}}{ }^{\mathrm{a}}$ & $\mathrm{Mo}_{\mathrm{T}}^{\mathrm{a}}$ & $\mathrm{Ca}^{2+}$ & $\mathrm{Mg}_{+}^{2}$ & $\mathrm{Cl} \cdot$ & $\mathrm{SO}_{4}^{2-}$ & $\begin{array}{r}\mathrm{NO}_{3}+ \\
\mathrm{NO}_{2} \\
\text { (as W) } \\
\end{array}$ & $\begin{array}{r}\text { Alkalinity } \\
\left(\text { as } \mathrm{CaCo}_{3}\right)\end{array}$ \\
\hline $8(79)$ & 87 & 12 & 59 & 1.2 & 0.7 & 34 & 18 & 85 & 34 & 8 & 600 \\
\hline $8(80)$ & 120 & 18 & 205 & 24 & 0.9 & 82 & 40 & 47 & 7 & $<0.1$ & 1340 \\
\hline $25 / 21(79)$ & 37 & 4 & 25 & 0.2 & 0.3 & 21 & 3 & 42 & 56 & 15 & 80 \\
\hline $25 / 21(80)$ & 11 & 1 & 35 & 6 & 0.6 & 10 & 3 & 12 & $<5$ & $<0.1$ & 104 \\
\hline GW(BW) & 15 & 12 & 2 & $<1$ & $<0.1$ & 4 & 0.2 & 3 & 17 & $<0.1$ & 61 \\
\hline \multicolumn{12}{|c|}{ Sheffield Site } \\
\hline $14 A(79)$ & 50 & 13 & 5 & 11 & 1.6 & 52 & 17 & 20 & 78 & 0.1 & 200 \\
\hline $18(79)$ & 67 & 72 & 9 & 0.4 & 1.1 & 190 & 94 & 28 & 190 & 0.4 & 850 \\
\hline $18(82)$ & 76 & 73 & 9 & $<0.1$ & b & 219 & 126 & 27 & 199 & b & 1060 \\
\hline $\mathrm{GW}(\mathrm{SH})$ & 35 & 1 & $<0.1$ & 10 & 0.2 & 74 & 34 & 13 & 47 & $<0.1$ & 320 \\
\hline
\end{tabular}

${ }^{a}$ Represents total dissolved iron and manganese.

'Not determined.

'Average value based on leachate sampling conducted in September 1976, May 1978, and October 1979 (Dayal et al., 1984).

(FROM DAYAL, 1986) 
Appendix 1. Chemistry of Leachates

Table A1.3 Various water types showing nature and extent of chemical variability in trench leachates and ambient ground waters.

\begin{tabular}{|c|c|}
\hline Water Sample & Water Type \\
\hline \multicolumn{2}{|l|}{ Maxey Flats Site } \\
\hline $2(76), 7(76), 18(76), 19 s(76,81)$ & $(\mathrm{Na}+\mathrm{K})-\mathrm{Mg}-\mathrm{HCO}_{3}$ \\
\hline \multicolumn{2}{|l|}{$23(81), 26(76), 30(79), 32(76),(35(81)$} \\
\hline $37(76), \mathrm{GW}(\mathrm{MF})$ & $\mathrm{Mg}-(\mathrm{Na}+\mathrm{K})-\mathrm{SO}_{4}$ \\
\hline $7(81)$ & $(\mathrm{Na}+\mathrm{K})-\mathrm{Cl}$ \\
\hline $27(\mathrm{Av}), 27(81)$ & $(\mathrm{Na}+\mathrm{K})-\mathrm{Mg}-\mathrm{Cl}$ \\
\hline $33 \mathrm{~L} 4(78,81), 33 \mathrm{~L} 8(81)$ & $\mathrm{Ca}-\mathrm{HCO}_{3}$ \\
\hline \multicolumn{2}{|l|}{ West Valley Site } \\
\hline GW(WV) & $\mathrm{CA}-\mathrm{HCO}_{3}$ \\
\hline $5(78), 9(78), 2(77)$ & $(\mathrm{Na}+\mathrm{K})-\mathrm{HCO}_{3}$ \\
\hline $4(77), 3(78)$ & $(\mathrm{Na}+\mathrm{K})-\mathrm{Cl}-\mathrm{HCO}_{3}$ \\
\hline \multicolumn{2}{|l|}{ Barnwell Site } \\
\hline $25 / 21(80), 8(80)$ & $(\mathrm{Ca}+\mathrm{Mg})-\mathrm{Na}-\mathrm{HCO}_{3}$ \\
\hline $8(79), \mathrm{GW}(\mathrm{BW})$ & $(\mathrm{Na}+\mathrm{K})-\mathrm{HCO}_{3}$ \\
\hline $6(80), 25 / 21(79)$ & $\left.(\mathrm{Na}+\mathrm{K})-\mathrm{Cl}+\mathrm{SO}_{4}\right)$ \\
\hline \multicolumn{2}{|l|}{ Sheffield Site } \\
\hline $18(82), 18(79), 14 \mathrm{~A}(79)$ & $(\mathrm{Ca}+\mathrm{Mg})-\mathrm{HCO}_{3}-\mathrm{SO}_{4}$ \\
\hline GW(SH) & $(\mathrm{Ca}+\mathrm{Mg})-\left(\mathrm{Cl}+\mathrm{SO}_{4}\right)$ \\
\hline
\end{tabular}

(FROM DAYAL, 1986) 
Appendix 1. Chemistry of Leachates

Table A1.4 Average radionuclide concentrations in trench leachates sampled during the period 1976-1982.

\begin{tabular}{|c|c|c|c|c|c|c|c|c|}
\hline \multicolumn{9}{|c|}{ Concentration $(\mathrm{pCi} / \mathrm{L})^{\mathrm{a}}$} \\
\hline Trench & $\mathrm{H}-3$ & $\mathrm{Sr}-90$ & $\mathrm{Pu}-238$ & $\mathrm{Pu}-239,240$ & Am-241 & Cs-134 & Cs-137 & $\mathrm{Co}-60$ \\
\hline \multicolumn{9}{|c|}{ Maxey Flats Site } \\
\hline 2 & $1.7 \times 10^{7}$ & $4.6 \times 10^{3}$ & $6.4 \times 10^{3}$ & $3.5 \times 10^{2}$ & $4.0 \times 10^{3}$ & $<1.0 \times 10^{2}$ & $<1.0 \times 10^{2}$ & $7.9 \times 10^{3}$ \\
\hline 7 & $3.0 \times 10^{8}$ & $3.1 \times 10^{6}$ & $7.1 \times 10^{0}$ & $2.6 \times 10^{\circ}$ & $3.9 \times 10^{2}$ & $1.0 \times 10^{2}$ & $3.6 \times 10^{4}$ & $1.7 \times 10^{4}$ \\
\hline 18 & $3.4 \times 10^{8}$ & $4.7 \times 10^{4}$ & $5.7 \times 10^{2}$ & $5.1 \times 10^{1}$ & $<2.0 \times 10^{1}$ & $<1.0 \times 10^{2}$ & $4.8 \times 10^{3}$ & $1.2 \times 10^{4}$ \\
\hline $19 s$ & $7.0 \times 10^{7}$ & $2.4 \times 10^{5}$ & $2.0 \times 10^{8}$ & $5.8 \times 10^{8}$ & $1.4 \times 10^{4}$ & $<5.0 \times 10^{1}$ & $6.1 \times 10^{3}$ & $6.9 \times 10^{3}$ \\
\hline 23 & $1.0 \times 10^{9}$ & $1.9 \times 10^{4}$ & $2.2 \times 10^{4}$ & $6.9 \times 10^{1}$ & $1.4 \times 10^{2}$ & $<2.0 \times 10^{1}$ & $3.2 \times 10^{3}$ & $1.5 \times 10^{3}$ \\
\hline 26 & $1.1 \times 10^{8}$ & $2.9 \times 10^{4}$ & $8.0 \times 10^{4}$ & $3.1 \times 10^{3}$ & $1.0 \times 10^{3}$ & $3.6 \times 10^{2}$ & $5.2 \times 10^{3}$ & $5.7 \times 10^{2}$ \\
\hline 27 & $2.3 \times 10^{9}$ & $1.4 \times 10^{5}$ & $1.3 \times 10^{4}$ & $1.3 \times 10^{3}$ & $4.8 \times 10^{3}$ & $7.6 \times 10^{1}$ & $9.3 \times 10^{3}$ & $5.3 \times 10^{3}$ \\
\hline 30 & $1.1 \times 10^{10}$ & $1.9 \times 10^{4}$ & $2.0 \times 10^{2}$ & $3.3 \times 10^{2}$ & $1.2 \times 10^{2}$ & $2.2 \times 10^{2}$ & $5.6 \times 10^{4}$ & $2.2 \times 10^{4}$ \\
\hline 32 & $1.3 \times 10^{9}$ & $3.8 \times 10^{5}$ & $5.0 \times 10^{4}$ & $1.3 \times 10^{3}$ & $6.0 \times 10^{8}$ & $5.6 \times 10^{1}$ & $4.1 \times 10^{3}$ & $2.0 \times 10^{3}$ \\
\hline $33 \mathrm{~L} 4$ & $4.0 \times 10^{7}$ & $1.7 \times 10^{4}$ & $3.5 \times 10^{3}$ & $5.3 \times 10^{3}$ & $2.0 \times 10^{2}$ & $<4.0 \times 10^{1}$ & $1.9 \times 10^{2}$ & $1.8 \times 10^{2}$ \\
\hline $33 \mathrm{~L} 8$ & $7.0 \times 10^{6}$ & $4.4 \times 10^{2}$ & $7.9 \times 10^{0}$ & $1.2 \times 10^{0}$ & $<3.0 \times 10^{1}$ & $<2.0 \times 10^{1}$ & $1.4 \times 10^{2}$ & $1.6 \times 10^{8}$ \\
\hline 33L9 & $3.3 \times 10^{7}$ & $9.7 \times 10^{3}$ & b & $b_{\text {s }}$ & $<4.0 \times 10^{1}$ & $<1.0 \times 10^{1}$ & $3.4 \times 10^{3}$ & $1.4 \times 10^{4}$ \\
\hline $33 \mathrm{~L} 18$ & $3.8 \times 10^{7}$ & $3.1 \times 10^{4}$ & $7.7 \times 10^{3}$ & $2.4 \times 10^{3}$ & $4.3 \times 10^{3}$ & $6.4 \times 10^{2}$ & $2.6 \times 10^{4}$ & $4.1 \times 10^{3}$ \\
\hline 35 & $3.7 \times 10^{9}$ & $1.5 \times 10^{4}$ & $5.1 \times 10$ & $7.1 \times 10^{1}$ & $3.4 \times 10^{2}$ & $1.2 \times 10^{2}$ & $5.2 \times 10^{3}$ & $1.5 \times 10^{2}$ \\
\hline 37 & $7.8 \times 10^{6}$ & $1.7 \times 10^{8}$ & $1.7 \times 10^{4}$ & $3.1 \times 10^{2}$ & $1.9 \times 10^{4}$ & $2.5 \times 10^{2}$ & $6.2 \times 10^{3}$ & $2.3 \times 10^{4}$ \\
\hline \multicolumn{9}{|c|}{ West Valley Site } \\
\hline 2 & $8.3 \times 10^{7}$ & $3.1 \times 10^{4}$ & $3.2 \times 10^{2}$ & $1.9 \times 10^{2}$ & $<2.1 \times 10^{2}$ & $<1.2 \times 10^{2}$ & $2.5 \times 10^{4}$ & $2.0 \times 10^{2}$ \\
\hline 3 & $3.5 \times 10^{8}$ & $8.4 \times 10^{5}$ & $6.9 \times 10^{1}$ & $8.7 \times 10^{1}$ & $<5.1 \times 10^{2}$ & $<1.9 \times 10^{2}$ & $1.2 \times 10^{6}$ & $2.3 \times 10^{4}$ \\
\hline 4 & $2.8 \times 10^{8}$ & $1.5 \times 10^{7}$ & $1.8 \times 10^{1}$ & $4.3 \times 10^{2}$ & $<1.1 \times 10^{3}$ & $2.9 \times 10^{1}$ & $1.5 \times 10^{4}$ & $5.0 \times 10^{2}$ \\
\hline 5 & $1.3 \times 10^{9}$ & $3.5 \times 10^{5}$ & $2.6 \times 10^{2}$ & $5.7 \times 10^{1}$ & $<2.7 \times 10^{2}$ & $6.8 \times 10^{2}$ & $1.1 \times 10^{5}$ & $5.3 \times 10^{2}$ \\
\hline 8 & $2.9 \times 10^{9}$ & $1.4 \times 10^{5}$ & $1.4 \times 10^{5}$ & $3.3 \times 10^{2}$ & $3.6 \times 10^{2}$ & $3.4 \times 10^{2}$ & $1.3 \times 10^{5}$ & $9.8 \times 10^{1}$ \\
\hline 9 & $3.5 \times 10^{1}$ & $2.0 \times 10^{5}$ & $2.5 \times 10^{2}$ & $2.7 \times 10^{0}$ & $<2.2 \times 10^{2}$ & $5.0 \times 10^{2}$ & $3.0 \times 10^{4}$ & $7.3 \times 10^{2}$ \\
\hline \multicolumn{9}{|c|}{ Barnwell Site } \\
\hline 3 & $1.0 \times 10^{4}$ & $\mathbf{b}$ & $\mathbf{b}$ & b & b & $<2.1 \times 10^{1}$ & $<2.3 \times 10^{1}$ & $<2,2 \times 10^{i}$ \\
\hline 5 & $8.5 \times 10^{5}$ & $3.9 \times 10^{1}$ & $1.4 \times 10^{6}$ & $<2.8 \times 10^{-1}$ & $b$ & $<2.4 \times 10^{1}$ & $1.6 \times 10^{2}$ & $1.2 \times 10^{2}$ \\
\hline 6 & $6.2 \times 10^{5}$ & $<4.3 \times 10^{0}$ & $3.6 \times 10^{1}$ & $<2.8 \times 10^{-1}$ & $\mathrm{~b}$ & $<2.2 \times 10^{i}$ & $<2.2 \times 10^{1}$ & $<2.2 \times 10^{1}$ \\
\hline 8 & $0.9 \times 18^{8}$ & $4.1 \times 10^{1}$ & $1.2 \times 10^{\circ}$ & $4.6 \times 10^{-1}$ & $\mathrm{~b}$ & $<2.2 \times 10^{\prime}$ & $<4.9 \times 10^{2}$ & $3.1 \times z 10^{1}$ \\
\hline 13 & $<1.4 \times 10^{6}$ & $<4.6 \times 10^{0}$ & $7.3 \times 10^{-1}$ & $9.3 \times 10^{-1}$ & $b$ & $<2.3 \times 10^{1}$ & $1.0 \times 10^{\circ}$ & $<2.0 \times 10^{1}$ \\
\hline 18 & $<7.1 \times 10^{2}$ & $<4.6 \times 10^{0}$ & $<3.6 \times 10^{-1}$ & $<2.8 \times 10^{-1}$ & b & $<2.3 \times 10^{1}$ & $<2.1 \times 10^{1}$ & $<2.4 \times 10^{1}$ \\
\hline $25 / 21$ & $2.6 \times 10^{5}$ & $<4.6 \times 10^{0}$ & $4.5 \times 10^{0}$ & $2.8 \times 10^{-1}$ & $b$ & $<2.3 \times 10^{1}$ & $<2.5 \times 10^{1}$ & $<2.8 \times 10^{1}$ \\
\hline
\end{tabular}


Appendix 1. Chemistry of Leachates

Table A1.4 Continued

\begin{tabular}{lllllllll}
\hline \multicolumn{7}{c}{ Concentration (pCi/L) } \\
\hline Trench & $\mathrm{H}-3$ & $\mathrm{Sr}-90$ & $\mathrm{Pu}-238$ & $\mathrm{Pu}-239,240$ & Am-241 & Cs-134 & Cs-137 & Co-60 \\
\hline Sheffield Site & & & & & & & & \\
\hline $14 \mathrm{~A}$ & $5.4 \times 10^{5}$ & $2.1 \times 10^{\circ}$ & $1.4 \times 10^{0}$ & $2.2 \times 10^{-1}$ & $\mathrm{~b}$ & $6.1 \times 10^{3}$ & $2.6 \times 10^{4}$ & $1.0 \times 10^{4}$ \\
18 & $4.7 \times 10^{5}$ & $3.1 \times 10^{\circ}$ & $4.0 \times 10^{\circ}$ & $1.5 \times 10^{\circ}$ & $\mathrm{b}$ & $<2.3 \times 10^{1}$ & $4.9 \times 10^{1}$ & $2.0 \times 10^{2}$ \\
\hline
\end{tabular}

(FROM DAYAL, 1986)

Redox potential measurements reflect the redox level of aqueous systems; however, a redox buffered system is one in which reducible or oxidizable constituents are both present so that they prevent changes in Eh during additions of small amounts of strong oxidizing or reducing agents. Maxey Flats and West Valley leachates have redox levels that correspond to buffering by the $\mathrm{Fe}_{2} \mathrm{O}_{3} / \mathrm{Fe}^{2+}$ and $\mathrm{SO}_{4}{ }^{2-} / \mathrm{H}_{2} \mathrm{~S}$ redox pairs, reflecting the presence of reactive organic matter and relatively long residence times for infiltrated water in the trenches. In contrast, the Barnwell and Sheffield samples generally appear to be less reducing, indicating a relatively low amount of degradable organic matter or a relatively high soil-water (leachate) renewal rate (i.e., short residence times).

The geochemical speciation code, WATEQF, was used by Dayal et al. [1986] to perform solubility calculations. The saturation index, SI (defined as the $\log$ of the ion activity product over the solubility product) was used to indicate the saturation state of the leachate with respect to various minerals. The results indicate that because of strongly reducing conditions, Maxey Flats and West Valley leachates tend to show supersaturation (positive SI) with calcite, dolomite, and rhodochrosite, implying that the $\mathrm{Ca}^{2+}, \mathrm{Mg}^{2+}, \mathrm{Mn}^{2+}$, and $\mathrm{CO}_{3}{ }^{2-}$ concentrations are controlled by the precipitation of these minerals. The saturation of these carbonate minerals is caused by the high carbonate concentrations as a result of $\mathrm{CO}_{2}$ generation by biodegradation reactions of organic matter. High $\mathrm{Mn}^{2+}$ concentration may be due to the oxidation of $\mathrm{Mn}$ oxide phases $\left(\delta \mathrm{MnO}_{2} \rightarrow \mathrm{Mn}^{2+}\right)$ during anaerobic degradation processes. For the less reducing Barnwell and Sheffield leachates, these carbonate minerals are distinctly undersaturated, showing the effect of redox conditions on carbonate equilibria [Dayal et al., 1986]. In another study of pore water chemistry at the Sheffield site carried out by the U.S. Geological Survey [Peters et al., 1992], geochemical modeling shows that nearly all unsaturated zone pore water and saturated zone water are supersaturated with respect to calcite and dolomite, and that concentrations of $\mathrm{Ca}^{2+}$, $\mathrm{Mg}^{2+}$, and $\mathrm{CO}_{3}{ }^{2+}$ in the unsaturated zone pore water are increased by the dissolution of carbonate minerals. The USGS pore water samples which were collected by above-trench lysimeters are more enriched in $\mathrm{Ca}$ and $\mathrm{Mg}$ than the leachate samples collected by Dayal et al., [1986]. 
Dayal et al. [1986] also found that most trench leachates are undersaturated with respect to gypsum, because the sulfate concentrations are lowered by sulfate reducing bacterial action. There is only one sample of considerably high concentration of sulfate from Maxey Flats which is supersaturated with respect to gypsum. It appears that the sulfate concentration in this sample is controlled by gypsum solubility.

Carbon steel drums are often used as containers for LLW. The corrosion of these containers provides a significant source of iron in the leachate, and it may also provide a redox buffering effect in the immediate area next to such a container. The calculation of Dayal et al. [1986] also indicates that Maxey Flats and West Valley leachates are generally supersaturated with siderate, pyrite, and iron monosulfides. However, they also pointed out that the possible complexing of $\mathrm{Fe}^{2+}$ with organic chelating agents may have reduced the activity of $\mathrm{Fe}^{2+}$ in the solution, thus suppressing the precipitation of these iron minerals. The Barnwell and Sheffield samples are relatively less reducing. They are undersaturated with respect to vivianite $\left(\mathrm{Fe}_{3}\left(\mathrm{PO}_{4}\right)_{2} .8 \mathrm{H}_{2} \mathrm{O}\right)$ and supersaturated with respect to the iron hydroxides minerals, goethite and amorphous $\mathrm{Fe}(\mathrm{OH})_{3}$.

Cement is commonly used as a solidification agent for LLW. Lime or calcium oxide $(\mathrm{CaO})$ is the main component of cement, and it is mostly derived from decomposition of calcium carbonate from various raw materials, such as limestone, chalk, and marl. Cement is set by hydration reactions changing the lime into calcium hydroxide $\left(\mathrm{Ca}(\mathrm{OH})_{2}\right)$. Therefore, when cement waste forms are leached, they provide a source of $\mathrm{Ca}^{2+}$ as well as a buffering effect on the $\mathrm{pH}$ of the leachate. In leaching experiments carried out at $\mathrm{BNL}$ using Portland cement and distilled water, the $\mathrm{pH}$ of the leachate was increased to as high as 12.4 and the alkalinity, to 7.0 meq/l [Fuhrmann and Colombo, 1989]. Therefore, in the presence of cement waste forms, the $\mathrm{pH}$ and alkalinity of the leachate may be strongly elevated relative to the uncontaminated pore water. Furthermore, since calcium hydroxide also reacts with carbon dioxide, generated by biodegradation of organic matter, forming calcium carbonate, the leachate is expected to be supersaturated with calcite as exemplified by the Dayal et al.'s [1986] data from Maxey Flats and West Valley.

References (See Section 8) 


\section{APPENDIX 2}

\section{Summary of the Chemistry and Available Data for the Significant Radionuclides}

\section{A2.1 The Actinides}

The three most significant actinide radionuclides identified by Cowgill and Sullivan [1992] are Th-232, U-238, and Pu-239. These radionuclides are subjected to sorption processes in soil, and their solubility is controlled by changes in $\mathrm{pH}-\mathrm{Eh}$ as well as the presence of complexing agents.

\section{Thorium}

Thorium-232 is a long-lived $\left(\mathrm{t}_{1 / 2}=1.39 \times 10^{10} \mathrm{yr}\right.$.) principal isotope of naturally occurring thorium in sediments. The primary mineral for thorium is monazite $(\mathrm{Ce}, \mathrm{La}, \mathrm{Y}, \mathrm{Th}) \mathrm{PO}_{4}$. Thorium has a valence of +4 , and it does not undergo oxidation and reduction. The mobility of thorium in natural waters was studied by Langmuir and Herman [1980], who also summarized the thermodynamic data for 32 dissolved thorium species and 9 thorium-bearing solids. The most common salt is $\mathrm{Th}\left(\mathrm{NO}_{3}\right)_{4} \cdot \mathrm{H}_{2} \mathrm{O}$ which is very soluble in water, but $\mathrm{ThO}_{2}$ has very low solubility. The high charge on $\mathrm{Th}^{4+}$ makes it susceptible to complex formation if ligands are present. Dissolved thorium is almost invariably complexed in natural waters. This greatly enhances the mobility of thorium. In a typical ground water, the dissolved thorium species are:

- $\quad \mathrm{Th}\left(\mathrm{SO}_{4}\right)_{2}, \mathrm{ThF}_{2}{ }^{2+}$, and $\mathrm{Th}\left(\mathrm{HPO}_{4}\right)_{2}{ }^{0}$, for $\mathrm{pH}$ below about 4.5;

- $\quad \mathrm{Th}\left(\mathrm{HPO}_{4}\right)_{3}{ }^{2-}$, for $\mathrm{pH}$ from about 4.5 to 7.5 ;

- $\quad \mathrm{Th}(\mathrm{OH})_{4}$ above $\mathrm{pH}$ 7.5.

Thorium also forms complexes with EDTA, citrate, and oxalate. Based on their stability constants, the organic complexes predominate over the inorganic complexes in environments rich in organic matter [Langmuir and Herman, 1980]. Thorium is also adsorbed by clay, oxyhydroxides, and organic matter. Thorium adsorption increases with $\mathrm{pH}$ above $\mathrm{pH} 2$, and maximum adsorption is attained at $\mathrm{pH}$ values above 5.5 to 6.5 . At $\mathrm{pH} 6.5$, adsorption is almost total (95-100\%). However, strongly complexing agents such as EDTA, fulvic, and citric acids can inhibit adsorption to such an extent that they could even lead to partial desorption of thorium [Langmuir and Herman, 1980].

\section{$\underline{\text { Uranium }}$}

Uranium occurs naturally as U-238 and U-235. U-238 is the primary isotope in nature $(99.2739 \%)$ with a long half-life of $4.50 \times 10^{9}$ years. The geochemistry of uranium is more complex than thorium because uranium can exist in three valance states, $+4,+5$, and +6 . Accordingly, the oxidation-reduction reactions of uranium species are a controlling factor for uranium solubility in water. Langmuir [1978] studied the uranium solution-mineral equilibria at low temperatures $\left(25^{\circ} \mathrm{C}\right)$, using thermodynamic data for uranium minerals and aqueous species. Under conditions of natural waters, dissolved uranium is usually complexed. In the system U$\mathrm{O}_{2}-\mathrm{H}_{2} \mathrm{O}$, the predominant species include: 
Appendix 2. Summary for Significant Radionuclides

- $\quad \mathrm{U}^{4+}, \mathrm{UOH}^{3+}$, and $\mathrm{U}(\mathrm{OH})_{4}$, for +4 valence state;

- $\mathrm{UO}_{2}{ }^{2+}, \mathrm{UO}_{2} \mathrm{H}^{+},\left(\mathrm{UO}_{2}\right)_{3}(\mathrm{OH})_{5}^{+}$, and $\left(\mathrm{UO}_{2}\right)_{3}(\mathrm{OH})_{7}^{-}$, for +6 valence state.

The oxide, $\mathrm{UO}_{2}$ (uraninite), is insoluble. In natural ground waters, uranium can form complexes with a wide range of inorganic anions, such as, sulphate, fluoride, phosphate, and carbonate. For example, uranium carbonate complexes greatly increase the mobility of uranium and the solubility of uraninite. The solubility of uranium complexes also depend upon the $\mathrm{pH}$ of the solution [Langmuir, 1978]. In the presence of $\mathrm{HS}^{-}$or $\mathrm{Fe}^{2+}$ under reducing environments, $\mathrm{U}^{6+}$ can be reduced to $\mathrm{U}^{4+}$, thereby precipitating the uranium from solution in the form of the mineral uraninite $\left(\mathrm{UO}_{2}\right)$ by the following reactions:

Oxidation of $\mathrm{HS}^{-}$to $\mathrm{SO}_{4}^{2-}$ :

$$
4 \mathrm{UO}_{2}\left(\mathrm{CO}_{3}\right)_{3}^{4-}+\mathrm{HS}^{-}+15 \mathrm{H}^{+}=4 \mathrm{UO}_{2}(\mathrm{~s})+\mathrm{SO}_{4}^{2-}+12 \mathrm{CO}_{2}(\mathrm{~g})+8 \mathrm{H}_{2} \mathrm{O}
$$

Oxidation of ferrous ion to ferric hydroxide:

$$
\mathrm{UO}_{2}\left(\mathrm{CO}_{3}\right)_{3}^{4-}+2 \mathrm{Fe}^{2+}+3 \mathrm{H}_{2} \mathrm{O}=\mathrm{UO}_{2}(\mathrm{~s})+2 \mathrm{Fe}(\mathrm{OH})_{3}+2 \mathrm{CO}_{2}(\mathrm{~g})
$$

Other oxidation reactions, including oxidation of pyrite $\left(\mathrm{FeS}_{2}\right)$ to $\mathrm{Fe}^{2+}$ and $\mathrm{SO}_{4}^{2-}$, methane $\left(\mathrm{CH}_{4}\right)$ to carbon dioxide $\left(\mathrm{CO}_{2}\right)$, and $\mathrm{H}_{2}$ to $\mathrm{H}_{2} \mathrm{O}$.

Hsi and Langmuir [1985] showed that in oxidizing environments at low temperatures $\left(25^{\circ} \mathrm{C}\right)$, sorption is generally a more important control on uranium mobility than the precipitation of uranium minerals. They measured the adsorption of uranium in well characterized systems, and found that at $\mathrm{pH}$ above 5 to 6 , dissolved uranium species are strongly adsorbed onto amorphous ferric oxyhydroxide, and goethite $(\alpha-\mathrm{FeOOH})$, and less strongly onto synthetic and natural hematite $\left(\alpha-\mathrm{Fe}_{2} \mathrm{O}_{3}\right)$. Adsorption reactions equilibrate rapidly and reach pseudo-reversible equilibrium conditions within a few hours to a few days. The presence of competing cations $\mathrm{Ca}^{2+}$ and $\mathrm{Mg}^{2+}$ at concentrations of $10^{-3} \mathrm{~mol} / \mathrm{l}$ do not significantly affect uranium adsorption. However, uranium carbonate complexes strongly inhibit adsorption and increase mobility, especially in alkaline solutions. The effect is a function of the total dissolved carbonate content.

\section{Plutonium}

Plutonium is not considered to be a natural occurring element. It is generated by nuclear reactions from U-238 in nuclear reactors. Therefore, plutonium largely concentrates in used fuel elements as high-level waste. The only significant quantity of $\mathrm{Pu}$ found in nature is at the OKLO natural reactor in Gabon [Brookins, 1978]. Plutonium chemistry is similar to that of uranium. Plutonium occurs in several oxidation states: $+3,+4,+5$, and +6 , and forms numerous complexes in solution. These complexes can be positively or negatively charged and controlled by the redox state of the solution. Cleveland [1981] gave a critical review of Pu equilibria data of environmental concern available at the time and concluded that the knowledge of $\mathrm{Pu}$ geochemistry was not sufficient to permit chemical modeling with any degree of confidence. 
Appendix 2. Summary for Significant Radionuclides

Since then, many more studies on Pu geochemistry have been completed. Rai et al. [1980a] studied the solubility of $\mathrm{Pu}-239$ contaminated soils from Hanford and compared the results with experimentally obtained values for $\mathrm{PuO}_{2}(\mathrm{~s})$ and $\mathrm{Pu}(+4)$ hydrous oxide $\left(\mathrm{Pu}(\mathrm{OH})_{4}(\mathrm{am})\right)$. The results suggested that $\mathrm{Pu}(\mathrm{OH})_{4}(\mathrm{am})$ was absent from the soil, but $\mathrm{PuO}_{2}(\mathrm{~s})$ was present as the solubility controlling phase. Rai et al [1980b] calculated the $\mathrm{Pu}$ speciation based on thermodynamic data. They constructed the $\mathrm{pH}-\mathrm{Eh}$ diagram for $\mathrm{Pu}$ in aqueous solutions, and found that $\mathrm{Pu}(+3)$ would be the expected predominant species under relatively reducing conditions, and $\mathrm{Pu}(+5)$, under relatively oxidizing conditions. $\mathrm{Pu}(+4)$ was not considered because of the lack of reliable data. Without exception, the mobility of Pu is controlled by speciation in solution. In general, $\mathrm{Pu}$ is mobile when in anionic or neutral form, but relatively immobile when it exists as cations. However, in the presence of strong organic ligands, Pu can be mobilized by complexation, as shown by field data from Maxey Flats [Cleveland and Rees, 1981]. In addition, $\mathrm{Pu}$ is subject to significant degree of sorption, but the degree of sorption of $\mathrm{Pu}$ highly depends on $\mathrm{pH}$, as indicated by a study of Savannah River soils [Hoeffner, 1985]. The variation of $\mathrm{Pu} \mathrm{K} \mathrm{d}_{\mathrm{d}}$ values with $\mathrm{pH}$ from this study is shown in Tables 2.6 and $\mathrm{A} 2,1$.

Table A2.1 Site Specific Distribution Coefficients (for ground water with $\mathrm{pH}=4.7$ )

\begin{tabular}{lrcc}
\hline ELEMENT (SPECIFICATION) & $\mathrm{Kd}(\mathrm{m} 1 / \mathrm{g})$ & Min. $(\mathrm{pH}=3.4)$ & Max. $(\mathrm{pH}=7.3)$ \\
\hline $\mathrm{Am}\{\mathrm{Am} 3+\}$ & 1,600 & 90 & $2,500 @$ \\
$\mathrm{Co}\{\mathrm{Co} 2+\}$ & 10 & 4 & $>10,000$ \\
$\mathrm{Cs}\{\mathrm{Cs}+\}$ & 500 & 330 & 1,800 \\
$\mathrm{I}\{\mathrm{I}-\}$ & 5 & 3 & 10 \\
$\mathrm{Pu}(\mathrm{VI})\{\mathrm{PuO} 2(\mathrm{OH}) 2\}$ & 9 & 7 & 250 \\
$\mathrm{Pu}(\mathrm{IV})\{\mathrm{Pu} 4+\}$ & 150 & 120 & 7,100 \\
$\mathrm{Pu}(\mathrm{III})\{\mathrm{Pu} 3+\}$ & 8,000 & 800 & $>10,000$ \\
$\mathrm{Ru}$ & 175 & 65 & $300 \#$ \\
$\mathrm{Sb}\{\mathrm{HSbO} 2, \mathrm{Sb}(\mathrm{OH}) 3\}$ & 3,800 & 180 & $>4,000$ \\
$\mathrm{Sr}\{\mathrm{Sr} 2+\}$ & 8 & 2 & 3,000 \\
$\mathrm{Tc}\{\mathrm{TcO} 4-\}$ & 0.5 & $(0.1)$ & $(1.3)^{*}$ \\
\hline
\end{tabular}

Adapted from Hoeffner, 1985

Note: Cations are assumed to be hydrolyzed.

@ Range of $\mathrm{Kd}$ for Am is a function of soil/solution ratio (variation with $\mathrm{pH}$ not measured) (from Czyscinski et al., 1981).

\# Upper limit to $\mathrm{Ru} \mathrm{Kd}$ at $\mathrm{pH} 6$.

* Range of $\mathrm{Kd}$ for $\mathrm{Tc}$ varies with clay content (variation with $\mathrm{pH}$ not measured). 
Appendix 2. Summary for Significant Radionuclides

\section{A2.2 Transition Elements}

Fe-55, Co-60 and Tc-99 are three significant radionuclides of transition elements identified in LLW commercial sites. Among them, iron, and cobalt belong to the first series of transition metals with similar geochemical behaviors. Both of them occur naturally in significant amounts, and they have well documented thermodynamic data. Technetium is not a naturally occurring element, and therefore, thermodynamic data for $\mathrm{Tc}$ are not as well known as those for $\mathrm{Fe}$ and $\mathrm{Co}$.

Iron

Iron is the second most abundant metal after aluminum, and the fourth most abundant element in the earth's crust. Iron comprises approximately $3.8 \%$ of the average soil content (see Table 2.4). It occurs largely in ferromagnesium minerals among the primary minerals of soils. The solubility of iron in soils is mainly controlled by $\mathrm{Fe}(+3)$ oxides and hydroxides, which are insoluble. However, iron mobility can be modified by a number of processes, such as hydrolysis, complexation, and redox reactions in solution. Lindsay [1979] summarized the chemical equilibrium data for iron in the soil environment. Though iron hydroxides and oxides are insoluble, they are important in controlling the mobility of other metals, such as Co, by adsorption onto their surfaces. This was documented by Suarez and Langmuir [1976].

Iron $(3+)$ in aqueous solution can be readily hydrolyzed and/or form complexes. The hydrolyzed species include $\mathrm{FeOH}^{2+},(\mathrm{FeOH})_{2}{ }^{+}, \mathrm{Fe}(\mathrm{OH})_{3}, \mathrm{Fe}(\mathrm{OH})_{4}^{-}$, and the polymer $\mathrm{Fe}_{2}(\mathrm{OH})_{2}{ }^{4-}$. Like other trace elements, the various $\mathrm{Fe}^{3+}$ hydrolysis species in soils are controlled by the $\mathrm{pH}$ in solution. At normal soil $\mathrm{pH}$, the hydrolyzed species are more abundant than the free ion, but they are governed by the activity of $\mathrm{Fe}^{3+}$ which in turn is controlled by the equilibria established by other iron minerals. The hydrolysis reactions are important because they increase the total iron in solution. Iron has a minimum solubility in the $\mathrm{pH}$ range of 7.4 and 8.5 .

In addition to hydrolysis, $\mathrm{Fe}^{3+}$ combines with various anions to form complexes, for example, $\mathrm{Cl}^{-}, \mathrm{Br}^{-}$, and $\mathrm{F}^{-}$. Iron $(3+)$ also form complexes with nitrate, sulfate and phosphate, but the inorganic complexes are not significant compared to hydrolysis reactions. However, iron (both $2+$ and $3+$ ) forms complexes with organic ligands, which are more significant in controlling iron mobility than the inorganic complexes. Chellating agents, such as EDTA, readily form iron complexes which increase the solubility of iron in the leachate or soil solution. Stability constants for various organic complexes are given in Table A2.2.

Iron $(2+)$ is generally more soluble and therefore, more mobile in soils than iron( $3+)$. Under anaerobic (reducing) conditions, iron $(3+)$ can be reduced to iron $(2+)$ by processes such as biodegradation. The ratio of $\mathrm{Fe}^{3+}$ to $\mathrm{Fe}^{2+}$ in solution is a function the electron activity according to the following relation $-\log \left(\mathrm{Fe}^{2+} / \mathrm{Fe}^{3+}\right)=13.04-\mathrm{pe}^{-}$. Thus the ratio of $\mathrm{Fe}^{2+} / \mathrm{Fe}^{3+}$ in aqueous media can be readily determined from $\mathrm{pe}^{-}$or Eh. Hydrolyzed ferrous iron species in aqueous solution include $\mathrm{FeOH}^{+}, \mathrm{Fe}(\mathrm{OH})_{2}, \mathrm{Fe}(\mathrm{OH})_{3}{ }^{-}, \mathrm{Fe}(\mathrm{OH})_{4}{ }^{2-}$, and $\mathrm{Fe}_{3}(\mathrm{OH})_{4}{ }^{2+}$. Below pH 6.75, $\mathrm{Fe}^{2+}$ is the major iron $(2+)$ species in solution, between $\mathrm{pH} 6.75$ and $9.30, \mathrm{FeOH}^{+}$is the predominant species while above $\mathrm{pH} 9.3, \mathrm{Fe}(\mathrm{OH})_{2}$ is the major solution species. 
Cobalt

Cobalt is a trace element in soil. It has similar chemical behavior as iron. It also has +2 and +3 valence states. However, under the Eh-pH range of natural soil environments, only +2 valence state is stable. Means et al. [1978b] studied LLW sites at Oak Ridge National Laboratory, and found that Co-60 and various actinides are associated with Mn oxides. Based on a study on a LLW site at Chalk River Nuclear Laboratories, Killey et al. [1984] also found that Co-60 is sorbed by iron oxide coatings on ferromagnesium minerals. In addition, Co- 60 is strongly adsorbed by ion-exchange resin, and $80 \%$ of the dissolved cobalt was found to be in hydrophilic organic complexes. Stability constants for some complexes formed with chelating agents, such as EDTA, are given in Table A2.2. Means et al. [1978a] determined the $\mathrm{K}_{\mathrm{d}}$ values for Co-60 in weathered shale at $\mathrm{pH} 6.7$ and 12.0 were approximately $7.0 \times 10^{4}$ and $0.12 \times 10^{4}$, respectively. Hoeffner [1985] measured the $\mathrm{K}_{\mathrm{d}}$ values as a function of $\mathrm{pH}$ for Savannah River site soils (Tables 2.6 and $\mathrm{A} 2.1$ ). At $\mathrm{pH}=7$, the value of $\mathrm{K}_{\mathrm{d}}$ is at the maximum $(12,000)$ and it decreases to 10 at $\mathrm{pH}=10$, and 5 at $\mathrm{pH}=4$.

Table A2.2 Stability Constants $\left(\log K_{0.1}^{\mathrm{c}}\right)$ at $25^{\circ} \mathrm{C}$ For Metal-ligand Reactions and Corrected to Mixed Constants $\left(\log K^{m}{ }_{0.01}\right)$ using Davis' Equation

\begin{tabular}{lcccc}
\hline & \multicolumn{2}{c}{ HEDTA } & \multicolumn{2}{c}{ EDTA } \\
Reaction & $\mathrm{K}_{01}^{\mathrm{c}}$ & $\mathrm{K}_{0.01}^{\mathrm{m}}$ & $\mathrm{K}_{01}^{\mathrm{c}}$ & $\mathrm{K}_{0.01}^{\mathrm{m}}$ \\
\hline $\mathrm{Fe}(1 \mathrm{ll})+\mathrm{L}=\mathrm{Fe}(1 \mathrm{ll}) \mathrm{L}$ & 12.2 & 12.95 & 14.27 & 15.27 \\
$\mathrm{Fe}(\mathrm{ll})+\mathrm{H}+\mathrm{L}=\mathrm{Fe}(\mathrm{ll}) \mathrm{HL}$ & 14.95 & 15.87 & 16.97 & 18.27 \\
$\mathrm{Fe}(11)+\mathrm{L}=\mathrm{Fe}(11) \mathrm{OHL}+\mathrm{H}$ & 3.23 & 3.68 & 5.20 & 5.79 \\
$\mathrm{Fe}(111)+\mathrm{L}=\mathrm{FeL}$ & 19.8 & 20.92 & 25.0 & 26.20 \\
$\mathrm{Fe}(111)+\mathrm{H}+\mathrm{L}=\mathrm{FeHL}$ & & & 26.3 & 27.97 \\
$\mathrm{Fe}(111)+\mathrm{L}=\mathrm{FeOHL}+\mathrm{H}$ & 18.82 & 19.77 & 17.15 & 18.36 \\
$\mathrm{Fe}(111)+\mathrm{L}=\mathrm{Fe}(\mathrm{OH}) \mathrm{L}+2 \mathrm{H}$ & 9.80 & 10.46 & 8.10 & 8.89 \\
$\mathrm{Co}(11)+\mathrm{L}=\mathrm{CoL}$ & 14.50 & 15.25 & 16.26 & 17.26 \\
$\mathrm{Co}(11)+\mathrm{H}+\mathrm{L}=\mathrm{CoHL}$ & & & 19.26 & 20.56 \\
\hline
\end{tabular}

Adapted from W.L. Lindsay, Chemical Equilibrium in Soils, Copyright (O) 1979 John Wiley \& Sons. Reprinted by permission of John Wiley \& Sons, Inc. 
Appendix 2. Summary for Significant Radionuclides

Technetium

All isotopes of technetium are radioactive, and the longest lived isotope (Tc-97) has a half-life of $2.6 \times 10^{6}$ years. Therefore, technetium does not occur naturally in any significant amounts. It can only be found in traces as the fission product of uranium. As a result, the geochemistry of technetium is not well known. In aerobic soils, most (90\%) of contaminating technetium can be assumed to be in solution either as free ion or weakly absorbed to ionexchange sites [Coughtrey et al. 1983].

Mobility of Tc-99 $\left(\mathrm{t}_{1 / 2}=2.1 \times 10^{5} \mathrm{yr}\right)$ depends strongly on the redox environment. In an oxidizing environment, typical of near surface unsaturated zones, the septavalent $(+7)$ element takes the form of a soluble oxyanion, pertechnetate $\mathrm{TcO}_{4}^{-}$, which is responsible for technetium mobility in most soil environments. Other $\mathrm{Tc}(+7)$ aqueous species do not exist in the stability field of water. Under reducing conditions, $\mathrm{TcO}_{4}^{-}$can be reduced to a less soluble oxidation state, $\mathrm{TcO}_{2}$ [Bondietti and Francis, 1979]. Technetium oxides have low solubilities and are believed to be relatively immobile.

In soils with high organic matter, significant adsorption and precipitation due to reduction have been observed [Gee et al, 1981]. Strickert et al. [1980] investigated the sorption of $\mathrm{TcO}_{4}^{-}$by a number of commonly occurring sulfide minerals, including pyrite, chalcopyrite, and bornite, and compared the results to those of other geological materials, such as granite, tuff, and basalt. They found that $\mathrm{TcO}_{4}{ }^{-}$can be sorbed by a variety of sulfide minerals through mechanisms other than ion exchange. There was evidence that redox reactions are involved because minerals containing cuprous, plumbous, or ferrous ions are more effective sorbents than those containing metals ions in the highest oxidation state. They suggested that reduction of $\mathrm{TcO}_{4}{ }^{-}$to $\mathrm{TcO}_{2}$ may play a role in the sorption mechanism.

\section{A2.3 Iodine}

Iodine is a trace element in soil with an average concentration of about $5 \mu \mathrm{g} \cdot \mathrm{g}^{-1}$. I-129 exists in waste streams and soil solutions mainly as the anion iodide, $\mathrm{I}$, and under strongly oxidizing conditions iodate, $\mathrm{IO}_{3}^{-}$. They are both soluble in water. At low pH in soils capable of anion exchange, adsorption of $\mathrm{I}^{-}$and $\mathrm{IO}_{3}^{-}$is expected. At high $\mathrm{pH}$ (5 to 9), anion exchange capacity of most temperate soils are small, and therefore, adsorption of iodine is expected to be minimal. Strickert et al. [1979] also measured the $K_{d}$ values of iodide and iodate for sulfide minerals. The results showed that they can be strongly sorbed by these minerals $\left(100 \leq \mathrm{K}_{d} \leq\right.$ 2000 ), in contrast to little or no adsorption in other geological materials (such as basalt, granite and tuff). Bird and Lopata [1980] also reported that $\mathrm{I}^{-}$can be removed from solution by biotite, galena, and copper metal.

\section{A2.4 Strontium}

Strontium occurs in +2 valence state, and has similar geochemical behavior as calcium. Hence, it is capable of replacing $\mathrm{Ca}$ in $\mathrm{Ca}$-bearing mineral phases, such as feldspar. The exchange of $\mathrm{Sr}$ and $\mathrm{Ca}$ in soils is well documented. Tikhomirov and Sanzharova [1978] showed 
strong correlations between exchangeable Sr-90 in soil and exchangeable Ca in soil. The $\mathrm{K}_{\mathrm{d}}$ values for $\mathrm{Sr}$ exchange from solutions containing one and two competing cations using a mass action exchange approach has been successfully used [Gee, et al., 1981]. Strontium carbonate $\mathrm{SrCO}_{3}$, like calcium carbonate, is not soluble $\left(\mathrm{K}_{\mathrm{sp}}=7 \times 10^{-10}\right)$. However, strontium sulfate, $\mathrm{SrSO}_{4}$ has a $\mathrm{K}_{\mathrm{sp}}$ of $10^{-6.4}$. This suggests that if sulfate is present in solution and not reduced by bacteria, there may be an equilibrium control on the $\mathrm{Sr}$ concentration in solution. Jackson and Inch [1983] discussed the partitioning of Sr-90 among minerals species based on a study of the Chalk River site. They found that the vast amount of $\mathrm{Sr}-90$ were present as $\mathrm{Sr}^{2+}$. They also identified feldspar and vermiculite ( $\mathrm{Fe}(3+)$-Al-silicate, a clay mineral) are the primary absorbent onto which $90 \%$ of all adsorbed $\mathrm{Sr}-90$ is associated.

\section{A2.5 Cesium}

Cesium is strongly adsorbed by clay minerals. Like other exchange reactions, ion exchange adsorption of Cs is strongly dependent on other competing cations in solution [Gee et al., 1981; Coughtrey and Thorne, 1983]. The kinetics and reversibility of Cs sorption on illitic clays was examined by Comans et al. [1991]. They proposed a two-process model to describe the sorption behavior: a reversible process for rapidly accessible sorption sites; and a slow irreversible or semi-reversible process. The former accounts for rapid equilibrium over a time scale of a few days or less, while the latter takes a much longer time scale. Field data reported, for example, by Polzer et al. [1981], showed Cs-137 was sorbed to a very high degree (over 95\%) by the soils. The $\mathrm{K}_{\mathrm{d}}$ values from Hoeffner [1985] are included in Tables 2.6 and A2.1.

\section{A2.6 Hydrogen (Tritium) and Carbon}

Both of these are the most abundant elements in the soil-water system. Hydrogen is the main component of the liquid phase, and carbon is the main component of organic matter.

Tritium released from waste forms is expected to be primarily in the form of liquid water or water vapor. Therefore, tritium is transported in solution by the physical processes of advection, dispersion, and molecular diffusion without any significant retardation caused by chemical reactions. It can also be released to the surface in the form of water vapor diffusing through the porous soil. For these reasons, H-3 is identified as a significant radionuclide despite its relatively short half-life (12.6 yr.). Accordingly, H-3 has been found to be more mobile than other radionuclides released from LLW sites [for example, Schulz, et al. 1981].

Carbon can exist as organic carbon and as inorganic carbon. Organic carbon constitutes the basic structure of organic matter, and inorganic carbon occurs primarily as carbonate and bicarbonate ions. C-14 in LLW is expected to be mostly as inorganic carbon. However, a substantial fraction will occur as organic carbon which can be released by biodegradation processes as $\mathrm{CO}_{2}$ and $\mathrm{CH}_{4}$ gases. Similar to $\mathrm{H}-3$, significant amounts of C-14 can also be transported in the gaseous phase. In addition, $\mathrm{C}-14$ in organic carbon can be released in solution in the form of soluble organic substances, such as fulvic acids, which are products of the decomposition of more complex organic molecules in the biomass. Furthermore, carbon dioxide is moderately soluble in water forming carbonic acid $\left(\mathrm{H}_{2} \mathrm{CO}_{3}, \log \mathrm{K}=-1.46\right)$. Hence, $\mathrm{CO}_{2}$ 
Appendix 2. Summary for Significant Radionuclides

generated by biodegradation can be dissolved. Once in solution, the speciation of inorganic carbon species is governed by the equilibrium reactions in the well studied $\mathrm{CO}_{2}-\mathrm{H}_{2} \mathrm{O}$ system. Consequently, some $\mathrm{C}-14$ can be bound by insoluble carbonates, such as calcite, $\mathrm{CaCO}_{3}$.

References (See Section 8) 


\section{APPENDIX 3}

\section{Colloid Facilitated Contaminant Transport}

The system of equations outlined below describe the process of colloid facilitated contaminant transport in one dimension. By invoking simplifying assumptions this system can be reduced to a single equation involving a "modified" retardation coefficient. This "modified" retardation coefficient can easily be implemented in an existing single-species (solute) transport code. Although the formulation is presented for transport in one dimension, the final result applies directly to transport in multidimensions.

Contaminant Transport:

$$
\frac{\partial}{\partial t}\left(\rho c_{s}+\theta c_{j a}\right)=\frac{\partial}{\partial x}\left(\theta D \frac{\partial}{\partial x} c_{j a}\right)-\frac{\partial}{\partial x}\left(v_{a j a} c_{j a}\right)+r_{j a}
$$

with

$$
\frac{\theta_{a} c_{j s}}{\rho_{b}}=K_{d j} c_{j a}
$$

Colloid Transport:

$$
\frac{\partial}{\partial t}\left(\theta_{a} n\right)=\frac{\partial}{\partial x}\left(\theta_{a} D_{c a} \frac{\partial}{\partial x} n\right)-\frac{\partial}{\partial x}\left(v_{a} n\right)+r_{c}
$$

Colloid Facilitated Transport:

$$
\frac{\partial}{\partial t}\left(\theta_{d} n \gamma c_{j c}\right)=\frac{\partial}{\partial x}\left(\theta_{a} D_{c a} \frac{\partial}{\partial x} n \gamma c_{j c}\right)-\frac{\partial}{\partial x}\left(\nu_{a} n \gamma c_{j c}\right)
$$

where $\rho_{b}$ is the bulk soil density, $c_{j s}$ is the mass of contaminant per mass of soil, $c_{j a}$ is the dissolved chemical concentration, $\theta_{\mathrm{a}}$ is the moisture content, $\mathrm{v}_{\mathrm{a}}$ is the Darcy velocity, $\mathrm{r}_{\mathrm{ja}}$ is a souce/sink term for the contaminant, $\mathrm{n}$ is the number of colloids per unit volume of liquid, $\mathrm{c}_{\mathrm{jc}}$ is the mass of contaminant adsorbed per mass of colloid, and $\gamma$ is the average mass of a colloid. 
Appendix 3. Colloid Facilitated Contaminant Transport

The four equations given above may be solved for the four primary dependent variables (unknowns), $\mathrm{c}_{\mathrm{ja}}, \mathrm{c}_{\mathrm{j} s}, \mathrm{c}_{\mathrm{jc}}$, and $\mathrm{n}$. However, this system can be reduced to a single equation and $\mathrm{a}$ single unknown by invoking the following simplifying assumptions:

(1) The concentration of colloids is uniform and constant.

(2) The Darcy velocity is uniform and constant.

(3) The dispersivities $D_{1}$ and $D_{c}$ are equal and constant.

(4) All source/sink terms are negligible.

Introducing equation (A3.2) into equation (A3.1) and adding the result to equation (A3.4)(note equation (A3.3) is zero because of assumption (1)) and using assumptions 1 through 4 we get:

$$
\begin{aligned}
& \frac{\partial}{\partial t}\left(\rho_{b} K_{d j} c_{j a}+\theta_{a} c_{j a}+\theta_{a} \gamma n c_{j c}\right) \\
& \quad=\theta_{a} D_{j a} \frac{\partial^{2}}{\partial x^{2}}\left(c_{j a}+\gamma n c_{j c}\right)-v_{a} \frac{\partial}{\partial x}\left(c_{j a}+\gamma n c_{j c}\right)
\end{aligned}
$$

We next define a "mixture" concentration (i.e., contaminated colloids and solution) as:

$$
c_{m a}=c_{j a}+\gamma n c_{j c}
$$

Equation (A3.5) can then be written as:

$$
\frac{\partial}{\partial t}\left(\rho_{b} K_{d} c_{j a}+c_{m a}\right)=\theta_{a} D_{j a} \frac{\partial^{2}}{\partial x^{2}} c_{m a}-v_{a} \frac{\partial}{\partial x} c_{m a}
$$

We next assume that contaminant adsorption onto colloids is described by:

$$
c_{j c}=K_{j c} c_{j a}
$$

where $\mathrm{K}_{\mathrm{jc}}$ is the colloid distribution coefficient. Therefore, the mixture concentration can be expressed as: 
rypendix 3. Colloid Facilitated Contaminant Transport

$$
c_{m a}=c_{j a}\left(1+\gamma n K_{j c}\right)
$$

Using this result to eliminate $c_{\mathrm{ja}}$ in equation (A3.7) allows equation (A3.7) to be written in terms of a single unknown $\mathrm{c}_{\mathrm{ma}}$ :

$$
R_{c j} \frac{\partial}{\partial t} c_{m a}=\theta_{a} D_{j a} \frac{\partial^{2}}{\partial x^{2}} c_{m a}-v_{a} \frac{\partial}{\partial x} c_{m a}
$$

where the modified retardation $R_{c j}$ is given by:

$$
R_{c j}=\left(1+\frac{\rho K_{d j}}{\left(1+\gamma n K_{c}\right)}\right)
$$

Thus a standard transport code can be used to simulate colloid facilitated transport, under the simplifying assumptions noted above, by simply replacing the standard retardation coefficient with the modified retardation coefficient given by equation (A3.11). 


\section{APPENDIX 4}

\section{Adjustments to Equilibrium Constants and Activity Coefficients}

In general, equilibrium constants $\mathrm{K}_{\mathrm{j} \alpha}$ and activity coefficients $\gamma_{\mathrm{j} \alpha}$ are functions of temperature and solution ionic strength [Allison et al., 1991]. Common representatives are provided in this appendix.

\section{Equilibrium Constant Correction}

Two approximations commonly used to correct equilibrium constants for temperature variations are employed in BLT-EC. If the necessary data is available a power law of the form is used:

$$
\log K_{j a}=A_{j}+B_{j} T+C_{j} / T+D_{j} \log (T)+E_{j} T^{2}+F_{j} / T^{2}+G_{j} T^{1 / 2}
$$

where $\mathrm{T}$ is temperature $\left(\mathrm{K}^{0}\right)$ and $A_{\mathrm{j}}, B_{\mathrm{j}}, \ldots, G_{\mathrm{j}}$ are empirical constants for species $\mathrm{j}$ in the aqueous phase. If the necessary data is not available to specify the empirical constants, $\mathrm{K}_{\mathrm{ja}}$ are approximated by the van't Hoff equation:

$$
\log K_{j a}=\log K_{j a}^{0}-\frac{\Delta H_{r}^{o}}{2.303 R}\left[\frac{1}{T}-\frac{1}{T_{r}}\right]
$$

where $\mathrm{T}_{\mathrm{r}}$ is the reference temperature $\left(298.16^{\circ} \mathrm{K}\right), \mathrm{K}_{\mathrm{ja}}{ }^{\circ}$ is the equilibrium constant at the reference temperature, $\Delta \mathrm{H}_{\mathrm{r}}^{\circ}$ is the standard enthalpy change of the reaction, and $R$ is the molar gas constant.

\section{$\underline{\text { Activity Coefficient Correction }}$}

Activity coefficients of all aqueous species are functions of ionic strength. For species in the gaseous, sorbed, and precipitated phases, activity coefficients are typically taken to be unity. Two common formulations for calculating activity coefficients $\gamma_{\mathrm{ja}}$ are available in BLT-EC:

1) the Debye-Huckel equation:

$$
\log \gamma_{j \alpha}=\frac{-A_{d} Z_{j}^{2} I^{1 / 2}}{1+B_{d} a_{j} I^{1 / 2}}+b_{j} I
$$


Appendix 4. Adjustments to $\mathrm{K}_{\mathrm{ja}}$ and $\gamma_{\mathrm{ja}}$

and (2) the Davies equation:

$$
\log \gamma_{j a}=-A_{d j} Z_{j}^{2}\left[\frac{I^{1 / 2}}{1+I^{1 / 2}}-0.24 I\right]
$$

in which $A_{d}$ and $B_{d}$ are constants that depend on the dielectric constant and temperature, $Z_{j}$ is the charge on species $j$, $I$ is the ionic strength, $a_{j}$ is the ion size parameter, and $b_{j}$ is the ion specific parameter. The Davies equation is used when values of parameters $a_{j}$ and $b_{j}$ are not available.

The ionic strength, $\mathrm{I}$, is represented by:

$$
I=\frac{1}{2} \sum_{j=1}^{N_{s}} Z_{j}^{2} c_{j a}
$$

where $\mathrm{N}_{\mathrm{s}}$ is the number of species and $\mathrm{c}_{\mathrm{ja}}$ is the aqueous concentration of species $\mathrm{j}$. Activities of neutral aqueous species are estimated from the relationship:

$$
\log \gamma_{j l}=0.1 I
$$

Finally, the activity of water is estimated from:

$$
X_{H_{2} O}=1-0.017 \sum_{j=1}^{N_{s}} c_{j a}
$$




\section{APPENDIX 5}

\section{Adsorption Models}

The adsorption models in BLT-EC represent metal surface reactions as complexation reactions analogous to complexation reactions in solution. In the following equation presentation, unreacted surface hydroxyl sites are represented as $\mathrm{SOH}$, where $\mathrm{S}$ represents metals associated with the porous structure and are located at the solid-aqueous phase interface. For each sorption reaction at equilibrium, the concentrations of sorbent, sorbate, and surface sites satisfy a mass-action equation. $\mathrm{M}$ is used to denote an ionic adsorbate and $\mathrm{SOH} \cdot \mathrm{M}$ is the symbol for the surface-ion complex in the solid phase. Brackets are used to denote activity, e.g., [M] represents the activity of $M . K_{\mathrm{ms}}$ represents the equilibrium constant for the surface reaction, in the case of ion exchange $\mathrm{K} \underset{\mathrm{ms}}{\mathrm{ex}}$ denotes the selectivity coefficient. The models are divided into non-electrostatic and electrostatic models. The BLT-EC code user has the option to select, through proper choice of input variables, any one these models to represent adsorption.

\section{Non-Electrostatic Models}

\section{Activity $\mathrm{K}_{d}$ Adsorption Model}

Surface Reaction:

$$
S O H+M \rightarrow S O H \cdot M
$$

Mass-Action Equation:

$$
K_{m s}=\frac{[S O H \cdot M]}{[S O H][M]}
$$

\section{Activity Langmuir Model}

Surface Reaction:

$$
\mathrm{SOH}+\mathrm{M} \leftrightharpoons \mathrm{SOH} \cdot \mathrm{M}
$$

Mass balance equation for adsorption sites:

$$
[\mathrm{SOH}]_{\text {Total }}=[\mathrm{SOH} \cdot \mathrm{M}]+[\mathrm{SOH}]
$$


Appendix 5. Adsorption Models

Mass-Action Equation:

$$
K_{S O H \cdot M}=\frac{[S O H \cdot M]}{\gamma[M][S O H]}
$$

Introducing (A5.5) into (A5.4)

$$
K_{S O H \cdot M}=\frac{[S O H \cdot M]}{\gamma[M]\left([S O H]_{\text {Total }}-[S O H \cdot M]\right)}
$$

Activity Freundlich Model

Surface Reaction:

$$
S O H+(1 / n) M \rightarrow S O H \cdot M
$$

Mass-Action Equation:

$$
K_{m s}=\frac{[S O H \cdot M]}{[M]^{1 / n}[S O H]}
$$

Ion-Exchange Adsorption Model

Surface Reaction:

$$
S O H \cdot M_{1}-M_{1}+M_{2} \rightarrow S O H \cdot M_{2}
$$


Appendix 5. Adsorption Models

Mass-Action Equation:

$$
K_{m s}^{e x}=\frac{\left[M_{1}\right]\left[S O H \cdot M_{2}\right]}{\left[M_{2}\right]\left[S O H \cdot M_{1}\right]}
$$

\section{Electrostatic Models}

In this section, brief descriptions of two electrostatic models, constant capacitance and diffuse-layer, provided in BLT-EC are presented. A third electrostatic model, the triple-layer model, is also provided in BLT-EC but not described here. Application of this model may be desirable in some transport-geochemistry problems, but its added complexity is likely not justified for most applications. For details on this model we refer the reader to the MINTEQA2 manual [Allison et al., 1991].

Electrostatic sorption reactions at equilibrium also satisfy mass-action equations. However, electrostatic models include "coulombic" terms in the mass-action equations that modify the activities of the sorbate ions near charged surfaces. The difference in activities between ions near a charged surface and those in bulk solution is the result of electrical work in moving ions across the potential gradient between the bulk solution and the charged surface. The activity change in this region is related to the ion charge, $z$, and the electrical potential, $\psi$, near the adsorbing surface by:

$$
\left[X_{s}^{z}\right]=\left[X^{z}\right]\left(e^{-\frac{\psi F}{R T}}\right)^{z}
$$

where $\left[\mathrm{X}^{z}\right]_{\mathrm{s}}$ is the activity of an ion $\mathrm{X}$ of charge $\mathrm{z}$ near the surface, $\left[\mathrm{X}^{z}\right]$ is the activity of ion $\mathrm{X}$ in the bulk solution, $e^{-\psi F / R T}$ is the Boltzman factor, $F$ is the Faraday constant, $R$ is the ideal gas constant, and $\mathrm{T}$ is the absolute temperature.

\section{Constant Capacitance and Diffuse-Layer Models}

In these models there is a single surface or plane, defined as the "o" plane within which specifically adsorbed ions define the surface charge $\sigma_{0}$. This charge is given by the charge balance equation:

$$
\sigma_{o}=\sum_{m} \bar{v}_{k m}^{s} Z_{m a}
$$


Appendix 5. Adsorption Models

where $Z_{\mathrm{ma}}$ is the charge density of adsorbate species $m$ and $\bar{v}_{\mathrm{km}}^{\mathrm{s}}$ is the stoichiometry of the electrostatic component pertaining to the "o" plane. This charge is assumed to be balanced by a charge, $\sigma_{\mathrm{d}}$, associated with the diffuse layer of counterions, that is:

$$
\sigma_{o}+\sigma_{d}=0
$$

The difference between the constant capacitance and diffuse-layer models are the functions relating surface potential $\psi_{0}$ and surface charge density $\sigma_{0}$; these are:

Diffuse-layer model

$$
\sigma_{o}=0.1174 I^{1 / 2} \sinh \left(Z \Psi_{o} F / 2 R T\right)
$$

\section{Constant capacitance model}

$$
\sigma_{o}=C \psi_{o}
$$

where $\mathrm{I}$ is the ionic strength of solution and $\mathrm{Z}$ is the valency of the synetrical electrolyte (assumed to be unity).

The charge balance and mass action equations for specifically adsorbed species to the "o" plane are identical for both models. These are summarized below.

Protonation Reaction:

$$
\mathrm{SOH}+\mathrm{H}_{s}^{+} \rightleftharpoons \mathrm{SOH}_{2}^{+}
$$

Mass-Action Equation:

$$
K_{m s}=\frac{\left[\mathrm{SOH}_{2}^{+}\right]}{[\mathrm{SOH}]\left[\mathrm{H}_{s}^{+}\right]}
$$


where $\mathrm{H}_{s}^{+}$denotes a hydronium ion near the surface and

$$
\left[H_{s}^{+}\right]=\left[H^{+}\right] e^{-\psi_{o} F / R T}
$$

Therefore the mass-action equation becomes:

$$
K_{m s}=\frac{\left[\mathrm{SOH}_{2}^{+}\right]}{[\mathrm{SOH}]\left[\mathrm{H}^{+}\right] e^{-\psi_{o} F / R T}}
$$

Deprotonation Reaction:

$$
\mathrm{SOH}-\mathrm{H}_{s}^{+} \rightleftharpoons \mathrm{SO}^{-}
$$

Mass-Action Equation:

$$
K_{m s}=\frac{\left[S O^{-}\right]\left[H^{+}\right] e^{-\psi_{o} F / R T}}{[S O H]}
$$

Surface Reaction (Multivalent species):

$$
S O H+M_{s}^{2+}-H_{s}^{+} \rightleftharpoons S O \cdot M^{+}
$$

Mass-Action Equation:

$$
K_{m s}=\frac{\left[S O \cdot M^{+}\right]\left[H^{+}\right]}{[S O H]\left[M^{2+}\right] e^{-\Psi_{o} F / R T}}
$$


BLT-EC (Breach, Leach, Transport, and Equilibrium Chemistry) a Finite-Element Model for Assessing the Release of Radionuclides from Low-Level Waste Disposal Units: Background, Theory, and Model Description

5. AUTHOR(S)$$
4 \text {. }
$$

$\sqrt{6.7}$

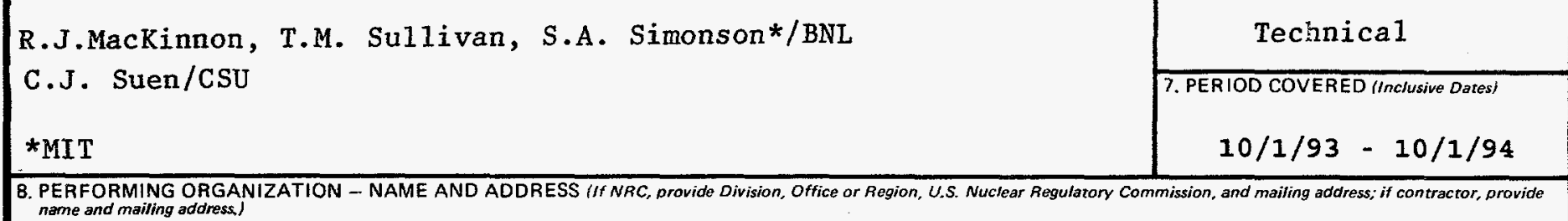

Department of Advanced Technology

Brookhaven National Laboratory

Upton, New York 11973

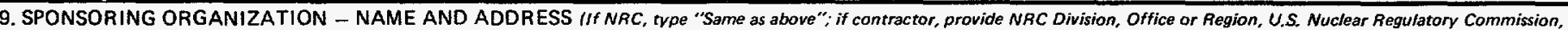
and mailing address.).

Division of Regulatory Applications

Office of Nuclear Regulatory Research

U.S. Nuclear Regulatory Commission

Washington, DC 20555-0001

10. SUPPLEMENTARY NOTES

R.E. Cady, NRC Project Manager

11. ABSTRACT (200 words or less)

Performance assessment models typically account for sorption and dissolution-

precipitation by using an empirical distribution coefficient ( $K_{d}$ ) that combines the effects of all chemical reactions between solid and aqueous phases. There is an increasing awareness that performance assessments based solely on empirically based $\mathrm{K}_{\mathrm{d}}$ models may be incomplete, particularly for applications involving radionuclides having soxption and solubility properties that are sensitive to variations in the in situ chemical environment. To accommodate such variations and to assess impact on radionuclide mobility, one must model radionuclide release, transport, and chemical processes in a coupled fashion. This modeling was incorporated into the twodimensional, finite-element, computer code BLT-EC which can predict container degradation, waste-form leaching, and advective-dispersive, multispecies, solute transport. BLT-EC accounts for retardation directly by modeling the chemical processes of complexation, sorption, dissolution-precipitation, ion-exchange, and oxidationreduction reactions. Herein we: (1) describe in detail physical and chemical processes that control the release and migration of radionuclides from shallow land LLW disposal facilities; (2) formulate the mathematical models that represent these processes; (3) outline how these models are incorporated and implemented in BLT-gC; and (4) demonstrate application of BLT-EC on sample problems.

Low-Level Radioactive Wastes - Ground disposal, Low-Level Radioactive Wastes - Radionuclide Migration, Radionuclide Migration - Simulation, B Codes, BNL, Chemical Reactions, Computer Codes, Computerized Simulation, Environmental Transport Equilibrium Chemistry, Flow Rate, Leaching, Mass Transfer

13. AVAILABILITY STATEMENT
IIn] imited
$\begin{gathered}\text { 14. SECURITY CLASSIFICATION } \\ \text { Unclassified } \\ \text { (This Report) } \\ \text { Unclassified }\end{gathered}$
15. NUMBER OF PAGES

